NIST Technical Note 1493

\title{
Aspects of the Fire Behavior of Thermoplastic Materials
}

T.J. Ohlemiller

J.R. Shields 



\section{Aspects of the Fire Behavior of Thermoplastic Materials}

T.J. Ohlemiller

J.R. Shields

U.S. Department of Commerce

Building and Fire Research Laboratory

National Institute of Standards and Technology

Gaithersburg, MD 20899

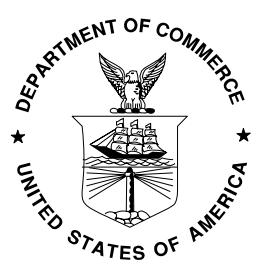

U.S. Department of Commerce Carlos M. Gutierrez, Secretary

National Institute of Standards and Technology James M. Turner, Acting Director 
Certain commercial entities, equipment, or materials may be identified in this document in order to describe an experimental procedure or concept adequately. Such identification is not intended to imply recommendation or endorsement by the National Institute of Standards and Technology, nor is it intended to imply that the entities, materials, or equipment are necessarily the best available for the purpose.

National Institute of Standards and Technology Technical Note 1493

Natl. Inst. Stand. Technol. Tech. Note 1493, 160 pages (January 2008)

CODEN: NSPUE2 


\title{
Aspects of the Fire Behavior of Thermoplastic Materials
}

\author{
T. J. Ohlemiller and J. R. Shields
}

\begin{abstract}
Thermoplastic polymers pose unique new challenges (resulting from the movement of burning melt material) for the understanding and control of fire growth on objects that incorporate them. Both full density thermoplastics such as polypropylene and polystyrene, as well as low density polyurethane foams are examined in this study, which has two overall goals: (1) assessment of potential test methods for quantitatively judging the flammability hazard of a thermoplastic (focused most specifically on polyurethane foams) and (2) fostering the development and validation of a model of fire growth over generic configurations of thermoplastic materials suggested by their end product use (particularly upholstered furniture). One such configuration is that used in the flammability test method, but early model development steps emphasize simpler configurations and materials. A critical aspect of modeling these materials is an adequate description of the viscosity of the polymer melt as a function of temperature; the viscosity can vary by several orders of magnitude. A procedure for deriving an empirical description of viscosity for full density thermoplastics, dependent only on temperature, is given but it requires extrapolation of melt viscosity out to burning temperatures. The procedure may be stymied by the complex behavior of polyurethane foam melts, indicating a need for further work. Gasification kinetics of the material, also needed in the fire growth model, are derived here from thermogravimetry for four full density thermoplastics. The more complex degradation behavior of polyurethane foam requires further work to derive these kinetics. The modeling process has been proceeding in stages of increasing complexity in conjunction with an outside contractor. The current stage focuses on two-dimensional, non-flaming melting plus gasification at heat fluxes comparable to those seen in fire growth. The present study has produced data on four full density thermoplastics and several polyurethane foams in this configuration which serves to test the developing model. Among the experimental results is the flux-dependent fraction of mass lost as melt flow from the heated sample surface. For polyurethane foams of varied composition, these results were found to vary over a wide range. This helped in understanding the relative fire growth behavior of these same foams when tested as roughly $30 \mathrm{~cm}$ by $60 \mathrm{~cm}$ slabs under the National Institute of Standards and Technology (NIST) Furniture Calorimeter. Similar scale tests were also done with thin sheets of polypropylene (the fire growth configuration which the model will attempt to predict first); these tests revealed complex flow dynamics in the melt pool fire and provided clues about the role of a pool fire in the overall fire growth process. As a result of the large scale foam tests we have proposed a tentative test configuration for polyurethane foams that are intended for use in upholstered chairs and a validation test series is being planned. The question of whether this test can be scaled down to use smaller amounts of foam is addressed; the scaling is difficult because of a mis-match in transient behaviors.
\end{abstract}

Introduction. In this report the phrase "thermoplastic materials" is generalized to include any solid which produces a significant amount of a liquid phase during its burning. Thus we include not only traditional full-density thermoplastics like polypropylene or polystyrene but also such materials as polyurethane foam which, though 
it is a thermosetting polymer, degrades to yield, in part, a liquid phase when burning or when subjected to heat flux levels comparable to those seen during burning.

Full density thermoplastics are commonly used in consumer electronics devices as, for example, the outer case or shell of a TV set or a computer monitor, keyboard, speakers, etc. They are increasingly common in office furniture and in automobiles, both under the hood and in the passenger cabin. Low density materials, in particular, polyurethane foam (which is actually an entire broad class of materials) are found as the soft cushioning in upholstered chairs, car seats and in mattresses.

All of these thermoplastic materials yield extra complexity when they burn in the context of the products in which they are found. Under the influence of gravity, the liquid phase formed during thermal degradation flows downward. If, as is typical, this liquid is burning, then it extends the flaming zone on the solid downward onto whatever surfaces are available to catch the liquid (ultimately a horizontal floor or ground surface). This constitutes, at the least, a new form of flame spread on the object containing the thermoplastic (in addition to normal forms of flame spread over solid surfaces, which are typically fastest in the upward direction), extending the area of fuel that is burning and thereby increasing the overall heat release rate from the object. In many cases this downward flow of flaming liquid results in a pool fire under the object. If that pool fire is close enough to the object that its plume reaches the object, the result can be a selffeeding ${ }^{1}$ pool fire that further enhances the rate of heat release from the burning system $[1,2,3,4]$.

In addition to this penchant for liquid-assisted flame spread, thermoplastic materials also tend to deform significantly as they burn. Thus large changes in the geometric shape of the burning object are common. These two aspects of thermoplastics make modeling fire growth on them, or on objects containing them, extraordinarily difficult.

From the standpoint of U. S. residential fire statistics, the thermoplastic objects (or objects which are in large part thermoplastic) that are of most relevance to a goal of fire loss reduction are upholstered chairs and mattresses. The general problem posed by modeling of fire growth on such objects is essentially intractable due to the very wide variety of poorly characterized materials present as well as an almost infinite variation in construction details. A detailed fire growth model requires input parameters describing such things as the kinetics of degradation and gasification of each significant component, its melt viscosity-temperature relationship, its thermal properties, etc ${ }^{2}$. This information is quite time-consuming to measure (and then it is only approximate; see below). The

\footnotetext{
${ }^{1}$ Self-feeding here means that the pool fire plume increases the rate of melt generation on the surface of the thermoplastic. In turn this increases the size of the pool fire whose taller height, in turn, further increases the melt flow rate to the pool. This can potentially lead to exponential fire growth though this is frequently curtailed by the finite thickness of the materials involved.

${ }^{2}$ It is apparent from the visual behavior of some fabric systems that prediction of their behavior in a fire also requires a description of their very thermally sensitive state of mechanical stress. Thermoplastic fabrics can split open and curl back abruptly as a result of tension forces. Chars from cotton fabrics shrink and then split in seemingly random ways. The behavior of fabric blends, of which there are unlimited numbers, is dependent on the nature of the constituent polymers and the details of their weaving.
} 
variability of the chemical composition of the components in these real objects, driven as it is by yearly fashion changes and economic considerations, is essentially unlimited. One could spend several years doing a detailed model of the fire behavior of a specific chair design only to find that it is irrelevant to what is currently on the market ${ }^{3}$. The best one can eventually hope for in modeling fire growth on upholstered chairs and beds is generic representations of classes of such objects ${ }^{4}$ that may be useful in such applications as design fires for performance-based fire codes. Successfully validated versions of such models are very likely a decade away.

Such complex models are not the only path forward, if, by forward, we mean movement toward less flammable soft furnishings. Such movement has typically been predominantly empirical in nature and often occurs only when prompted by regulation.

A nearer-term goal is a less complex model and a test method, used interactively as research tools, to assess and help improve the likely behavior of a given thermoplastic material if it were placed in the context of one of the types of objects mentioned above. One half of the goal is a test method whose results reliably predict that a thermoplastic material will be a major or minor hazard ${ }^{5}$ if used in the context of a real object such as a chair or computer monitor. The other half of the goal is a model of the behavior of thermoplastic materials in the test method context and its purpose is to help gain a detailed understanding of how and why a material behaves as it does in the test context, thus providing clues as to how to improve the material's behavior in real objects.

For a test method to yield outputs that accurately reflect how a material will behave in the more complex context of a real object, such as a chair or a video monitor, which incorporates other materials and typically more complex geometries, it is necessary to capture the dominant factors that influence how the thermoplastic material of interest behaves. ${ }^{6}$ Work toward the goal of developing such a test is part of the study discussed here.

\footnotetext{
${ }^{3}$ The cone calorimeter was developed in large part as a means of dealing with this daunting variety of materials combinations. The goal was to empirically characterize the heat release rate behavior per unit area of combinations of materials as a system and use that information in fire growth models. Because of significant differences in behavior in the cone versus that in the real objects, this goal has remained largely elusive, especially for soft furnishings [23, 24].

${ }^{4}$ For example, a generic upholstered chair of intermediate mass covered by a thermoplastic fabric or a sofa covered by a charring fabric.

${ }^{5}$ Hazard level in this context is to be primarily judged by the peak rate of heat release from the object and the time to that peak. These same metrics are carried over to the test method and to the model of the test method.

${ }^{6}$ It is also necessary that the thermoplastic material that is the subject of the test be the dominant flammable material in the object. The approach being advocated here will not work if the fire growth of the real object is largely governed by factors other than the thermoplastic material that is the focus here. For many chairs and mattresses the heat release rate is essentially dominated by polyurethane foam behavior, especially when it is covered by a thermoplastic fabric. A charring fabric can significantly suppress some of the worst behavior of the foam but the test method would still seek to reveal the worst case potential of the foam, were it to be used with a thermoplastic fabric. Similarly, in objects such as a computer monitor or TV set, the fire behavior is dominated by the thermoplastic case and the test results on that material should give a good indication of the fire behavior of the real object.
} 
Modeling the growth of fire on thermoplastic materials or objects has long been recognized as a very difficult undertaking. In the present study we have approached this in a stepwise fashion with parallel experiments to test each model step. As a first step we have focused on non-burning behavior, looking just at the behavior of a simple vertical thermoplastic slab heated uniformly on one vertical face. The slab, in general, can respond to the heating by both melting and gasifying. In the next step, it can be burning on that face. In the following step it can be burning on its face and interacting with its own melt pool fire. In the final step, the slab is extended laterally, ignited locally and a melt pool-assisted flame can spread over and consume the entire slab. That, at least, is the plan. In practice, the first step has proven to be a major challenge. Commercial computational fluid dynamics (CFD) codes applied to this problem give impractically long solution times (many days per case) [5]. Currently, NIST has contracted to Reaction Engineering International (REI) of Salt Lake City for the development of a condensed phase code that can be coupled to the NIST Fire Dynamics Simulator (or similar gas phase flame model) as a description of the gas phase flame and its thermal feedback to the condensed phase. The outcome of this effort remains to be seen but significant progress is being made [25, 26]. K. Butler of NIST is also exploring the viability of particle methods, a relatively new class of numerical techniques for problems involving large geometry changes [27]. Much of the experimental work described in this report is in support of these modeling efforts, providing both model inputs and experimental results against which to test model predictions. In this report, modeling efforts are described only in relation to the experiments reported here.

Emphasis in this study has generally been shifting from full-density thermoplastics toward polyurethane foams. The latter are part of the products involved in many more fatal fires in the U. S. and thus there is a stronger incentive to address this class of materials. These foams are, however, distinctly more complex than simple thermoplastic resins like polypropylene. This prompted an initial focus on the full density thermoplastics and the REI contract is aimed strictly at these. Thus many of the experiments described here (all those dealing with full density thermoplastics) have this focus. We have also begun exploring the behavior of polyurethane foams in certain situations, looking for viable configurations that could form the basis for a predictive flammability assessment. That work is also summarized here.

\section{EXPERIMENTAL MATERIALS AND METHODS.}

Materials. Three types of full-density thermoplastic polymer resin were looked at for this study; only two, polypropylene and polystyrene, proved to be suitable. Low molecular weight poly methylmethacrylate (PMMA, mean molecular weight of 120,000) was examined in a few radiative heating experiments (vertical slab, $25 \mathrm{~kW} / \mathrm{m}^{2}$; the experimental set-up for all such tests is described below). It was known that normal commercial PMMA (mean molecular weight of ca. $10^{6}$ ) does not exhibit melt flow

\footnotetext{
${ }^{7}$ Numerous variations of this final configuration become possible, once the model is in hand. Of particular interest is a pair of thermoplastic slabs arranged symmetrically about a central plane so that the flame zones on each exchange radiation which intensifies the burning of each slab. Such an effect can be seen in the burning of upholstered furniture. A Vee configuration is used below in the test method development study.
} 
because its unzipping character during thermal degradation leaves its molecular weight largely unchanged, yielding a melt viscosity that is too high to permit significant flow at normal gravity. The lower MW PMMA has a melt viscosity that is at least $1000 \times$ less and it did exhibit a tendency to flow downward. It also exhibited a behavioral aspect which the present study deemed too difficult to deal with - two phase flow. PMMA degrades exclusively to its monomer which is highly volatile at the conditions of interest. As a result it nucleates bubbles in depth, turning the surface region of the sample into a froth. Such a two-phase flow system cannot be effectively characterized by the available rheometric instrument. Thus it was decided not to pursue this polymer further.

Polypropylene and polystyrene resins were also explored and they showed a minimal tendency to bubble in our melt flow experiments. Both of these resins tend to undergo random scission when heated sufficiently (above the ca. $200{ }^{\circ} \mathrm{C}$ to $250{ }^{\circ} \mathrm{C}$ range where they are molded commercially), lowering the mean molecular weight. This, along with heat-induced increases in polymer chain mobility, lowers the melt viscosity, yielding a fluid melt. These two resin types thus became the exclusive focus for the full density thermoplastic aspects of the study ${ }^{8}$. Samples of commercial resins were obtained in bead form. Extremes (low and high) of initial melt viscosity were sought, as indicated in the manufacturer's reported melt flow index; this proved to cover only about one order of magnitude (or less), presumably to keep the moldability of the resins within bounds set by commercial machines. Table 1 lists the properties of the four thermoplastic resins used in the two-dimensional radiative heating and burning studies described below. Higher melt index indicates lower melt viscosity (at the measurement conditions).

The test samples were molded from beaded commercial resins in a heated press. The available mold system could not remove all air bubbles from the mid-depth of the $2.5 \mathrm{~cm}$ deep samples. This resulted in a sort of sandwich structure in which the two faces of a sample, to a depth of roughly $7 \mathrm{~mm}$ to $8 \mathrm{~mm}$ was bubble-free; in the middle, between these two clear areas, the sample had myriad fine bubbles, more or less evenly dispersed. This had no visible effect on the experiments and the bubbles did not noticeably affect the melt flow process.

A commercial polypropylene, generally similar in its melt and burning behavior to those in Table 1, was obtained in the form of large thin sheets ( $3 \mathrm{~mm}$ and $6 \mathrm{~mm}$ thick); this was used in the exploratory lateral fire spread studies described below. No further data on this polymer are available.

As noted above, polyurethane foam is a class of materials, based on the reaction of an isocyanate with a polyol. Commercial formulations may contain as many as eight different ingredients, including these two plus catalysts, blowing agents, surfactants and fire retardants. The nature of the polyol can be widely varied but typically, for the

\footnotetext{
${ }^{8}$ It is worth noting that there is a variety of other widely-used thermoplastics that do not exhibit the relatively simple behavior seen here with polypropylene and polystyrene. In earlier work we found polyethylene to be prone to form a seemingly cross-linked skin on the sample face that captured melting polymer behind it. In other studies ABS was prone to form a bubbly, partially charring, viscous mass, as was polycarbonate.
} 
applications of interest, it consists of a polyether based on ethylene and/or propylene oxide. The isocyanate is typically toluene diisocyanate (TDI) but may also be methylene diphenyl diisocyanate (MDI). The physical properties can be widely varied by adjusting the nature and proportions of these many ingredients. All of these in turn affect the details of the fire behavior of polyurethane foams. For this study we obtained samples of foams of widely varying fire behavior. Table 2 lists the limited information available on them. The fire retardant content ranges from zero to high; the graphited foam passes the FAA kerosene burner test in the context of an aircraft seat [28]. Two viscoelastic foams were included; these are becoming increasingly popular in mattress applications.

There have been several types of experiments involved in developing input data for modeling, in obtaining comparison data for the models and in exploring the threedimensional spread of pool fire-assisted flames. These are described briefly here along with some limitations where appropriate.

Thermogravimetry (TG). This is a common laboratory technique for characterizing the weight loss characteristics (via gasification) of a condensed phase material. A representative sample of a few milligrams in size is programmed upward in temperature at a fixed rate in an inert atmosphere (nitrogen) while it is being weighed on a very accurate balance. The weight is accurate to approximately $\pm 1 \%$ and the temperature to approximately $\pm 2{ }^{\circ} \mathrm{C}$. Here we are interested in using this technique to estimate the Arrhenius kinetic parameters that provide a simple description of the gasification process of our thermoplastic materials. The technique has thus far been applied to two polypropylene resins and two polystyrene resins. All four of these can be reasonably well described by a single gasification reaction that leaves no residue. The technique can also yield information on the relative stability of differing materials. We have applied it for this purpose to the polyurethane foams in this study.

To obtain the kinetic parameters of a gasification reaction, it is necessary to obtain data at two or more heating rates. Those heating rates must be low enough that the sample, as it is programmed upward in temperature, is spatially uniform in temperature. This necessitates quite low heating rates. Values of $(0.5,2.0 \text { and } 5)^{\circ} \mathrm{C} / \mathrm{min}$ were used here. As the heating rate is increased, the reaction is shifted to higher temperatures (the result of a simple competition between the rate of reaction and the rate of heating). This shift is a measure of the effective activation energy of the gasification reaction. There have been numerous methods proposed in the thermal analysis literature for obtaining the kinetic parameters from these types of experiments. One of the oldest and simplest is that due to Kissinger [6], which was used here. It uses the shift in the peak reaction rate to obtain the kinetic parameters. This leads to some deficiency in the exact description of the overall weight loss curve as will be seen below ${ }^{9}$.

There are two other concerns with this mode of obtaining kinetic parameters that apply to the fire-level heat fluxes used in the experiments below. The first concern is that these

\footnotetext{
${ }^{9}$ Appendix 3 describes the exploration of a different TG data reduction technique which uses all of the data. This technique pointed to more complex behavior for the one polypropylene resin to which it was applied.
} 
fire level heat fluxes heat the resin at a substantially higher rate than is the case in the thermogravimetric experiments. This higher heating rate pushes the reaction to higher temperatures where the controlling mechanism could, in principle, be changed. One can only assume that no such change takes place. With simple resins like polystyrene and polypropylene this is more likely to be the case $\mathrm{e}^{10}$ than for a complex material like polyurethane, but direct evidence of change (or not) is very difficult to obtain.

The other concern has to do with the atmosphere. In the thermogravimetric experiments it is nitrogen; in the radiative melt/gasification experiments (described below) it is usually air. The degradation of all polymers of interest is potentially affected by oxygen ${ }^{11}$. When a polymer is burning, oxygen typically cannot reach its surface, having been consumed in adjacent flames. We are ultimately interested only in flaming but some of the modeling and experiments do not involve flaming. Rather than build an elaborate enclosed apparatus for these non-flaming experiments, we have conducted them in room air. We have made some attempt (described below) to assess whether excluding most oxygen influences these results, but this issue is not entirely resolved and should be kept in mind when model and experiment for non-flaming conditions are compared.

Polymer Melt Viscosity. This is a fundamental issue which must be dealt with in any modeling effort aimed at thermoplastic materials; one must have an appropriate description of the flow properties of the liquid phase of the polymer of interest. In general, and especially at lower temperatures, polymer melts exhibit non-Newtonian flow behavior, exhibiting such features as a shear rate dependence to their effective melt viscosity. Fortunately, at higher temperatures, comparable to those near the surface of a burning object, most polymer melts become more nearly Newtonian. Our first major simplification then is to assume that the melt behavior is always Newtonian and that all one needs to describe the polymer flow is its melt viscosity.

The problem is still complex. At these high temperatures the polymer is degrading and its mean molecular weight is decreasing as a result. Both increased molecular mobility

\footnotetext{
${ }^{10}$ The degradation of such polymers proceeds by a free-radical mechanism. The initial, randomly-placed break of the polymer backbone, forming a pair of highly reactive free radicals, is probably the controlling step. It is followed by a series of rapid, free-radical chain propagation, chain transfer and chain termination reactions occurring in series and parallel that serve to lower the mean molecular weight of the broken chain and others in its neighborhood. As this sequence progresses (given a high enough temperature), species are generated which are volatile enough and concentrated enough to be able to nucleate vapor bubbles. These bubbles grow by diffusion of low molecular weight species from the surrounding melt. The pressure in the bubbles builds, causing them to swell toward the nearest free surface (open to the atmosphere) and burst. The degradation of polyurethanes is probably not greatly dissimilar but the larger number of types of bonds between a larger variety of types of atoms opens the way to more competing paths and the possibility that this competition will be more likely to shift the dominant mechanism as conditions change.

${ }^{11}$ The extent to which polymer degradation can be affected by oxygen tends to be limited by the very slow diffusion of oxygen into the condensed phase and the time available for this diffusion. Running the thermogravimetric experiments in an air atmosphere would tend to give an exaggerated oxygen effect because the sample exposure time is much longer than in the non-flaming experiments. One would have to develop a specialized model, applicable only to the non-flaming experiments, to fully account for the possible impact of oxygen on the observed behavior. This would be a major diversion from the present goals.
} 
and decreased molecular weight contribute strongly to the decreased viscosity of a polymer melt in the temperature range of interest (roughly $300{ }^{\circ} \mathrm{C}$ to $450{ }^{\circ} \mathrm{C}$ ). The decrease in molecular weight is a consequence of a complex series of chemical reactions that are shortening the average length of the polymer backbone. If this kinetic aspect of the polymer behavior had to be included in a model, the thermoplastic fire growth modeling problem would essentially be intractable. Appropriate kinetic constants for the various degradation steps are not available for commercial polymers and, in any event, solving for the shifting mean molecular weight would add too much complexity to the model to make it practical. Instead, for the full density thermoplastics, we have developed an approximate, empirical approach that yields a viscosity description that appears to be a function of only one variable - temperature. This single variable description is obtained piecemeal. The bulk of it (at lower to intermediate temperatures) comes from straightforward rheometry on the virgin polymer resin. The rheometer is a sophisticated instrument (Paar-Physica Model UDS 200) ${ }^{12}$ that, in this case, measures the force needed to sustain steady, constant shear rate rotation of a circular (typically $25 \mathrm{~mm}$ dia) flat plate on top of a $1 \mathrm{~mm}$ thick layer of molten resin which, in turn, rests atop a fixed plate. An attached computer converts the force measurements into a melt viscosity via a standard mathematical solution for this shear flow. This device can yield viscosity results for standard materials at a fixed temperature within $10 \%$ of their specified value. With successive measurements on melt samples from a given experiment, the results for viscosity as a function of temperature may vary by $\pm 10 \%$ or somewhat more if the melt is contaminated with particles. The entire measurement assembly is enclosed in a nitrogen purged oven that is programmed upward in temperature at $1{ }^{\circ} \mathrm{C} / \mathrm{min}$ until the sample degradation process has reached such an extent that gas bubbles from the sample disrupt the force measurement. The materials examined typically do show a mild shear rate dependence of melt viscosity (shear thinning is a non-Newtonian effect) so the applied shear rate (set by the rotation rate) is kept at a rate (typically $0.1 \mathrm{~s}^{-1}$ ) estimated to apply to the falling films seen in the polymer melt experiments described below. In this manner, with the virgin resin one might get melt viscosity data from under $200{ }^{\circ} \mathrm{C}$ to somewhat over $300{ }^{\circ} \mathrm{C}$ for a polypropylene or polystyrene.

Simply extrapolating these data out to $400{ }^{\circ} \mathrm{C}$ or higher would be highly risky since the viscosity is changing over a couple orders of magnitude and the temperature dependence, on a semi-log plot, is not a straight line once thermal degradation sets in (as it does well before bubbling is seen). Instead, we have obtained two (or three) approximate "data points" on this extrapolated line by capturing melts generated at higher temperatures in radiation-driven melt flow experiments (described below). The surface temperatures (at two different heat fluxes) that are associated with these melts are measured in the experiments. The captured melts are then subjected to rheometry in the same manner as the virgin resin. Their entire viscosity curve is shifted downward by the fact that they have been thermally degraded to a lower mean molecular weight. This viscosity, again,

\footnotetext{
12 Certain trade names and company products are mentioned in the text or identified in an illustration in order to specify adequately the experimental procedure and equipment used. In no case does such identification imply recommendation or endorsement by the National Institute of Standards and Technology, nor does it imply that the products are necessarily the best available for the purpose.
} 
can only be measured up to temperatures at which further degradation sets in. These results are then extrapolated out to the measured surface temperature at which the melt was generated to get an estimate of the point on the viscosity curve represented by the degraded melt on the heated sample surface. There are further reservations/limitations one must consider with these results, as discussed below. However, one has, from this procedure, a first approximation to a temperature-only dependence for polymer melt viscosity. Ultimately this dependence is fitted with a polynomial description of the behavior on a semi-log plot and this becomes the input for a model.

It should be noted that the viscosity-temperature behavior for the polymer melts is nonreversible because of the chemical degradation involved. That is, when the melt cools to a lower temperature after it escapes from the hot polymer surface, its viscosity does not go back up along the extrapolated curve described above. Rather it follows the temperature behavior measured for the melt obtained from the highest incident heat flux seen by the polymer surface.

Two-Dimensional Radiation-Driven Melt/Gasification/Flaming Experiments. These are the counterparts (and test cases) to the early stages of fire growth model development described above. The cone heater in the cone calorimeter is used as the radiation heat source. Incident radiant heat fluxes on the samples are measured with a water-cooled Schmidt-Boelter gage, previously calibrated to an accuracy of approximately $\pm 3 \%$.

There have been a few variants of the exact way in which these experiments were done; here we describe the most recent since it is the source of the data presented later. Figure 1 shows a schematic side view of the layout of the experiment. The cone heater is oriented vertically on the left. The irradiated sample face is also oriented vertically and it is contained within a square, stainless steel sheath that constitutes a feed tube. The front of this tube is $7.5 \mathrm{~cm}$ from the front (wider) face of the cone heater. This greater than normal spacing between sample face and cone heater permits better visual access needed for thermocouple measurements of the sample surface temperature. It reduces the maximum available heat flux but does little to diminish the uniformity of the heat flux falling on the sample face. It also permits easier access for insertion of pans or bottles for capturing the melt flowing downward off of the sample face. As the sample face recedes, the sample is fed forward in the tube to keep its face very nearly fixed at the tube exit plane. This feeding process is stepwise and manually driven in the case of full density polymer samples; it is continuous and motor-driven in the case of polyurethane foam samples $^{13}$.

The sheath tube cross-section is $10 \mathrm{~cm}$ square and this is the face size of the full density thermoplastic samples. Typically they were $5 \mathrm{~cm}$ thick, formed from back-to-back $2.5 \mathrm{~cm}$ thick samples. As noted above, the $2.5 \mathrm{~cm}$ thick samples had a central layer of fine bubbles from the molding process that formed them. Again, any effect of this bubble layer did not visually manifest itself in the experiments. However, they must have had

\footnotetext{
${ }^{13}$ The same slide mechanism is used for both types of samples but the available motor drive could not handle the very slow feeding rates seen with the solid polymer samples. Foam, with its much lower density, requires a much faster feed rate to keep the regressing sample face fixed at the tube exit.
} 
some effect on the thermal conductivity of the samples, presumably reducing it locally, and this affects, to some extent, any comparison with model results.

The polyurethane foam samples posed a different problem. If they were the same crosssectional size as the full-density resins, they behaved very poorly, receding unevenly over their face, especially at their outer edges. They appeared to be highly sensitive to heat loses around their periphery. ${ }^{14}$ In order to minimize this effect for the foams, the sample cross-section was reduced to $5 \mathrm{~cm}$ square. The lateral sides and top of this smaller sample were additionally insulated by $2.5 \mathrm{~cm}$ thick layers of polyisocyanurate foam $^{15}$ fixed within the stainless steel sheath tube (the sample bottom could not be similarly insulated because the feed mechanism came through the bottom of the tube). This essentially eliminated the problem. The foam samples were $40 \mathrm{~cm}$ long and, as noted above, were fed forward by a motor drive at a rate (set by the test operator) that matched their regression rate.

As shown in Fig. 1, the sample assembly (sample, sheath tube, motor-driven slide, base plates) sits on top of a high capacity scale with a $0.1 \mathrm{~g}$ resolution. As noted, when the sample was a full-density thermoplastic, the sample was manually fed forward at intervals by turning a crank on the slide mechanism. This momentarily interrupted the weighing process but this had essentially no effect on the ability to follow the decreasing sample weight. The steady-state rates of weight loss reported here are obtained by fitting a straight line to the weight vs time data; they are accurate to approximately $\pm 3 \%$.

The material flowing from the sample face was captured either in an aluminum foil pan or in a bottle. The weight of this was followed by a scale with a resolution better than $0.1 \mathrm{~g}$. In some experiments, the sample face was burning. In such cases it was desirable that the captured melt not continue to burn. This prompted the use of deep bottles as the capture vessel having the top opening partially covered with aluminum foil (and in some cases the base of the capture bottle was water cooled). This caused burning to halt as a result of a lack of oxygen.

Some of the polyurethane foams tended to accumulate a denser char-like "skin" on the sample face as the bulk of the foam both gasified and melted, flowing downward. Ultimately it was noted that this skin probably served to block oxygen from participating in the melt process immediately behind it. The skin was therefore allowed to stay in place during most of each foam experiment, being removed (with tweezers) only when it threatened to slide off into the melt capture bottle. The skin typically began re-forming within $10 \mathrm{~s}$ to15 s of removal, but it required removal only every several minutes.

The sample surface temperature was measured in these experiments with a $0.05 \mathrm{~cm}$ dia stainless steel sheathed thermocouple (chromel/alumel) that was moved forward at

\footnotetext{
${ }^{14}$ The stainless steel tube sheath was insulated on its outer surface with $1.3 \mathrm{~cm}$ of ceramic fiber insulation. This left the tube wall itself (ca. $0.6 \mathrm{~mm}$ thick) as a weak heat sink which had no effect on the full density thermoplastics but a large effect on the foam.

${ }^{15}$ The ends of the isocyanurate foam blocks were baked at the highest flux to be used. This charred the ends of the blocks and eliminated them as a spurious source of weight loss from the sample assembly.
} 
intervals through the central hole in the cone heater; typically three measurements were made per test, after the sample was in a steady regression state. The lead length of the thermocouple was supported on a $3 \mathrm{~mm}$ dia ceramic tube (kept small to minimize shadowing of the cone heater during surface temperature measurements) ${ }^{16}$. The last 6 $\mathrm{mm}$ of the sheath before the end with the junction was bent downward at $90^{\circ}$ so that this section of the thermocouple contacted the surface in a parallel manner, essentially eliminating conductive lead losses (a length equal to12 diameters of the sheath was in the surface melt). When a surface temperature measurement was to be made, the thermocouple support was fed forward manually on a mechanical slide. When it contacted the surface, a mark was placed in the computer file. The thermocouple was typically oscillated back and forth a mm or so within the surface melt layer to assure that it was thoroughly wetted and to seek a maximum value. (In the case of the polyurethane foams that formed a skin, the thermocouple stayed to the outside of the skin; when, in a few cases, the measurement was made right after skin removal, the results were not consistently different.) The thermocouple was kept in contact for ca. $60 \mathrm{~s}$ and then removed, with a second mark being made in the data file.

The accurate measurement of surface temperature in this manner is not trivial (and there are no easy alternative methods given the strong infrared flux from the cone heater). There are two significant sources of error arising from (1) the finite size of the thermocouple in comparison to the thermal wave in the solid and (2) radiative heating of the thermocouple by cone heater radiation that penetrates the outer layers of the sample. The first source of error can be estimated using the steady-state temperature profile based on neglect of the melt flow layer (see Appendix 1 for a steady-state model of the melt/gasification process). The characteristic depth of this profile is

$$
\ell_{c}=\left(\lambda_{s} / m_{s s} C_{s}\right)
$$

where $\lambda_{s}$ is the thermal conductivity of the condensed phase, $m_{s s}$ is the steady-state mass loss rate from unit area of the sample and $C_{s}$ is the sample heat capacity. This length, coupled with the measured surface temperature values, allows one to estimate the temperature gradient at the sample surface. The thermocouple spans a non-negligible segment of this gradient. Assuming that the thermocouple in such a situation would tend to read the temperature value at the middle of the segment, one finds that, for this reason, it will tend to read a value less than the actual surface temperature and this error varies from about $7{ }^{\circ} \mathrm{C}$ at $20 \mathrm{~kW} / \mathrm{m}^{2}$ to $20^{\circ} \mathrm{C}$ at $45 \mathrm{~kW} / \mathrm{m}^{2}$. This estimate assumes that the sheath of the thermocouple is immersed in the sample surface, and flush with it.

The second source of error has the opposite effect - it tends to give a higher reading than the actual value at the sample surface. It is more difficult to estimate and the estimate requires information on radiation penetration that is currently only available for polypropylene. Measurements of cone heater radiation penetration in a sheet of commercial polypropylene were made several years ago using the NIST Building and

\footnotetext{
${ }^{16}$ It is estimated that the shadow of this support blocked less than $5 \%$ of the cone heater radiation in the vicinity of the thermocouple junction.
} 
Fire Research Laboratory (BFRL) gasification apparatus (which uses the same type of cone heater). We assume that they apply to the two polypropylene resins used here. We cannot assume that they apply to the polystyrene resins or the polyurethane foams since the differing compositions of these materials result in differing infrared spectra. The black, char-like "skin" that forms on some of the polyurethanes probably absorbs the cone radiation in a very short depth, but this needs to be checked. Available infrared spectra for polystyrenes (Sadtler Standard Spectra) are ambiguous as to whether they differ appreciably from the polypropylene ${ }^{17}$.

For polypropylene, the available radiation penetration data show that about half of the incident radiation reaches a depth of $4 \mathrm{~mm}$. Then the thermocouple, just immersed in the surface, as assumed above, sees a largely undiminished radiant flux on the side facing the heat source. It is immersed in a slow downward flow of melt around it that removes the absorbed radiant heat. As a first approximation, we do a steady-state heat balance on this cylindrical object which has a flow, parallel to the cylinder axis, over its entire periphery while absorbing radiation on half of its surface. That flux is taken as the value at $1 / 4$ of the thermocouple sheath diameter, which, for polypropylene, is about $87 \%$ of the flux incident on the sample surface. This heat balance yields an estimate that, at an incident flux of $20 \mathrm{~kW} / \mathrm{m}^{2}$ the thermocouple reads about $20^{\circ} \mathrm{C}$ higher than the surrounding melt and at a flux of $45 \mathrm{~kW} / \mathrm{m}^{2}$ it reads $45^{\circ} \mathrm{C}$ higher than the melt. This estimate has significant uncertainties due the fact that the heat flow situation around the thermocouple is substantially more complex than assumed. The melt flowing past the thermocouple in the area closest to the sample surface is thin and thus less effective in cooling the thermocouple. On the other hand, the melt behind the thermocouple is in its shadow and receives less radiant heat, is cooler, and thus is more effective at cooling the thermocouple. The "front" half of the thermocouple does not actually receive the full radiant flux over its area; a diminishing view factor with respect to the cone heater lowers it on the sides parallel to the longitudinal axis of the sample. Although these effects are beyond any simple estimate, the overall implication appears to be that the preceding estimate of the radiation-induced error in the thermocouple reading is probably high. When combined with the above opposite effect that lowers the thermocouple reading, it is likely that the overall effect is that the reading is still somewhat high, but probably not more than $20^{\circ} \mathrm{C}$ at the high flux end and substantially less high at the low flux end.

Much of the data reported here is for non-flaming experiments. In those experiments the cone heater was allowed to come to a steady temperature (corresponding to a measured heat flux level at the sample face) while the sample was protected from its radiation. At time zero, a heat shield was removed from the sample face to give a square-wave start to the radiation exposure. As the sample heated up and began to gasify/melt, its surface would begin to recede. The test operator would use the manual or motor-driven feed assembly to feed the sample forward to keep it approximately in the same plane ${ }^{18}$. The

\footnotetext{
${ }^{17}$ See Appendix 4 for a further discussion. That work was completed only after the bulk of this report was written.

${ }^{18}$ The radiant flux varied by about $2.5 \% / \mathrm{mm}$ in the neighborhood of the end of the square tube sheath enclosing the sample. The full density thermoplastics, whose feeding speed was adjusted manually at
} 
sample and melt capture weights were displayed continually during each test. When it was apparent that the melt capture weight was increasing linearly with time, indicating a quasi-steady state was achieved, surface temperature measurements were begun. The polyurethane foam samples tended to develop a non-planar face with the upper $1 / 4$ to $1 / 3$ of the surface sloping somewhat away from the heat source; this did not appear to have any major effect on the results obtained. For the full density thermoplastic tests, the experiments were carried out for $10 \mathrm{~min}$ to $13 \mathrm{~min}$ and the regressing surface was less than midway into the front, $2.5 \mathrm{~cm}$ thick sample (typically into the bubble layer there). For the polyurethane foams, about $2 / 3$ of the $40 \mathrm{~cm}$ length of the foam sample was consumed.

For analogous burning experiments, the test was started and generally conducted in the same manner except that the radiant flux levels were lower and the sample face was ignited as the radiation exposure began, using a multiple jet methane flame waved over the face.

Three-Dimensional, Melt Pool Fire-Assisted, Fire Growth Tests. These intermediate scale tests were carried out under the NIST 3 meter calorimeter hood. These were exploratory tests, aimed mainly at examining the behavior of several compositions of polyurethane foam but also included some tests on a commercial polypropylene (as noted, it was different from the two resins used in the cone heater tests described above). Figure 2 shows a photo of the test apparatus. The sample, in this case, is a sheet of this commercial polypropylene (30 cm tall and $60 \mathrm{~cm}$ long). The sample has a set of grid lines forming squares $5 \mathrm{~cm}$ on a side which facilitate measuring the rate of flame spread $^{19}$. The sample is held by two clamps, one along its top edge and one along it right vertical end. The sample is to be ignited on its left vertical end. Here the sample is suspended with its base $77 \mathrm{~cm}$ above a catch surface made of calcium silicate board (Marinite $\mathrm{P}$, chosen because its thermal inertia ${ }^{20}$ is generally similar to that of wood). This height is the one of two used in these tests. The other was approximately $4 \mathrm{~cm}$. The two heights were chosen to minimize the interaction (large height) between the sample and any pool fire on the catch surface or maximize that interaction (small height). When the sample was in its lower location, it rested on a fine nichrome wire "grid" formed by winding the wire back and forth between the two rods visible in the figure above the Marinite surface. $^{21}$ It was still supported by a clamp on the right end, as well. When the sample was a slab (typically $7.5 \mathrm{~cm}$ to $10 \mathrm{~cm}$ thick) of polyurethane foam, it was mainly supported by impaling the right end of the slab on a set of spikes inserted into the right end face at mid-depth. Many of the foam tests involved a Vee configuration with two foam slabs held at an approximately $30^{\circ}$ angle, each impaled on its own set of spikes (see

\footnotetext{
intervals, were generally held within about $\pm 1 \frac{1}{2} \mathrm{~mm}$; the polyurethane foam samples varied by about twice this due to the shape changes they tended to exhibit.

${ }^{19}$ Post-test measurements of flame front position, typically along the top edge of a foam slab were made using video tapes of the test and were accurate to better than $\pm 1 \mathrm{~cm}$.

${ }^{20}$ Thermal inertia is the product of thermal conductivity, heat capacity and density. It is a measure of the amount of heat the material will absorb when brought into contact with another material, in this case, the melt from the test sample.

${ }^{21}$ The average spacing between successive wires was $10 \mathrm{~cm}$ or more. They posed no noticeable barrier to flame propagation on the base of any of the test samples.
} 
Fig. 3). It proved desirable to add additional stiff steel wires between the two foam slabs in two or more locations near the opposite (open) end of the Vee configuration to keep the samples in place for as long as possible as they burned away.

The sample and the large framework supporting it all ultimately rest on a scale placed on the floor; this scale has a better than $0.1 \mathrm{~g}$ resolution. The catch surface and the pan containing it rest on a separate scale ${ }^{22}$; this scale has a $0.1 \mathrm{~g}$ resolution. In this manner, the mass of the sample and of the melt pool it generates can be separately measured.

In initial tests, several configurations of fire growth were examined with one of the foam types (Z0 FR Foam), mostly with the close spacing above the Marinite catch surface. These included a single slab burned in the orientation shown in Fig. 2, a single slab laid flat on the wire support, ignited on one end and a single slab oriented with its long axis vertical, ignited on the bottom of one face. A few foam experiments were also run in the Fig. 2 orientation but close to the Marinite and with a radiant flux incident on one large face. The two-slab experiments were all in the Vee configuration described above, mostly with the sample close to the Marinite.

Single slabs (both full density samples and foams) were ignited with a propane-fed Tee burner, visible to the left end of the sample in Fig. 2. These were fire growth studies, not ignition studies so for tests with the sample near the Marinite catch surface, the igniter was held on until a pool fire was clearly present with a plume that could begin to interact with the lower parts of the sample. The same time was used when the sample was raised above the Marinite, too high for there to be an interaction with any pool fire. In the Vee configuration tests (done only with foams) the igniter (of a different design) was at the narrow end of the Vee (see Fig. 3) and ignited adjacent ends of the two foam slabs simultaneously.

All tests were recorded with two video cameras. One camera gave an overall view and allowed following the flame spread over the $5 \mathrm{~cm}$ grid system on the sample face(s). The other was used to get close-up pictures of the melt coagulation and flow process for mechanistic insights. Heat release rate ${ }^{23}$ and sample/pool weights were also recorded as a function of time.

\footnotetext{
${ }^{22}$ The pan was insulated from the scale with a $2.5 \mathrm{~cm}$ thick slab of ceramic fiber insulation. Two thermocouples placed on top of the scale, beneath this insulation, never showed more than $2{ }^{\circ} \mathrm{C}$ temperature rise during a test. We infer that the scale readings were unaffected by thermal transients from the fires above.

${ }^{23}$ There is no complete analysis of the accuracy of heat release rate measurements in this calorimeter available as yet. However, there is a detailed analysis of this issue for the NIST 6 meter calorimeter which operates in a very similar manner [23]. The heat release rate has an expanded uncertainty ( $95 \%$ confidence interval) of $11 \%$. To a first approximation this same uncertainty can be applied here to HRR measurements in the NIST furniture calorimeter and in the cone calorimeter.
} 


\section{RESULTS AND DISCUSSION}

Gasification Kinetics from Thermogravimetry. As noted previously, one step Arrhenius gasification kinetic descriptions were obtained by the Kissinger method for two polypropylene and two polystyrene resins. No thermogravimetry-based kinetics have as yet been obtained on any of the polyurethanes used in this study. However, it is known from previous work $[7,8]$ that polyurethanes are substantially more complex, requiring two or more reaction steps to capture their behavior (especially given the fact that they start out the heating process as a cross-linked polymer).

Figures 4a , 4b, and 4c show the experimental and predicted thermogravimetric weight loss curves at the three experimental heating rates for PD 702N polypropylene. The predicted curves come from plugging the Kissinger-Method kinetic constants into the following rate of weight loss equation

$$
\beta d\left(w / w_{0}\right) / d t=A_{\text {tga }}\left(w / w_{0}\right)^{n} \exp \left(-E_{\text {tga }} / R T\right)
$$

where $\beta$ is the constant heating rate, $\left(w / w_{0}\right)$ is the fractional weight of sample remaining (also called the conversion), $t$ is time, $A_{t g a}$ is the pre-exponential factor, $n$ is the reaction order, $E_{t g a}$ is the effective activation energy of the thermogravimetric weight loss process, $R$ is the gas constant and $T$ is the absolute temperature of the sample. The above equation has been solved using a fourth-order Runge-Kutta numerical scheme to produce the "predicted" curves in Figure 4.

In the calculated curves for Figure 4, we have taken the reaction to be first order in the quantity $\left(w / w_{0}\right)$. A reaction order other than unity does not make much physical sense in the present context. In fact, in the actual experiments, the effect of reaction order should be indiscernible since the "reactant", i.e., the polymer, appears to remain at full concentration (full density) as it regresses. However, inspection of Fig. 4 shows that, with a reaction order of unity, the match is best for the lowest heating rate and looks increasingly poor at higher heating rates as the conversion progresses past about 0.2 . The results do still accurately catch the upward shift of the onset of the reaction with heating rate.

The match between the predicted curves and the thermogravimetric curves can, on average, be improved by taking into account a non-unity value of reaction order. In effect, the values of reaction order, $n$, and the pre-exponential factor, $A_{\text {tga }}$, interact - as $n$ goes down, $A_{\text {tga }}$ goes up to compensate; the value of $E_{\text {tga }}$ is not affected at all by this trade-off. By lowering the value of $n$ from 1.0 to 0.85 for this particular polypropylene, the slope of the mid-section of the reaction rate curve is made to come substantially closer to the experimental behavior. This mid-range agreement tends to come at the expense of the early reaction rate behavior - the predicted curve with the lower value of $n$ tends to be delayed in the onset of the reaction. The experimental curves cannot be 
matched perfectly with this single reaction model but this description should be generally adequate for describing the gasification reaction as it competes with other processes in the experiments described below ${ }^{24}$.

Table 3, which summarizes the kinetic parameters for the four polymer resins, includes two sets of values for PP702N polypropylene based on the above discussion of the effect of reaction order. The value of $E_{t g a}$ shifts slightly in the second set of parameters, not because of the change in reaction order, but because a somewhat different fit was used to the available data from replicate tests. The two sets thus represent two plausible versions of the gasification rate parameters for this polymer resin.

Fig. 5 shows the prediction of how that reaction rate (in this case, for PS 666D polystyrene) shifts still further upward as the heating rates are raised up to the sort of level seen in the radiative heating experiments. The upward shift in significant onset of the reaction is substantial. The amount of the shift depends on the magnitude of the effective activation energy, $E_{t g a}$; the larger that value, the less is the upward shift. Table 3 shows that all of the activation energies are roughly comparable so all should shift by an amount comparable to that shown in Fig. 5, given equal heating rates. However, the effective heating rate in a radiative gasification experiment, or in more complex burning configurations, depends on the overall rate of mass loss from the sample. This can vary substantially among polymer resins so the heating rate can also vary substantially and thus also can the absolute upward shift of the onset of the gasification reaction.

As noted previously, it must be assumed here that this upward temperature shift in the gasification reaction does not change the controlling mechanism and so the kinetic parameters in Table 3 are valid under fire-like conditions.

Thermogravimetric Scan of Polyurethane Foam Behavior. Single heating rate tests $\left(5{ }^{\circ} \mathrm{C} / \mathrm{min}\right.$ in nitrogen) were run on the various polyurethane foams used in the present study. These foams tended to behave quite differently in the fire tests described below. The present data provide one set of clues as to why this is so.

Figures 6 and 7 are examples of the thermogravimetric curves for two of the polyurethane foams, NFR and P, respectively. The other foams gave qualitatively very similar results. There are two principal peaks of weight loss, rather than one as for the full density thermoplastics discussed above. As discussed further below, the first peak is due to the loss of the isocyanate-related moieties and the second is due to the gasification of the polyol. (The source of the minor intermediate peak for the $\mathrm{P}$ foam is unknown.)

The relative thermal stability of the foams is of interest in interpreting their fire behavior results below. Actually, there are several measures of foam stability which one might apply. Table 4 lists four such measures. The first three come directly from the thermogravimetric curves: temperature at which $2 \%$ of the sample mass is lost (as a

\footnotetext{
${ }^{24}$ See Appendix 3 for further TG kinetic analysis, using a different data reduction technique, performed after the bulk of this report was written.
} 
measure of the onset of foam gasification), the temperature of the first major weight loss peak and the temperature of the second major weight loss peak. Thermogravimetry does not allow observation of the sample as it is heated and one other desirable measure of foam stability is the temperature at which its physical structure collapses (essentially the temperature at which the foam appears to melt). Here this was measured by placing a small (few $\mathrm{mg}$ ) sample of foam on the heated stage of the rheometer as it was programmed upward at $5{ }^{\circ} \mathrm{C} / \mathrm{min}$. The stage is enclosed by an insulated, nitrogen-purged oven with windows. The sample was observed during its temperature rise and the onset of physical collapse was noted. This extended over a range of temperatures that is probably a result of both kinetic and heat transfer limitations; the low end of the range should suffer least from the heat transfer effects. The melt initiation temperatures are accurate to approximately $\pm 5{ }^{\circ} \mathrm{C}$.

The first point to notice from Table 4 is that the onset of the physical collapse of the foam is associated fairly closely with the first weight loss peak. This makes sense - this peak involves the loss of the moieties which hold the polyol chains together in a rubber-like structure. What is somewhat surprising is that these cross-links appear to have to be so extensively destroyed before the foam actually collapses. ${ }^{25}$ In any event, it is noteworthy, in light of the fire behavior results below, that Foam $\mathrm{P}$ tends to collapse at the lowest temperature (though not by a great margin). ${ }^{26}$

Another point to note is that the first two columns in Table 4 do not give a consistent message about which foam is most/least prone to gasification. Foam Z” reaches $2 \%$ weight loss at the lowest temperature but the graphited foam has the lowest temperature for the first mass loss peak. This mixed story is, at least in part, a result of the fact that these foams are complex mixtures of ingredients of varying volatility/stability. The early weight loss (2\%) could be due to a "secondary" component (in Z", most likely one of the flame retardants) that is more volatile than the foam itself. Thus the first weight loss peak is probably a more relevant indicator of overall thermal stability and, surprisingly, the graphited foam is thus judged least stable. Foam $\mathrm{P}$ is next.

Inspection of the placement of the first and second weight loss peaks (and the onset of foam collapse) for NFR, Z0 and Z" foams suggests they are all of similar composition. It is noteworthy that they all came from the same manufacturer and have nominally the same density.

The $\mathrm{K}$ and $\mathrm{L}$ viscoelastic foams do not seem to stand out strongly in any particular way here (aside from having the highest temperatures for $2 \%$ weight loss). Their fire behavior, as seen below, was unique, however.

\footnotetext{
${ }^{25}$ This need to reach near the peak of the first reaction may be, to some extent, a result of the way the sample was heated mainly from below in the rheometer experiments

${ }^{26}$ The graphited foam did not collapse. The recorded temperature range corresponds to that over which the graphite granules could be seen expanding. There was no liquid phase discernible at any point with this foam.
} 
Finally, it is necessary to add a caveat deriving from the low heating rate used in these thermogravimetry experiments. It is related to points made above - the low heating rate here and the high heating rate in actual burning could, in principal, lead to a re-ordering (or an accentuation of differences) of the various measures in Table 4. All should shift to higher temperatures at higher heating rates but some may shift more than others.

Polymer Melt Viscosity. The procedure for obtaining a temperature-only depiction of polymer melt viscosity was described above. Figures 8, 9, 10 and 11 show the results for the four full density thermoplastics used in this study. Again, in all cases, the viscositytemperature relation is that passing through the indicated data for the undegraded resin and then through the two (or three) points inferred at higher temperatures using the extrapolated data from the melt samples obtained in radiative heating experiments.

There are significant shortcomings in the process used here to get an approximate viscosity-temperature (only) relationship. The extrapolation of the data for the captured melt is linear and, in some cases, it is a long extrapolation. The linear extrapolation essentially assumes that the slope of the melt data being used for this purpose is a result of enhanced polymer chain mobility, not decreasing mean molecular weight. The fact that the slope of the melt data generally parallels that of the lower temperature portion of the undegraded polymer tends to confirm this assumption. In effect, the melt sample appears to have undergone as much degradation as it is going to undergo until it reaches temperatures comparable to or greater than those at the surface of the sample which generated that melt. There are degradation kinetics issues underlying this that need further discussion; we address this further below. Another concern in the extrapolation is that the temperatures we extrapolate to are themselves subject to the measurement uncertainties described above. Furthermore, all of this is being done on a semi-log plot. Given this, the melt viscosity values that are inferred, especially at the highest temperatures that are ultimately of most relevance to a burning polymer sample, are uncertain to at least a factor of two to three. This uncertainty may not seem too bad when one looks at the enormous ranges over which melt viscosity is changing for all of the polymer resins considered here. Note, however, that the part of the curve which counts the most in explaining/predicting fire behavior of thermoplastics is at the right side in Figs. 8-11 and this is where the uncertainty is greatest.

The melt samples used for the above extrapolations were obtained from $10 \mathrm{~cm}$ high samples. The polymer melt/gasification model that uses these data as input is to be compared with data from samples of this same dimension so this is not a concern in that context. However, the same viscosity data will eventually be used to test fire growth models on larger samples. The reason that this could be a concern relates to the degradation kinetics issue, just mentioned above. The melt samples whose behavior was used in Figs. 8 to 11 are a product of a certain exposure time to the elevated temperatures. The "average" element of the melt sample originated at mid-height on the sample and then flowed down off the sample and cooled to room temperature. The time required for this depends on the viscosity of the melt at the sample surface temperature. The polymer degradation process may have been proceeding at a finite rate during this flow process 
and so its extent could depend on the length of time spent at the surface temperature. A taller sample, with its longer flow time could then yield a melt sample that is further degraded, a fact not reflected in the viscosity-temperature relations derived from Figs. 8 to 11 .

To check for the possibility of this effect, experiments were run with both $10 \mathrm{~cm}$ and 20 $\mathrm{cm}$ tall samples. Here it was necessary to switch from the cone heater to a gas-fired radiant panel to obtain a uniform flux over samples of both heights. With this set-up the only useable radiant flux level was $20 \mathrm{~kW} / \mathrm{m}^{2}$; at higher fluxes the samples could not be prevented from igniting to flaming rather than simply undergoing the desired process of passively melting/gasifying. Replicate samples of PD702N polypropylene and PS 666D polystyrene were tested at this flux using the two sample heights. Viscosity measurements were then made on the captured melts. For the polypropylene, the variability between replicate melt samples (a factor of about 1.8 in this case) was equal to the variation seen with melt samples from the two different sample heights. For the polystyrene, the results were basically the same - there was no clear cut effect of the increased sample height on the melt viscosity of the captured melts.

In addition, for the polystyrene, gel permeation chromatography ${ }^{27}$ was applied to all of the melt samples and to the original resin. This technique reveals the molecular weight (MW) distribution of a polymer sample. It showed that all of the melt samples were essentially indistinguishable though clearly lower in mean MW that the original resin. These results imply that the degradation kinetics are proceeding slowly at the surface temperature - slow enough to obscure any pronounced effect of sample scale on the melt viscosity-temperature relationships derived here.

Interestingly, at this $20 \mathrm{~kW} / \mathrm{m}^{2}$ flux, the viscosity of the polystyrene melt has dropped by only a factor of ten and that of the polypropylene by a factor of thirty. Since the weightmean molecular weight (MW) is expected to have a 3.4 power effect on polymer melt viscosity [12], this implies the weight-mean molecular weight is dropping by only a factor of two or three. For a typical polymer, the ratio of weight-mean MW to numbermean MW is greater than one and this ratio is expected to increase in a thermal degradation process driven by random chain scission, as we have here. This means that the change in the number-mean MW will be less than the factor of two or three. In other words, the melt flowing off the samples at $20 \mathrm{~kW} / \mathrm{m}^{2}$ is still a long chain polymer. The melts from higher fluxes shown in Figs 8-11 drop by factors ranging up to a maximum of 30,000 (6523 polypropylene at $40 \mathrm{~kW} / \mathrm{m}^{2}$ ). This corresponds to the weight-mean MW being cut by a factor of 21 and a number-mean MW cut by a lesser factor. Since these polymers likely start out with number-mean molecular weights in the range of a few hundred thousand [12], we are still dealing with long chains (> 1000 monomer units) in the melt and limited polymer degradation, on average (even though some volatile molecules are being generated $)^{28}$. One implication of this is that the amount of energy required to break the polymer down to the point where it can readily flow (as it does from

\footnotetext{
${ }^{27}$ These GPC results were obtained by B. Cipriano of the University of Maryland.

${ }^{28}$ When the number-mean MW drops below a critical value, the 3.4 power no longer holds. We are probably entering that domain at the higher heat flux levels.
} 
the sample face, especially at the higher radiant fluxes) is small. i.e., it is a small fraction of the heat given off during the polymerization process.

The "melt" from polyurethane foam is the result of more extensive polymer degradation, at least in one sense. The foam is originally a cross-linked polymer, i.e., its molecular weight is effectively infinite and it cannot flow. These cross-links must be broken before any flow can occur. The cross-links take several forms and the proportions depend on the particular foam formulation. They include urethane, urea, biuret and allophanate bonds. There seems to be some question as to whether these last two bond types actually exist to any significant extent in a typical polyurethane foam [13]; in any event they are easily broken at temperatures well below $200{ }^{\circ} \mathrm{C}$ [14]. The urethane and then the urea bonds begin to break at temperatures somewhat over $200{ }^{\circ} \mathrm{C}$ by several routes [15], one of which (de-polymerization) can regenerate the isocyanate and active hydroxyl group on the original polyol. This last fact seems particularly relevant here, as will be seen below. The polyol itself, which typically is based on polymers of either ethylene oxide or propylene oxide (or co-polymers of both), degrades only at substantially higher temperatures, reported to be up to $375^{\circ} \mathrm{C}[15]^{29}$. As a result of this dichotomy in ease of bond breakages (which leads to the separate weight loss peaks in the thermogravimetry discussed above), one expects the "melt" from a flexible polyurethane foam to be dominated by largely intact polyol; Ref. 15 shows several lines of evidence to support this.

Polyurethane "melt" was captured from several foam compositions either in flaming experiments or in radiative heating experiments (and sometimes in both). Unlike the melt from the full-density thermoplastics discussed above, the captured material for most of the foams was a liquid at room temperature ${ }^{30}$. It was, however, significantly contaminated with bits of the blackened "skin" that tends always to form on the face of a degrading polyurethane foam. The samples were centrifuged to separate what was typically a light brown liquid from the (semi-)solid black particles. Figure 12 shows an example of the viscosity versus temperature for this liquid (here, for melt from the Z0 flame-retarded foam). Two curves are shown - one for a melt sample collected from the radiation-driven melt experiments in the cone calorimeter (at a radiant flux of $40 \mathrm{~kW} / \mathrm{m}^{2}$ ) and one for a melt sample collected during a three-dimensional fire growth experiment (with flames as the only heat source) ${ }^{31}$. Much of the noise in the data is a result of the low viscosity levels here, though some residue of solid particles may be contributing as well. The behavior in the neighborhood of $200{ }^{\circ} \mathrm{C}$ is unexpected - the viscosity, which decreases with increasing temperature above room temperature in a more or less normal

\footnotetext{
${ }^{29}$ Note that the temperature range of significant decomposition will be pushed upward in experiments such as those here in which the heating rate of the polymer is higher than those in the typical polymer decomposition study.

${ }^{30}$ The captured samples were kept frozen in sealed containers in the time between the experiment that generated them and the subsequent rheometry. The two viscoelastic foams gave a melt that turned into a rubber-like material at room temperature. Rheometry on these materials could only be achieved by an oscillatory method. It showed the effective viscosity of these "melts" at room temperature to be ca. 10,000 times higher than those from the other foams.

${ }^{31}$ The viscosity of the melt from flaming was, for some of the foams, up to ten times lower than that from the $40 \mathrm{~kW} / \mathrm{m}^{2}$ cone calorimeter radiation-driven melt experiments.
} 
manner, suddenly reverses the trend and increases to near or above the original level before decaying once more at still higher temperatures.

Figure 13 is an annotated viscosity curve for the melt from a different foam (NFR, nonretarded foam). There are two unexpected phenomena seen there. First, the sample spreads from under the rotating "tool” that is applying the controlled shear. Such spreading is not unusual as a consequence of simple expansion of the sample with increasing temperature. What is unexpected is that by $180^{\circ} \mathrm{C}$ the volume that has escaped from under the tool appears to be comparable to the volume that the tool can capture beneath itself. One might conclude that the subsequent increase in measured viscosity is a result of this sample migration. However, at a temperature around $250{ }^{\circ} \mathrm{C}$ another phenomenon that evidently was already in process becomes evident - arc-shaped "islands", which stand somewhat above the surrounding liquid level, begin to break away from the meniscus region surrounding the edge of the rotating tool. These "islands" appear distinctly non-fluid and as the temperature goes still higher they appear to "melt" back into the liquid surrounding the tool ${ }^{32}$. In short, the increased viscosity (and its subsequent decrease) appears to be caused by a transient "solidification" or, at least, a partial gelling, of the polyurethane melt.

As noted above, Ravey and Pierce [15] give evidence that de-polymerization of the urethane bonds is one degradation pathway. Breakage of both urethane bonds on a crosslink would regenerate toluene diisocyanate (TDI) which boils at about $250{ }^{\circ} \mathrm{C}$. The TDI would normally tend to escape from the liquid phase; according to Ref. 15 it then is consumed in the vapor phase via reaction with amines generated during the polymer degradation. In the present tests, there is not necessarily enough time for all of the TDI to escape from the melt which flows from the sample and then cools. In Ref. 15 it is shown that residual TDI in the melt depends on the pyrolysis conditions. The above behavior suggests that urethane bonds are re-forming in the melt sample at about $200{ }^{\circ} \mathrm{C}$ and then breaking again as the sample temperature increases further. This anomalous viscosity behavior was seen with the melt samples from all of the polyurethane foams though the onset temperature and curve shapes showed some variation with foam composition. All except Foam L viscoelastic foam (Foam K was not measured and, of course the graphited foam could not be measured since it gave no melt) gave very noisy data at the upper temperature limits of the measurement $\left(\mathrm{ca} .300^{\circ} \mathrm{C}\right.$ ) but were roughly the same in viscosity (ca. 0. $1 \mathrm{~Pa}$-s, comparable to $\mathrm{PD} 702 \mathrm{~N}$ polypropylene at $400{ }^{\circ} \mathrm{C}$ ). Foam $\mathrm{L}$, measured in an oscillatory manner, gave results at this temperature that were 1000 to 10,000 times higher. Since this foam (and Foam K) did manage to flow off the sample surface at temperatures not too much higher than this we infer that the oscillatory method does not provide a pertinent measure of viscosity, at least for these foams. ${ }^{33}$

\footnotetext{
${ }^{32}$ Note that a few bubbles are being generated beneath the tool as the viscosity is peaking but serious bubbling that would definitely affect the viscosity measurement is delayed to well over $300{ }^{\circ} \mathrm{C}$. This presumably reflects accelerating degradation of the polyol.

${ }^{33}$ The oscillatory method does not directly provide a melt viscosity. One has to apply the Cox-Merz [18] rule to infer a viscosity and that rule is most accurate when the viscosity is low and the fluid is Newtonian.
} 
The practical implications of this behavior for modeling of fires involving polyurethane foam are not yet entirely clear. In particular we note that we have not obtained a measure of the foam melt viscosity at temperatures higher than about $300{ }^{\circ} \mathrm{C}$ and the results below this are odd, to say the least. Such lower temperature results are relevant mainly to how far the melt can spread on a catch surface and this, in turn, affects the diameter of a pool fire and also its plume height. It is possible that the complications seen here are largely irrelevant, if the re-polymerization reactions are kinetically-limited. In the above rheometric measurements, the heating rate was $1^{\circ} \mathrm{C} / \mathrm{min}$; in a real fire heating and cooling processes are at least an order of magnitude faster and there may not be enough time for re-polymerization. It may be more profitable to study the viscosity-temperature relation of a few representative polyols in isolation since we have inferred that the melt is mainly composed of polyol.

Another real complication in a polyurethane melt fire is that the melt is frequently seen to be bubbling, especially in the flaming areas. The flow behavior of a two phase fluid like this may not be readily predicted from our existing rheometric measurements. This remains an area in need of further study; we make further observations below on the behavior of polyurethane melts in burning pool fires. In any event, it is worth noting that the foam melts remain much more fluid at low temperatures than do the melts from the full-density thermoplastics discussed above.

Two-Dimensional Radiation-Driven Melt/Gasification/Flaming Experiments. As noted above, these experiments were mainly done to provide data to test intermediate stages of models in the process of developing a full three-dimensional model of fire growth on a mass of a thermoplastic material. These experiments are essentially twodimensional in nature and, though they are initially transient in character, they yield steady-state results for mass loss rate by melt flow and by gasification along with the corresponding surface temperature. All of these data are to be compared to the Reaction Engineering International (REI) model of the same basic set-up. These experiments also provide a context in which to develop a greater understanding of the factors affecting the behavior of these melt/gasification systems. The processes occurring in these simplified experiments are the same as those occurring locally on any surface element during threedimensional fire growth over the same material.

Appendix 1 presents a one-dimensional, steady-state model of these melt/gasification experiments. The model, though it is a simplified description of what is happening in the present experiments, succeeds in capturing the correct trends of behavior and provides some useful insights into what would be required to alter this behavior appreciably.

Figures 14a, 14b and 14c show an example of the direct experimental outputs from a radiative melt/gasification experiment, i.e., the sample assembly weight, the weight of the melt flowing off of the front face of the sample and the output from the surface thermocouple probe. These results are all for a $10 \mathrm{~cm}$ by $10 \mathrm{~cm}$ cross-section slab of PS666D polystyrene heated on one face by a radiant flux of $20 \mathrm{~kW} / \mathrm{m}^{2}$. In Fig. 14a the weight of the entire apparatus on top of the scale is shown but the change is due only to weight loss from the sample (after the slight downward step at ca. $35 \mathrm{~s}$ indicating the 
removal of the shield on the face of the sample $)^{34}$. The sample soon begins to show some weight loss (combined gasification and melt flow). At about $500 \mathrm{~s}$ it rather abruptly begins losing weight more rapidly as the melt layer begins flowing smoothly from its entire face. Soon thereafter, the rate of weight loss is essentially steady for the rest of the experiment. Fig. 14b shows an essentially steady rate of melt flow onto the catch pan after about $600 \mathrm{~s}$. (When melt was being captured for later rheometry, two different catch pans were used. One was used for the transient period of changing weight loss and one was used for the steady-state period. Rheometry was done only on the melt from the steady-state portion of the test.)

Figure 14c shows the rather problematical nature of the surface temperature measurement. As described above, the thermocouple probe is brought into contact with the molten surface and worked in and out slightly to wet it fully with the melt; the movement is then continued in an attempt to find the maximum temperature in the surface region. The movement is also intended to counteract the difficult visual situation presented to the test operator in which it is not easy to tell exactly where the probe is with respect to the sample surface (because of reflections from an uneven surface and refraction below the surface). We are interested in the maximum temperature and assign it to the surface. ${ }^{35}$ How many of the temperature peaks in a plot like Fig. $14 \mathrm{c}$ to include in the surface temperature estimate is a judgment call and here it gives an $8{ }^{\circ} \mathrm{C}$ ambiguity, depending on whether one averages just the three highest peaks or averages all of the peaks. This is in addition to the other sources of surface temperature measurement error discussed above. Note that this interacts with the extrapolation of the melt viscosity to the sample surface temperature, as well.

The results of the various radiative melt/gasification experiments for four full density thermoplastic polymer resins are summarized in Table 5; virtually all test conditions were run at least in duplicate. Results for PD702N polypropylene and for PS666D polystyrene are plotted in Figures 15a, 15b, 15c and 16a, 16b, 16c, respectively, since these are used in the Appendix 1 to compare with the simplified steady-state model presented there.

Figures 15 and 16 show essentially the same trends with increasing radiant flux on the sample face, though quantitatively, of course, the two polymer resins yield differing results. As expected, the total mass loss rate (due to combined gasification and melt flow from the sample face) increases with increasing heat flux, as does the surface temperature and the melt flow rate (not plotted). What one might not a priori anticipate is that both resins show a decreasing fraction of material lost as melt when the heat flux is increased. This is a result of a shifting competition between gasification and melt flow as mass loss mechanisms. Evidently the increasing surface temperature has a stronger effect on the gasification process than on the melt flow process. All of these trends are correctly

\footnotetext{
${ }^{34}$ The stepped nature of the weight signal is due to the rather low resolution of the available analog output board for this scale. The occasional upward spikes are due to the operator moving the sample forward to keep its face in the outlet plane of the sample holder tube.

${ }^{35}$ Actually, since the radiation is absorbed in-depth and there is heat loss from the surface, the maximum temperature is slightly below the surface $[9,10]$ but this tends to be at a depth that is smaller than the thermocouple probe diameter and would not be resolved here.
} 
predicted by the simplified steady-state model presented in Appendix 1, where there is more discussion of these issues.

Table 5 shows that the two resins of differing "Melt Flow Index" from each polymer type did not yield greatly differing behavior. Fig. 17 shows a comparison of the total mass loss rates for the two polystyrenes. Inspection of Figs. 10 and 11 shows that, at $300{ }^{\circ} \mathrm{C}$, PS663 has a melt viscosity that is about 2.5 times higher than that of PS666D at the same temperature. In Fig. 17, at $30 \mathrm{~kW} / \mathrm{m}^{2}$, this yields a total mass loss rate that is reduced by only about $20 \%$. The limited data for the two polypropylenes indicate practically no change in total mass loss rate between the two resins. This resistance to change in the amount of melt flow is predicted by the model in Appendix 1 and is discussed further there.

An issue raised above was whether these experiments, when done in an open air atmosphere, are affected by oxygen attack on the molten polymer surface. To get some information on this point, two tests were run on PD702N polypropylene at an incident flux of $30 \mathrm{~kW} / \mathrm{m}^{2}$, using a nitrogen purge around the sample area. This was not an easy set-up and it was probably not fully effective in precluding all access of air to the sample face. It required surrounding the space between, and generally below, the sample face and cone heater with an enclosure and feeding a well-dispersed flow of nitrogen into the base of that enclosure so that it flowed upward past the sample face. The set-up appeared moderately successful at its goal; the nitrogen flow certainly tended to somewhat disrupt the smoky boundary layer on the sample face, especially at the higher of the two flow rates tested. The resulting data points fall into the scatter seen in Figs. 15 at $30 \mathrm{~kW} / \mathrm{m}^{2}$. This implies that the effect of oxygen attack on the sample face was a minor factor. The enclosure was very difficult to work with, blocking access to the melt capture area, so it was not generally adopted.

Experiments were also done with these resins in which the sample face was burning; Table 6 summarizes those results. The heat release rate (HRR) was measured since these tests were conducted in a cone calorimeter; the accuracy of HRR measurements in this device are within $\pm 10 \%$. The burning of the melt as it left the sample face was suppressed as quickly as possible though it tended to continue on a triangular "drip lip" of about $3 \mathrm{~cm}$ to $4 \mathrm{~cm}$ length that channeled the melt into a catch bottle. For the polypropylenes, surface temperature measurements here were even more challenging since the maximum reading of the thermocouple was not necessarily the value at the surface - the thermocouple was in the flame zone if it emerged from the surface. Generally, the temperature measurement results showed substantially more scatter. For the polystyrenes the technique used in all of the preceding measurements failed completely - it was impossible to see the thermocouple through the visually opaque flame so its position in the surface could not be determined. Instead, a smaller sheathed thermocouple $(0.25 \mathrm{~mm}$ dia.) was placed in the melt downflow from the sample surface as it passed through the semi-funnel-shaped lip immediately at the bottom of the sample face. The thermocouple lead was approximately parallel to the melt flow. This was only moderately successful since it was difficult to position reproducibly in a newly-shaped aluminum foil funnel lip in each test. Also, since the thermocouple was now within the 
(still-burning) melt, it tended to measure some average of the melt flow layer rather than the surface temperature. In two tests with polypropylene, where both types of temperature measurements were possible, there was not a clear indication that one method gave results much different than the other though the tests were done in the most difficult conditions (flame flux plus $20 \mathrm{~kW} / \mathrm{m}^{2}$ from the cone heater) and both results were correspondingly noisy. In any event, this is what is reported for the flaming polystyrenes under the "Surface Temperature" heading in Table 6.

Fig. 18 shows an example of the effect of the flame on the overall mass loss rate from the sample, in this case, PS 666D polystyrene. The net effect of the flame for this polymer and this configuration appears to be the equivalent of adding an additional $25 \mathrm{~kW} / \mathrm{m}^{2}$ to the sample face; it does not otherwise change the physics of the problem. This heat flux differential is slightly lower than what one might expect here [11] and may indicate that this very sooty polystyrene flame is not entirely transparent to the radiant flux from the cone heater. The equal slopes of the flaming and non-flaming cases imply that the heat of gasification is unchanged by the presence of the flame; this concept is discussed further in Appendix 1.

The heat release rate (HRR) measurement results are reported in Table 7. These are data for comparison with a first stage flaming model, when it is available (REI model of the condensed phase, coupled with the NIST Fire Dynamics Model of the gas phase flaming). Most of the heat release rates were fairly steady and for these an average value is reported. A few showed a tendency to rise over the test duration; for these we report beginning and ending values. All of these values are roughly $20 \%$ higher than they would have been if there had not been burning melt on the drip lip, in addition to the burning on the sample face.

In Table 7 the limited data (6523 polypropylene and PS666D polystyrene) on the effect of doubling the radiant heat flux from $10 \mathrm{~kW} / \mathrm{m}^{2}$ to $20 \mathrm{~kW} / \mathrm{m}^{2}$ show a minimal effect for the polypropylene and a moderate effect (roughly $50 \%$ increase) for the polystyrene. Note the comparison with HRR results on the same materials obtained in the normal cone calorimeter configuration with the sample oriented horizontally. Here the values reported are for the bulk of the test, i.e., before the sample is reduced to a boiling melt pool that gives a spike in HRR. The range shown indicates a slow increase with time; the earlier values are probably more relevant here since they correspond to thermally thick behavior. The 6523 polypropylene shows a clear dichotomy between the two types of experiment the normal cone calorimeter gives more than double the HRR level seen in the experiments where the melt is allowed to escape by flowing off the sample face. Although we lack the complete data to prove it, the above observation about the effect of the radiant flux on HRR for polypropylene, coupled with the results in Table 7, implies that a similar dichotomy holds for PD702N polypropylene. This HRR ratio may also be the case for PS663 polystyrene (though $<2 \mathrm{X}$ ) but it appears less clear for the case of PS666D polystyrene ${ }^{36}$. Of course, we expect there to be a lower HRR for all cases in

\footnotetext{
${ }^{36}$ When the results from the cone melt experiment are reduced by $20 \%$ to account for the extra flaming on the drip lip, there does appear to be a significantly lesser HRR in the cone melt experiments with
} 
which the melt flow escapes - it is taking a substantial amount of sensible heat with it. The amount of heat removed depends on the melt flow rate which, in turn, depends on the melt viscosity. The melt viscosity depends on the surface temperature which depends on a heat balance (see Appendix 1); we cannot a priori estimate which polymer will come out with the greatest or least heat loss via melt flow.

Table 7 also includes some results for two mildly flame-retarded formulations. This was one small step in a direction that needs much further work since it is likely that minimizing the flammability hazards of these materials will call for an optimum combination of both viscosity modifiers and flame retardants. Magnesium hydroxide decomposes to give off water, absorbing heat as it does so. In the quantity used here it has virtually no effect on polymer melt viscosity. It also appears to have no significant effect on the HRR here, probably because the add-on level is much lower than the levels used in commercial FR polymers.

Radiation-driven melt experiments were also carried out on most of the polyurethane foams in Table $2^{37}$. The goal was to determine the differences in ease of melting among these foams which, as will be seen below, exhibited widely differing fire growth behavior. Recall that the thermal analysis curves of these foams did not differ greatly, suggesting that they all share similar controlling steps, as least as far as their weight loss is concerned. As noted above, in an overall sense, the foams first lose their isocyanaterelated constituents and then their polyol-related constituents. This does not tell us when they become fluid, nor how fluid. The experiments above (in the rheometer oven) provided information about the temperatures at which the foams collapse to liquids. The radiation-driven melt experiments provide direct information on how much fluid is produced by the collapse.

Figure 19 summarizes the melt flow rate results for the six foam formulations which were tested. Reported there is the steady-state value of absolute flow rate of melt from the sample face $(2.5 \mathrm{~cm}$ by $2.5 \mathrm{~cm})$. The data at $40 \mathrm{~kW} / \mathrm{m}^{2}$ are probably most relevant to what one could expect in actual flaming ${ }^{38}$. Note that there seem to be substantial differences in response to a varied incident radiant flux among the foam formulations (though the data are rather sparse in this respect). The most striking result, however, is the roughly $10 \times$ variation in the rate of mass lost as melt among these six formulations (compared at $40 \mathrm{~kW} / \mathrm{m}^{2}$ ).

Figure 20 shows the percent of mass lost as melt at $40 \mathrm{~kW} / \mathrm{m}^{2}$. This removes the issue of the differing foam densities. Now the difference among foam formulations is about a factor of six. There seems to be a dichotomy in behavior with the two viscoelastic foams

polystyrene than in the normal cone experiments. This is to be expected since fuel is escaping from the burning zone.

${ }^{37}$ The graphited foam was not tested in this mode since it showed no tendency to melt in the fire growth experiments described below. It also left a char-like residue on the sample surface (from the expanded graphite) which would have precluded a steady-state regression of the type being examined here.

${ }^{38}$ Very limited work was done with flaming foams in this cone calorimeter-based apparatus. Considerable difficulty was encountered with uneven regression of the sample face (faster at the top). It is not clear, at present, if these problems are inherent or can be overcome. 
and the high melamine foams losing by far the greatest mass as melt. The other three foams (which come from the same manufacturer and are probably similar in formulation) yield roughly half as much melt. The non-retarded foam is rather strikingly resistant to melting.

In Fig. 20, for the three foams on the left, mass which was not lost as melt was lost as gas. For the other three foams (on the right), some mass also went into the formation of a black surface "skin" which was periodically removed. The mass going into this skin was highest for the non-flame retarded foam (NFR) and amounted to $20 \%$ of the total mass of the foam.

Since we lack any details regarding the formulation of these foams, we cannot pin down the reasons underlying their widely varying behavior. We can point out some aspects, however. The "conventional" polyurethane foam studied in Ref. 15 was about 2/3 polyol by mass and $1 / 3$ isocyanate. Thermogravimetry on their foam looked generally similar to that seen here (e.g. Figs 6 and 7). They report that the second DTG peak is primarily due to gasification of the polyol and it accounts for about $2 / 3$ of the total mass lost. Those proportions (and, presumably the underlying reasons) are also roughly true for all of our foams. If the thermogravimetry behavior carries over into the radiative heating experiments we then expect, as a first approximation, that we will have $1 / 3$ mass lost due to gasification of the isocyanate-related species and 2/3 mass lost due to the more thermally stable polyol left behind and then flowing off of the sample face. A glance at Fig. 20 shows that the foams fall either distinctly higher or distinctly lower than this expected value.

In fact the picture underlying this expectation is too simple. It ignores the issue of whether and how fast the melt (whatever it is) can get off of the sample surface and how hot that surface is. Temperature measurements were made on these sample surfaces though the contact between thermocouple and surface material was less effective than it was for the full-density thermoplastics discussed above. Table 8 summarizes the measurement results. Focusing on the results at $40 \mathrm{~kW} / \mathrm{m}^{2}$, one sees that the surface temperatures did vary by more than $100{ }^{\circ} \mathrm{C}$ with the $\mathrm{P}$ (high melamine) foam giving the lowest result and the non-flame-retarded foam giving the highest. Comparing the temperature values to those seen in thermogravimetry for the same foams (Table 4) and even allowing that the temperature on these higher heating rate experiments are shifted upward somewhat, one infers that, with the probable exception of Foam P, the surface temperature is high enough to be partially degrading/gasifying the polyol as the "melt" tries to flow off of the sample surface. This might explain the lower melt yields seen with the three foams on the right in Fig. 20. It does not explain the higher than expected melt yields for the three foams on the left in this figure. Particularly anomalous there are the two viscoelastic foams which give high viscosity "melts" that do not easily flow off of the sample face. These three foams have the lowest "collapse" temperatures in Table 4. Foams $\mathrm{K}$ and $\mathrm{L}$ also have the highest peak temperatures for the second weight loss peaks in thermogravimetry (Table 4), possibly implying more stable polyols. These combinations seem to help explain the trends in Fig. 20, but it is not clear that they fully explain them. 
We will see below that this diverse range of melt/gasification behaviors with foam formulation carries over into the fire growth behavior.

Preliminary Fire Growth Experiments. A limited number of experiments has been done on melt-pool assisted fire growth over sheets of full-density thermoplastic (a commercial polypropylene with no flame retardant). Much more experimentation has been carried out on polyurethane foams. Here we discuss the full density thermoplastic results first.

The goal here was simply to explore the phenomena and obtain some quantitative data that can be used to compare with the REI or particle method models when either reaches full three-dimensional capability.

Polypropylene. Figure 21 sets the stage, showing a melt-pool assisted fire for a case in which the polymer sheet is very close to the horizontal, Marinite $\mathrm{P}$, catch surface $(4 \mathrm{~cm}$ to $5 \mathrm{~cm}$ ), thus bringing the pool fire plume into good contact with the sheet. Note that the sample is $30 \mathrm{~cm}$ tall and $60 \mathrm{~cm}$ long; the grid lines on the sample are $5 \mathrm{~cm}$ apart. The fire was initiated by igniting the full left vertical end of the polymer sheet. In the figure the fire is propagating to the right with the flames on the vertical sheet being assisted by the fire plume of the pool fire created by the polymer melt.

Inspection of Fig. 21 shows several interesting features. The pool fire is centered near the rear edge of the sample, not under the leading edge of the flames on the sheet. This is because it is being fed flaming polymer melt most rapidly from an area several centimeters behind the forward-most portion of the sample flame front where the shape of the trailing edge of the sheet curves rapidly from near vertical toward the horizontal. There is a flow separation region there that tends to dump nearly all of the melt flow accumulated from higher up on the trailing edge of the sheet. From this flow impingement area on the catch surface, the melt tends to flow radially at first. That portion of the melt that is going forward (in the direction of flame spread) under the leading edge of the flames on the base of the sheet encounters a cold catch surface that extracts heat from the melt, lowers its temperature and rapidly raises its viscosity. This nearly halts the flow in this direction, which, in fact, greatly slows the potential rate of fire spread ${ }^{39}$. Because much of the "forward" flow of melt is inhibited and, because the catch surface in the opposite direction has been pre-heated by the pool fire in its march

\footnotetext{
${ }^{39}$ The forward rate of flow is limited by the rate at which the melt can heat the catch surface and so it could vary strongly with the thermal inertia of that surface (as can the heat release rate of the pool fire [3]). This "reluctance" to flow onto the cold catch surface in the direction of fire spread can be readily overcome by tilting the catch surface downward just a few degrees in the direction of fire spread. The result is erratic, however, since the front of the moving melt still tends to freeze and thus create a local dam blocking the melt behind it. The dam is then bypassed to one side or the other and this can move the center of the pool fire away from the polymer sheet causing very erratic behavior. Too much tilt will move the pool fire rapidly in the direction of tilt and preclude enough local pool fire dwell time to ignite (or melt) the sheet above it. Finally, with a sheet-like fuel such as this, a tilt in any direction away from the long axis of the sheet will remove the pool fire from under the sheet and defeat the self-feeding mechanism.
} 
forward, there is a preferential melt flow backward, away from the direction of fire spread and toward the rear end of the pool fire. This tends to somewhat disengage the pool fire from the overall forward fire spread process. The melt flow on the catch surface appears to be driven by the small hydrostatic head that develops due to the finite thickness of the melt layer on this horizontal surface. Near the foot of the pool fire flames, the flow is also driven outward, away from the pool fire center, by the surface tension gradient that is large in this region. (One can often see a step up in melt layer thickness beneath the flame foot.) Note that the region of the pool directly beneath the flames is bubbling, indicating in-depth generation of gaseous degradation products from the polymer melt. Also note that, on the left (just to the left of the flame foot), the pool fire has burned out by locally consuming all of the melt, leaving a dry central area ${ }^{40}$. Around this area, however, there is a substantial amount of melt that has not burned and is left by the fire. Evidently, this residue has cooled sufficiently (and remains sufficiently heat-sunk to the catch surface) that it will not allow flame spread onto its surface (in effect, its temperature cannot be raised to the point where it will ignite).

Note that the polymer sheet itself is somewhat wavy on its rear edge (warped out of the plane defined by the cold portion of the sample sheet). This is a consequence of the heatinduced softening (and, perhaps, expansion) of the sheet before it actually begins to melt and flow at an appreciable rate. This aspect of the sample behavior was not reproducible. It interacts with the location of the separation point on the rear edge of the sample and thus influences where the bulk of the melt gets deposited in relation to the leading edge of the fire on the base of the sample. This appeared to be a major source of scatter in the evolution of the heat release rate from the fire, as described further below.

The above processes could conceivably produce an essentially steady-state, propagating fire after some initial transient. Interestingly, while the flame spread rate along the bottom edge of the sample sheet is nearly steady in all cases, other aspects of the fire, including the heat release rate, are not steady.

Figures 22a, 22b, 22c and 22d show the results as a function of time from one of the tests (in this case, a $3 \mathrm{~mm}$ thick polypropylene sheet placed $4.3 \mathrm{~cm}$ above the Marinite catch surface); this is the same condition as that for the photo in Fig. 21.

Fig. 22a shows the overall heat release rate (HRR) which includes the heat released from all surfaces - the sample and the pool. ${ }^{41}$ Clearly there is a large transient effect that increases the HRR strongly about half-way through this test. Fig. 22b shows just a hint as to what is causing this. In this Figure, one sees that the progress of the flame front along the bottom edge of the sample is fairly steady. Progress of the flame front near

\footnotetext{
${ }^{40}$ The Marinite $\mathrm{P}$ is somewhat porous and some of the melt penetrates into its pore structure. Since these Marinite boards were used in repeated tests, the "infused" melt was burned out with a torch after every test. ${ }^{41}$ An initial goal was to attempt to separately measure the HRR from the sample and its pool. Further thought reveals that this can only be done by separately measuring the mass loss rates due to flaming from these two burning areas. That , in turn requires that the flow of mass between the sample and its pool be interrupted periodically. This would be, however, highly disruptive of the overall burning process since the disruptions would have to last tens of seconds (given the response time of the calorimeter). Thus, given present technology, it is impractical to separately resolve the HRR from the sample and its pool fire.
} 
the top of the sample (along the top grid line visible in Fig. 21) seems to proceed at two distinct rates. The early progress is much slower than that along the bottom edge of the sample, but, just after $600 \mathrm{~s}$, the rate of flame spread near the top accelerates to a rate faster than that along the sample bottom ${ }^{42}$. Figure 22c shows a related phenomenon which is directly tied to the increased HRR - the length of the pool fire (in a direction parallel to the long axis of the sample) increases strongly at about the same time as the top edge flame spread rate accelerates and the HRR increases. It is the increase in pool fire size (somewhat roughly measured by this pool fire length) which causes the increase in HRR.

Fig. 22d shows the mass of the sample and the pool as a function of time. A notable feature here is the amount of mass still in the pool at the end of the experiment ${ }^{43}$. This fire spread process is more efficient at melting the sample onto the catch surface than it is at burning up the melt. (Again, since it is due in large measure to heat lost to the catch surface, this "inefficiency" will vary with the thermal inertia of the catch surface material.)

The phenomenon underlying the increase in pool fire length/size is somewhat complex (and poorly reproducible). Recall that the fire spread process is initiated by igniting the full height of one edge of the vertical sheet. This purely vertical flame front is not stable. The bottom edge portion of the front tends to move forward faster that that above it; the reason appears to be related to the sensible heat content carried by the polymer melt flowing down the burning area ${ }^{44}$ of the sample. The bottom-most portion of the sample has flames on both sides, on the rear-most edge and also on the bottom edge of the sample. This slightly greater heat input in this location (versus any higher location), coupled with the heat input this region receives from down-flowing melt from regions above, tends to create a slight slope on the bottom edge, going downward in the direction of flame propagation. This slope feeds melt in this direction and its heat content accentuates the rate of flame propagation on the bottom edge. The amount of melt being fed toward the leading edge of the propagating flame front on the bottom edge of the sample is rather small ${ }^{45}$. As noted, above, the bulk of the melt flow from higher portions of the sample is lost at a separation point part way up the now curved trailing edge of the sample. This flow separation is presumably occurring at a location where the gravity vector (corrected for the local slope of the surface on which the melt flow is occurring) just exceeds the surface tension force that keeps the melt attached to the sample surface. This location is not necessarily stable since the out-of plane curling of the heat-softened sheet varies with time, altering the local slopes. In any event, as soon as the flame begins to move faster on the bottom edge ${ }^{46}$, it alters the heat transfer to those positions of the

\footnotetext{
${ }^{42}$ The reported spread rates are for the rate of movement along a horizontal line. The flame front is always actually moving normal to itself. If the front is nearly parallel to the horizontal line of interest (which happened in some tests near the top of the sample) the movement rate along that line can appear to be exceptionally fast.

${ }^{43}$ The experiment was typically ended after the sample flames had ended and the pool fire was dying down to a fraction of its peak size.

${ }^{44}$ The sample burns on its trailing edge surface and on a length of $2-3 \mathrm{~cm}$ ahead of this.

${ }^{45}$ It is the melt that is generated below the separation point.

${ }^{46}$ This can take ten or more minutes.
} 
sample sheet above it since that flame begins to impinge on those areas (for a limited height above the bottom). The heat transfer is increased in these areas due to greater flame contact. This can have two effects: increasing the flame spread rate at these areas above the bottom and increasing the melt flow rate off of the sample. The flow separation point also moves somewhat further back (and higher up) on the sample with the result that the pool fire gets somewhat longer (growing in the direction opposite that of the fire propagation $)^{47}$. The greater area of the pool fire tends to increase its heat release rate. This curvature-inducing effect can be self-reinforcing so that the curved trailing edge of the sample becomes still more curved and all of these trends become more pronounced. Countering this are at least two non-reproducible factors: (a) as noted, the out-of-plane curling of the sample seemed random and it tends (when the curling is partially upward) to disengage the flames from the sample surface above the curl (b) random flow disturbances seen under the three meter calorimeter hood tended to move the flames around and also disengage them from the sample surface. The net result was that two nominally identical tests produced substantially differing HRR vs time curves such as those shown in Fig. 23. It should be noted that both of these tests were conducted with the sample elevated high above the pool fire on the Marinite catch surface so interactions with its fire plume were not a factor in the propagation process.

Figures 24, 25 and 26 summarize the results of the six tests performed with this polypropylene material. The variables were sheet thickness and height above the catch surface. All conditions were tested in replicate; these are shown as gray and black bars for each test condition.

Figure 24 shows the spread rate of the fire along the bottom edge of the sample. It is denoted there as the "dominant" spread rate because the flame front on the bottom always led that elsewhere on the polymer sheet. Note first the absolute numbers - this is not a rapid fire spread process; it required times on the order of $20 \mathrm{~s}$ to $30 \mathrm{~s}$ to move $1 \mathrm{~cm}$. It appears to be dominated by the rate at which heat from the flames and from the flowing melt can raise the temperature of the polymer at the bottom edge of the sample. Because of this slow spread, both sample thicknesses are essentially thermally thin so that the thicker sample yields only a slightly slower spread rate. One would expect further thickness increases to slow the spread rate significantly (assuming all other parameters are fixed). There is a modest but significant effect of moving the sample far above its pool fire suggesting that, when it is close to that pool fire, the additional radiative/convective heat from the pool fire plume does accelerate the heating of the bottom edge somewhat. The effect is less than one might expect. The limitation appears to be an inability of the pool fire to move further under the sample because, as noted, above, the melt cools and becomes too viscous to flow in this direction on a horizontal surface. An implication here is that the forward progress of the melt fire on the catch surface is largely determined by the forward progress of the flame front on the bottom of the sample sheet (and not the other way around). (In effect, the pool fire is being pushed forward by the forward movement of the separation point on the trailing edge of the

\footnotetext{
${ }^{47}$ The pool fire may also get somewhat wider. The camera view did not provide useful data on this issue. The actual pool area is the most pertinent parameter in HRR. The length values were sometimes rather poor representatives of area since the pool shape, on the trailing end, could be quite irregular.
} 
sample sheet that dumps melt into the pool.) In turn this means that, for this particular situation, the fire spread process is dominated by the spread of flames on the bottom edge of the polymer sheet. At the same time, the fire size (as measured by its HRR) is determined by more stochastic factors affecting the area of the pool fire behind the separation point.

This particular balance of factors can be skewed readily by tilting the catch surface slightly downward in the direction of propagation. A $3^{\circ}$ tilt produced the erratic behavior described in a footnote above. A lesser tilt could be more effective if it simply encouraged the melt pool to move somewhat more rapidly under the unburned portion of the sheet at a rate that allowed the pool fire to feed itself more rapidly; then control of spread could shift to the leading edge of the pool fire. These are the sorts of issues one can explore extensively when a verified model of this rather complex fire spread situation is available.

Figures 25 and 26 provide a somewhat unclear story. In Fig. 25, the $6 \mathrm{~mm}$ thick sheet clearly gives the highest HRR. The result in Fig. 24 implies that this doubled thickness sheet is dumping melt onto the catch surface at nearly twice the rate of that from the 3 $\mathrm{mm}$ thick sheet. Fig. 26 does not confirm that the resulting peak pool size is larger, however. As noted previously, this peak pool length measurement was not necessarily a reliable measure of pool area. At this point no other measures of pool area are available since we did not have a camera looking along the length of the sample. Fig. 25 shows that the thinner polymer sheet, when far removed from its pool fire, gave the smallest peak HRR. Figures 24 and 26 suggest that this is due, at least in part, to a slower melt flow rate and a smaller pool fire; it is very likely also due in part to a reduced HRR from the two fire zones (object and pool fire) since they were too far apart to reinforce each other by radiative/convective interactions. (In fact, it is rather surprising that a material such as polypropylene, with its high heat of combustion and very mobile melt, gives such a weak fire in the case where the source object is far removed from its pool fire.)

Polyurethane Foam. We turn next to the preliminary fire growth experiments on polyurethane foam. Here the goals were: (1) to explore the fire behavior phenomena and how they vary with foam properties; (2) to explore possible configurations for a test method which will give an assessment of how a foam would behave when placed within a real product.

Before describing the actual fire growth experiments, it is useful to introduce data on the cone calorimeter heat release rate (HRR) behavior of these foams. These were standard cone calorimeter tests with the irradiated surface of the sample facing upward. All of the foams were tested at an incident heat flux of $35 \mathrm{~kW} / \mathrm{m}^{2}$; the $5.1 \mathrm{~cm}$ thick samples were contained in aluminum foil so that their melt could not escape. Table 9 summarizes the results. Figure 27 shows the HRR vs time for the NFR foam, which is qualitatively fairly typical in its shape (note the two exceptions in Table 9). The HRR process is divided into two stages. In the first the HRR is roughly constant; it corresponds to a burning process above a collapsing, receding foam surface. When the foam has "melted" to the bottom of 
the foil container, the melt proceeds to burn more vigorously as the liquid is effectively pre-heated $^{48}$.

Note that we expect the burning process on the foam surface of a sample in the experiments below to reflect (see caveat, next paragraph) the HRR given for the plateau, not the peak (except for the graphited foam). Table 9 reports the approximate average HRR value of this initial plateau and the value of the peak HRR. Also included is the range of computed heats of combustion obtained by dividing the rate of heat release by the rate of mass loss from the sample. The sample mass measurement data had to be smoothed and differentiated to obtain the heat of combustion. This process gave rather noisy results (Fig. 27 shows the raw data points and a running average through them) but it was clear that, in general, the heat of combustion always increased with time over the course of the burn. The values given are the range as the burning progressed from the start of the initial HRR plateau to the end of significant combustion.

The primary purpose of these standard cone calorimeter experiments was to assess how the heats of combustion varied with foam composition. The incident radiant flux of $35 \mathrm{~kW} / \mathrm{m}^{2}$ was chosen to assure complete burning of the flame-retarded samples. This flux is much higher than the samples see in the tests below so the HRR values do not directly apply. We assume here that the relative HRR values (for the plateau) apply, but the experimental situations with their much lower heat fluxes may actually accentuate these relative differences.

Table 9 shows that there are significant differences in the plateau HRR as a function of foam formulation. The flame retardant(s) in $\mathrm{ZO}$ and $\mathrm{Z}$ " lower both the initial heat of combustion and the plateau value of HRR that goes with it (compared to NFR, which is probably a similar, non-retarded composition). In this table, it is difficult to distinguish the behavior of these two FR foams though Z" contains more retardant materials (Table 2). The viscoelastic foams appear to be slightly lower in their plateau HRR than NFR but their heats of combustion are essentially the same. The $\mathrm{P}$ foam, with its high melamine content, resists ignition for more than $300 \mathrm{~s}$ at this heat flux. This is much more than the time necessary to melt the foam down to a pool, so we infer that ignition requires that much of the melamine be driven out of this pool during continued heating. Melamine has a high melting point $\left(354{ }^{\circ} \mathrm{C}\right.$ ) but sublimes at temperatures above $200{ }^{\circ} \mathrm{C}$; the endothermicity (230 cal/g) and oxygen dilution effects of this sublimation are part of the mode of action of this retardant. When it does finally burn, the HRR peak is not particularly low and the heat of combustion of the residue is typical of the non-retarded foams in the Table. The graphited foam exhibits a HRR vs. time curve qualitatively similar to charring materials such as wood - an early HRR peak is followed by a monotonic decay. This is consistent with its physical behavior - the heated surface does not melt or recede but rather turns black and fuzzy as the graphite expands. Note that the peak is quite low compared to the other foams.

\footnotetext{
${ }^{48}$ This "pool” burning is sensitive to heat loses to the substrate below the sample. In the cone calorimeter, this substrate is a ceramic fiber insulation. In the fire growth experiments below, the pool fire occurs on the Marinite P surface which is a significant heat sink, slowing the HRR. See also the caveat in the text about the differing heat fluxes.
} 
The medium scale fire growth experiments on these foams were carried out in the same apparatus as that used for the polypropylene sheet experiments described above (shown in Fig. 2). As described above, they included a few different configurations. The ultimate configuration of principal interest for its test method potential is the $30^{\circ}$ Vee that uses a pair of foam slabs. Some interesting results were obtained with other configurations, however, and they are summarized here. Note that all of the foam samples were thermally thick ( $7.6 \mathrm{~cm}$ or $10 \mathrm{~cm}$ thick) in contrast to the thin sheets of fulldensity polypropylene.

The manner in which melt flows from a vertical polyurethane foam surface is very different than that seen with the full density thermoplastics. This was evident in the cone calorimeter, radiation-driven steady feed experiments, but it is much clearer here since it is stretched out in space over the sample surface. Figure 28 shows a close-up view of the area ahead of and behind a laterally-advancing flame front on a single vertical slab of Z" foam (there is a melt pool fire below and to the left of the area shown in the figure; the overall fire is moving from left to right in the photo). Again, the grid lines on the unburned portion of the sample surface are $5 \mathrm{~cm}$ apart. The flame front appears to be attached to the sample face along a line roughly connecting the points where the horizontal grid lines disappear. To the right of this there is some darkening of the foam surface which could be due to soot deposition or to a limited amount of foam cell collapse due to pre-heating from the flickering flame (or both). Immediately to the left of the flame attachment line the foam surface is covered by a pattern of fine dots. These dots grow and their numbers decrease as one moves further to the left behind the flame front where the burning process is penetrating further into the depth of the foam. This trend continues until it is apparent the dots are coagulating melt. When the local melt drop size is sufficiently large, the melt begins to flow down the face of the foam, forming the dark, continuous rivulets seen there. The melt can be seen dripping from the foam at two closely-spaced locations about $7 \mathrm{~cm}$ behind the flame attachment line (near the bottom of the photo.).

The behavior seen in Figure 28 is largely a consequence of the very low density of the foam (it is roughly $97 \%$ to $98 \%$ open space). When it is heated by the flame front, the foam cell structure collapses yielding a much smaller volume of "melt". As the flame heating continues and the local temperature increases, a portion of this melt is gasified; that portion varied strongly with foam composition in the cone calorimeter, radiation driven, steady feed experiments described above (Fig. 20). The non-gasified portion of the melt accumulates in the outer portion of the remaining cell structure. One might expect that this melt, being fully chemically compatible with the foam surface, would wet it and be pulled into the foam structure by capillary forces, disappearing below the sample surface. While wetting seems to occur, the capillary forces seem insufficient to pull in the melt ${ }^{49}$. This may be a result of the rapid decrease in temperature below the

\footnotetext{
${ }^{49}$ In a configuration in which the melt is accumulating on top of a burning layer of polyurethane foam, one does see a tendency for melt to ultimately flow down through the foam and out the bottom. This probably requires the "pre-heating" of the lower foam that occurs as the thermal wave approaches the bottom boundary of the foam mass so that the melt can stay fluid enough to pass through this hot foam layer.
} 
foam surface; the increased melt viscosity may make it essentially unresponsive to capillary action so the melt stays very near the surface. It is essentially stuck there until the melt droplets grow by agglomeration with their neighbors and with more droplets being formed by the local recession of the foam surface as the heating continues to force it to melt and/or gasify. Finally the melt droplets reach a size where gravity overcomes their attachment to the outer portion of the foam structure via surface tension and they begin to run downward. That size appears to be roughly $3 \mathrm{~mm}$ for the foam in Fig. 28 . The rivulets form and flow on a very uneven surface consisting of the partially and fully collapsed foam cells ${ }^{50}$. This is a much more difficult flow situation to model than the simple laminar shear flow used for the full density polymers in the Appendix 1 . Note that, for this foam, Fig. 28 shows only about half of the foam surface is covered by the flows, adding further complexity to a description of the heat transfer to and within the condensed phase ${ }^{51}$.

Other foams, with their differing melt vs. gasification tendencies and differing melt viscosities, look qualitatively similar but quantitatively different from that in Fig. 28.

Figure 29 provides an overall view of the same sample as is seen in Fig. 28; Fig. 30 shows a similar view but the sample there is Foam $\mathrm{L}$, a viscoelastic formulation with no flame retardant (Table 2). Both are burning in a configuration fundamentally similar to that used for the full-density thermoplastics - a vertical slab (here both are $7.6 \mathrm{~cm}$ thick), close to the Marinite $\mathrm{P}$ catch surface, ignited on one vertical end. Both have fires propagating to the right with the accompaniment/assistance of a melt pool fire. The Z' foam, with its halogen-based flame retardant, is showing signs of influence of its flameinhibiting effects. The foam is burning preferentially on the top surface of the vertical slab where the residence time for gas phase oxidation reactions is greater than on the sides of the slab. The flames on the sides probably require the constant re-ignition provided by the pool fire in order to overcome (in a weakened manner) the gas phase flame retardant.

It is apparent that the pool fire in Fig. 30 is larger (ca. 50 \%) than that in Fig. 29 even though more of the sample has been consumed in Fig. 29. This is a result of both the higher density of the foam in Fig. 30 and the higher melt fraction for that foam as measured in the cone-based radiation experiments described above (see Fig. 20). The reach of the pool fire is higher, as well. Despite this and the lack of flame retardants in Foam L of Fig. 30, there is very little flame attached to the sample itself (see the lower trailing edge of the foam). Its shape suggests that it is reacting in a mostly passive manner to heat from the pool fire plume. Both viscoelastic foams (K and $\mathrm{L}$ ) showed this type of behavior in further tests described below.

The results for the above type of test configuration, using varied polyurethane foam formulations, are summarized in the first two pages of Table 10 in terms of peak HRR and average flame spread rates along the top and bottom surfaces of the foam slab. All

\footnotetext{
${ }^{50}$ The cells in most of these foams were on the order of $1 / 2 \mathrm{~mm}$ in diameter.

${ }^{51}$ Some appropriate, larger-scale continuum description (probably with empirical parameters) of this finely-detailed flow behavior is needed.
} 
tests with this configuration gave transient behavior, i.e., the fire growth process was not steady and the reported spread velocities are averages over a $25 \mathrm{~cm}$ length away from the sample ends. The overall HRR peaked (and that is the value reported in Table 10) but the peak was not associated with early (ignition-dominated) or late (end of sample) behavior (NFR foam was an exception, as described below).

In the early tests, the intent was to cover the Marinite $\mathrm{P}$ catch surface with a thin layer of aluminum foil for two reasons: (1) it would halt any polymer melt infusion into the pores of the Marinite ${ }^{52}$ and (2) it would greatly facilitate clean-up between tests. The first two tests in Table 10 were done with foil covered Marinite. Two unrealistic effects of the foil cover were seen. It tended to form a low "ridge" around the pool fire due to thermal expansion of the foil; this inhibited the free movement of the polymer melt. The foil also greatly boosted the tendency of flame to spread on the lower surface of the foam sample (and the speed of that spread); this had a substantial effect on the peak HRR, as can be seen in Table 10. Evidently the high infrared reflectivity of the foil boosted the net heat flux impinging on the bottom of the sample, overcoming much of the inhibiting effects of the flame retardant in the $\mathrm{Z0}$ foam. Since both of these effects are unrelated to the conditions the foam would encounter in the real world, the use of the foil was halted ${ }^{53}$.

All of the polyurethane foams in Table 2 were subjected to this test of lateral spread on an up-standing foam slab with a maximum chance for pool fire interaction facilitated by the close spacing above the Marinite. As Table 10 shows, the results varied widely. Two of the foams (P and Graphited) would not sustain post-ignition flame propagation in this configuration. Foam $P$ readily yielded a melt but neither it nor the sample itself sustained burning after igniter flame removal (recall its long ignition delay in the standard cone calorimeter tests described above). The melt pool on the Marinite would not sustain ignition after repeated applications of a propane torch flame (in a situation where it could not flow away from the igniter flame as it had flowed off of the sample). The graphited foam sample sustained local flames for a few tens of seconds after igniter removal, but these died out without spreading onto unheated portions of the sample. This foam produced no visible melt and simply appeared to retain its original shape while becoming black and "fuzzy" with expanded graphite granules (exactly the same behavior as in the standard cone calorimeter tests above, although there the continued radiant flux forced continued burning) $)^{54}$.

At the opposite extreme of behavior was the NFR foam, a conventional formulation with no flame retardants. Table 10 shows somewhat variable flame spread rates but some values more than quadruple the spread rate seen on the $\mathrm{Z0}$ foam (similar density and same manufacturer but with a halogen-phosphorus retardant). Flame spread over the

\footnotetext{
${ }^{52}$ There is apparently no high temperature-resistant, medium thermal inertia material available which is not somewhat porous.

${ }^{53}$ The flammability-enhancing effects of aluminum foil could prove useful in other contexts to boost the severity of a test, e.g., by simulating radiative feedback from above in a room fire environment. It is a very inexpensive substitute for external radiation, though, of course, it can only make the burning process more adiabatic.

${ }^{54}$ This foam may have a pronounced tendency to smolder after it has been flaming. This issue emerged more clearly in other tests described below.
} 
surfaces of the NFR foam was so fast that it left the melt/flow process roughly $15 \mathrm{~cm}$ behind the flame front ${ }^{55}$. As a result, the melt pool fire had no participation in the flame spread process over the foam surfaces. This rapid surface flame spread has an important corollary - it increases the burning surface area on the sample. This, in turn, raises the HRR of the sample. This is the one foam for which the HRR peak would have been higher if the sample were longer; flame spread reached the end of the sample about $15 \mathrm{~s}$ before the HRR peaked. Clearly, a longer sample would have allowed more area to be burning at a given time. Since the burn-out process at the ignited end had yet to be reached (the sample itself was gone but its pool fire on that end was still substantial), the peak HRR for a sample of unlimited length could have been perhaps $50 \%$ higher. At the time of the reported HRR peak, a visual estimate indicates that $3 / 4$ of the burning area was on the sample and $1 / 4$ was in the pool fire ${ }^{56}$.

The Z0 and Z” foams both have flame retardants, with Z” having slightly more of the same halogen-phosphorus compound as Z0 plus a modest amount of melamine. Their strong effect on reducing the flame front velocity is much more than one might expect given their modest effects in the standard cone calorimeter tests (at $35 \mathrm{~kW} / \mathrm{m}^{2}$ ) above. Opposed flow flame spread of this sort is simply a process of successive ignitions of surface elements as a result of heat input from the close approach of the flame foot (especially in a foam with its poor thermal conductivity). The halogen (and perhaps the phosphorus) content of the retardant inhibit the oxidation kinetics of the flame. Evidently they increase the flame stand-off distance significantly and thereby help slow the flame spread rate. The small amount of melamine adds modestly to the endothermicity in the condensed phase at the flame foot.

As noted above in connection with Fig. 29, gas phase flame retardants such as those in Foams Z0 and Z", by slowing the oxidation kinetics in the gas phase ${ }^{57}$, inhibit flame spread onto the vertical surfaces of the foam slab. A major difference between the flame spread on the NFR foam and on the $Z$ foams is the ready spread on all surfaces of the NFR foam and the predominance of spread only on horizontal surfaces (preferably the top $^{58}$ ) for these flame-retarded (FR) foams. The boundary layer residence time of gas phase species is evidently insufficient for the FR foams to anchor a flame on surfaces where the upward buoyant flow velocity is high. This is a Damkohler number ${ }^{59}$ effect and it presents a challenge in correct modeling of the gas phase behavior during the fire growth process. Another implication of the above behavior is that these foams do not have enough of this gas phase retardant to squelch flames in a wake zone such as that on

\footnotetext{
${ }^{55}$ Recall that this foam produced the lowest melt fraction in the radiation-driven melt/gasification experiments. This clearly helps slow the melt accumulation process on the surface, separating the flame front from the melt run-off location.

${ }^{56}$ We cannot directly translate this to the assertion that the HRR contributions were similarly distributed. The burning rate (and HRR) of heat-sunk pool fires tends to be suppressed [16] and, in any event would not be expected to equal that on the thermally-thick burning area of the foam slab.

57 They do this presumably by inhibiting free radical reactions, thereby cutting the net heat release rate and the local temperature upon which the overall kinetics depend.

${ }^{58}$ Spread on the bottom of the FR foams is enabled by the pool fire as a pilot source.

${ }^{59}$ Ratio of a flow time to a chemical reaction rate time.
} 
top of the slab (or in the pool fire). If they did, they would resist post-ignition flame spread in this configuration ${ }^{60}$ as well as the $\mathrm{P}$ and Graphited foams.

The observed effects of these two retardants on the overall fire growth processes here do not follow the expectation one would have from the relative amounts of flame retardants. Note that Z" has twice the peak HRR in Table 10 as does Z0. This higher peak HRR was a result of a seemingly more facile spread of flames on the bottom of the sample for the Z” as compared to the Z0 foam (though the actual spread velocities are essentially the same in Table 10). Note that the flame spread on top of Z" was slower than that for Z0 as one would expect from the relative flame retardant levels. The pool fire was definitely larger for Z" and this aided the amount of sample area burning on the bottom of the sample. Though the available melt viscosity data for these foam melts are poor in quality at the temperatures of interest, the viscosity for the Z” foam appears to be somewhat lower than that for the $\mathrm{Z} 0$ foam and this may help explain the larger pool fire it generated. Whether the melamine in Z" is responsible for this is not clear. It is interesting to note that, by slowing the surface flame spread process on the sample, the retardants in Z" and $\mathrm{Z0}$ do appear to enhance the relative role that the pool fire plays in driving the fire growth process forward. This implies (not unexpectedly) that one must deal with both aspects of fire growth in attempting to control it.

The viscoelastic foams ( $\mathrm{L}$ and $\mathrm{K}$ ) yield a fire growth process in this configuration that is clearly dominated by the melt pool fire. They burn vigorously in their self-generated melt pools and attach flames weakly on the foam surface, with the aid of the heat input from the pool fire plume. (This is demonstrated more convincingly below with the Vee tests.) The entire shape of the sample is dominated by the fact that the pool fire leads the lateral spread process. (The higher top velocities in Table 10 are deceptive in this regard; they are a result of the top playing catch-up with the bottom when the pool fire flames got large enough to really boost flame spread near the top.) Unlike the polypropylene sheet discussed above, there is not necessarily a concentrated melt separation location on these foams; they can feed melt to the pool fire over a $20 \mathrm{~cm}$ to $25 \mathrm{~cm}$ length (this grew with time). Of course this means that most of the melt is fed to the pool well behind its leading edge, away from the lateral fire growth process (as was the case with the polypropylene sheet). Close inspection of the fire spread process strongly suggests that for most of the test the forward movement of the melt pool fire is prodded by flaming melt dripping into the pool at the leading edge of the flames on the pool (a non-burning melt zone extends about $2 \mathrm{~cm}$ ahead of this). That is, the two fronts are very closely coupled in their spread. As the fire grows, the rate of melt flow into the pool grows and, near the end of the test, it appears that the overall melt flow to the pool is starting to push the pool and its leading edge flame front ahead somewhat faster than the flame front on the base of the sample (in the hydrostatic flow manner inferred above for the polypropylene sheets) ${ }^{61}$.

\footnotetext{
60 They might still allow spread in more adiabatic configurations such as the Vee studied below.

61 Two factors complicate the pool burning process more than with the polypropylene or polystyrene: (1) The melt, especially for these viscoelastic foams, seems to swell in depth as it burns suggesting a foaming process. This would de-couple the upper portion of the melt from the heat sink provided by the Marinite below and, conceivably could boost the burning rate. (2) Burning of the melt leaves a swollen char residue.
} 
Two other single slab fire propagation situations were explored to see how they compared with the results above. Foam $\mathrm{Z} 0$ gave faster flame spread and a substantially enhanced peak HRR when it was laid flat rather than oriented vertically as in the preceding tests. This orientation puts more of the mass close to the catch surface and allows a stronger interaction with a larger melt pool. It also puts more of the slab surface on top where flame spread is more readily sustained on this FR foam. However, the overall behavior was also hard to reproduce and very obstructive of viewing the pool fire dynamics. The NFR foam, which did not appreciably interact with its own pool fire when vertical, did much the same here giving comparable flame spread and peak HRR results.

Foam $\mathrm{P}$ was tested here (and above, see Table 10) with a wrap of a medium weight polypropylene fabric because the present senior author had seen high melamine foams give serious fires when combined with non-flame-retarded materials in prior projects. Polypropylene fabric is generally regarded as quite challenging to a foam in furniture flammability tests such as California Technical Bulletin 133. The horizontal orientation for a fabric-wrapped Foam P cushion clearly gave a more serious fire than did the vertical cushion, aided by the flaming melt drip from the fabric onto the pool surface but, overall, the spread and burning processes were very erratic.

Foam Z0 was also examined with the slab having its long axis vertical and the igniter at the bottom of one large face. This gave a very rapid (igniter assisted) vertical fire growth process on the ignited face of the sample (with no melt pool having time to develop). After this, however, the burning process became quite erratic, interacting strongly with exactly how the sample was held. The results were not reproducible.

Finally, three of the foams were subjected to external radiation from a large area, electric, radiant panel. The flux was not highly uniform (ca. $\pm 12 \%$ about an average of $7.5 \mathrm{~kW} / \mathrm{m}^{2}$; it was higher on the upper half of the sample) since these preliminary tests were aimed mainly at determining how the foam would respond to a steady radiant flux that preceded the flame front. (Would this flux level ${ }^{62}$, which is about equal to the minimum flux for ignition of some unretarded foams, cause the foam to melt and shrink before flames reached it?)

As one would expect, the presence of this external heart flux heavily biased the fire growth process to occur fastest on the irradiated side of the sample. In no case did the foam surface show any degradation or shrinkage before the flame front reached it but that front was strongly accelerated by the flux as Table 10 shows (compare Z0 in tests 2, 3 and 5 with test 49; compare Z" in tests 23 and 24 with test 51 . Note also that flame

The two issues may be related by the chemistry that is transforming the melt as it burns. Any relation to the complex viscosity-temperature curves discussed above is unclear. None of this is apparent near the leading edge of the pool fire as it aids in the fire spread; however, anything that affects the pool size and burning rate affects the plume height and thus its contact with the sample which is feeding the pool. This may pose a substantial modeling challenge.

${ }^{62}$ This level of flux is relevant to the type of radiative interchange that can occur among surfaces on a piece of somewhat fire resistant upholstered furniture. 
spread was sustained on the graphited foam in the presence of this rather low heat flux though the resultant HRR was quite low. This graphited foam had flame spread over the entire radiated surface followed by some weak sustained flames on the top of the sample during a ten minute exposure. The flames ultimately died back but the sample went into a smolder mode which was difficult to extinguish, apparently because the expanded graphite limited access of the water used for extinguishing to the smolder zone beneath it.

These results did confirm, as expected, that relatively low levels of radiant heat flux can substantially enhance the flammability behavior of flame-retarded foams. These flux levels could be introduced into a foam flammability test method with some difficulty and expense via an electric-powered radiant panel such as that used here or they can be produced by configurations that provide radiative feedback among surface elements in much the manner that occurs in such polyurethane foam applications as upholstered furniture. With this in mind we focused further tests on a configuration that can provide spatially-varying levels of radiative feedback - two foam slabs arranged in a Vee (see Fig. 3). The point of a non-parallel arrangement such as this is the same as in ASTM 1354 (Lateral Ignition and Flame Spread test, known as the LIFT test). The configuration provides a decreasing feedback flux as flames move outward from the base of the Vee where ignition occurs; this provides one basis for differentiating the performance of differing foam formulations which have differing responses to an added heat flux. Unlike the LIFT test and unlike the radiant panel tests above, this two slab configuration ${ }^{63}$ provides self-generated feedback. This is more like the actual situation for an object such as an upholstered chair. This system generates and responds to its own radiation rather than responding to a rigidly fixed external flux.

Note that a two-slab configuration of this type could have any angle between the slabs, from $0^{\circ}$ to $180^{\circ}$. An angle of $0^{\circ}$ (parallel flaming surfaces at some spacing) gives a nearly non-variant (except near the slab edges) feedback flux which is at a maximum. The sample is effectively rendered adiabatic because all radiation from the flames and the burning surface is returned. (This does not correspond to any fixed level of external radiation; the returned flux depends on the surface temperature and the temperature/emissivity of the flames.) Here we have chosen an angle of $30^{\circ}$ as one which is relatively harsh in terms of feedback but still open enough to allow following the progress of the flames on the inner surfaces of the slabs. ${ }^{64}$ The angle can be viewed as a potential parameter of any foam test method along these lines.

Another parameter of such a test is the spacing between the bottom of the sample and a melt catch surface. In the tests here this was varied at the same extremes as were used for the polypropylene sheet tests, i.e., either very close or very far. Still another parameter is the nature of the catch surface; this has been shown to have a potentially strong effect [3]. We have used Marinite $\mathrm{P}$ throughout this test series because it is inert and comparable to

\footnotetext{
${ }^{63}$ In principle the second slab could be replaced by a front surface mirror but combustion deposits on its surface would very quickly inhibit its function.

${ }^{64} \mathrm{An}$ angle of $0^{\circ}$ would render the test more harsh but also more go/no-go in nature. It is unlikely that foam in furniture would be subjected to such a configuration. The $30^{\circ}$ angle is probably already conservative in this regard.
} 
wood in its thermal properties. The implicit assumption is that the residential soft furnishing fires of primary interest here occur over wood floors. We avoid wood itself because it would introduce a need for a standard material that would be difficult to obtain.

Figures 31 and 32 show examples of two foam behaviors in the $30^{\circ}$ Vee test with the sample close to the catch surface. The foam in Fig. 31 is NFR (non-flame-retarded); that in Fig. 32 is L (viscoelastic, also without flame retardant). Fig. 31 illustrates one of two non-idealities which showed up in these preliminary tests. The flame has surged ahead on the right hand slab, especially on its top. This occurred on at least three tests in the series but only on one test day and it always occurred on the right hand slab ${ }^{65}$. We infer that it was due to some intermittent asymmetry in the hood flow, but the cause could not be identified. The other non-ideality that was more common, especially in the earlier tests of the series, was collapse of the foam slabs, sometimes before the HRR had peaked. This was simply the result of a loss of support when the material at the small end of the Vee burned away (the slabs were impaled on spikes at that end). As the series went on, various added supports were explored. The three wires between the two slabs seen in Figs 31 and 32 were reasonably successful and they did not in any way interfere with flame spread. ${ }^{66}$

Examination of Figs. 31 and 32 shows that, as in the single slab tests with these two foams, there are large differences in the role of the melt pool fire. The NFR foam has a minor, trailing pool fire which has little to do with the forward spread of flames over the slabs. The $\mathrm{L}$ foam has a substantial pool fire which is advancing at the same rate as the fire on the bottom of the slabs. This suggests that the same growth controlling mechanisms inferred above for lateral spread on a single slab apply here as well though, in most cases, the absolute behavior is modified by the new configuration.

The flame spread behavior exhibited in these tests (as measured by the rate of movement of the front on the inner surface, upper left edge) covered nearly the full gamut of possibilities: constant, decelerating, decelerating then accelerating and accelerating. Figures 33, 34, 35 and 36 show these variations, which were a result of the varied foam composition.

Figure 33 shows a result for the NFR foam. The jumpiness of the velocity values is mainly due to the use of two point derivatives to infer velocity from flame front position; the average result is essentially a constant spread rate. Here the flame front tended to race ahead of the pool fire, as noted, and in both tests with this foam the flames surged forward on the right hand slab, probably causing some artificial speed-up in this left hand side result as well. A second test gave a similar but noisier result. Comparison of the spread velocity in Fig. 33 with those in Table 10 (single slab) shows, rather surprisingly, no significant difference (though both sets of data are noisy).

\footnotetext{
${ }^{65}$ We report only flame spread data for the left hand slab but, of course, there is some influence when the flame surges ahead on the other slab.

${ }^{66}$ Further development of this approach into a potential test method requires improved sample holding.
} 
Figure 34 shows a result for the Z” foam (flame retarded). There is a clear slowing of the spread velocity as the flame front proceeds away from the narrow end of the Vee. A replicate gave somewhat lower initial numbers and still greater decrease with distance out from the corner. In the replicate, the velocity dropped to the levels seen in Table 10 (single slab) as the flame front reached the outer end of the Vee; in Fig. 34, the velocity at the outer end of the Vee is still appreciably higher than that for the single slab case.

Figure 35 shows a similar result for the $\mathrm{Z} 0$ foam (flame retarded). Note that the foam slabs used here were longer than the Z" foam slabs in Fig. 34. Comparing Figs. 34 and 35 (in the latter, only the two curves marked "close to catch surface”), one sees similar rates of flame spread and similar decreases in the flame spread rate, out to about $40 \mathrm{~cm}$. Beyond this, the longer $\mathrm{Z} 0$ samples show an acceleration of the flame spread rate. This is a result of the increasing role of the pool fire, trumping the effect of decreased radiative interaction between increasingly separated surfaces. Recall from Fig. 20 that these two foams yielded comparable melt mass fractions with Z” being slightly greater. Here the somewhat greater amount of melt from Z" is reflected in the fact that the two melt pools (one from each slab forming the Vee) merged into one roughly $20 \mathrm{~s}$ to $25 \mathrm{~s}$ sooner for this foam, as compared to Z0. (That growth differential was reflected also in a somewhat greater mass of Z" melt on the catch surface at any given time.) However, Foam Z” contains more flame retardants and this presumably weakened the effect of this somewhat more rapid growth of the lateral dimensions of the pool fire. Tests with both foams gave increasingly rapid forward spread of the pool fire (as the test progressed) and it is quite probable that, had the Z” samples been longer ${ }^{67}$, the same reversal in flame spread rate would have been seen.

A "hidden" factor affecting the radiative feedback between the two slabs in this type of Vee test (particularly for foams with a moderate amount of flame retardant such as the Z foams above where, as noted, the flame zone tends to be predominant on upward facing surfaces) is the shape of the actively burning area of the foam. This is not simply an exchange of radiation between two vertical surfaces at a $30^{\circ}$ angle; the hottest surfaces (and flame attachment regions) are on the receding portions of the slab (top and trailing edge, which tended toward a continuous, upward sloped surface). The shapes were not well-monitored in these preliminary tests and they are not easy to record through the semi-opaque flame. An available photo shows that the burning surfaces open out sharply behind the advancing flame fronts thereby greatly diminishing their mutual radiative view factor (and pointing them more toward the pool fire plume between the slabs).

Figure 36 shows the same type of flame spread data but here it is for the $\mathrm{L}$ viscoelastic foam. The entire trend of the spread rate with increasing spread toward the open end of the Vee is the opposite of what one would expect from a dominance of radiative interchange between the two slabs. Results for the other viscoelastic foam (Foam K) were very similar. Comparison to Foam L results in Table 10 (single slab) shows that here the spread velocity starts at the single slab level and goes monotonically upward as it progresses. The spread process here is dominated early on by the pool fire which grows rapidly due to the strong propensity of this foam to "melt". In contrast to the NFR and Z

${ }^{67}$ Longer samples were not available. 
foams above, the leading portion of the flame spread on the foam slab surfaces here is on the bottom, reflecting control by the pool fire spread process (see below for a more definitive proof of this pool fire control).

Foam P was not expected to yield a propagating fire by itself in this configuration. However, an ad hoc test was made with this configuration, including added materials of the type found in soft furnishings. Thus the two foam slabs were wrapped with the same medium weight polypropylene fabric as was used above in the single slab test of this foam. In addition, the area on the Marinite, beneath the Vee, on which a pool fire would tend to form was covered with a double layer of cotton-polyester shoddy pads ${ }^{68}(33 \mathrm{~cm} \mathrm{x}$ $38 \mathrm{~cm}$ by ca. $4 \mathrm{~mm}$ thick). The pads are themselves flammable and tend to char; they form a porous layer that can hold and pilot the burning of any polyurethane foam melt. The resulting test gave full fire propagation along the interior of the Vee surfaces largely without burning through the sample slabs themselves. This and the subsequent burning strongly suggest a fire in which the flames on the polypropylene fabric and on the top of the shoddy pad melted foam onto the shoddy pad where a significant fraction of the melt did burn. Roughly half of the original mass of organic materials remained after the fire. The fire was modest in size $-35 \mathrm{~kW}$ at its peak. This result does make a point, however: quite fire-resistant foams placed into the context of other flammable materials, can make a significant contribution to the overall burning process ${ }^{69}$. In assessing the flammability of such foams, it is necessary to factor in this sort of response. This issue is discussed in more detail below.

The graphited foam did show a limited amount of flame propagation (ca. $22 \mathrm{~cm}$ ), especially along the top of the foam slabs while the igniter was on (this is more than four times that seen with the single slab configuration) but it spread very little more after the igniter was turned off. The weak flaming on the inner surfaces of the Vee (a few $\mathrm{kW}$ ) provided little radiative interchange with which to force further flame front progress (and, again, there was absolutely no melt flow from the samples). The sample proceeded to weakly flame and then smolder. The smolder became so intense after about 15 min (presumably because it was boosted by the radiative interchange) that it caused a brief episode of renewed flaming. This alternation between smolder (predominantly) and flaming appeared to be capable of proceeding cyclically until the bulk of the sample was consumed. Note that this smoldering tendency is not a real problem in the aircraft context for which this foam was developed, but it could prove problematical for residential soft furnishings applications.

A few tests were run with this Vee configuration in which the sample was elevated sufficiently far above the catch surface $(77 \mathrm{~cm})$ as to remove it from the heat of any pool fire plume. The goal was to clarify the role that the pool fire was playing in the preceding tests where it was much closer to the sample. Flame spread rate results for the $\mathrm{Z} 0$ foam are shown in Fig. 35. Given the rather noisy data, it appears that prior to about the $40 \mathrm{~cm}$ point the pool fire had no effect on the fire growth rate along the top edge of

\footnotetext{
${ }^{68}$ These shoddy pads are commonly used in mattress construction, immediately above the inner spring.

${ }^{69}$ It also makes another point: such material assemblies are very likely always going to burn to some extent; the goal must be to limit the peak burning to a level that poses a minimal life threat [17].
} 
the sample. The behavior at the bottom of the sample was substantially different, however, with the large-spaced configuration slowed to about 1/3 the spread rate of the small-spaced configuration. All of this had a dramatic effect on the peak HRR as seen in Table 11. The roughly factor of five decrease in peak HRR is a result of both a slowed rate of overall fire growth and a substantially decreased contribution from the pool fire. Although we could not get a separate measure of the HRR contributions from the sample and pool fire, there were very evident visual differences as to the fate of the melt for the two separation differences. When the sample was close to the catch surface, the melt fell directly below it, establishing a local melt pool fire under the end of each foam slab which sustained burning within seconds ${ }^{70}$. By the time that the flames on the foam slabs were reaching the open end of the Vee, the pool fire clearly accounted for well over half (probably $3 / 4$ ) of the total HRR. When the same Z0 foam was elevated far above the catch surface, the melt tended to scatter over a much wider area, and being thereby much more effectively heat-sunk to the Marinite, most of it failed to sustain burning. Visually, it appeared that the pool fire never yielded more than roughly $10 \%$ of the HRR and nearly all of the mass that fell to the catch surface remained unburned. The results for the Z" foam (Table 11) were essentially the same. Clearly then, the pool fire can not only affect the sample burning, but the opposite is also true.

The only other spacing comparison made in these tests was with the L viscoelastic foam. Recall that it had a very strong (dominant) pool fire in tests where the sample was close to the catch surface. When the catch surface was far away, the fire on the sample went out $2 \mathrm{~s}$ after that igniter flame ended. The pool fire reported in Table 11 was generated by the igniter and it persisted only long enough to burn itself out (since it lacked a continuing supply of melt after the igniter was turned off). Although it was not tested here with a large spacing above the catch surface, it is probable that the other viscoelastic foam $(\mathrm{K})$ would behave the same way.

The two viscoelastic foams seem to have a somewhat paradoxical ability to shed melt at a temperature below the ignition temperature of that melt. This behavior in itself is not paradoxical, any low molecular weight polymer can do this. The paradoxical part comes from the fact that the melt, as seen in our radiation-driven melt tests and as captured from Vee tests above, is not a liquid at room temperature but, in fact, seems very rubber-like. In the radiation-driven experiments, even at $40 \mathrm{~kW} / \mathrm{m}^{2}$, the "melt" seemed not to flow easily/smoothly off the sample surface. The viscosity of the "melt", which could only be measured in oscillatory shear ${ }^{71}$ rather than rotational shear, was 10 to15 times lower (at $350{ }^{\circ} \mathrm{C}$ ) for the flaming sample than for the $40 \mathrm{~kW} / \mathrm{m}^{2}$ experiments but, in absolute terms, when compared to all the other melts in this study, it was high (ca. $50 \mathrm{~Pa}-\mathrm{s}$ ). Thus it seems quite surprising that it flows off the sample surface at a low enough temperature

\footnotetext{
${ }^{70}$ The rapid pool fire establishment in this case was assisted significantly by the proximity of the igniter flame and the flames on the sample engendered by the igniter.

${ }^{71}$ Recall the previous caveat about oscillatory testing for viscosity of these materials. It is, however, the only measure available at present.
} 
that it is not burning (except weakly, in areas of direct pool fire flame impingement, in the closely-spaced single and double slab experiments) ${ }^{72}$.

The melt from Foam P manages the same trick of not igniting as it flows off the foam surface but it has a low melt viscosity (comparable to the NFR and Z foams) plus a high level of melamine to help keep that melt from igniting. As Table 11 shows, the combination led to essentially no post ignition fire after removal of the igniter, even for the closely-spaced configuration. We did not pursue the large-spaced configuration for this foam on the expectation that it would again yield no fire.

Summary of Significant Observations. Although this study has not been definitive in many regards, it has produced a number of relevant points which we summarize briefly below before turning to possible implications for a polyurethane foam flammability test method.

A melting material poses a new mode of fire spread - flaming melt can flow downward to new locations, extending the burning area of fuel in new directions and thereby increasing the heat release rate. In worst case circumstances, the pool of burning melt that forms on some catch surface can augment itself by increasing the melt supply to the pool in a self-accelerating manner. When such a self-generated pool fire participates in the growth of fire on a thermoplastic material, the result is quite complex. For this situation to occur, the object must be close enough to the pool to exchange a significant amount of heat with it. When this happens, both the fire on the object and the pool fire itself are strengthened and the fire growth process is accelerated. The potential for pool fire-object fire growth is actually significantly diminished by the difficulty that the pool fire, on a horizontal surface, has in moving onto the cool area of the catch surface in a direction that will spread the fire on the object. This difficulty is caused by the heat loss experienced by the spreading melt and the subsequent increase in melt viscosity which this causes. The net movement of the pool front is closely coupled to the movement, on the lower surface of the melting object, of the point or region from which the melt is flowing onto the pool. The pool fire plume, which tends to trail the flame front significantly, helps drives the melt generation from the object, even as the pool fire adds significantly to the overall heat release rate of the fire. The flow within the melt pool is affected by simple hydrostatic pressure differentials, by surface tension gradients near the flame foot and by blockages set up around the pool periphery by cooled, immobile melt. With a highly mobile melt such as is seen with polypropylene (and perhaps various polyurethanes), the reluctance of the melt to spread forward onto a cold surface can be easily overcome by just a few degrees of downward tilting of that surface in the spread direction (thereby introducing a hydrostatic gradient that can trump the other forces).

\footnotetext{
${ }^{72}$ Conceivably such behavior could reflect the fact that a melt resists ignition because it has a higher ignition temperature than other melts. Thermogravimetry does in fact show that the $\mathrm{K}$ foam had the highest temperature for onset of weight loss but in absolute terms that temperature is still low (ca. $230^{\circ} \mathrm{C}$ to $250^{\circ} \mathrm{C}$ ) so that would seem to contribute little here.
} 
Modeling the above fire growth processes requires several parameters and/or functions. The most basic of these is a description of the melt viscosity as a function of melt temperature. At the temperatures of interest, the melt viscosity has achieved a value that is a result not only of thermal loosening of inter-chain forces but also of a pyrolytic degradation of the length of those chains. For polypropylene and polystyrene we have been reasonably successful in obtaining an empirical description of melt viscosity which appears to be only a function of temperature. However, the viscosity in the temperature range of interest involves some substantial extrapolations which limits its accuracy. For polyurethane foams, the melt exhibits unexpected non-monotonic behavior as a function of temperature and we have yet to obtain a suitable description for use as a model input. Further work is indicated on whether the unexpected results will actually carry over to a pool fire situation. Exploration of the behavior of pure polyols, as a simple alternative, is also indicated. Another complication is the complex sequence of interactive chemical and physical steps that ultimately result in polyurethane melt flowing off of a burning foam surface; this will require empirical approximation. The possible roles of foaming and charring in polyurethane melt pool fires also need investigation.

Fuel geometry and the direction of fire propagation have, as expected, been shown to have strong effects on the growth of fire on polyurethane foams. Because of their low density, even thick slabs of these materials tend to collapse in a fire test making sample holding (retention of the original sample geometry to the end of propagation over the foam) a special challenge. An inability to do so rendered some of the configurations examined highly non-reproducible, though some of these could probably be improved with further work. The configuration of greatest interest, however, is a Vee with lateral fire spread from the narrow end of the Vee outward. This provides a level of radiative interchange that should be comparable to that in upholstered chairs. The Vee can be kept close enough above a horizontal catch surface to stimulate substantial interactions between the pool fire and the foam fire making this a potentially severe test.

Several polyurethane foam formulations tested in this Vee configuration exhibited a wide variety of fire growth rates and peak heat release rate values. The results were generally in accord with expectations based on the amount and type of flame retardant(s) in the foam formulation. For non-FR foams, however, there was a strong dichotomy in melt and pool fire behavior depending on whether the foam was of a conventional formulation or a viscoelastic formulation. The behavior of the former was little dependent on the pool fire that it left well behind its spreading flame front. The behavior of the latter was entirely dependent on its pool fire, being unable to even sustain flaming when separated from that fire ${ }^{73}$. These differences apparently follow from the unknown nature and proportion of the isocyanates and polyols that went into these foam formulations. In a model they would have to be captured by the differing kinetic constants for the two overall degradation steps that gasify a foam and by the differing melt viscositytemperature relationships for the foams. All of these are expected to dictate whether the

\footnotetext{
${ }^{73}$ The tendency of some materials to "shrink away" from a small applied flame has sometimes been touted as a safety feature and, indeed, it can make a material pass some flammability tests. The viscoelastic foams can be seen as illustrators of the two-sided nature of such materials; in some applications the melting may simply be contributing to a serious pool fire.
} 
melt is generated at a low enough temperature and with low enough viscosity that it can or cannot escape from a fire-exposed foam surface without actually igniting.

The $\mathrm{Z}$ foams, with their gas phase flame retardants, revealed another aspect of fire growth that presents a modeling challenge - prevention of flame spread onto vertical foam surfaces where the slowed gas phase oxidation rates cannot support a flame. Proper description of this type of kinetic effect is a major challenge for existing gas phase flame models.

Overall it appears that the path to a model of fire growth on full density thermoplastics is reasonably clear and much of the data for testing the model from Reaction Engineering International (REI) is in hand (though there is certainly room for more experimental data on both coupled pool fire-object fire spread and on pool fire behavior alone). The path to the more relevant problem of fire growth on polyurethane foams is less clear and more extensive work is clearly needed. 


\section{Implications for Flammability Testing of Polyurethane Foam.}

Proposed Foam Flammability Test Configuration. Recall that the goal of the flammability test method we wish to develop is to determine whether a foam is likely to perform well in the context of an upholstered chair or mattress in which it comprises the majority (but not all) of the flammable material. By good performance we mean that the foam does not substantially increase the peak heat release rate ${ }^{74}$ that results from the burning of the other materials in the chair or mattress assembly nor does it substantially shorten the time to that peak. In its end product application, the foam is assumed to be exposed to the flaming of a potentially wide variety of non flame-retarded materials (cover fabrics, insulating pads, wood structure, etc.) which will most likely keep burning, once ignited, threatening to spread flames over and onto the foam. Ideally, in spite of these "external" fire insults and radiative feedback among chair surfaces and the potential for a self-feeding pool fire, the foam would respond only weakly, yielding a minimal fire threat. To assure this, the foam flammability test method must subject the foam to circumstances that are comparable to those it sees in the burning of the end product. This is a tall order since those circumstances have never really been quantified (and could be expected to vary considerably).

The upholstered chair end product application, in particular, poses an extremely wide range of potential fabric associations for a polyurethane foam. These in turn impose a wide variety of external fire insults on the foam, assuming that the fabric is ignited first. Here we want to think in terms of worst-case fabrics; we assume that these are based on fibers that are thermoplastic and have a high heat of combustion. These tend to open up to expose the foam while at the same time depositing vigorously flaming material on its surface. Such fabrics also drip flaming materials onto lower surfaces and/or the floor where they can serve as pilot flames for melt pool fires. The ideal test would reveal the likely behavior of a foam in these worst case conditions. We would then expect that the foam would be better behaved with less energetic and/or charring fabrics. (This is an assumption, based on some experience, but it needs checking. The real world of fabric blends can harbor an extraordinary range of behavior.)

The test configuration we are currently focused on derives from the Vee configuration studied above, with some enhancements to capture fabric effects (see Fig. 37). The motivation derives mainly from the application to upholstered furniture. The two vertical slabs present opportunities for radiative interactions (quantified further below) similar to those on the interior seating surfaces of a chair or sofa. Strong, full-height ignition in the narrow end of the Vee deliberately provokes a large area of the sample into a possible flaming condition to simulate a large area ignition threat to a chair (rather than a small,

\footnotetext{
${ }^{74}$ This is, of course, somewhat vague due to the fact that the proximity of flaming material will force some unknown amount of heat release from even a very good polyurethane. Ultimately it is up to a regulatory agency to decide what constitutes acceptable performance for the product in which the foam is used. For example, the Consumer Product Safety Commission has set an upper limit of $200 \mathrm{~kW}$ from a mattress tested in accord with CFR 1633 (simulating exposure of the mattress to burning bedclothes). Ref. 17 gives a methodology for assessing the relation between peak HRR from a product and the hazard this represents.
} 
localized flame). The increasing distance between foam slabs decreases the radiative interaction as fire growth attempts to progress out of the narrow end of the Vee. This provides one basis for differentiating foam performance since foam formulation should affect its susceptibility to "external” radiation. The configuration (and the response of the foam to it) determines the level of that radiation, although it is supplemented (see below). The proximity of a catch surface deliberately accentuates the threat posed by flaming melt material by having a lesser spacing above the "floor" than is the case in a typical chair. Flaming melt flow has the potential to enhance fire growth in a chair configuration even before it reaches the floor so we, in effect, bring the floor closer to accentuate any such tendency and give it the opportunity to show its worst characteristic - development of a self-feeding pool fire. The choice of Marinite $\mathrm{P}$ as the catch surface puts an inert and reproducible material with thermal properties comparable to wood in the role of a "floor" surface.

We add two further elements as a substitute for the additional impacts of a flaming fabric. It is not practical to use a fabric itself to fulfill this role even though it could come closer to reality. This would call for a standard fabric, something which has proven to be notoriously elusive. Furthermore, fabrics tend to burn in a very poorly reproducible manner. Instead we use additional gas burners to impose two effects of a flaming fabric. The first is piloting of a potential pool fire on the catch surface. This is achieved by adding small multi-jet gas burner tubes just above the catch surface, arranged diagonally under each foam slab and pointing their flames downward onto the catch surface. Second, we add another multi-jet gas burner tube as a (mainly radiative) heat source right in the plane of symmetry of the Vee, with its several flame jets pointing upward ${ }^{75}$. The objective is to operate this burner at conditions such that it provides a substantial additional heat flux to the inner surfaces of the foam slabs at the narrow end of the Vee (and then decaying as the fire spreads outward on the Vee). This is a substitute for the additional heat input that a burning fabric could impose. ${ }^{76}$

The foams that have been tested in this study would be expected to rank the same in this tougher test as they did here, although most would be expected to burn somewhat more vigorously and/or extensively. The two foams which did the best here (Foam P and Graphited) would be expected to do well in the enhanced test also. The additional heat sources are still needed, in general, to better simulate the real conditions in chair burning to which still other foam compositions might behave differently. Note that the proposed test particularly "punishes" flaming melt (even if it requires piloting to sustain that flaming) and a strong response to external radiation. These are two areas in which the two best foams in this study excel.

\footnotetext{
${ }^{75}$ The ultimate incarnation of this modified Vee test (to be published) places a solid body radiator in this role.

${ }^{76}$ A concern, which can only be addressed experimentally, is whether the added flames in this augmented Vee configuration are sufficient to capture the interaction between a foam with a gas phase flame retardant and the piloting effects of flaming thermoplastic fabrics on vertical foam slab surfaces. This configuration might give an overly optimistic prediction of the upholstered chair performance of such a foam if it underestimates the fire growth contribution from such surfaces. It should be possible to compensate for such a shortcoming, but it would probably make the test more complex.
} 
This proposed foam flammability test is plausible based on the available information from this study. However, it needs to be assessed against more realistic conditions. Plans are being made to test a set of foams in isolation in the configuration proposed above and also in the form of four cushion California Technical Bulletin 133 mock-ups to check the correlation between the two. As a practical matter, it would be highly desirable if the measure of fire intensity (peak heat release rate) could be replaced with reasonable accuracy by peak rate of mass loss since the required instrumentation is much reduced (at the cost of some accuracy in HRR assessment). This issue will also be examined.

Scaling Issues in a Foam Flammability Test Method. The proposed Vee test configuration is close to full-scale and thus demands rather large slabs of polyurethane foam. A major planned use of the test method, if it is successful, is as a basis for assessing new foam formulations using non-traditional flame retardant systems (such as nano-composites). A natural question is whether that same information about the flammability hazard level of a foam could be obtained with much less material, since this would facilitate more rapid assessment of alternative formulations. This leads us to a closer look at the relative roles of various processes during fire growth in the Vee configuration. A smaller scale test method can be expected to produce similar ranking results of varied foam compositions only if it brings approximately the same balance of elements that contribute to fire growth. The relevant processes include (1) the rate of flame spread over foam surfaces, (2) the radiative interchange between the hottest surface elements of the two slabs or between the fire plumes attached to them and those surfaces, (3) the radiative interchange between any pool fire and the slab surfaces and their flames, (4) susceptibility to a self-feeding pool fire.

To get an estimate of the roles of these processes we have focused on one of the $\mathrm{Z}$ foams used in the preceding study; this represents a moderately flame-retarded foam. We consider various processes for a foam with its characteristics both on the scale tested in the present study and on $1 / 3$ to $1 / 4$ of this scale (in terms of the length and height of the foam slabs, thickness is taken as unchanged ${ }^{77}$.

As noted previously, a significant effect of the gas phase flame retardant in the $\mathrm{Z}$ foams is its tendency to inhibit flaming on the inner vertical surfaces of the slabs. As a result, the rapid spread over these surfaces, seen in the unretarded NFR foam, is halted and flames spread stably only on surfaces that face upward (i.e., have a surface normal that has an appreciable upward component, thereby forming a flame-holding wake region for a buoyant fire plume). ${ }^{78}$ Such a wake region exists on the top of each slab. Another flame-holding region is formed on the "trailing edge" of each slab by the burner ignition process when the initially vertical slab surface at the narrow end of the Vee develops a finite slope (due to faster propagation on the top surface). It is then this burning "trailing

\footnotetext{
${ }^{77}$ Test samples of polyurethane foam on this smaller scale can be made in a laboratory bench-top apparatus generating a few liters of foam, though two batches would be needed to make two slabs.

${ }^{78}$ This has an interesting consequence. The normal flame spread process of successive ignitions can proceed along the top of the sample but the vertical sides are engulfed only as fast as the inward (in-depth) mass burning process can progress on the upward facing surfaces. That mass burning rate process is augmented by any "external” radiation it sees.
} 
edge" surface on each slab that is the source of radiation impinging on the same trailing edge surface of the other foam slab. Another source of such radiation is the fire plume attached to each trailing edge.

One can estimate the radiative view factors between these elements using a few plausible assumptions that reflect the behavior seen in the Vee tests reported above. As noted above, the burning, trailing edge surfaces of the foam slabs form a very obtuse angle with respect to each other and this greatly reduces their mutual radiative view factor; available data indicate an angle of the order of $120^{\circ}$. The fire plumes attached to them have a diameter roughly equal to the width of a foam slab and a height roughly equal to $1.5 \mathrm{X}$ the slab height. Using standard methods $[19,20]$ we can then estimate various view factors such as between the two solid burning surfaces or between an attached fire plume on one slab and the solid burning surface on the other slab. The results are shown in Table 12.

Note that the values in Table 12 all correspond to the condition in which the two foam slabs (on either scale) are half consumed by the fire growth process. To give some idea of how these numbers can vary as the fire progresses from the narrow end of the Vee outward, note the following for the large scale version of the radiation between the trailing edge fire plume of slab 1 and the trailing edge surface of slab 2:

\section{Fractional Length Consumed}

$1 / 4$

$1 / 2$

$3 / 4$ $\underline{\text { View Factor }}$

0.175

0.13

0.074

Table 12 shows that solid surface to solid surface radiation is likely to be minimal for these foams; the emissivity could be high but the temperature is roughly $400{ }^{\circ} \mathrm{C}$ and the view factor is quite small. Fire plume radiation, both between slabs and from the slabs to the pool fire is much more favored by the geometry, by the plume temperatures (expected to be roughly $1200^{\circ} \mathrm{C}$ ) and the moderate sootiness of the flames which can boost their emissivity. Furthermore, once a merged pool fire becomes fully established in the space just to the rear of the trailing edges of the two foam slabs, its view factor with respect to those trailing edges approaches unity at mid-height and 0.5 at the top and bottom of the trailing edged surfaces. For the $\mathrm{Z}$ foams in the present large scale study, this did not occur until about $2 / 3$ of the slabs were consumed. For the viscoelastic foams it occurred much sooner.

Table 12 seems to imply that there is good promise in the scaling down from the dimensions used in the above Vee tests to $1 / 3$ of this size. There are differences in view factors but they are not extreme. There are further complications, however, as described below.

Consider first the issue of susceptibility to a self-feeding pool fire. Appendix 2 addresses this issue in some detail and presents example calculations of the distance the bottom of the foam slabs would have to be above the surface on which the pool fire occurs in order 
to begin initiating a self-feeding pool fire. The results are given in terms of this separation distance versus the heat release rate from the object (here, the total from the two foam slabs). If we assume that the heat release rate from the object on the two scales of interest here is proportional to the foam slab areas on which flames are attached, then we have a factor of three difference for the $\mathrm{Z}$ foams. A change in peak HRR from $75 \mathrm{~kW}$ (seen for the Z" foam) to $25 \mathrm{~kW}$ in Fig. A2.1 implies that the separation distance should go from $0.22 \mathrm{~m}$ down to $0.15 \mathrm{~m}$ (no radiative boost curve) or from $0.42 \mathrm{~m}$ down to 0.27 $\mathrm{m}$ (pool fire burning rate doubled by radiation). Again, these are separation distances that would just begin the self-feeding pool fire process at the noted values of peak HRR. All of these numbers are much larger than the $0.04 \mathrm{~m}$ separation used in the actual experiments where we deliberately minimized the separation distance in order to maximize the chances of an interactive pool fire. To maintain the severity of the test at its current level (which we regard as necessary in order to focus the test on one of the most troublesome aspects of polyurethane foam fire behavior), we evidently need to keep the $0.04 \mathrm{~m}$ separation distance for the larger scale and decrease it for the smaller scale ${ }^{79}$ in accord with the model in Appendix 2, though reduced to much smaller fires (something more like $1 \mathrm{~kW}$ for the larger scale test). A problem here is that this pushes the scale right into the domain of laminar plume pool fires where it may be difficult to find plume height data for small fires (the calculations in Appendix 2 are for turbulent fire plumes). In principle, at least, the separation distance issue is addressable and would lead to an equivalent separation distance, less than $0.04 \mathrm{~m}$, which could be used for the smaller scale test.

All of the preceding arguments about scaling have essentially been static, comparing view factors, etc. for two fixed geometries. The actual test behavior is quite dynamic with no pool material at all in the beginning, followed by a period of pool material accumulation then ignition of that pool and growth to the point where it begins to interact with the base of the foam slabs before going on to dominate later. When one views a video of a Vee test on one of the $\mathrm{Z}$ foams while focusing on the one third of the foam material that would be included in a one-third scale test, it is apparent that there is a problem: the flames spread to the end of that section of the sample before the melt pool fire becomes significant. While the surface flame spread is forced in this case by the nearby igniter flame, so also is the accumulation of a melt pool from the taller sample. The implication is that the role of a pool fire in a potentially $1 / 3$ scale test is suppressed by a mismatch between the flame spread time over the shorter sample and the development time for a significant pool fire.

The pool fire development time is strongly affected by the thermal properties of the catch surface to which it is losing heat. Right from the start, the small scale and large scale test configurations flow melt onto the catch surface at differing rates because of the differing sample heights impinged by the igniter flames. We can estimate the differing results for the pool fire initiation process as follows. Assume that the melt pool can ignite only when it reaches a sufficient temperature and doing so in turn requires getting the surface

\footnotetext{
${ }^{79}$ We could not go much below $0.04 \mathrm{~m}(4 \mathrm{~cm})$ in the tests reported here due to the need to keep the sample separate from the catch surface since the two were weighed separately. We would drop this requirement, thus allowing the separation in a smaller scale test to be less.
} 
temperature of the catch surface beneath it up to some value (which does not enter into the calculation). Then to a first approximation the melt ignition process is controlled by the transient heating of the catch surface by what we will take to be a constant temperature melt flowing from the sample. The only thing that changes with the test scale is the flow rate of that melt onto the catch surface and that flow rate in turn affects the heat transfer coefficient between the melt and the surface. At the stagnation point where the flow impinges, the heating of the catch surface is approximately onedimensional. The temperature-time solution for this purely convective heating situation can be found in Ref. 21. The temperature of the top surface of the catch pan varies as follows:

$$
T_{\text {surf }}=T_{\text {amb }}+\left(T_{\text {melt }}-T_{\text {amb }}\right)\left[1-\exp \left(\hbar^{2} \alpha t\right) \operatorname{erfc}(\hbar \sqrt{\alpha t})\right]
$$

where $\hbar$ is the heat transfer coefficient in the neighborhood of the stagnation point and $\alpha$ is the thermal diffusivity of the catch surface material; $t$ is time from the start of impingement of a constant flow of constant temperature melt. The heat transfer coefficient in the neighborhood of a stagnation point is proportional to the square root of the Reynolds number [22]. For convenience we consider the situation in which the melt flow changes by a factor of four for the two test scales under consideration; the heat transfer coefficient, $\hbar$, thus varies by a factor of two. Applying the above relation to the two scales, we can find a relation between the time to reach the critical catch surface temperature on the small scale, given the time to reach it on the large scale.

$$
\exp \left(\hbar^{2} \alpha t_{2}\right) \operatorname{erfc}\left(\hbar \sqrt{\alpha t_{2}}\right)=\exp \left(4 \hbar^{2} \alpha t_{1}\right) \operatorname{erfc}\left(2 \hbar \sqrt{\alpha t_{1}}\right)
$$

where $\hbar$ is the value for the smaller scale (estimated in accord with Ref. 22), as is the time, $t_{2}$. For the value of $t_{1}$ we insert the 50 seconds seen in the full scale tests with a Z" foam. The value of thermal diffusivity, $\alpha$, is given by the manufacturer of the Marinite $\mathrm{P}$ used here. Once $t_{1}$ is chosen the right hand side takes on a fixed numerical value and the resultant equation can be solved for the value of $t_{2}$, the requisite time to get to the same temperature given the lower melt flow in the smaller scale test. One finds that the result is $4 t_{1}=200 \mathrm{~s}$, which is obvious from the nature of the above expression. In general the result is whatever the mass flow ratio is so, for our original factor of three scaling this implies that it would take $150 \mathrm{~s}$ to get pool fire ignition (and longer to get to the self-feeding pool fire condition).

The flame spread process for the $\mathrm{Z}$ foams had consumed the corresponding $1 / 3$ of the sample length in about $30 \mathrm{~s}$. Note that as it did so, the melt flow location moved along the sample. This implies an even less effective catch surface heating process than assumed in the above calculation, which implicitly assumes that it stays in the same location. There is thus a large mismatch in the pool fire development process between the two scales, relative to flame spread time over the sample. The only compensating factor that could bring this more in line on the two scales would be to use a catch surface with a lower thermal diffusivity than the Marinite P. The above calculation implies a 
need for a factor of three reduction but, as we have just noted, this is not sufficient. A factor of ten or more reduction may be necessary to allow the pool fire to develop as rapidly as it does in the larger scale test. It is not evident at this point whether such a material exists. Most non-metallic, thermally inert materials have thermal diffusivities on the order of $10^{-3} \mathrm{~cm}^{2} / \mathrm{s}$ and we are asking for an inert, preferably non-porous material with a thermal diffusivity on the order of $10^{-4} \mathrm{~cm}^{2} / \mathrm{s}$. An alternative might be to substitute a thermally-thin material as the catch surface. This may be worth further investigation. ${ }^{80}$

It is worth noting that useful information regarding new flame-retarded foam formulations can be obtained from other techniques, such as the radiation-driven melt/gasification experiments described above and this does require a much more limited amount of foam per test. Thus it is likely that the issue of how to reduce the melt fraction and/or increase the viscosity of the melt will be pursued in seeking less flammable foam formulations. Radiation-driven tests at $40 \mathrm{~kW} / \mathrm{m}^{2}$ can provide the melt fraction on samples of about one liter in volume. One can then capture the melt and measure its viscosity.

Summary of Issues Related to Foam Flammability Testing. We have proposed a modified version of the Vee test, on the scale used in this study, as the basis for assessing whether a polyurethane foam is likely to perform well in an upholstered chair subjected to a large flaming ignition source. The modifications (piloting of any pool fire, an added heat flux to the foam surfaces) attempt to mimic important aspects of the complexities associated with flaming thermoplastic fabrics. The viability of the test has yet to be assessed; a series of tests comparing foam behavior in the test versus that of fabricwrapped foam in a CTB 133 mock-up is planned. If the test is a reasonably good predictor of foam fire behavior in the context of chair mock-ups, it will become a useful procedure in the development of polyurethane foams of lesser flammability.

A valid test of this nature would be of even greater use in the search for improved foam formulations if it could be significantly reduced in scale so as to require a lesser amount of each new foam. While reducing the geometry by a factor of three does not introduce any large disparities in the important radiative interchange aspects of the fire growth in the Vee configuration, it does introduce a large mis-match between flame spread time and pool fire initiation time. Use of a thermally-thin catch surface in a smaller scale test appears may be a potentially viable means of countering this mis-match but this is requires further study. It is worth noting that the fire growth model which this study seeks to foster can, when validated, be used to help assess the viability of smaller scale test methods.

\footnotetext{
${ }^{80}$ There is another possibility and that is to heat the catch surface, as first suggested by W. Grosshandler. This idea has been exploited in subsequent developments on both the bench scale and intermediate scales.
} 


\section{References.}

1) Kashiwagi, T., Omori, A. and Brown, J., "Effects of Material Characteristics on Flame Spreading,” Fire Safety Science - Proceedings of the Second International Symposium, International Association of Fire Safety Sciences, Hemisphere Publishing, New York (1989) p.107

2) Zhang, J., Shields, T. and Silcock, G., "Effect of Melting Behavior on Upward Flame Spread Behavior of Thermoplastics,” Fire and Materials, 21, (1997) pp 16

3) Ohlemiller, T., Shields, J., Butler, K., Collins, B. and Seck, M. "Exploring the Role of Polymer Melt Viscosity in Melt Flow and Flammability Behavior," Proceedings of the Fall Conference of the Fire Retardant Chemicals Association, Ponte Vehdra, Florida, October, 2000

4) Sherratt, J. and Drysdale, D., "The Effect of Melt-Flow Process on Fire Behavior of Thermoplastics,” Proceedings of Interflam 2001, Interscience Communications, London (2001)

5) Butler, K., Ohlemiller, T. and Linteris, G., “A Progress Report on Numerical Modeling of Experimental Polymer Melt Flow Behavior,” Proceedings of Interflam 2004, Vol. 2 (2004) p. 937

6) Kissinger, H., "Reaction Kinetics in Differential Thermal Analysis,” Analytical Chem. 29, (1957) p. 1702

7) Rogers, F. and Ohlemiller, T., "Pyrolysis Kinetics of a Polyurethane Foam by Thermogravimetry; A General Kinetic Method,” J Macrmol. Sci - Chem.A15 (1981), p. 169

8) Rein, G., Lautenberger, C., Fernandez-Pello, C., Torero, J. and Urban, D., "Application of Genetic Algorithms and Thermogravimetry to Determine the Kinetics of Polyurethane Foam in Smoldering Combustion”, Comb. Flame 146 (2006) p. 95

9) Carslaw, H. and Jaeger, J, Heat Conduction in Solids, Oxford University Press, Oxford, UK (1959) p. 80 
10) Ohlemiller, T., "Radiative Ignition of Polymeric Fuels in an Oxidizing Gas", Ph.D. Thesis, Princeton University, Dept. of Aerospace and Mechanical Sciences (1969)

11) Ohlemiller, T. and Cleary, T., "Upward Flame Spread on Composite Materials," Fire and Polymers II, Materials and Tests for Hazard Prevention, (G. Nelson, ed.) American Chemical Society Symposium Series 599, Washington, DC (1995) p. 422

12) Fried, J., Polymer Science and Technology, Prentice-Hall, Upper Saddle River, NJ (1995) p. 18

13) Herrington, R., Broos, R. and Knaub, P., “Flexible Polyurethane Foams”, Chap. 4 in Polymeric Foams and Foam Technology (D. Klempner and V. Sendijarevic, eds.) Second Edition, Hanser Publishers, Munich (2004) pp. 60-61

14) Levchik, S. and Weil, E., “Thermal decomposition, combustion and fireretardancy of polyurethanes - a review of the recent literature," Polymer International 53, (2004), p. 1585

15) Ravey, M. and Pierce, E., “Flexible Polyurethane Foam. 1. Thermal Decomposition of a Polyether-Based, Water-Blown Commercial Type of Flexible Polyurethane Foam,” J. Appl. Poly. Sci. 63, (1997) p. 47

16) Babrauskas, V., "Heat Release Rates," Section 3 Chapter 1 in the SFPE Handbook of Fire Protection Engineering, $3^{\text {rd }}$ Edition, National Fire Protection Association, Quincy, Mass (2002) pp.3-25 ff

17) Ohlemiller, T. and Gann. R., "Estimating Reduced Fire Risk From an Improved Mattress Flammability Standard,” National Institute of Standards and Technology Technical Note 1446, August, 2002

18) Fried, J., op cit, p. 206

19) Anon., NFPA 555 Guide on Methods for Evaluating Potential Room Flashover, 1996 Edition, National Fire Protection Association, Quincy, Massachusetts 
20) Siegel, R. and Howell, J., Thermal Radiation Heat Transfer, Hemisphere Publishing Corp, New York (1981), Appendix B

21) Carslaw, H. and Jaeger, J., ibid, pp. 72 ff

22) Kays, W., Convective Heat and Mass Transfer, McGraw-Hill, New York (1966), p. 210

23) Sundstrom, B. (ed.), CBUF, Fire Safety of Upholstered Furniture - the final report on the CBUF research programme, European Commission Measurements and Testing Report EUR 16477 EN, Interscience Communication, London (undated, ca. 1995)

24) Ohlemiller, T. and Shields, J. R., "Behavior of Mock-Ups in the California Technical Bulletin 133 Test Protocol: Fabric and Barrier Effects,” National Institute of Standards and Technology NISTIR 5653, May 1995

25) Butler, K., Ohlemiller, T. and Linteris, G., “A Progress Report on Numerical Modeling of Experimental Polymer Melt Flow Behavior," Proceeding of the Interflam 2004, Interscience Communications, London (2004) pp. 937-948

26) Butler, K. and Ohlemiller, T., "Some Difficult Problems in the Modeling of Fire Spread," paper presented to the $7^{\text {th }}$ World Congress on Computational Mathematics, Los Angeles, CA (July 2006)

27) Butler, K., Onate, E. and Rossi, R., "Modeling Polymer Melt Flow Using the Particle Finite Element Method," paper presented at Interflam 2007, Edinburgh Scotland ( July 2007)

28) FAR 25.853 (a) Appendix F Part I (a) (1) (ii) Vertical Burn Test. Flame application of $12 \mathrm{~s}$ results in less than $15 \mathrm{~s}$ of burning and less than $20 \mathrm{~cm}$ of flame propagation. 


\section{Acknowledgements}

Most of the polyurethane foams were provided by the Consumer Product Safety Commission. Richard Harris and Michelle Donnelly performed the polymer viscosity measurements. Michael Smith and Richard Harris performed the thermogravimetric analyses. Michael Smith performed the standard cone calorimeter measurements. Bani Cipriano of the University of Maryland provided the gel permeation chromatograms on polymer melts. 
Table 1. Properties of Full Density Thermoplastics

\begin{tabular}{|l|c|c|c|c|}
\hline \multicolumn{1}{|c|}{ Resin Type } & Designation & $\begin{array}{c}\text { Melt Flow } \\
\text { Index }^{\mathbf{8}}\end{array}$ & $\begin{array}{c}\text { Density } \\
\left(\mathbf{g} / \mathbf{c m}^{\mathbf{3}}\right)\end{array}$ & Appearance $^{\mathbf{8 2}}$ \\
\hline Polypropylene & 6523 & 4.0 & 0.90 & White \\
\hline Polypropylene & PD702N & 35.0 & 0.90 & White \\
\hline & & & & \\
\hline Polystyrene & PS 663 & 1.5 & 1.04 & Clear \\
\hline Polystyrene & PS 666D & 8.0 & 1.04 & Clear \\
\hline
\end{tabular}

Table 2. Properties of Flexible Polyurethane Foams ${ }^{83}$

\begin{tabular}{|c|c|c|}
\hline Designation & $\begin{array}{c}\text { Density }\left(\mathbf{k g} / \mathbf{m}^{3}\right) \\
\left(\mathbf{l b} / \mathbf{f t}^{3}\right)\end{array}$ & Comment \\
\hline$\overline{N F R}$ & $23.2(1.45)$ & $\begin{array}{l}\text { Non-flame retarded; } 30-36 \text { lb IFD }^{84} \text {; standard } \\
\text { mattress quality foam }\end{array}$ \\
\hline Z0 FR Foam & $22.4(1.4)$ & $6 \%$ of bromine/phosphorus flame retardant \\
\hline Z' FR Foam & $22.4(1.4)$ & $\begin{array}{l}7 \% \text { of bromine phosphorus compound } \\
+ \text { ca. } 3 \% \text { melamine }\end{array}$ \\
\hline K Visco Foam & $43.2(2.7)$ & Viscoelastic foam; no flame retardants \\
\hline L Visco Foam & $36.8(2.3)$ & Viscoelastic foam; no flame retardants \\
\hline P FR Foam & $48.1(3.0)$ & $\begin{array}{l}28 \% \text { melamine + ca. } 3 \% \text { tris dichloro } \\
\text { isopropyl phosphate (TDCP) }\end{array}$ \\
\hline Graphited Foam & $56.0(3.5)$ & $\begin{array}{l}\text { Contains expandable graphite; gives positive } \\
\text { qualitative test for presence of a halogen } \\
\text { compound; aircraft rated }\end{array}$ \\
\hline
\end{tabular}

\footnotetext{
${ }^{81}$ Melt Flow Index is measured in accord with ASTM D 1238 and is reported by the manufacturer. It gives the flow rate of the melt through a standard orifice at a standard temperature and pressure condition. The polypropylene and polystyrenes are not reported at the same conditions.

${ }^{82}$ The white appearance of the polypropylenes reflects the presence of a crystalline phase dispersed in an amorphous phase; the crystals melt as the polymer is heated and it then becomes clear. The clear appearance of the polystyrenes indicates a lack of crystallinity.

${ }^{83}$ Information on flame retardant content provided by the Consumer Product Safety Commission.

${ }^{84}$ IFD is Indentation Force Deflection, measured in accord with ASTM D3574 and reported by the manufacturer. It is a measure of the hardness or stiffness of the foam under standardized conditions.
} 


\section{Table 3. Summary of Kinetic Parameters for Gasification of Full Density Thermoplastic Resins as Inferred from Thermogravimetry}

\begin{tabular}{|c|c|c|c|}
\hline Polymer Resin & $\begin{array}{c}\text { Reaction } \\
\text { Order }\end{array}$ & $\begin{array}{c}\text { Pre-Exponential } \\
\text { Factor, } A_{\text {tga }}\left(\mathrm{s}^{-1}\right)\end{array}$ & $\begin{array}{c}\text { Activation Energy } \\
E_{\text {tga }}(\mathrm{cal} / \mathrm{mol})\end{array}$ \\
\hline PD702N Polypropylene & 1.0 & $2.18 \cdot 10^{12}$ & 48,400 \\
\hline “ & 0.85 & $3.68 \cdot 10^{12}$ & 49,500 \\
\hline & & & 51,570 \\
\hline 6523 Polypropylene & 1.0 & $2.24 \cdot 10^{13}$ & \\
\hline PS 663 Polystyrene & 1.0 & $7.60 \cdot 10^{12}$ & 46,610 \\
\hline & & & 44,260 \\
\hline PS 666 Polystyrene & 1.0 & $1.24 \cdot 10^{12}$ & \\
\hline
\end{tabular}

Table 4. Polyurethane Foam Degradation Behavior ${ }^{85}$

\begin{tabular}{|c|c|c|c|c|}
\hline $\begin{array}{c}\text { Foam } \\
\text { Designation }\end{array}$ & $\begin{array}{l}\text { Temp. }\left({ }^{\circ} \mathrm{C}\right) \text { at } \\
2 \% \text { Wgt Loss }\end{array}$ & $\begin{array}{c}\text { Temp. }\left({ }^{\circ} \mathrm{C}\right) \text { of } \\
1^{\text {st }} \text { Wgt Loss } \\
\text { Peak }\end{array}$ & $\begin{array}{c}\text { Temp. }\left({ }^{\circ} \mathrm{C}\right) \text { of } \\
2^{\text {nd }} \text { Wgt Loss } \\
\text { Peak }\end{array}$ & $\begin{array}{c}\text { Temp. }\left({ }^{\circ} \mathrm{C}\right) \\
\text { Range of } \\
\text { Foam Collapse }\end{array}$ \\
\hline NFR & 227 & 281 & 360 & $295-312$ \\
\hline $\mathrm{K}$ & 252 & $277(301)^{86}$ & 377 & $280-308$ \\
\hline $\mathrm{L}$ & 254 & 292 & 384 & $280-330$ \\
\hline & & & & \\
\hline $\mathrm{Z} 0$ & 198 & 281 & 362 & $287-306$ \\
\hline Z" & 191 & 283 & 354 & $290-309$ \\
\hline $\mathrm{P}$ & 204 & $260(307)^{60}$ & 359 & $270-284$ \\
\hline Graphited & 209 & 250 & 374 & $\begin{array}{c}272-285 \\
\text { (Graphite } \\
\text { Expansion) }\end{array}$ \\
\hline
\end{tabular}

\footnotetext{
${ }^{85}$ The first three columns of results are from thermogravimetry in nitrogen at $5{ }^{\circ} \mathrm{C} / \mathrm{min}$. The last column of results is for the same heating conditions but used the NIST Paar-Physica rheometer oven as a hot stage.

${ }^{86}$ Parenthetic temperature refers to a secondary peak
} 
Table 5. Summary of Results from Radiative Melt/Gasification Experiments With Full Density Thermoplastics Using Cone Heater

\begin{tabular}{|c|c|c|c|c|c|c|c|}
\hline Resin & Test \# & $\begin{array}{c}\text { Heat } \\
\text { Flux } \\
\left(\mathbf{k W} / \mathbf{m}^{2}\right)\end{array}$ & $\begin{array}{l}\text { Avg. } \\
\text { Surface } \\
\text { Temp } \\
\left({ }^{\circ} \mathrm{C}\right)\end{array}$ & $\begin{array}{l}\text { Avg Total } \\
\text { Mass Loss } \\
\text { Rate (g/s) }\end{array}$ & $\begin{array}{l}\text { Avg. Melt } \\
\text { Flow } \\
\text { Rate (g/s) }\end{array}$ & $\begin{array}{c}\text { \% of } \\
\text { Mass } \\
\text { Lost as } \\
\text { Melt } \\
\end{array}$ & Comments \\
\hline & & & & & & & \\
\hline PP702, Low Visc. & PP702-10 & 20 & $338 \pm 2$ & 0.116 & 0.094 & 81.0 & Sheet-like flow; no bubbles \\
\hline “ & PP702-11 & 20 & $332 \pm 5$ & 0.117 & 0.091 & 85.5 & Like test above \\
\hline “ & PP702-1 & 30 & N. A. & $(0.14)$ & 0.11 & (79) & Unfused pellets ended test early \\
\hline “ & PP702-2 & 30 & $375 \pm 4$ & 0.15 & 0.11 & 74.7 & Bubble-free melt layer \\
\hline “ & PP702-3 & 30 & $373 \pm 3$ & 0.15 & 0.12 & 80.0 & “ \\
\hline “ & PP702-4 & 30 & $358 \pm 3$ & 0.173 & $(0.12)$ & (69) & Nitrogen Purge (Hi Flow) \\
\hline “ & PP702-5 & 30 & $384 \pm 3$ & 0.179 & $(0.12)$ & $(67)$ & Nitrogen Purge (Med Flow) \\
\hline “ & PP702-6 & 30 & $375 \pm 3$ & 0.182 & $(0.11)$ & $(60)$ & Air Purge (Med Flow) \\
\hline “ & PP702-7 & 46 & $448 \pm 2$ & 0.244 & 0.131 & 53.7 & No visible bubbles; much smoke \\
\hline “ & PP702-8 & 46 & $450 \pm 1$ & 0.24 & 0.128 & 53.3 & OK until vapors ignited at $6 \frac{1}{2} 2 \mathrm{~min}$ \\
\hline “ & PP702-9 & 46 & $460 \pm 3$ & 0.238 & 0.120 & 50.4 & Very much like PP702-7 \\
\hline & & & & & & & \\
\hline PP6523, Hi Visc. & PP6523-1 & 30 & $400 \pm 4$ & 0.15 & 0.073 & 48.7 & Bubble-free melt layer \\
\hline “ & PP6523-2 & 30 & $395 \pm 3$ & 0.156 & .068 & 43.6 & “ \\
\hline & & & & & & & \\
\hline $\begin{array}{c}\text { PP6523-FR } \\
(\mathrm{Br} / \mathrm{Sb})\end{array}$ & PP6523FR1 & 30 & $366 \pm 2$ & 0.180 & 0.139 & 77 & Very fluid melt; minimal bubbles \\
\hline & & & & & & & \\
\hline
\end{tabular}




\begin{tabular}{|c|c|c|c|c|c|c|c|}
\hline Resin & Test \# & $\begin{array}{c}\text { Heat } \\
\text { Flux } \\
\left(\mathbf{k W} / \mathbf{m}^{2}\right)\end{array}$ & $\begin{array}{l}\text { Avg. } \\
\text { Surface } \\
\text { Temp } \\
\left({ }^{\circ} \mathrm{C}\right)\end{array}$ & $\begin{array}{c}\text { Avg Total } \\
\text { Mass Loss } \\
\text { Rate (g/s) }\end{array}$ & $\begin{array}{l}\text { Avg. Melt } \\
\text { Flow } \\
\text { Rate (g/s) }\end{array}$ & $\begin{array}{c}\text { \% of } \\
\text { Mass } \\
\text { Lost as } \\
\text { Melt }\end{array}$ & Comments \\
\hline PS 666, Low Visc & PS666-3 & 20 & $339 \pm 6$ & 0.147 & 0.126 & 86 & Some large $(>5 \mathrm{~mm}$ ) bubbles \\
\hline “" & PS666-4 & 20 & $340 \pm 4$ & 0.159 & 0.132 & 83 & $\begin{array}{l}\text { Very few bubbles before bubble } \\
\text { layer in sample center }\end{array}$ \\
\hline “. & PS666-1 & 30 & $389 \pm 3$ & 0.228 & 0.179 & 78.5 & Minimal surface bubbling \\
\hline “ & PS666-2 & 30 & $392 \pm 3$ & 0.230 & 0.183 & 80 & “ \\
\hline “ & PS666-5 & 46 & $427 \pm 4$ & 0.331 & 0.248 & 74.9 & Few bubbles before bubble layer \\
\hline “ & PS666-6 & 46 & $423 \pm 6$ & 0.319 & 0.236 & 74.0 & Low density of surface bubbles \\
\hline & & & & & & & \\
\hline $\begin{array}{l}\text { PS 663, High } \\
\text { Visc. }\end{array}$ & PS663-5 & 20 & $332 \pm 3$ & 0.123 & 0.102 & 83 & Larger surface region bubbles \\
\hline “ & PS001 & 25 & $355 \pm 4$ & 0.132 & 00.123 & 93 & Sheet-like flow layer \\
\hline “ & PS663-2 & 25 & $350 \pm 0$ & 0.152 & 0.122 & 80 & $\begin{array}{l}\text { Machined Sheets; erratic } \\
\text { behavior of outer layer }\end{array}$ \\
\hline “ & PS663-3 & 30 & $403 \pm 3$ & 0.193 & 0.130 & 67 & Somewhat bubbly front layer \\
\hline “ & PS663-4 & 30 & $397 \pm 1$ & 0.188 & 0.144 & 77 & “ \\
\hline & & & & & & & \\
\hline & & & & & & & \\
\hline & & & & & & & \\
\hline & & & & & & & \\
\hline
\end{tabular}


Table 6. Summary of Full Density Thermoplastic Tests with Flaming Sample and Cone Heater

\begin{tabular}{|c|c|c|c|c|c|c|}
\hline Resin & Test \# & $\begin{array}{c}\text { Heat } \\
\text { Flux } \\
\left(\mathbf{k W} / \mathbf{m}^{2}\right)\end{array}$ & $\begin{array}{l}\text { Avg. } \\
\text { Surface } \\
\text { Temp } \\
\left({ }^{\circ} \mathrm{C}\right)\end{array}$ & $\begin{array}{c}\text { Avg } \\
\text { Total } \\
\text { Wgt } \\
\text { Loss } \\
\text { Rate } \\
\text { (g/s) } \\
\end{array}$ & $\begin{array}{c}\text { Avg. Melt } \\
\text { Flow Rate } \\
\text { (g/s) }\end{array}$ & $\begin{array}{c}\text { \% of Wgt } \\
\text { Lost as } \\
\text { Melt }\end{array}$ \\
\hline PP6523 & MBC-1 & 20 & N.A. & 0.23 & 0.15 & 65 \\
\hline “ & MBC-2 & 10 & $\begin{array}{c}(490 \pm \\
10)\end{array}$ & 0.17 & 0.12 & 70 \\
\hline “" & $-\mathrm{B} 1$ & 10 & N. A. & 0.179 & 0.122 & 68.2 \\
\hline “ & $-B 2$ & 10 & $\begin{array}{l}466 \pm 20 \\
457 \pm 14 \\
466 \pm 14\end{array}$ & 0.159 & 0.113 & 71 \\
\hline “ & -B3 & 10 & $453 \pm 13$ & 0.154 & 0.105 & 68.2 \\
\hline “ & -B4 & 20 & $\begin{array}{l}477 \pm 10 \\
477 \pm 10\end{array}$ & 0.212 & 0.151 & 71.2 \\
\hline “ & -B5 & 20 & $\begin{array}{l}479 \pm 4 \\
495 \pm 7 \\
\end{array}$ & 0.207 & 0.148 & 71.5 \\
\hline $\begin{array}{c}\text { FRPP6523 } \\
\mathrm{Mg}(\mathrm{OH})_{2} \text { as } \\
\text { FR }\end{array}$ & -B3 & 20 & $\begin{array}{l}463 \pm 10 \\
439 \pm 10\end{array}$ & 0.210 & 0.141 & 67.1 \\
\hline $\begin{array}{c}\text { FRPP6523 } \\
\mathrm{Mg}(\mathrm{OH})_{2} \text { as } \\
\text { FR }\end{array}$ & -B4 & 20 & $\begin{array}{l}440 \pm 19 \\
449 \pm 18\end{array}$ & 0.209 & 0.145 & 69.4 \\
\hline PP702 & $-\mathrm{B} 1$ & 10 & $\begin{array}{l}482 \pm 19 \\
494 \pm 14 \\
\end{array}$ & 0.172 & 0.125 & 72.7 \\
\hline " & $-\mathrm{B} 2$ & 10 & $\begin{array}{l}452 \pm 13 \\
450 \pm 13 \\
\end{array}$ & 0.175 & 0.129 & 73.7 \\
\hline
\end{tabular}


Table 6. Continued

\begin{tabular}{|c|c|c|c|c|c|c|}
\hline Resin & Test \# & $\begin{array}{c}\text { Heat } \\
\text { Flux } \\
\left(\mathbf{k W} / \mathbf{m}^{2}\right)\end{array}$ & $\begin{array}{c}\text { Avg. } \\
\text { Surface } \\
\text { Temp } \\
\left({ }^{\circ} \mathrm{C}\right)\end{array}$ & $\begin{array}{l}\text { Avg } \\
\text { Total } \\
\text { Wgt } \\
\text { Loss } \\
\text { Rate } \\
\text { (g/s) }\end{array}$ & $\begin{array}{c}\text { Avg. Melt } \\
\text { Flow Rate } \\
\text { (g/s) }\end{array}$ & $\begin{array}{c}\text { \% of Wgt } \\
\text { Lost as } \\
\text { Melt }\end{array}$ \\
\hline PS 663 & $-B 1$ & 10 & $\begin{array}{c}\text { (375) } \\
\text { Funnel Base }\end{array}$ & 0.196 & 0.115 & 58.7 \\
\hline " & $-\mathrm{B} 2$ & 10 & $\begin{array}{l}405 \pm 4 \\
\text { Melt in } \\
\text { Funnel }\end{array}$ & 0.20 & 0.11 & 55.0 \\
\hline PS 666 & $-B 1$ & 10 & $\begin{array}{l}394 \pm 3 \\
410 \pm 1 \\
\end{array}$ & $\begin{array}{c}0.22 / \\
0.29 \\
\end{array}$ & $0.14 / 0.19$ & 63.6 / 65.5 \\
\hline “ & $-\mathrm{B} 2$ & 10 & $357 \pm 3$ & 0.249 & 0.174 & 69.9 \\
\hline “ & -B3 & 20 & $442 \pm 4$ & 0.292 & 0.209 & 71.6 \\
\hline “ & -B4 & 20 & $457 \pm 4$ & 0.321 & 0.198 & 61.7 \\
\hline FR PS 666 & $-\mathrm{B} 1$ & 20 & $400 \pm 5$ & 0.250 & 0.142 & 56.8 \\
\hline “ & $-\mathrm{B} 2$ & 20 & $456 \pm 3$ & 0.261 & 0.138 & 52.9 \\
\hline
\end{tabular}


Table 7. Average Heat Release Rate (HRR) from Cone Melt Experiments and from Normal Horizontal Cone Tests

\begin{tabular}{|c|c|c|c|c|}
\hline Sample & Test \# & $\begin{array}{c}\text { Heat Flux } \\
\left(\mathrm{kW} / \mathrm{m}^{2}\right)\end{array}$ & $\begin{array}{c}\text { HRR }\left(\mathrm{kW} / \mathrm{m}^{2}\right) \\
\text { Cone Melt } \\
\text { Expt. }\end{array}$ & $\begin{array}{c}\text { HRR }\left(\mathrm{kW} / \mathrm{m}^{2}\right) \\
\text { Normal Horiz. } \\
\text { Cone }\end{array}$ \\
\hline $\begin{array}{c}6523 \\
\text { Polypropylene }\end{array}$ & MBC-1 & 10 & $150-200$ & \\
\hline “" & MBC-2 & “ & 130 & \\
\hline “ & 6523 B1 & “ & 155 & \\
\hline “ & 6523 B2 & “ & 160 & \\
\hline “ & $6523 \mathrm{~B} 3$ & “ & 165 & \\
\hline “ & 6523 B4 & 20 & 175 & 400-525 \\
\hline “ & 6523 B5 & “ & 160 & 400-550 \\
\hline $\begin{array}{c}6523 \mathrm{PP}+ \\
10 \% \mathrm{Mg}(\mathrm{OH})_{2}\end{array}$ & FR6523 B3 & 20 & 175 & \\
\hline “ & FR6523 B4 & “ & 175 & \\
\hline $\begin{array}{c}\text { PD702N } \\
\text { Polypropylene }\end{array}$ & PP702 B1 & 10 & 140 & \\
\hline “ & PP702 B2 & “ & 135 & \\
\hline “ & & 20 & & $375-520$ \\
\hline $\begin{array}{c}\text { PS666D } \\
\text { Polystyrene }\end{array}$ & PS666 B2 & 10 & 220 & \\
\hline “ & PS 666 B3 & 20 & $250-380$ & 330-475 \\
\hline “ & PS666 B4 & “ & $300-330$ & \\
\hline $\begin{array}{c}\text { PS 666 + } \\
10 \% \mathrm{Mg}(\mathrm{OH})_{2}\end{array}$ & FR666 B1 & 20 & 310 & \\
\hline “ & FR666 B2 & “ & $320-380$ & \\
\hline $\begin{array}{c}\text { PS663 } \\
\text { Polystyrene }\end{array}$ & PS663 B1 & 10 & 191-210 & \\
\hline " & PS663 B2 & “ & $190-250$ & \\
\hline “ & & 20 & & $410-540$ \\
\hline
\end{tabular}


Table 8. Summary of Surface Temperature Measurements

On Polyurethane Foams

In Cone Melt/Drip Experiments

\begin{tabular}{|c|c|c|}
\hline Foam & $\begin{array}{l}\text { Incident Heat } \\
\text { Flux }\left(\mathrm{kW} / \mathrm{m}^{2}\right)\end{array}$ & $\begin{array}{c}\text { Surface Temperature }\left({ }^{0} \mathrm{C}\right) \\
\text { Results }\end{array}$ \\
\hline \multirow[t]{2}{*}{ K Viscoelastic } & 30 & $\begin{array}{c}412 \pm 20 \text { (Poor Wetting?) } \\
349 \pm 7\end{array}$ \\
\hline & 40 & $392 \pm 12,366 \pm 15$ \\
\hline \multirow[t]{2}{*}{ L Viscoelastic } & 30 & $312 \pm 11,295 \pm 0$ \\
\hline & 40 & $340 \pm 14,340$ \\
\hline \multirow[t]{3}{*}{ P High Melamine } & 20 & $294 \pm 14,287 \pm 24$ \\
\hline & 30 & $353 \pm 9$ \\
\hline & 40 & $300 \pm 11,306 \pm 6$ \\
\hline \multirow[t]{3}{*}{$\mathrm{Z0}(\mathrm{P}-\mathrm{Br}-1)$} & 20 & $346 \pm 1$ \\
\hline & 30 & $370 \pm 9,379 \pm 9$ \\
\hline & 40 & $372 \pm 31,388 \pm 8$ \\
\hline \multirow[t]{2}{*}{ Z”' (P-Br-2) } & 30 & $359 \pm 13,374 \pm 10$ \\
\hline & 40 & $378 \pm 8,379 \pm 12$ \\
\hline \multirow[t]{2}{*}{ NFR } & 30 & $377 \pm 21$ \\
\hline & 40 & $410 \pm 8,412 \pm 12$ \\
\hline
\end{tabular}


Table 9. Summary of Cone Calorimeter Results for Polyurethane Foams at a Radiant Flux of $35 \mathrm{~kW} / \mathrm{m}^{2}$

(Average of Three Replicates)

\begin{tabular}{|c|c|c|c|}
\hline $\begin{array}{c}\text { Sample } \\
\text { Designation }\end{array}$ & $\begin{array}{c}\text { Initial HRR } \\
\text { "Plateau" } \\
\left(\mathbf{k W} / \mathbf{m}^{2}\right)\end{array}$ & $\begin{array}{c}\text { Peak HRR } \\
\left(\mathrm{kW} / \mathbf{m}^{2}\right)\end{array}$ & $\begin{array}{c}\text { Heat of Combustion } \\
\text { Variation } \\
(\mathrm{kJ} / \mathrm{g})\end{array}$ \\
\hline NFR & $290 \pm 30$ & $570 \pm 75$ & ca. 25 to ca. 31 \\
\hline L Viscoelastic & $240 \pm 10$ & $445 \pm 25$ & ca. 24 to ca. 30 \\
\hline K Viscoelastic & $260 \pm 10$ & $385 \pm 50$ & ca. 24 to ca. 30 \\
\hline $\mathrm{Z0}$ & $210 \pm 12$ & $590 \pm 6$ & са. 19 to са. 31 \\
\hline Z” & $225 \pm 5$ & $530 \pm 115$ & ca. 19 to ca. 31 \\
\hline $\mathrm{P}$ & one peak only & 400 (2 repl.) & ca. 25 to ca. 30 \\
\hline Graphited & one peak only & $175 \pm 15$ & $\begin{array}{l}\text { ca. } 20 \text { to } 25 \text {, constant with } \\
\text { time but very noisy }\end{array}$ \\
\hline
\end{tabular}


Table 10. Summary of Peak HRR and Average Flame Spread Rates in Single Foam Slab Tests

\begin{tabular}{|c|c|c|c|c|c|}
\hline Test \# & $\begin{array}{c}\text { Sample } \\
\text { Designation }\end{array}$ & Sample Dimensions & Test Configuration & $\begin{array}{l}\text { Peak } \\
\text { HRR } \\
\text { (kW) }\end{array}$ & $\begin{array}{l}\text { Average }^{87} \\
\text { Flame Front } \\
\text { Velocity }(\mathrm{cm} / \mathrm{s})\end{array}$ \\
\hline 1 & $\mathrm{ZO}$ & $\begin{array}{c}30 \mathrm{~cm} \times 60 \mathrm{~cm} \\
\text { by } 7.6 \mathrm{~cm}\end{array}$ & $\begin{array}{c}\text { Lateral spread along long dimension after ignition } \\
\text { of vertical } 30 \mathrm{~cm} \text { high end; close to Marinite } \\
\text { (with } \mathrm{Al} \text { foil covering Marinite) }\end{array}$ & 72 & $\begin{array}{l}\text { Top : } 0.28 \\
\text { Bot: } 0.38\end{array}$ \\
\hline 4 & “6 & 6 & 6 & 54 & $\begin{array}{l}\text { Top: } 0.31 \\
\text { Bot: } 0.37\end{array}$ \\
\hline 2 & “ & " & Same as above but no Al foil & 8 & $\begin{array}{l}\text { Top: } 0.22 \\
\text { Bot: } 0.17\end{array}$ \\
\hline 3 & “6 & 66 & “ & 14 & $\begin{array}{l}\text { Top: } 0.22 \\
\text { Bot: } 0.17\end{array}$ \\
\hline 5 & “ & "6 & “6 & 12 & $\begin{array}{l}\text { Top: } 0.21 \\
\text { Bot: } 0.14\end{array}$ \\
\hline 23 & Z” & “ & “ & 25 & $\begin{array}{l}\text { Top: } 0.14 \\
\text { Bot: } 0.15\end{array}$ \\
\hline 24 & “ & “" & “ & 27 & $\begin{array}{l}\text { Top: } 0.13 \\
\text { Bot: } 0.11\end{array}$ \\
\hline 21 & $\mathrm{P}$ & “6 & “6 & 0 post-ign. & No Spread \\
\hline 22 & “ & “6 & As above but wrapped with polypropylene fabric & 8 & Erratic Spread \\
\hline
\end{tabular}

\footnotetext{
${ }^{87}$ Averaged over $25 \mathrm{~cm}$ length well away from both ends of sample.

${ }^{88}$ For various reasons, “close” varied from about $3.8 \mathrm{~cm}$ to $5.1 \mathrm{~cm}$ in different tests. There was no indication that this variation in height above the Marinite had a significant effect.
} 
Table 10, Cont'd. Summary of Peak HRR and Average Flame Spread Rates in Single Foam Slab Tests

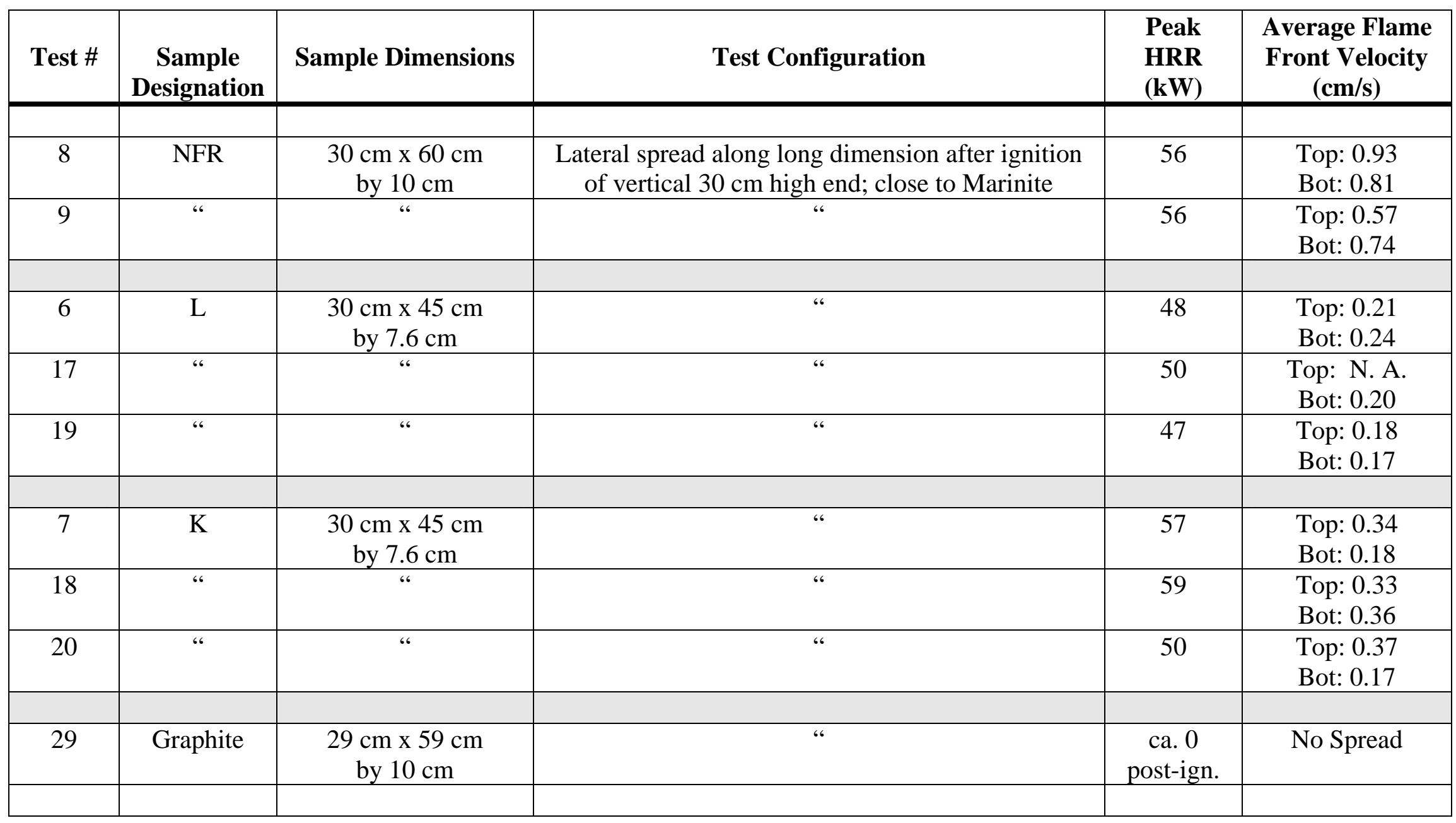


Table 10, Cont'd. Summary of Peak HRR and Average Flame Spread Rates in Single Foam Slab Tests

\begin{tabular}{|c|c|c|c|c|c|}
\hline Test \# & $\begin{array}{c}\text { Sample } \\
\text { Designation }\end{array}$ & Sample Dimensions & Test Configuration & $\begin{array}{l}\text { Peak } \\
\text { HRR } \\
(\mathbf{k W}) \\
\end{array}$ & $\begin{array}{l}\text { Average Flame } \\
\text { Front Velocity } \\
(\mathrm{cm} / \mathrm{s})\end{array}$ \\
\hline 10 & $\mathrm{Z0}$ & $\begin{array}{l}30 \mathrm{~cm} \mathrm{x} 60 \mathrm{~cm} \\
\text { by } 7.6 \mathrm{~cm}\end{array}$ & $\begin{array}{l}\text { Sample laid flat on wires, close to Marinite; ignited } \\
\text { at base of } 30 \mathrm{~cm} \text { wide by } 7.6 \mathrm{~cm} \text { high face }\end{array}$ & 50 & $\begin{array}{l}\text { Top: } 0.34 \\
\text { Bot: } 0.39\end{array}$ \\
\hline 11 & “ & “ & “ & 53 & $\begin{array}{l}\text { Top: } 0.45 \\
\text { Bot: } 0.30\end{array}$ \\
\hline 14 & “ & “ & “ & 50 & $\begin{array}{l}\text { Top: } 0.37 \\
\text { Bot: } 0.31\end{array}$ \\
\hline 16 & “ & “ & “ & 57 & $\begin{array}{l}\text { Top: } 0.49 \\
\text { Bot: } 0.48\end{array}$ \\
\hline 25 & $\mathrm{P}$ & “ & $\begin{array}{c}\text { As above but sample wrapped in polypropylene } \\
\text { fabric as in Test } 22\end{array}$ & 30 & Erratic spread \\
\hline 12 & NFR & $\begin{array}{l}30 \mathrm{~cm} \times 60 \mathrm{~cm} \\
\text { by } 10 \mathrm{~cm}\end{array}$ & $\begin{array}{l}\text { Sample laid flat on wires, close to Marinite; ignited } \\
\text { at base of } 30 \mathrm{~cm} \text { wide by } 7.6 \mathrm{~cm} \text { high face }\end{array}$ & 57,54 & $\begin{array}{l}\text { Top: } 1.14 \\
\text { Bot: } 0.89\end{array}$ \\
\hline 26 & $\mathrm{Z} 0$ & $\begin{array}{c}30 \mathrm{~cm} \times 60 \mathrm{~cm} \\
\text { by } 7.6 \mathrm{~cm}\end{array}$ & $\begin{array}{l}\text { Sample vertical with bottom close to Marinite; } \\
\text { ignited at base of } 30 \mathrm{~cm} \text { wide x } 60 \mathrm{~cm} \text { high face }\end{array}$ & 50 & $\begin{array}{l}\text { Spread to top in } \\
10 \mathrm{~s}\end{array}$ \\
\hline 27 & “ & “ & “ & 36 & “ \\
\hline 28 & “ & “ & “ & 21 & “ \\
\hline
\end{tabular}


Table 10, Cont'd. Summary of Peak HRR and Average Flame Spread Rates in Single Foam Slab Tests

\begin{tabular}{|c|c|c|c|c|c|}
\hline Test \# & $\begin{array}{c}\text { Sample } \\
\text { Designation } \\
\end{array}$ & Sample Dimensions & Test Configuration & $\begin{array}{l}\text { Peak } \\
\text { HRR } \\
(\mathbf{k W}) \\
\end{array}$ & $\begin{array}{c}\text { Average Flame } \\
\text { Front Velocity } \\
(\mathrm{cm} / \mathrm{s}) \\
\end{array}$ \\
\hline 49 & $\mathrm{Z} 0$ & $\begin{array}{c}30 \mathrm{~cm} \times 56 \mathrm{~cm} \\
\text { by } 7.6 \mathrm{~cm}\end{array}$ & $\begin{array}{l}\text { Lateral spread along long dimension after ignition } \\
\text { of vertical } 30 \mathrm{~cm} \text { high end; close to Marinite; } 30 \mathrm{~cm} \\
\text { tall by } 60 \mathrm{~cm} \text { long face irradiated with } 7-8 \mathrm{~kW} / \mathrm{m}^{2}\end{array}$ & 41 & $\begin{array}{l}\text { Normal Vel. of } \\
1.2 \mathrm{~cm} / \mathrm{s} \text { mid- } \\
\text { face }\end{array}$ \\
\hline 51 & Z” & $\begin{array}{c}31 \mathrm{~cm} \mathrm{x} 46 \mathrm{~cm} \\
\text { by } 7.6 \mathrm{~cm}\end{array}$ & “ & 27 & $\begin{array}{l}\text { Normal Vel. of } \\
\text { ca. } 0.8 \mathrm{~cm} / \mathrm{s} \text { mid- } \\
\text { face }\end{array}$ \\
\hline 50 & Graphite & $\begin{array}{c}30 \mathrm{~cm} \mathrm{x} 60 \mathrm{~cm} \\
\text { by } 10 \mathrm{~cm}\end{array}$ & “ & ca. 5 & $\begin{array}{l}\text { Normal Vel. of } \\
\text { ca. } 1.5 \mathrm{~cm} / \mathrm{s} \text { mid- } \\
\text { face }\end{array}$ \\
\hline
\end{tabular}


Table 11. Peak HRR Prior to Loss of Configuration Geometry in $30^{\circ}$ Vee Tests Of Polyurethane Foams

\begin{tabular}{|c|c|c|c|}
\hline $\begin{array}{c}\text { Foam } \\
\text { Designation }\end{array}$ & $\begin{array}{c}\text { Test } \\
\text { Number }\end{array}$ & $\begin{array}{l}\text { Spacing Above } \\
\text { Marinite (cm) }\end{array}$ & $\begin{array}{c}\text { Peak HRR }^{89} \\
(k W)\end{array}$ \\
\hline $\mathrm{ZO}$ & 32 & 4 & 100 \\
\hline " & 33 & 4 & $110 *$ \\
\hline " & 37 & 4 & 120 \\
\hline $\mathrm{ZO}$ & 43 & 77 & 21 \\
\hline “ & 44 & 77 & 22 \\
\hline Z” & 35 & 4 & $80 *$ \\
\hline “ & 36 & 4 & $74 *$ \\
\hline Z” & 45 & 77 & 15 \\
\hline “ & 46 & 77 & 15 \\
\hline $\mathrm{P}$ & 31 & 4 & 0 \\
\hline $\begin{array}{c}\mathrm{P}+\mathrm{PP} \text { wrap }+2 \\
\text { shoddy pads }\end{array}$ & 40 & 4 & 32 \\
\hline NFR & 41 & 4 & 125 \\
\hline “ & 42 & 4 & $150 *$ \\
\hline $\mathrm{L}$ & 38 & 4 & $120 *$ \\
\hline " & 39 & 4 & $120 *$ \\
\hline $\mathrm{L}$ & 47 & 77 & $\begin{array}{l}\text { Visual estimate } \\
30 \mathrm{~kW} \text {, pool only }\end{array}$ \\
\hline $\mathrm{K}$ & 34 & 4 & $125 *$ \\
\hline
\end{tabular}

\footnotetext{
${ }^{89}$ Especially in earlier tests with this configuration, the Vee geometry was lost before the flames had spread fully on the inner surfaces of the foam slabs. Cases where this appeared to have lessened the reported peak HRR are indicated here by an asterisk.
} 
Table 12. Estimates of Radiative View Factors in Vee Test Configuration (Small and Large Scale)

\begin{tabular}{|c|c|c|}
\hline $\begin{array}{c}\text { From Radiator to } \\
\text { Receiver }\end{array}$ & $\begin{array}{c}\text { Small Scale } \\
20 \mathrm{~cm} \text { long by } 10 \mathrm{~cm} \text { high }\end{array}$ & $\begin{array}{c}\text { Large Scale } \\
60 \mathrm{~cm} \text { long by } 30 \mathrm{~cm} \text { high }\end{array}$ \\
\hline $\begin{array}{l}\text { Trailing Edge Surface of } \\
\text { Slab } 1 \text { to Trailing Edge } \\
\text { Surface of Slab } 2^{90}\end{array}$ & 0.04 & 0.03 \\
\hline $\begin{array}{c}\text { Trailing Edge Fire Plume of } \\
\text { Slab } 1 \text { to Mid-Height on } \\
\text { Trailing Edge Surface of } \\
\text { Slab } 2^{89}\end{array}$ & 0.15 & 0.13 \\
\hline $\begin{array}{l}\text { Trailing Edge Fire Plumes } \\
\text { (2 slabs) to Pool Fire } \\
\text { Midway Between }\end{array}$ & 0.40 & 0.26 \\
\hline
\end{tabular}

\footnotetext{
${ }^{90}$ Assumes that slabs are at a $30^{\circ}$ angle and the trailing edges are at a $120^{\circ}$ angle. Also assumes that, on
} each scale, both slabs are half consumed and the trailing edge separations correspond to this condition. 


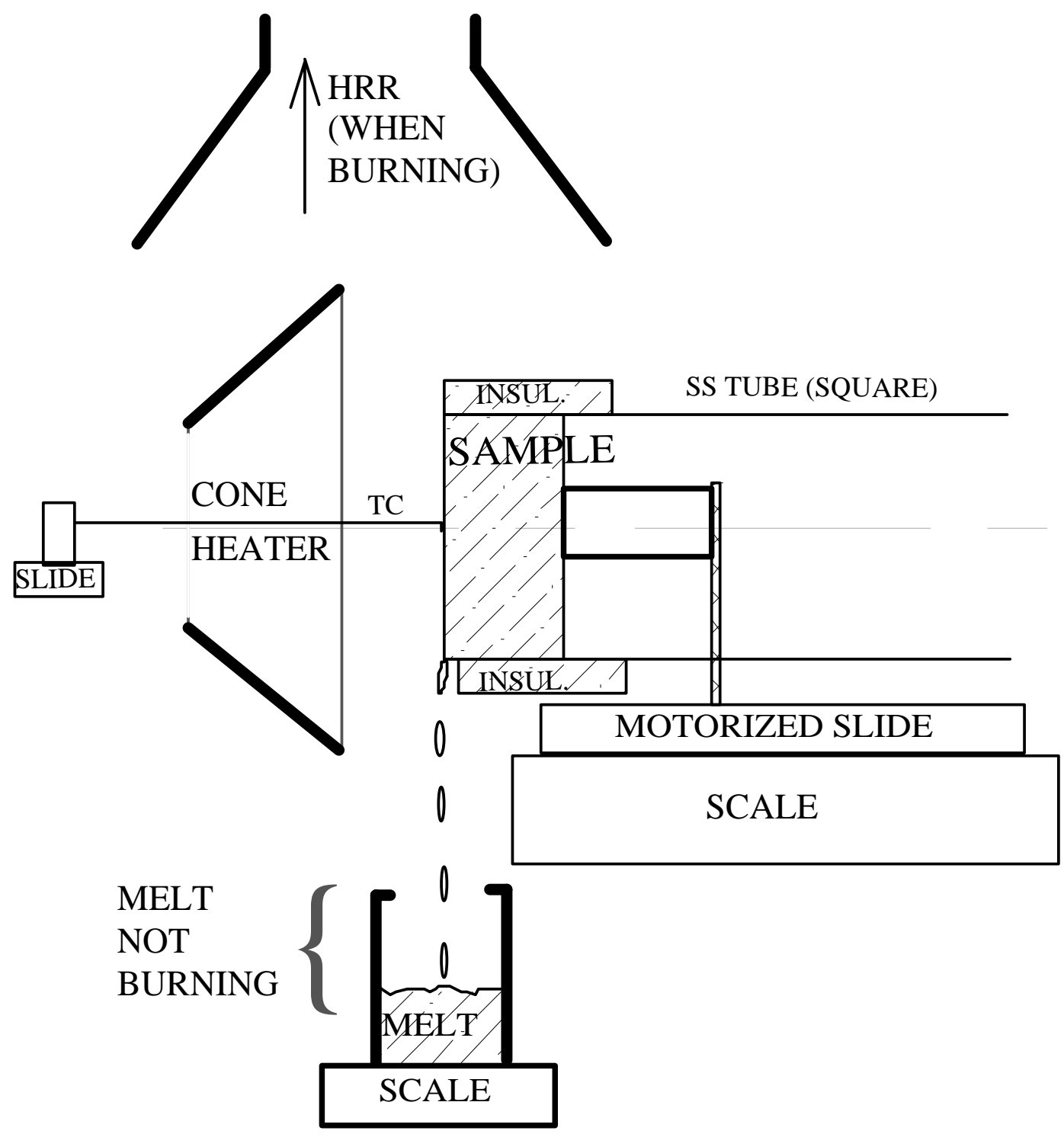

Figure 1. Schematic side-sectional view of cone calorimeter, radiation-driven melt apparatus. 


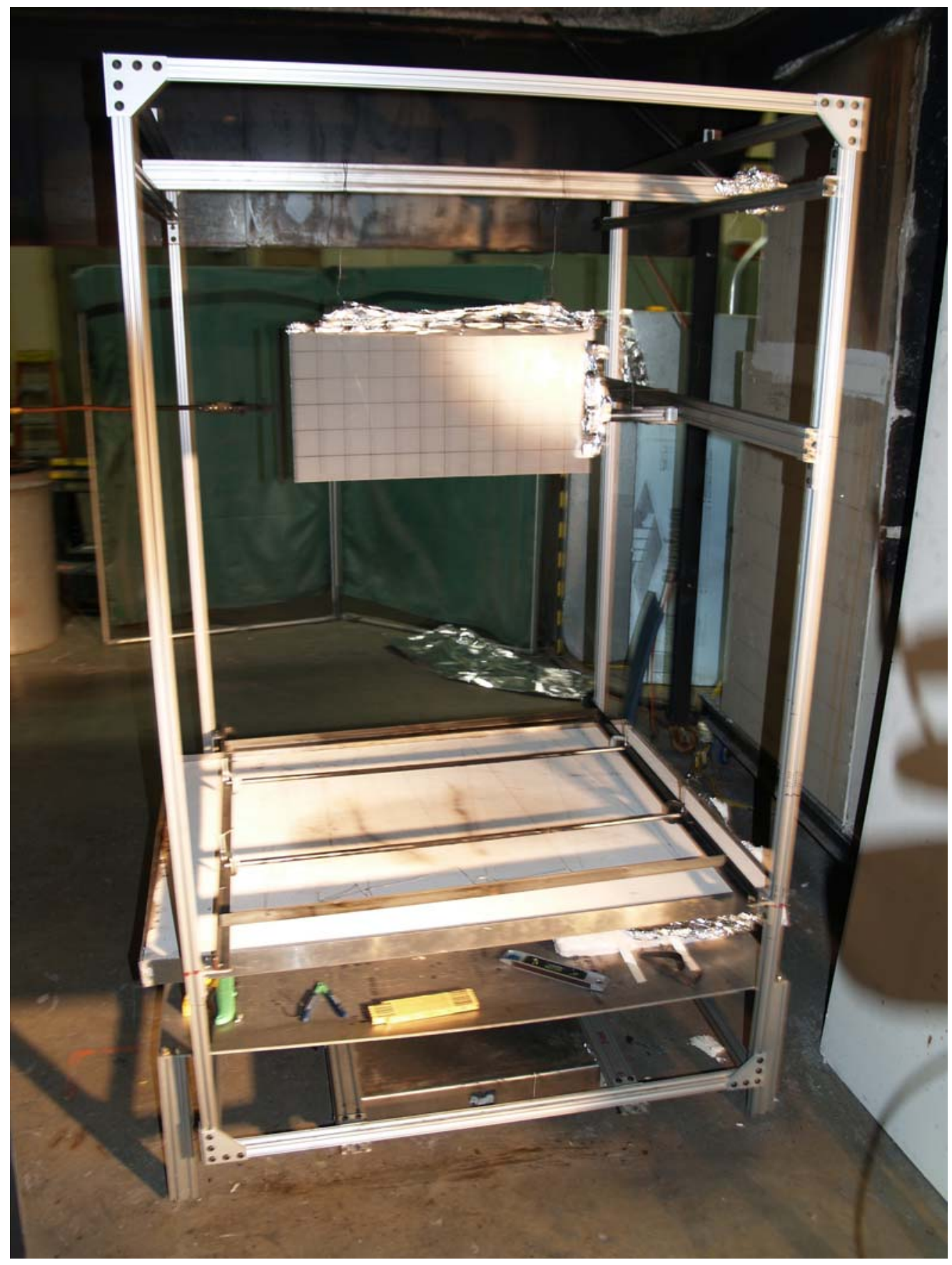

Figure 2. Overall view of the apparatus used for three-dimensional, melt pool fire-assisted fire growth tests. A thin sheet of polypropylene is shown in its high position above the Marinite catch surface (white sheet). 


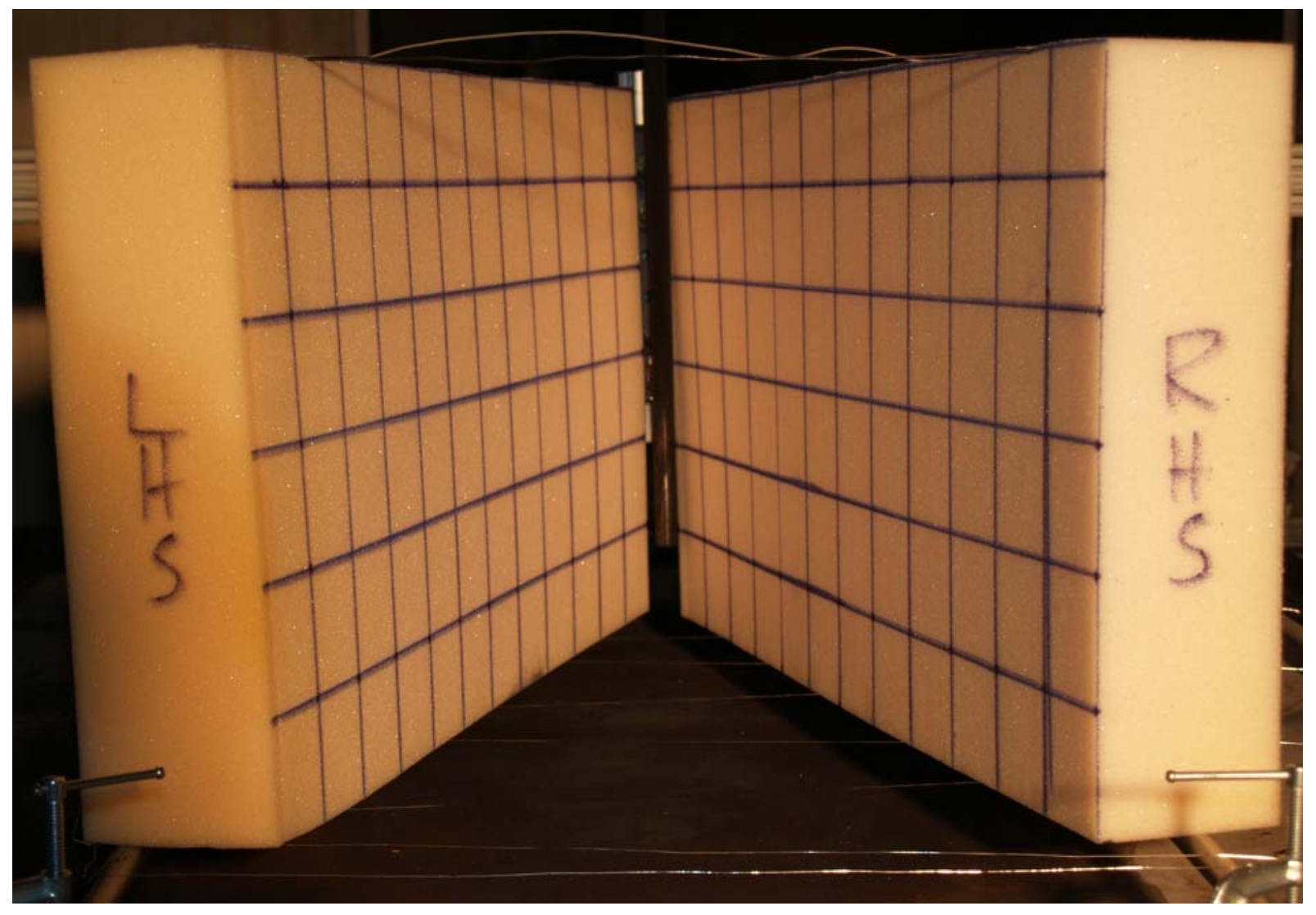

Figure 3. Front view of a pair of foam slabs in the Vee test configuration. The wire supports under the foam are weakly visible near the open end of the Vee. Brace wires between the tops of the slabs are also visible. The vertical igniter at the narrow end of the Vee is slightly visible (mainly its lower half). 


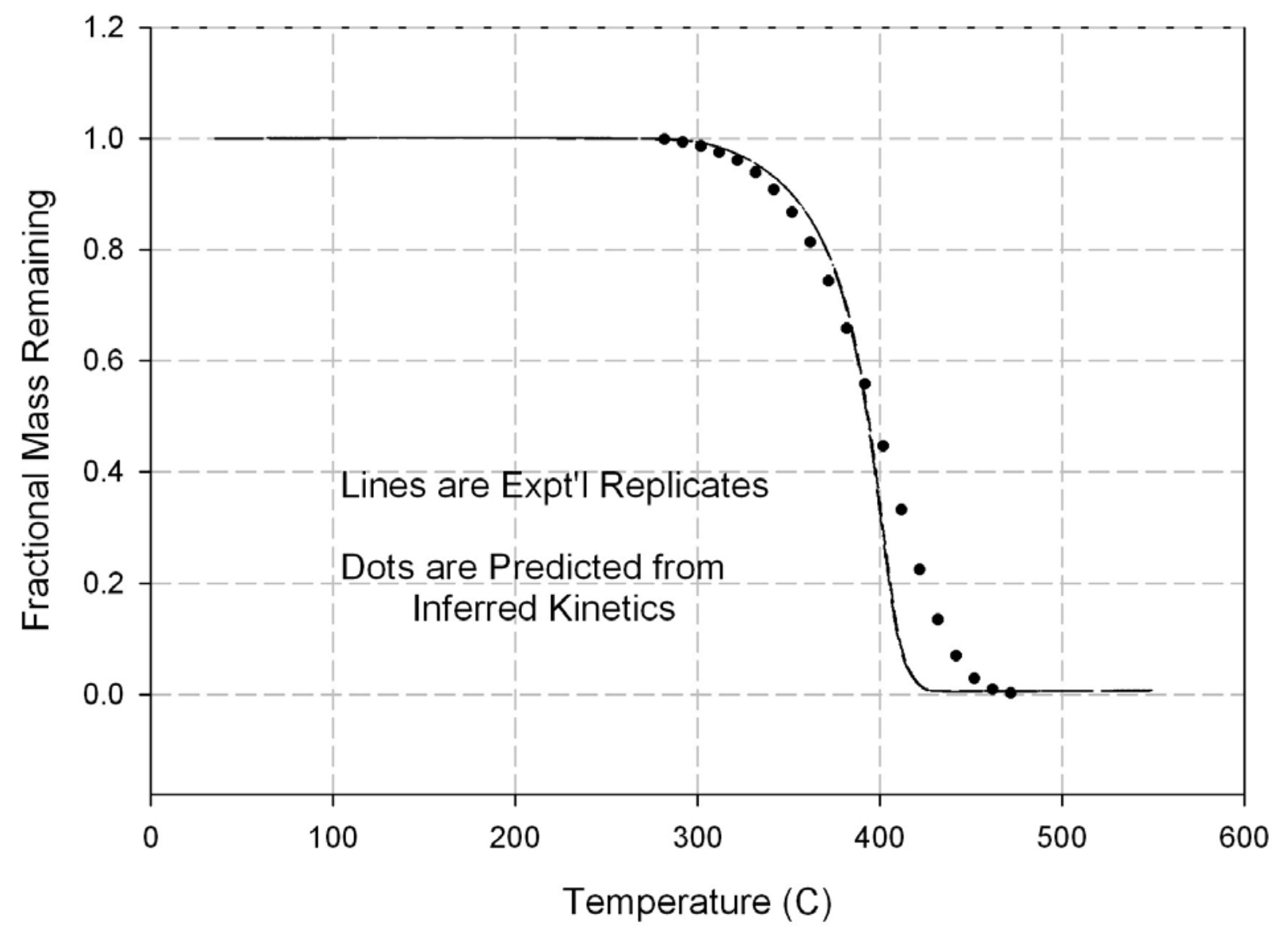

Figure 4a. Thermogravimetry of PD702N polypropylene @ 0.5 C/min; measured and predicted behavior. 


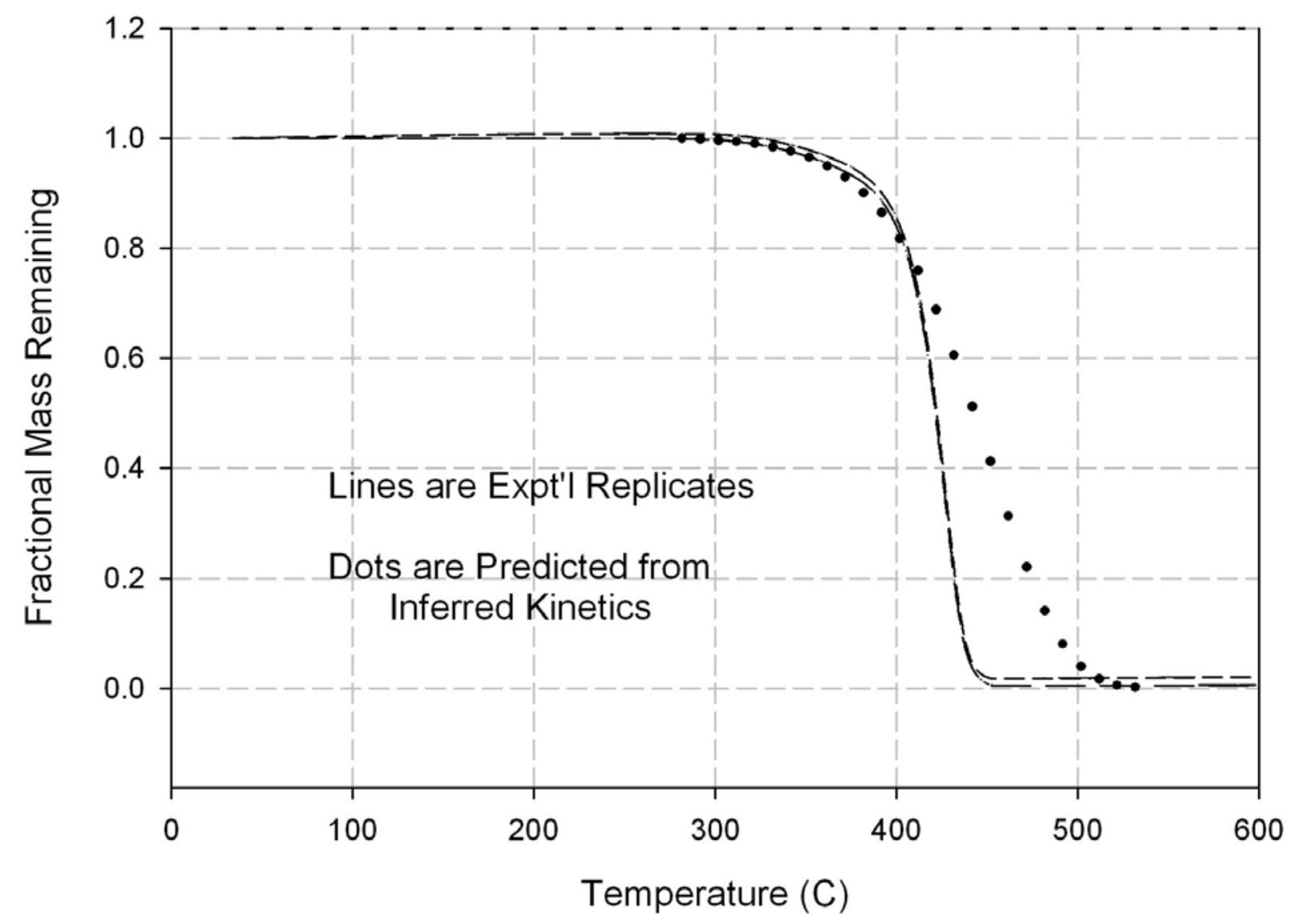

Figure 4b. Thermogravimetry of PD702N polypropylene @ 2 C/min; measured and predicted behavior. 


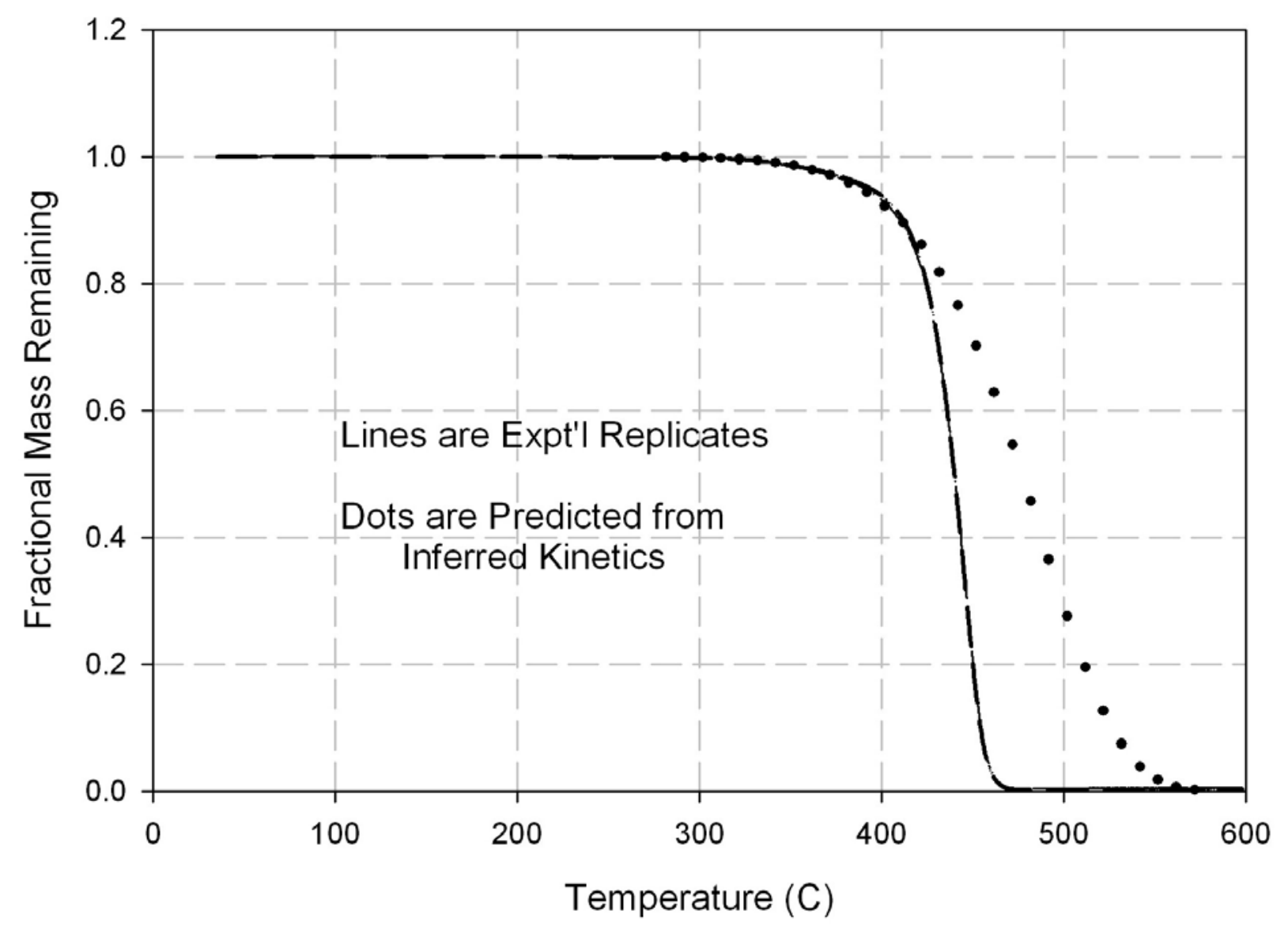

Figure 4c. Thermogravimetry of PD702N polypropylene @ $5 \mathrm{C} / \mathrm{min}$; measured and predicted behavior. 


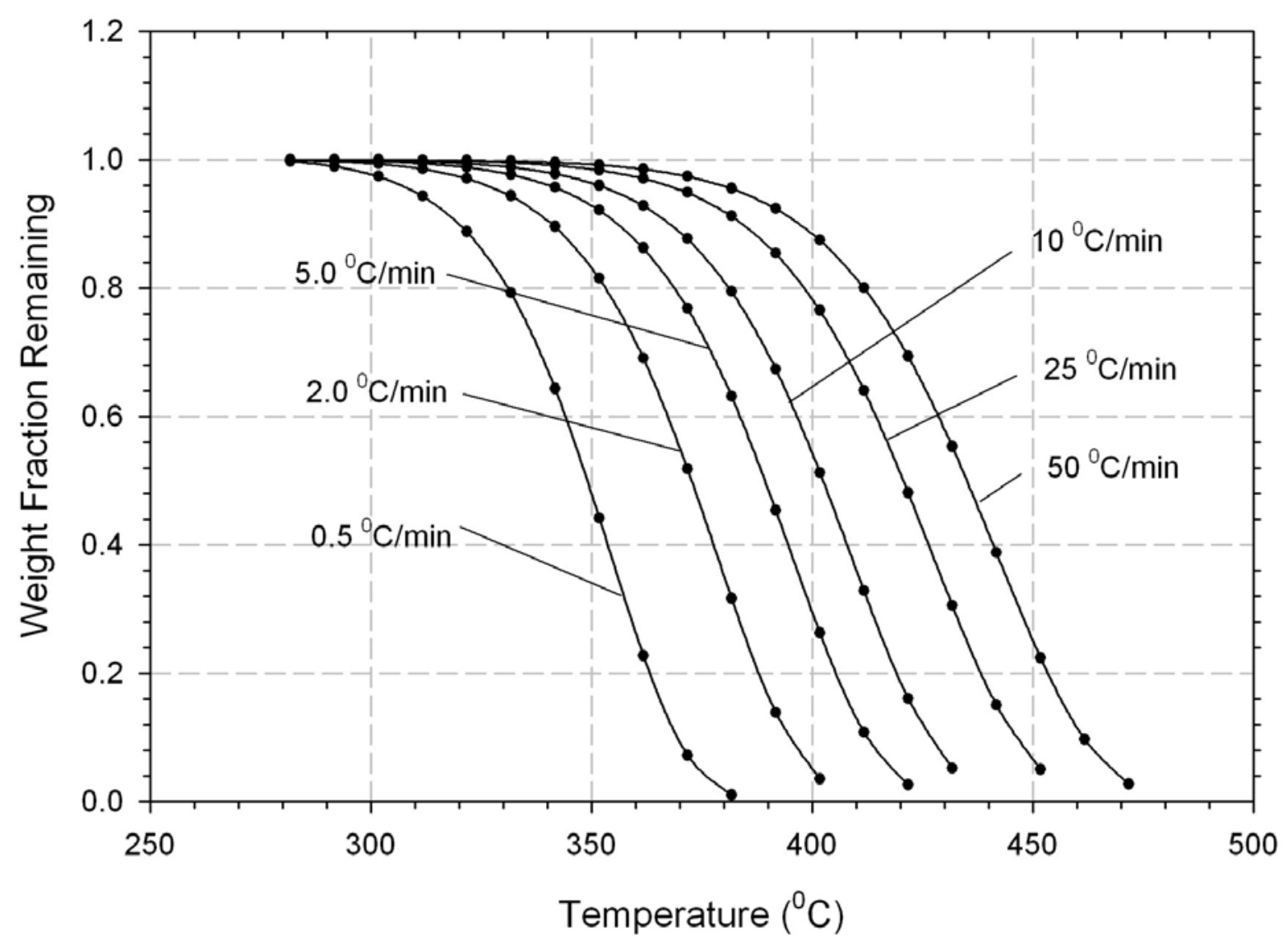

Figure 5. Prediction of thermogravimetry curves for PS666D polystyrene based on Kissinger kinetics. 


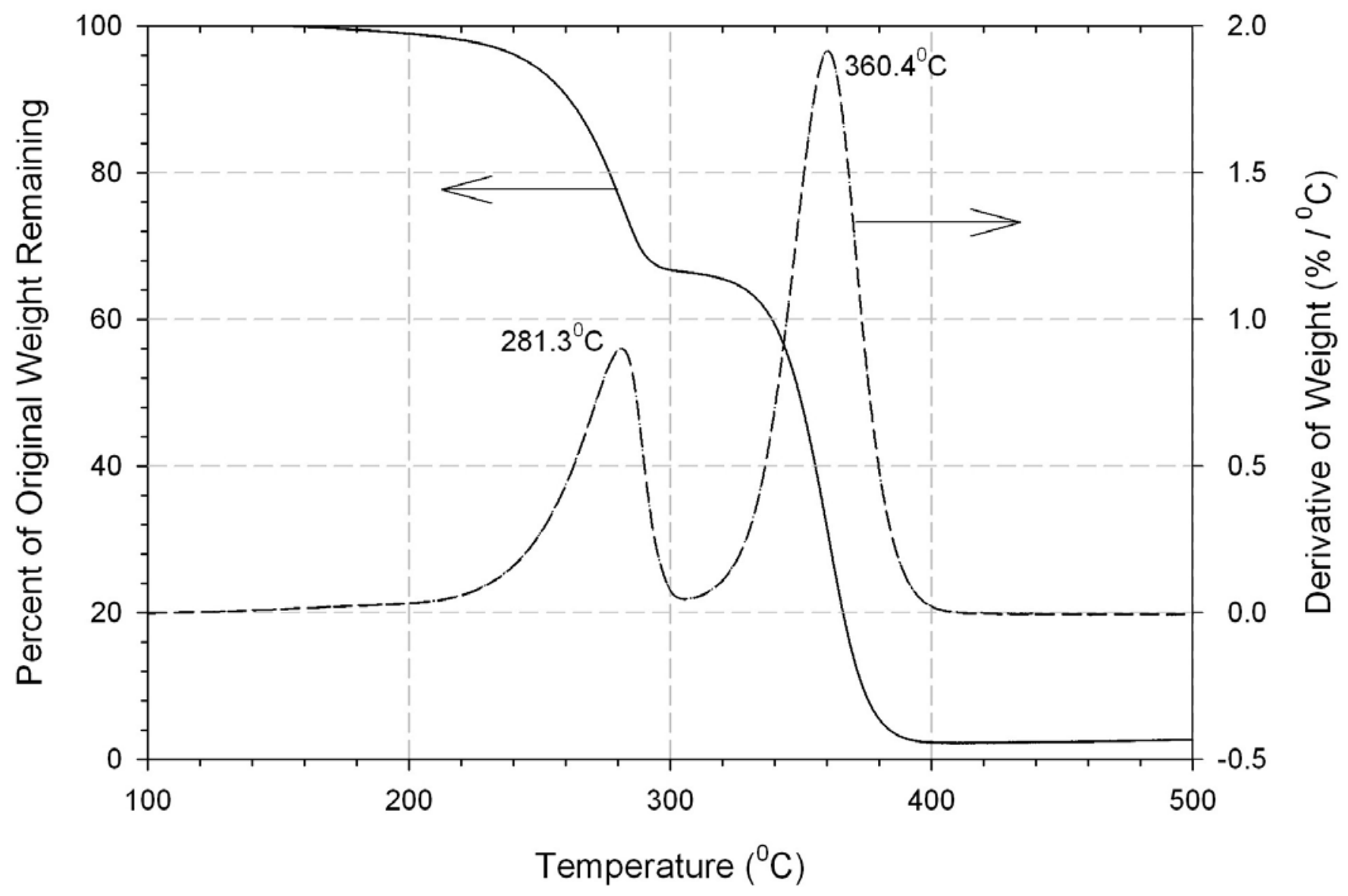

Figure 6. Thermogravimetry of non-flame-retarded (NFR) polyurethane foam in nitrogen at $5{ }^{\circ} \mathrm{C} / \mathrm{min}$ 


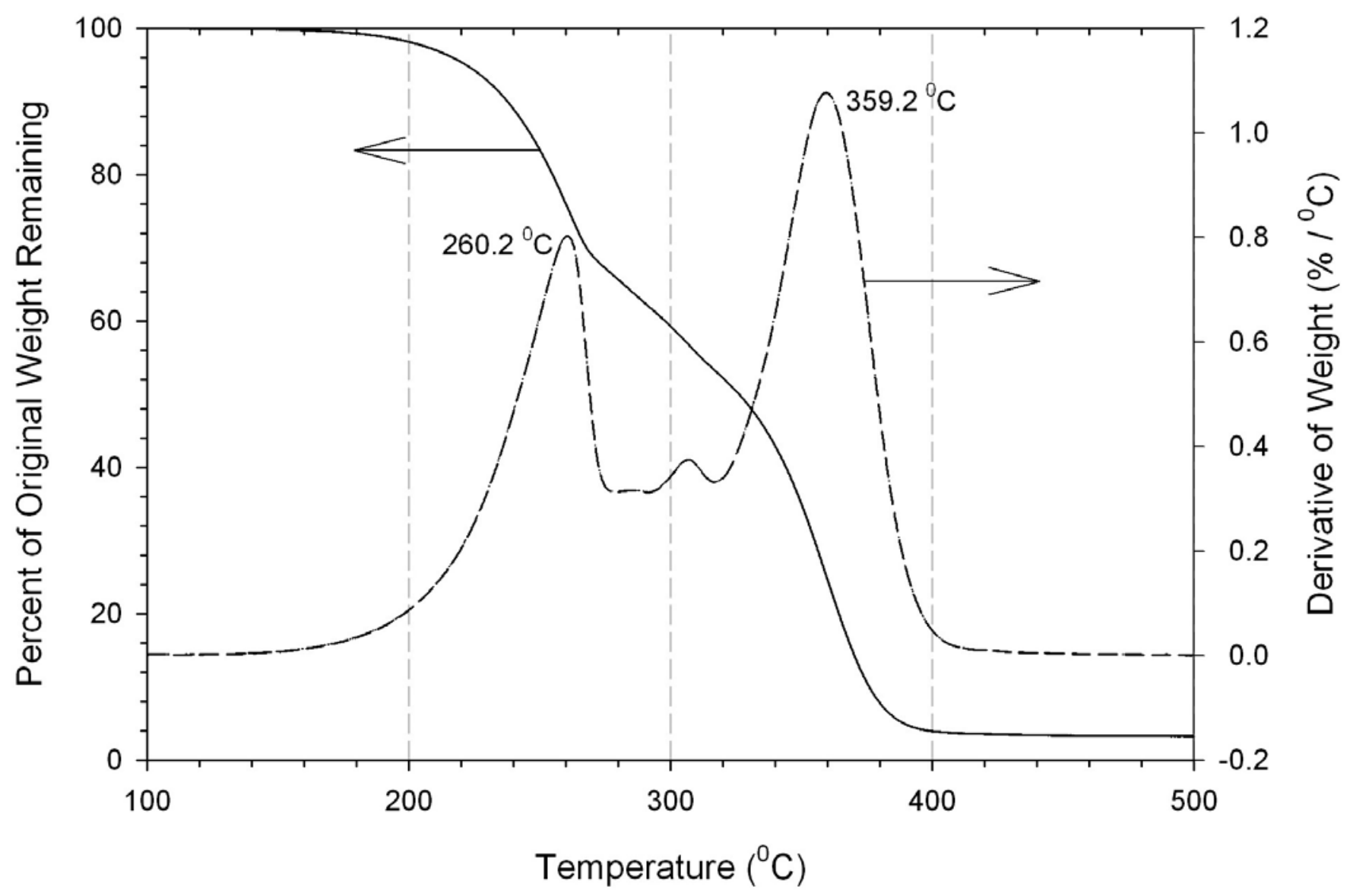

Figure 7 . Thermogravimetry of high melamine $(\mathrm{P})$ polyurethane foam in nitrogen at $5{ }^{\circ} \mathrm{C} / \mathrm{min}$ 


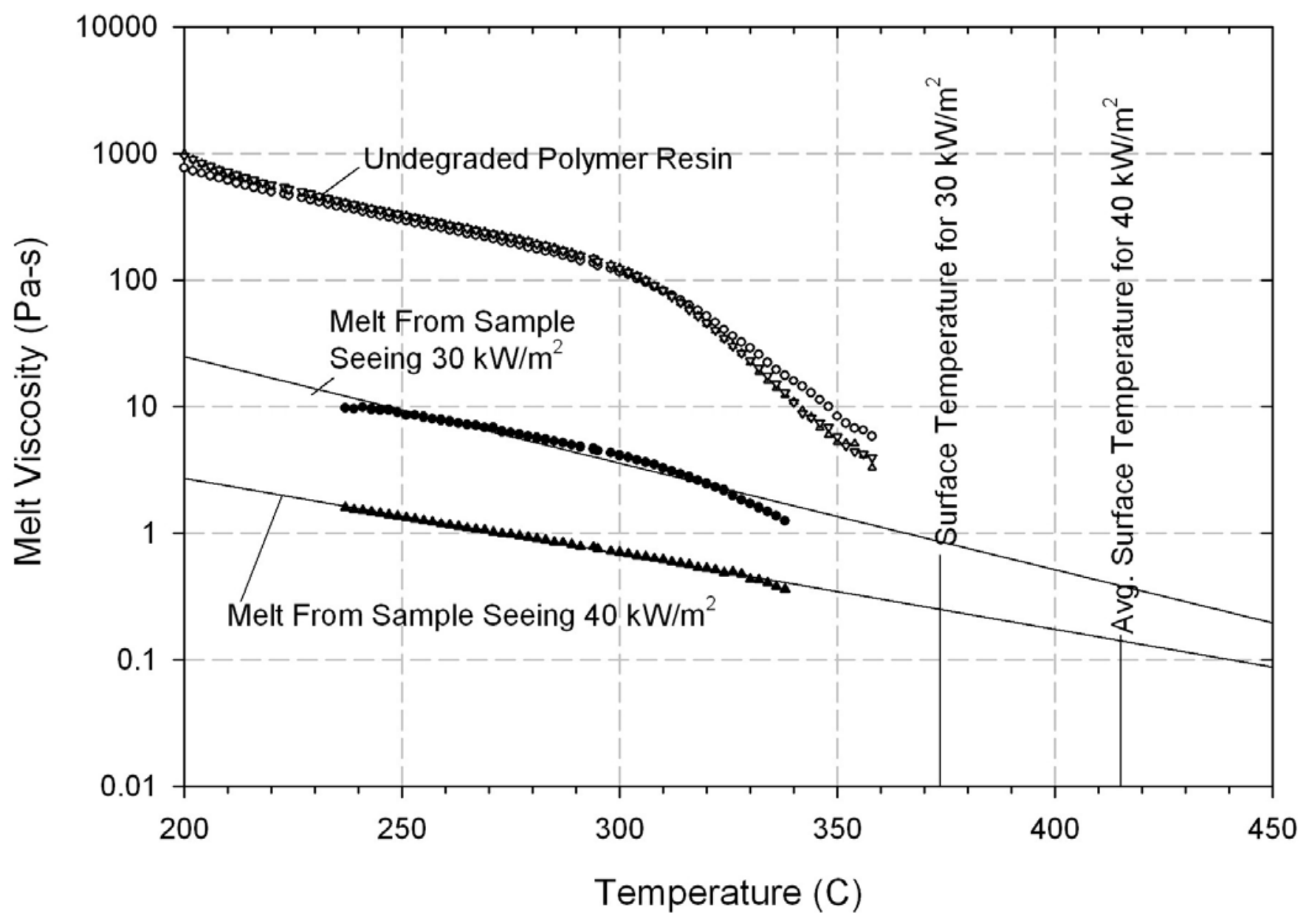

Figure 8. Development of approximate melt viscosity-temperature relationship for PD702N polypropylene. 


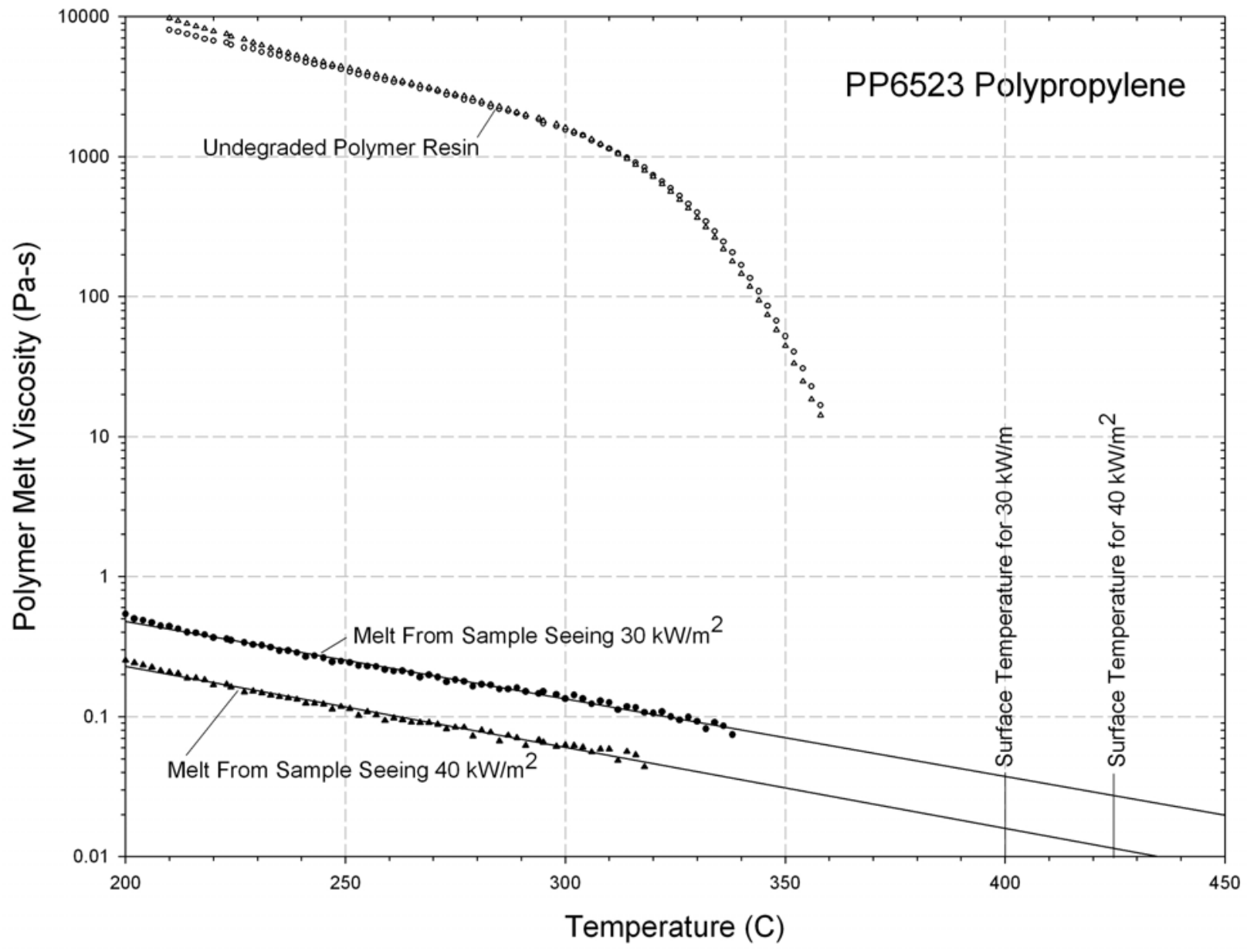

Figure 9. Development of approximate melt viscosity-temperature relationship for PP6523 polypropylene. 


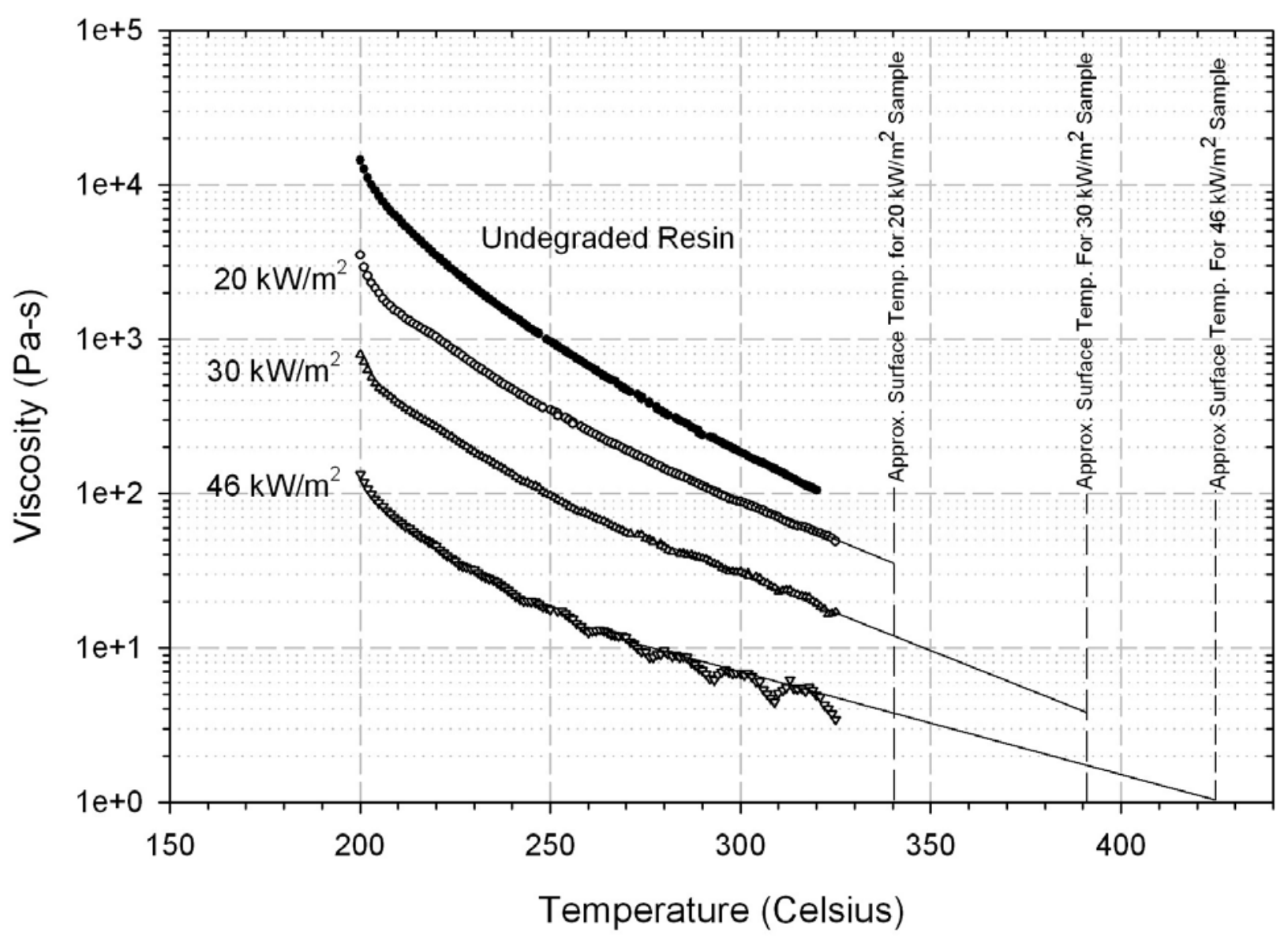

Figure 10. Development of approximate melt viscosity-temperature relationship for PS 666D polystyrene. 


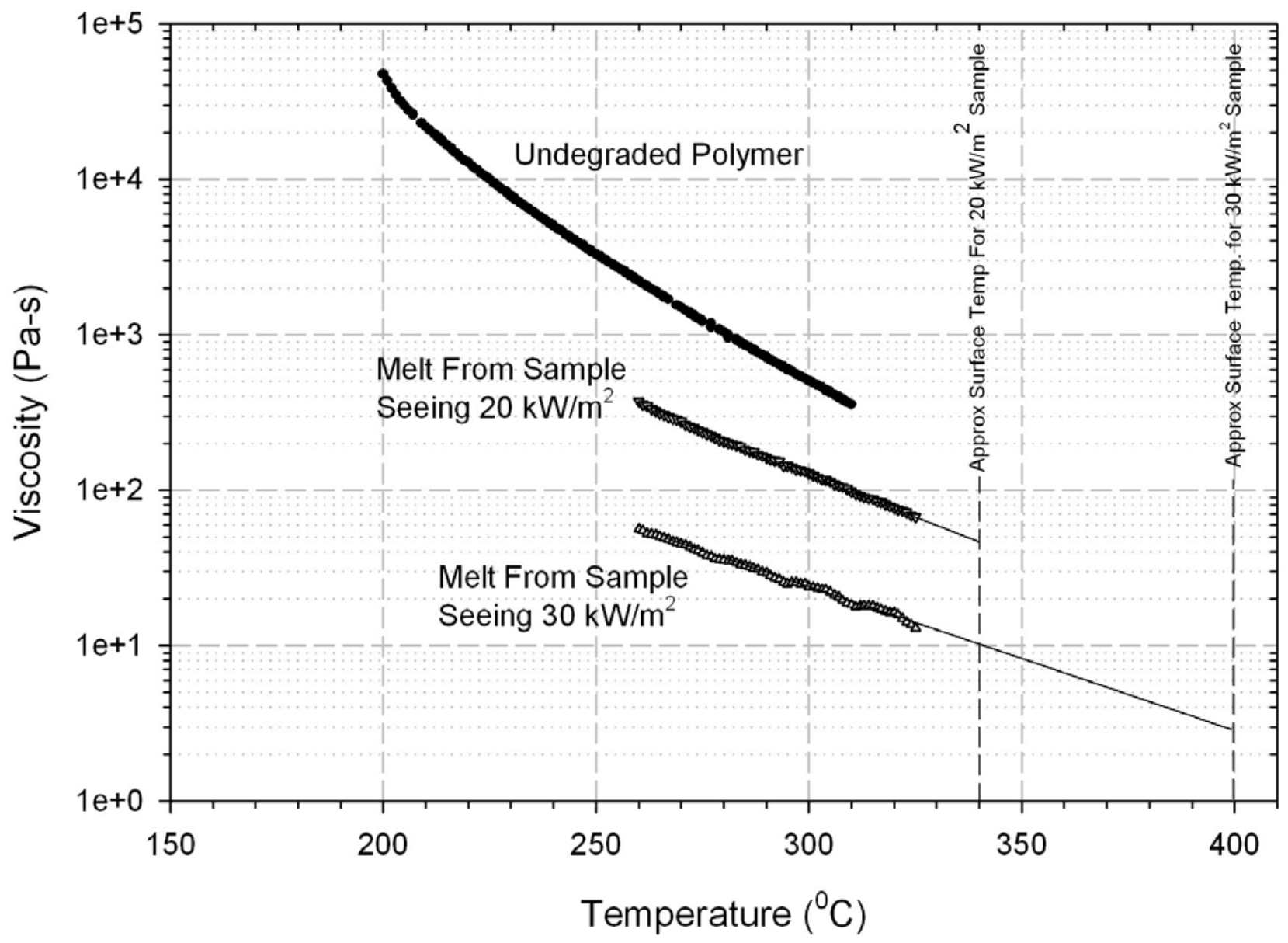

Figure 11. Development of approximate melt viscosity-temperature relation for PS 663 polystyrene. 


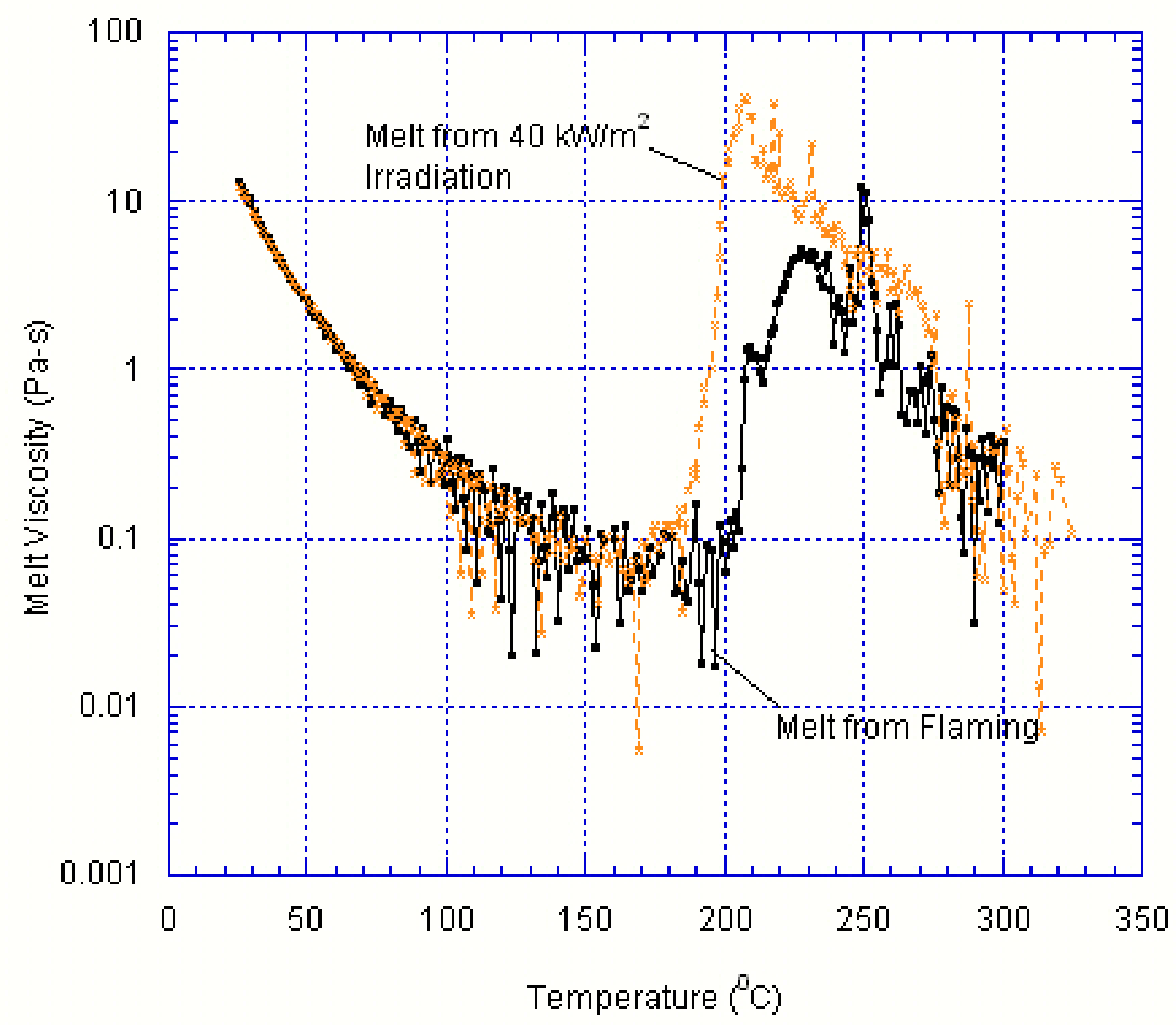

Figure 12. Viscosity of polyurethane foam melt captured from two types of experiment. Foam is Z0. 


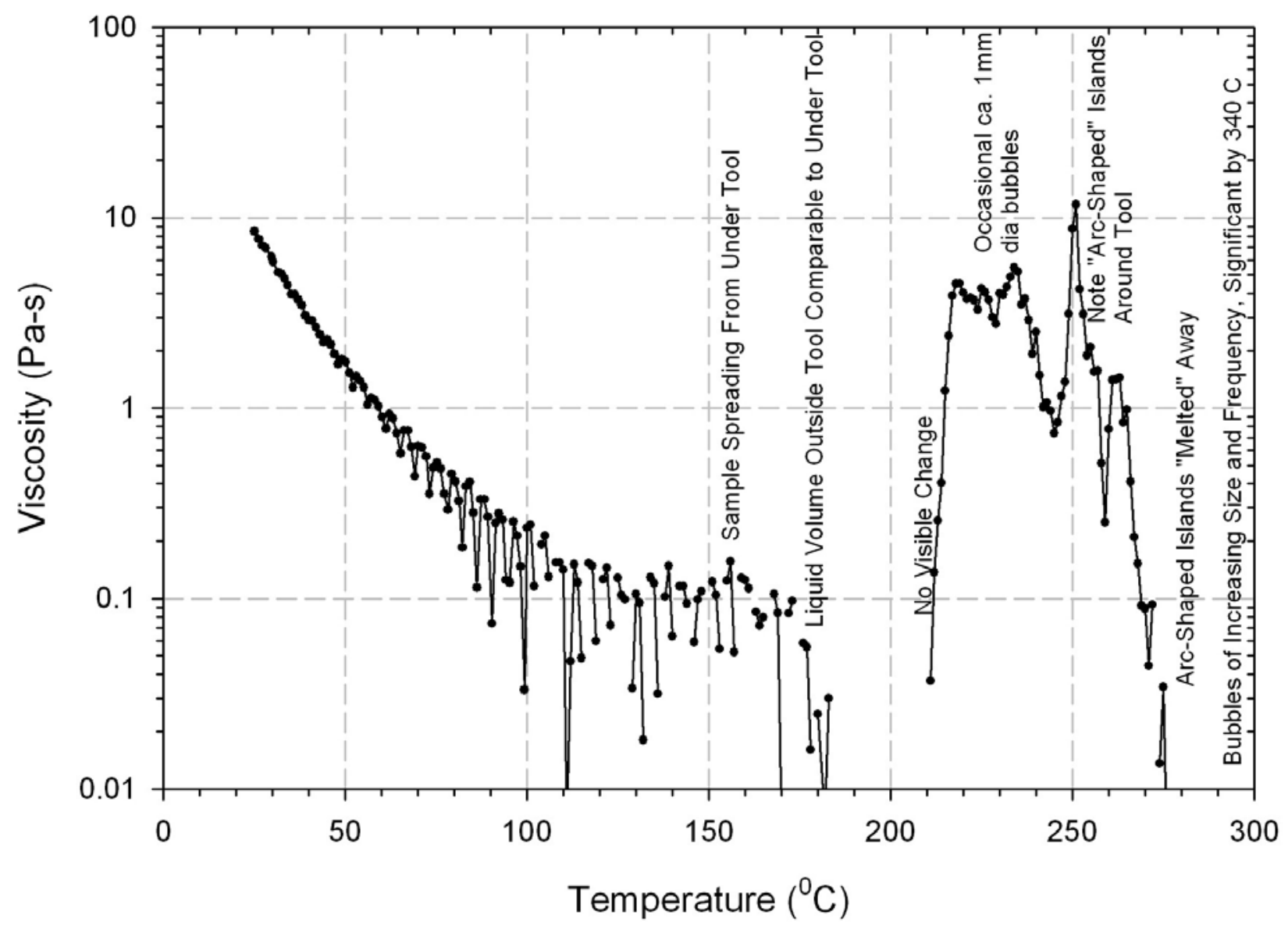

Figure 13. Viscosity of melt captured in cone melt/drip test; NFR polyurethane foam. Melt generated at a radiant flux of $40 \mathrm{~kW} / \mathrm{m}^{2}$ 


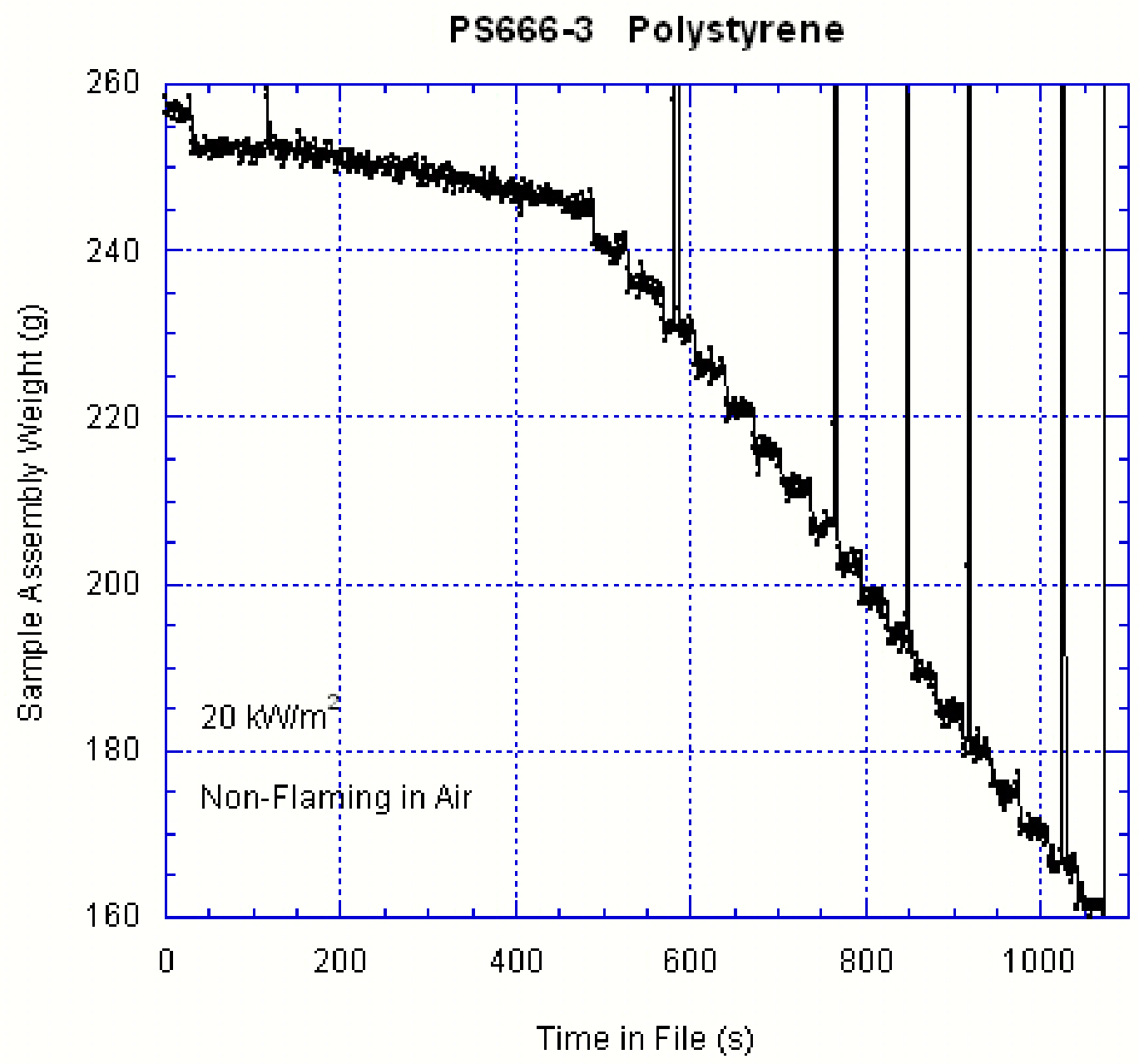

Figure 14 a. Example of sample assembly weight during a polymer melt/drip test. Sample is PS 666 polystyrene subjected to $20 \mathrm{~kW} / \mathrm{m}^{2}$; non-flaming. 


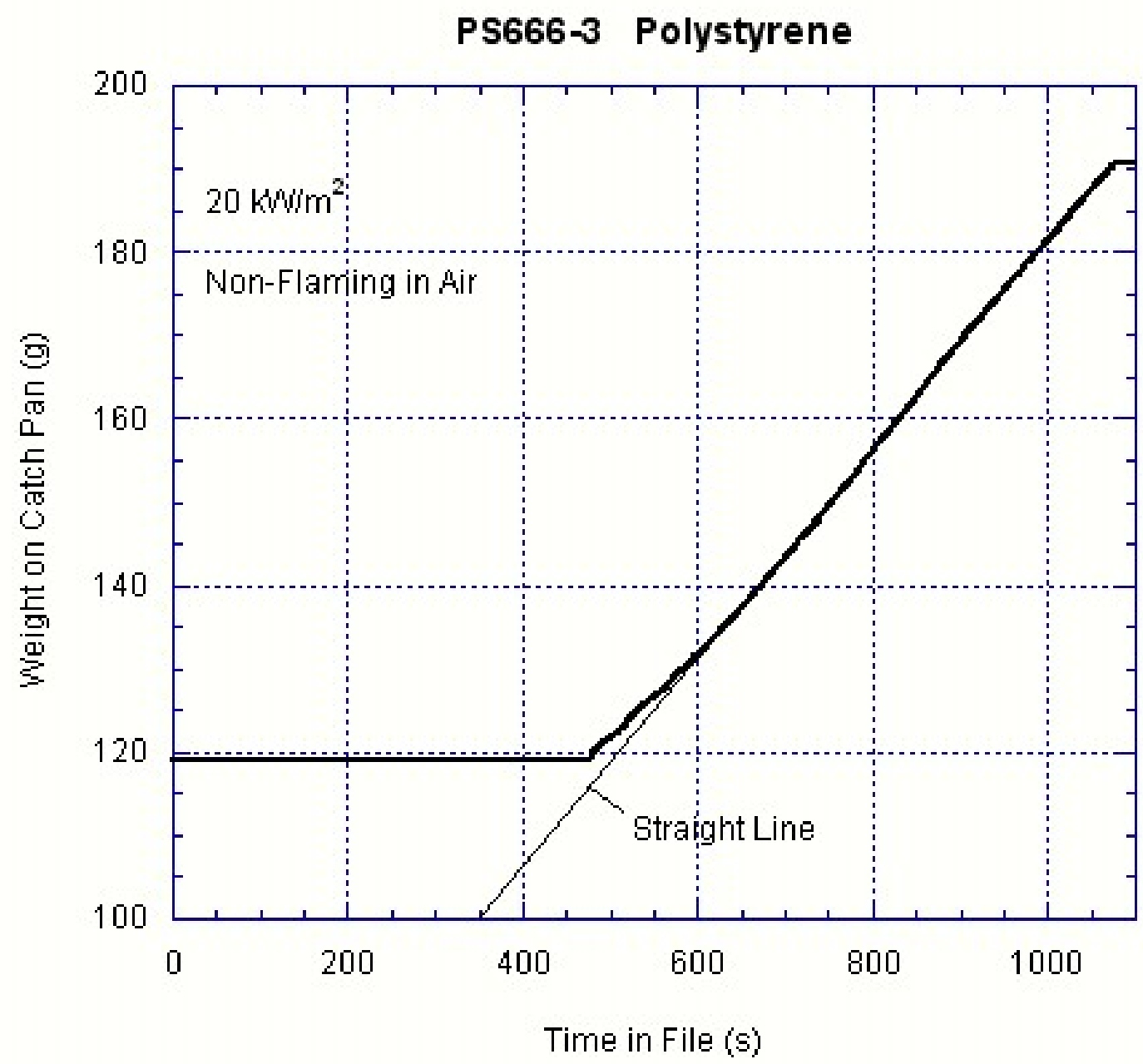

Figure $14 \mathrm{~b}$. Example of weight seen on catch pan during a polymer melt/drip test. Sample is PS666 polystyrene subjected to $20 \mathrm{~kW} / \mathrm{m}^{2}$; non-flaming. 


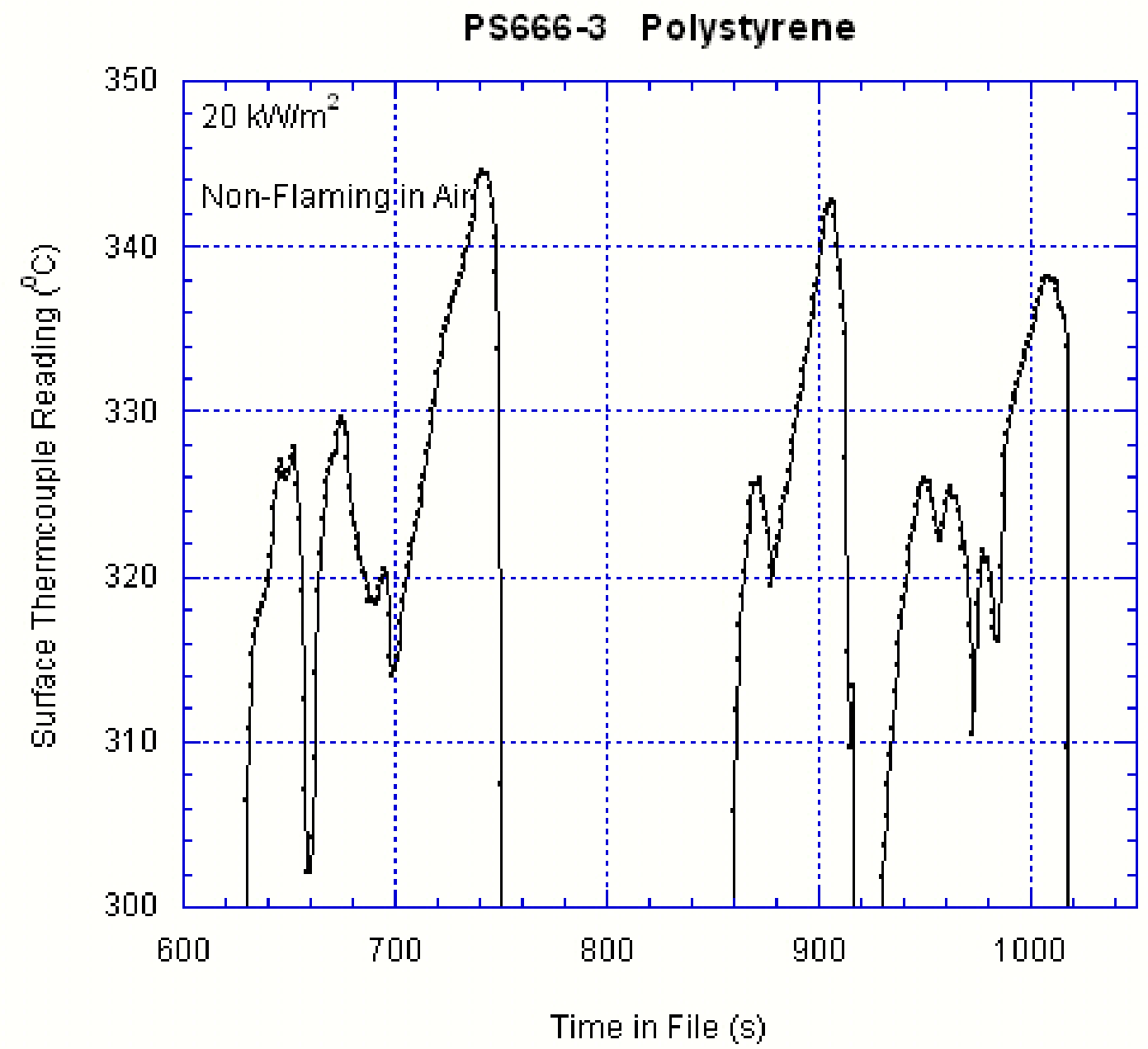

Figure 14 c. Example of surface thermocouple reading as it is moved into and out of surface melt layer. Sample is PS 666 polystyrene subjected to $20 \mathrm{~kW} / \mathrm{m}^{2}$; non-flaming. 


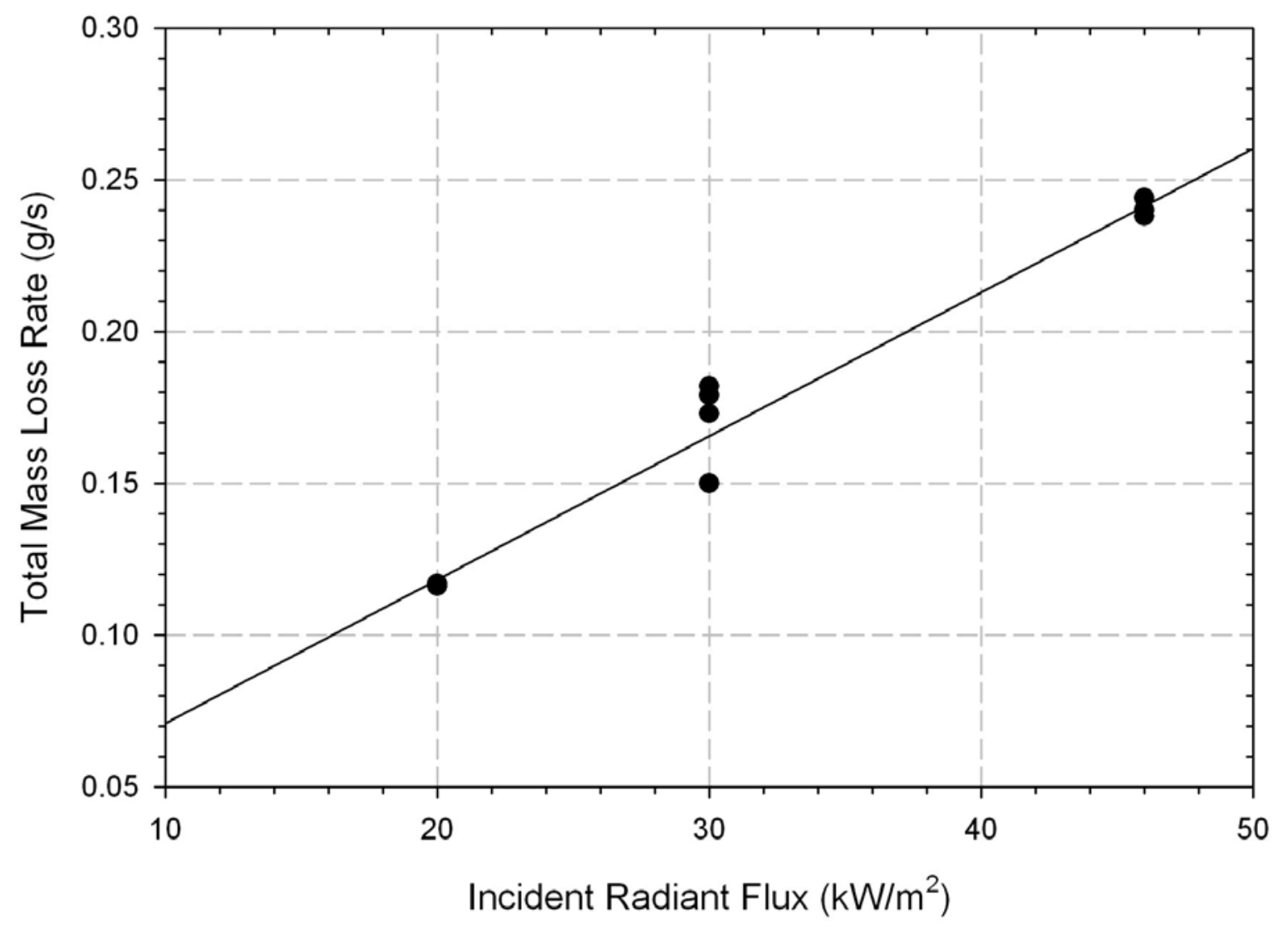

Figure 15 a. Total mass loss rate as a function of incident radiant flux; PD702N polypropylene; non-flaming, in air. 


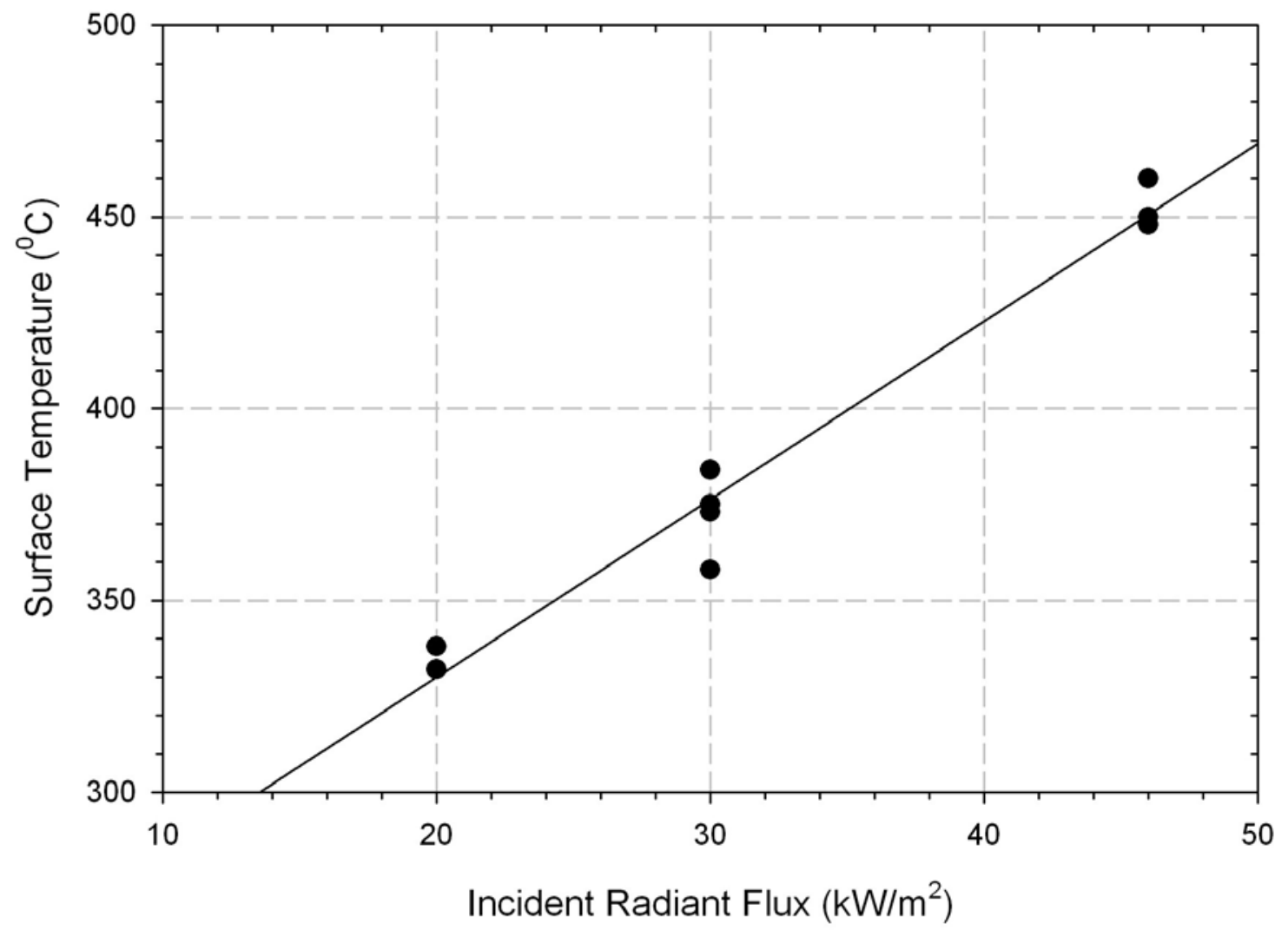

Figure $15 \mathrm{~b}$. Measured surface temperature as a function of incident radiant flux; PD702N polypropylene; non-flaming, in air. 


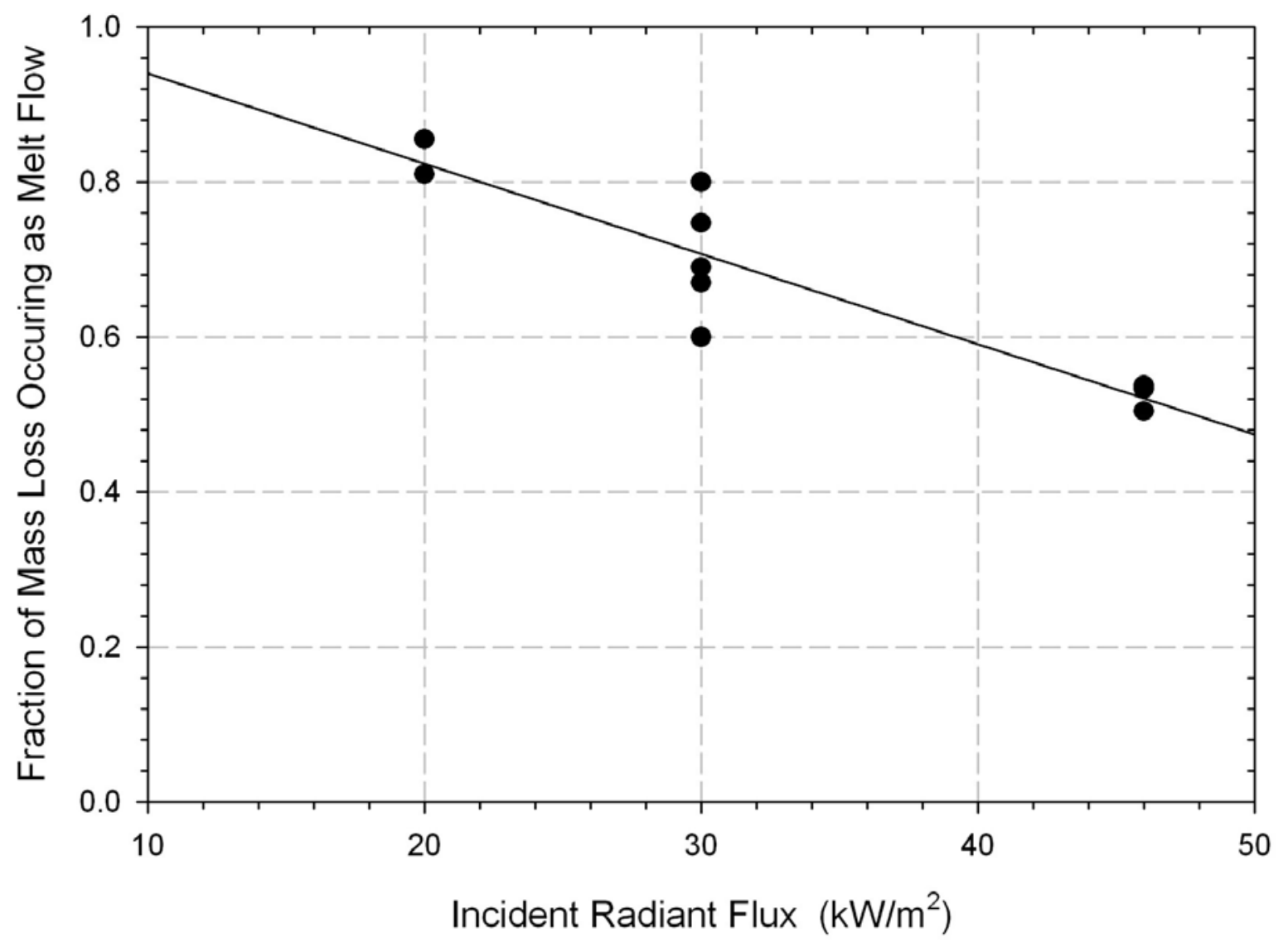

Figure $15 \mathrm{c}$. Fraction of mass loss via melting as a function of incident radiant flux; PD702N polypropylene; non-flaming, in air. 


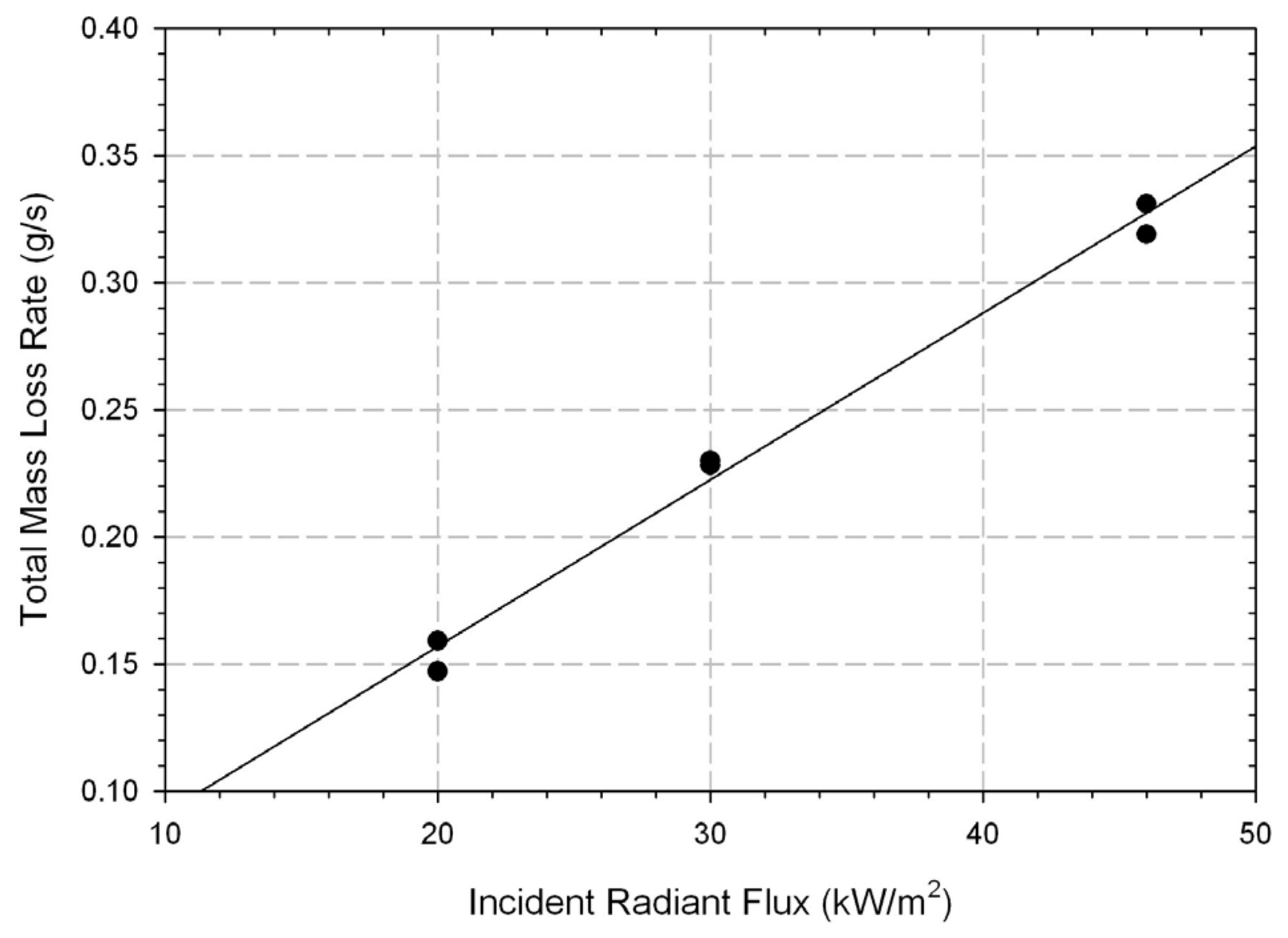

Figure $16 \mathrm{a}$. Total mass loss rate as a function of incident radiant flux; PS666 polystyrene; non-flaming, in air. 


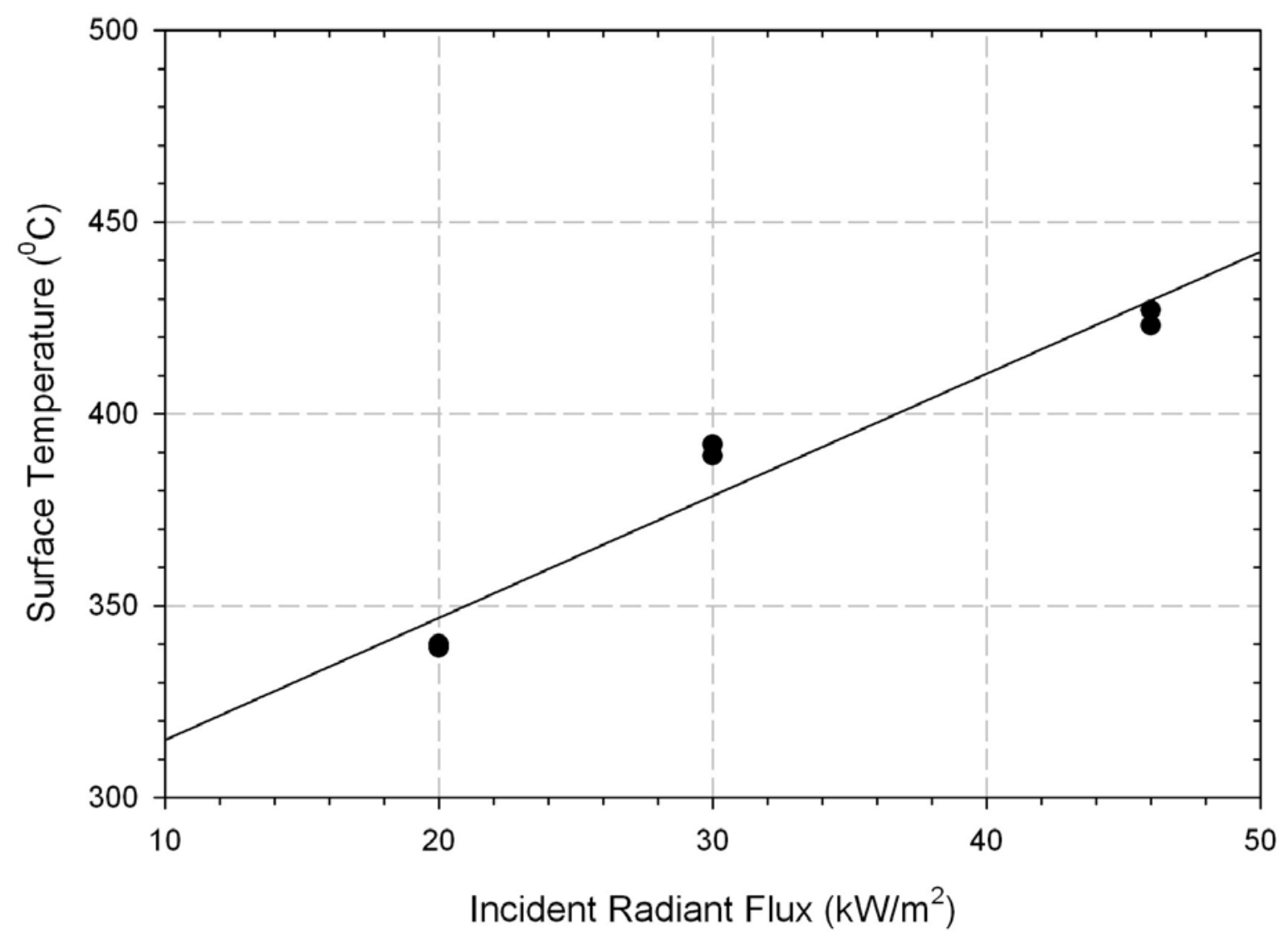

Figure $16 \mathrm{~b}$. Measured surface temperature vs incident radiant flux; PS666 polystyrene; non-flaming, in air. 


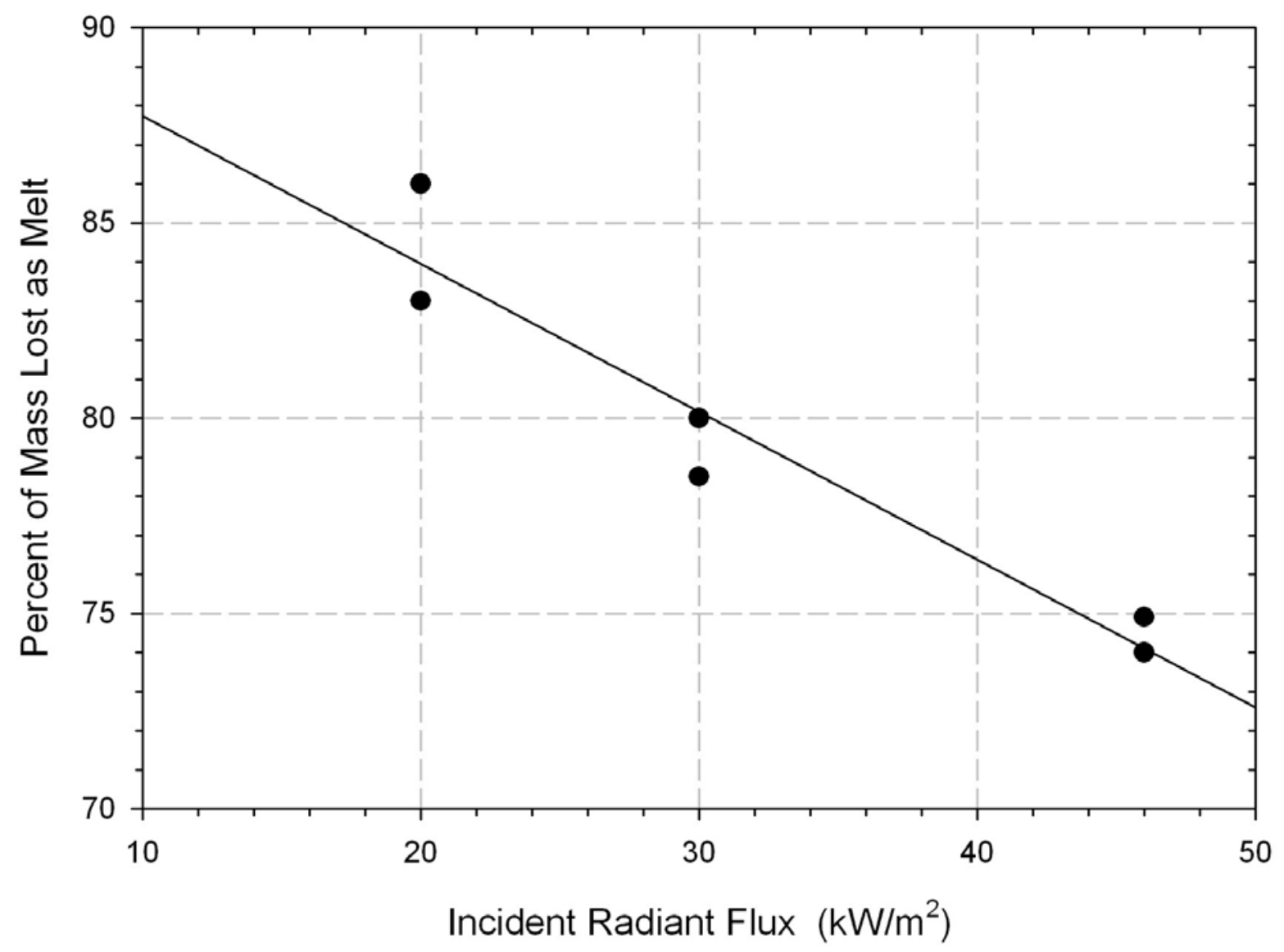

Figure 16 c. Percent mass lost as melt vs incident radiant flux; PS666 polystyrene; non-flaming, in air. 


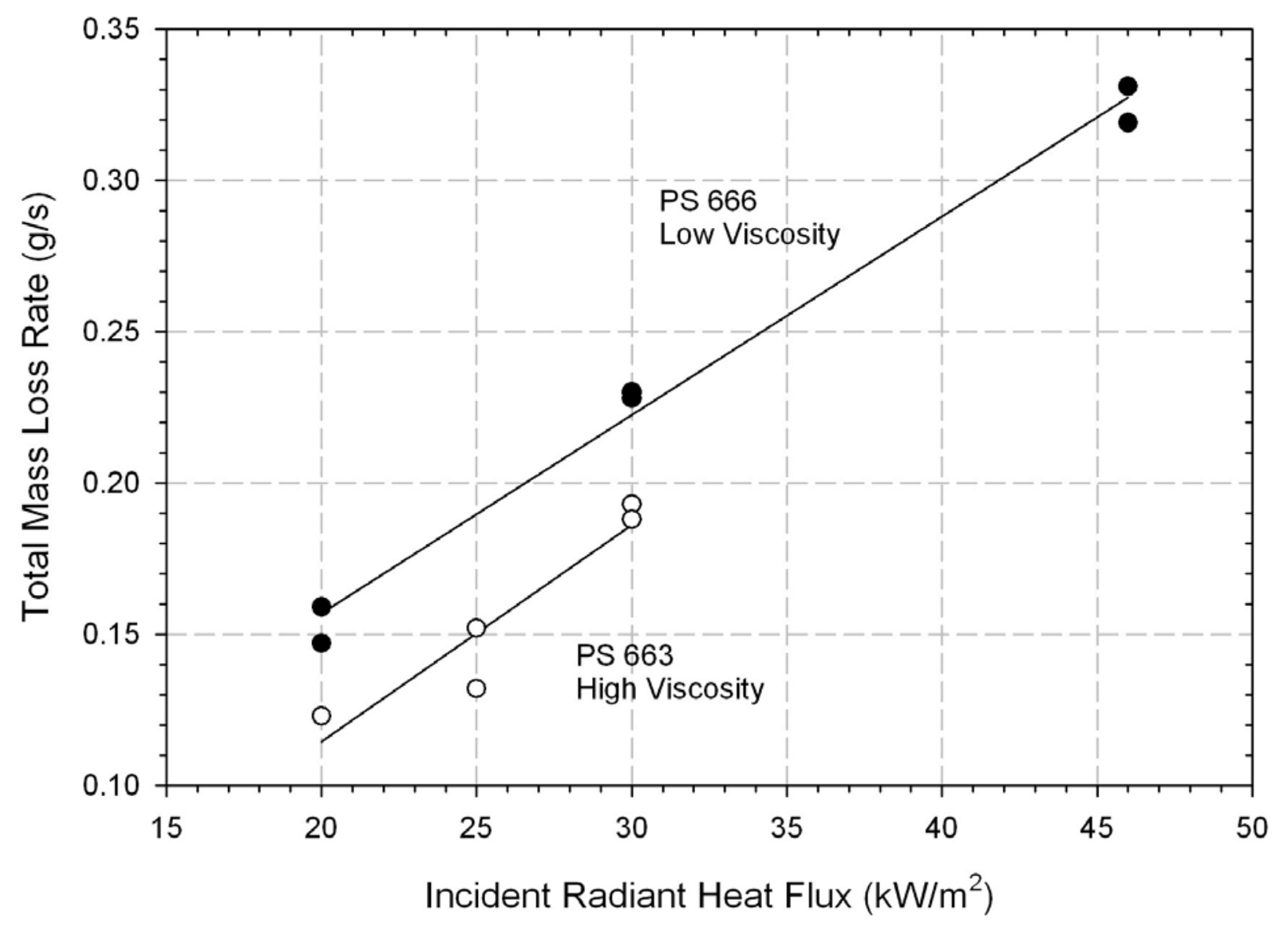

Figure 17. Total mass loss rate vs incident radiant flux; two polystyrenes. 


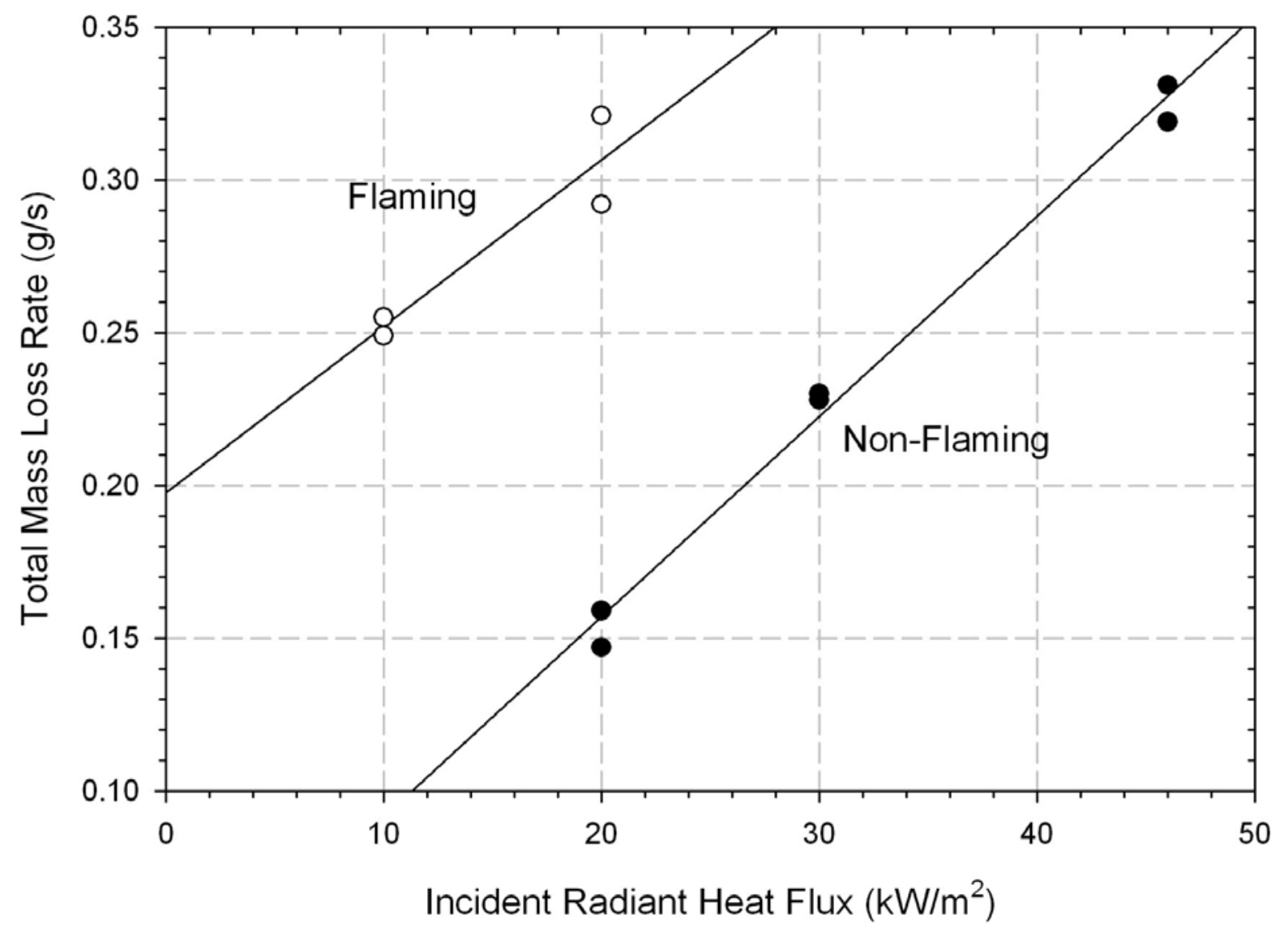

Figure 18. Total mass loss rate in both non-flaming and flaming modes as a function of incident radiant flux; PS 666 polystyrene. 


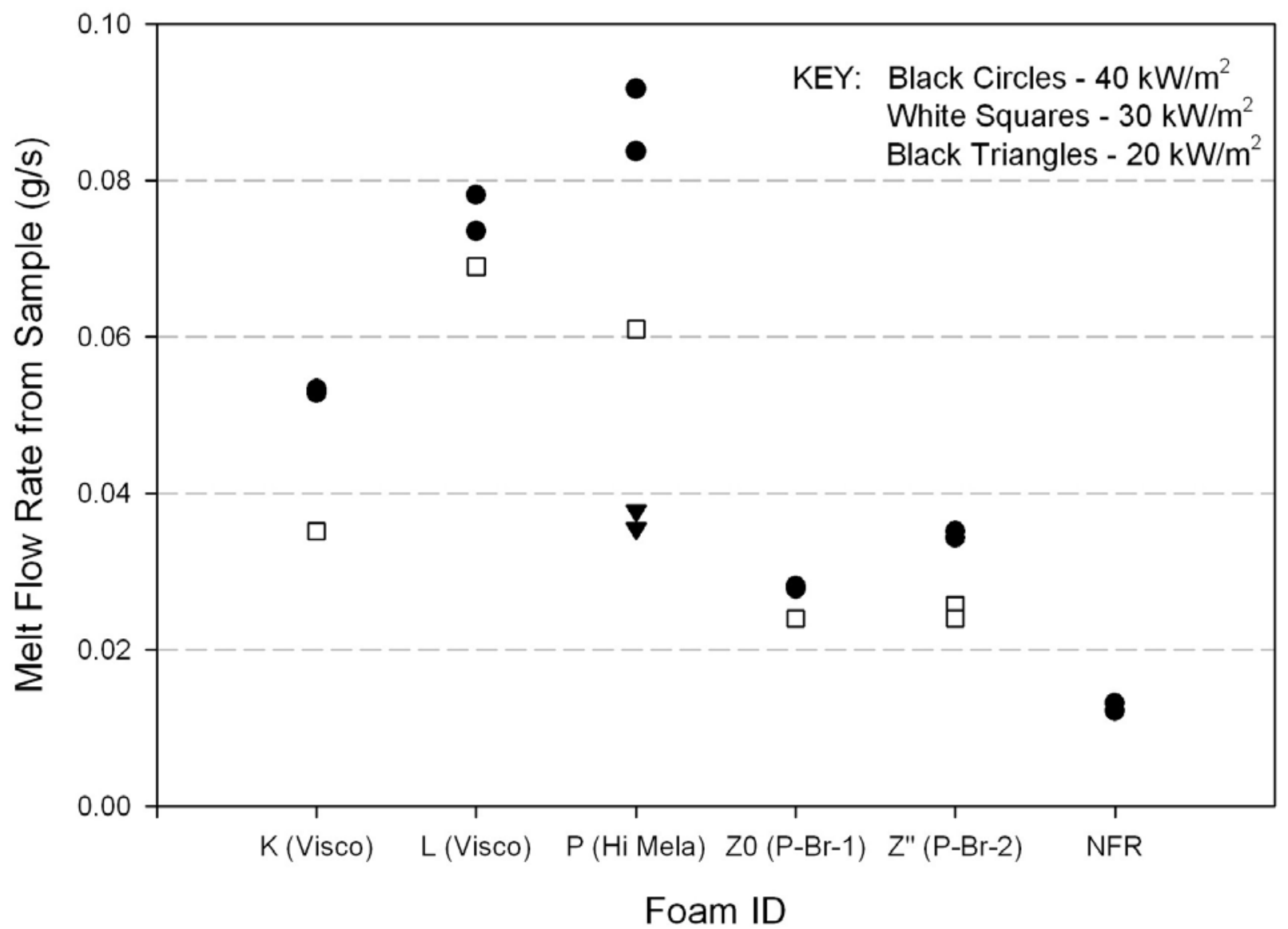

Figure 19. Melt flow rate from sample for various polyurethane foam compositions at three incident radiant flux levels. 


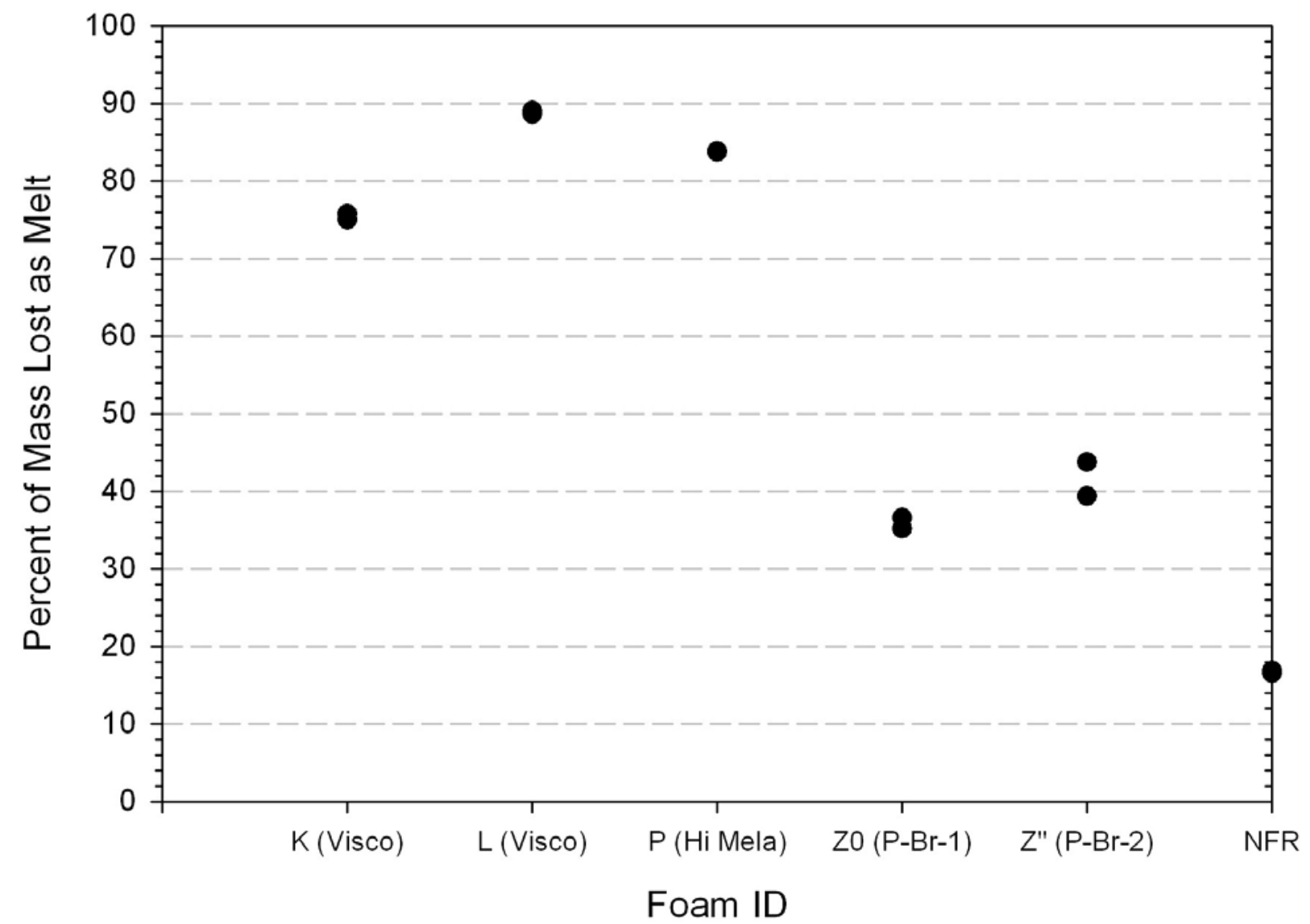

Figure 20. Percent of mass loss occurring as melt for several polyurethane foams at an incident radiant flux of $40 \mathrm{~kW} / \mathrm{m}^{2}$; non-flaming, in air. 


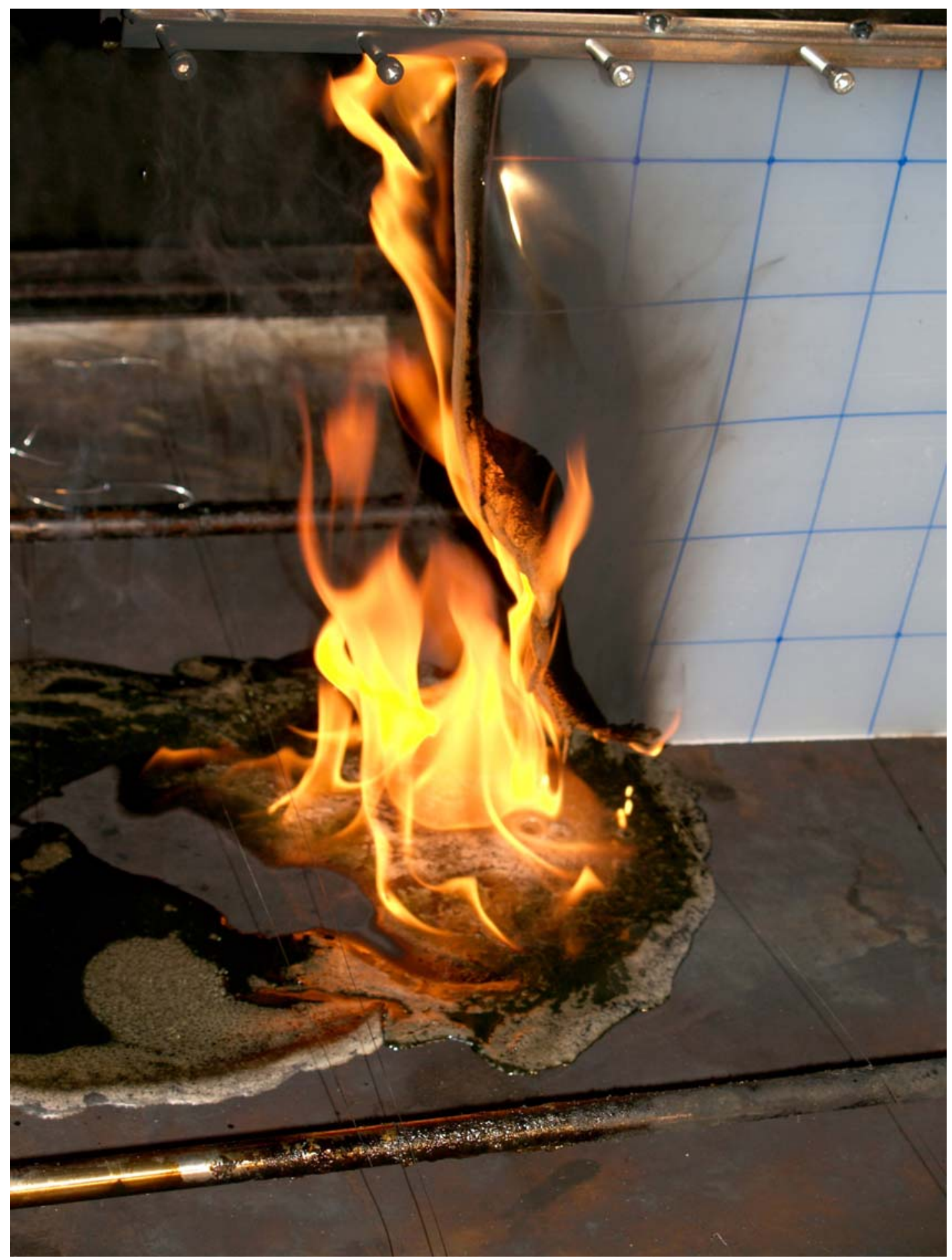

Figure 21. Pool-assisted fire growth on a vertical, $3 \mathrm{~mm}$ thick sheet of polypropylene. 


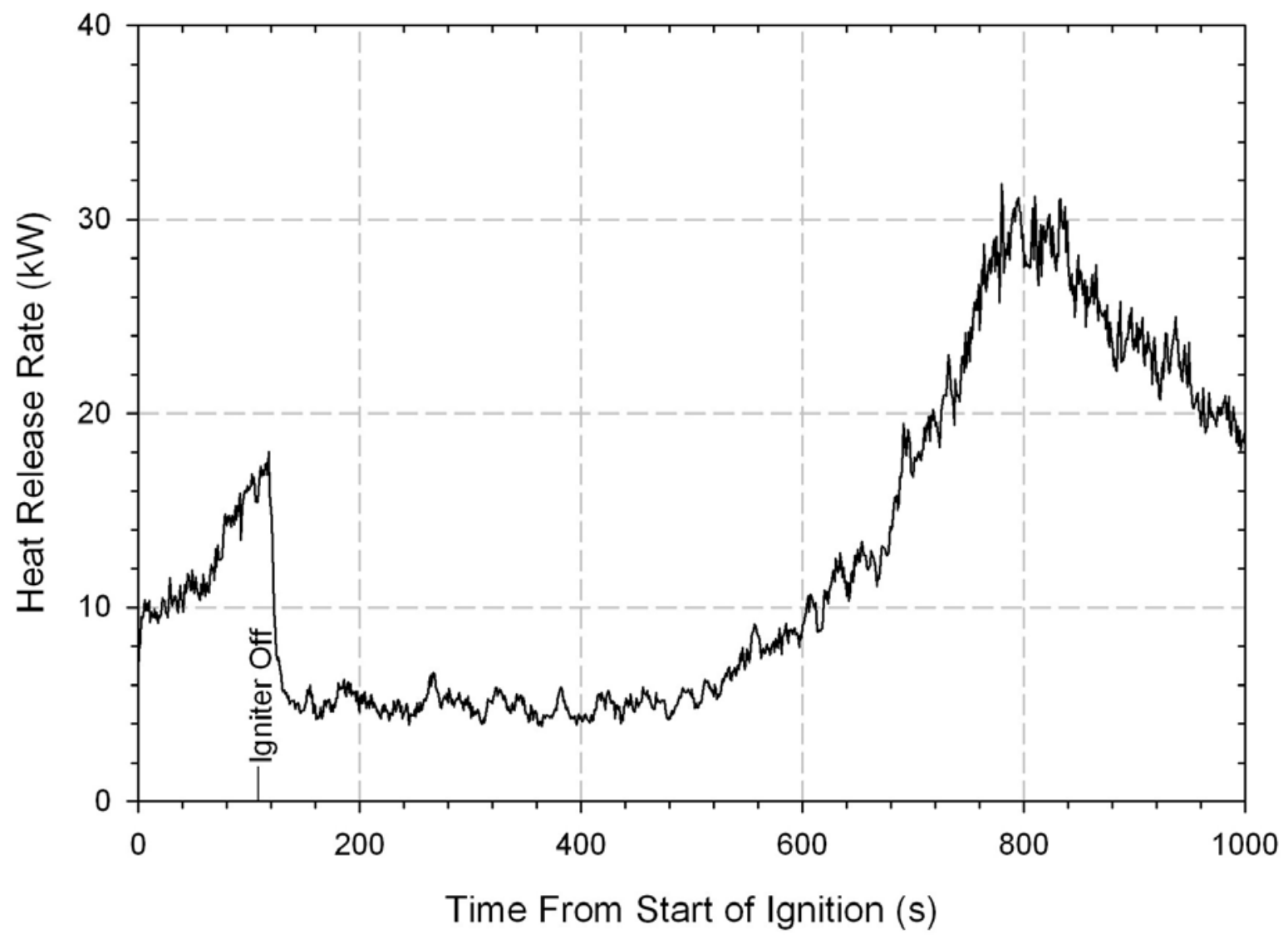

Figure 22 a. Heat release rate from pool fire-assisted lateral fire spread on a $3 \mathrm{~mm}$ thick, vertical sheet of polypropylene placed $4.3 \mathrm{~cm}$ above a catch surface. 


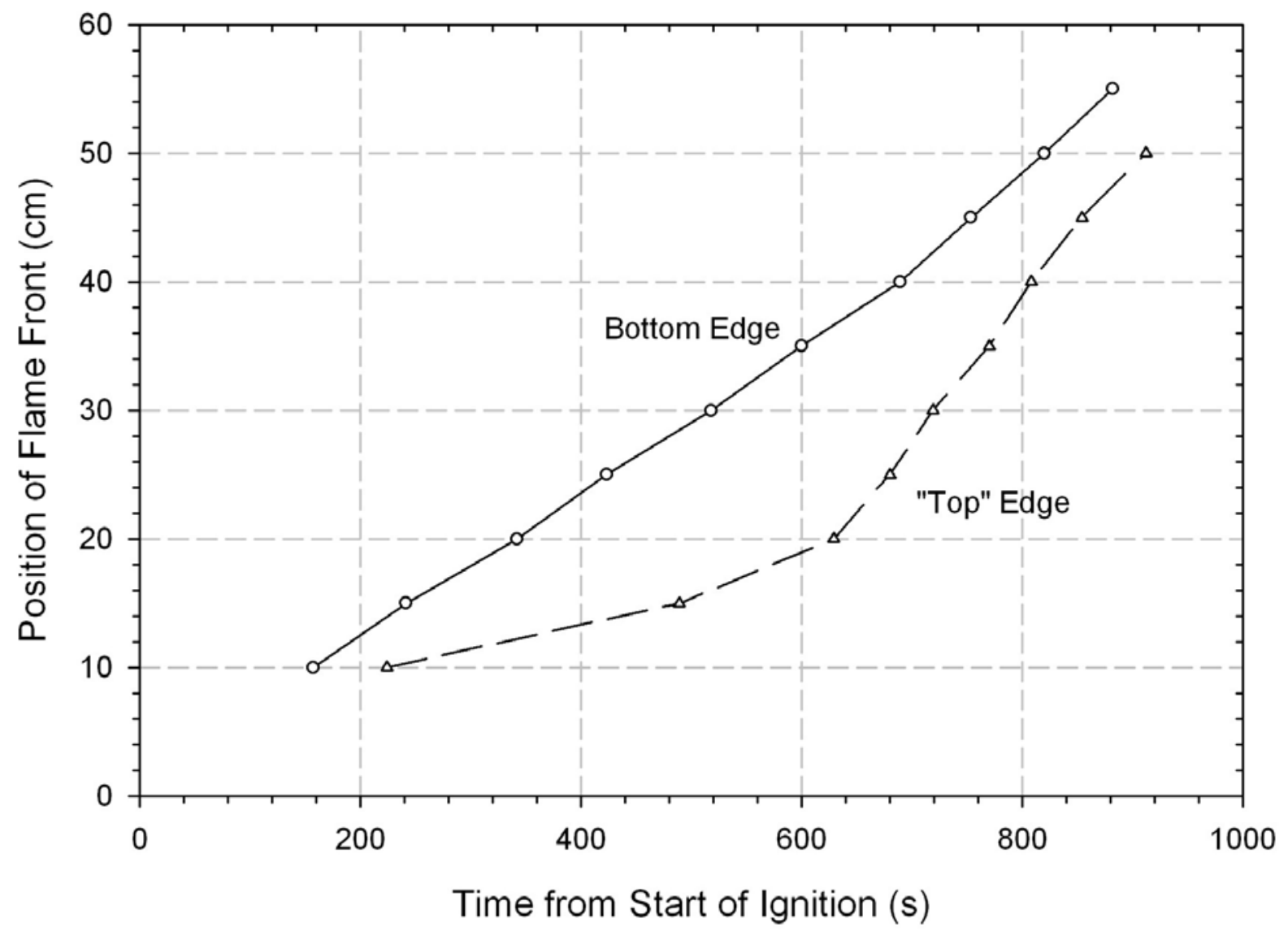

Figure $22 \mathrm{~b}$. Flame front position vs time for pool fire-assisted, lateral fire spread on a $3 \mathrm{~mm}$ thick sheet of polypropylene placed $4.3 \mathrm{~cm}$ above a catch surface. 


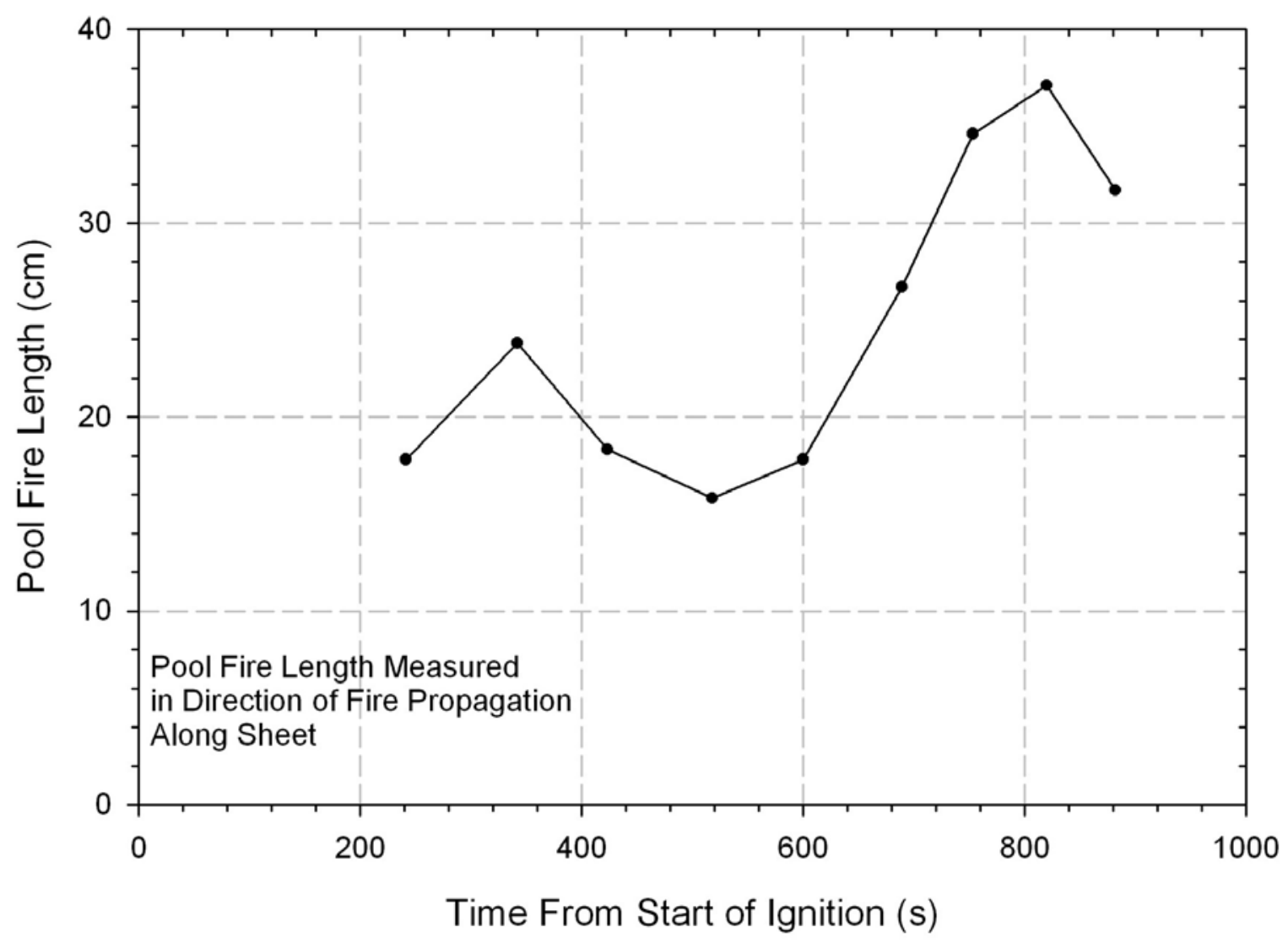

Figure $22 \mathrm{c}$. Pool fire length variation during pool fire-assisted lateral fire spread on a $3 \mathrm{~mm}$ thick sheet of polypropylene placed $4.3 \mathrm{~cm}$ above a catch surface. 


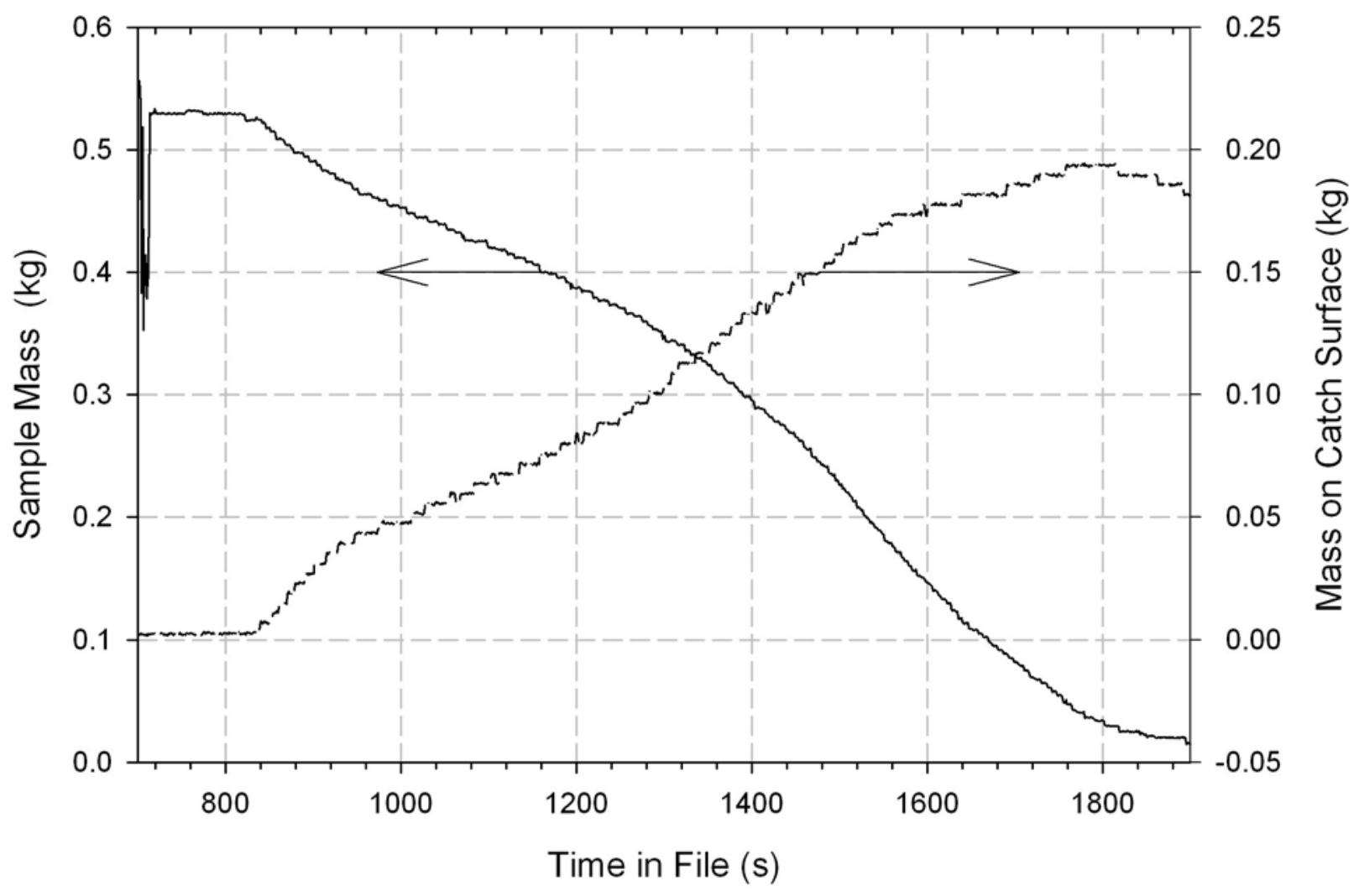

Figure $22 \mathrm{~d}$. Sample mass and melt pool mass vs time for fire spread on a $3 \mathrm{~mm}$ thick, vertical sheet of polypropylene. 


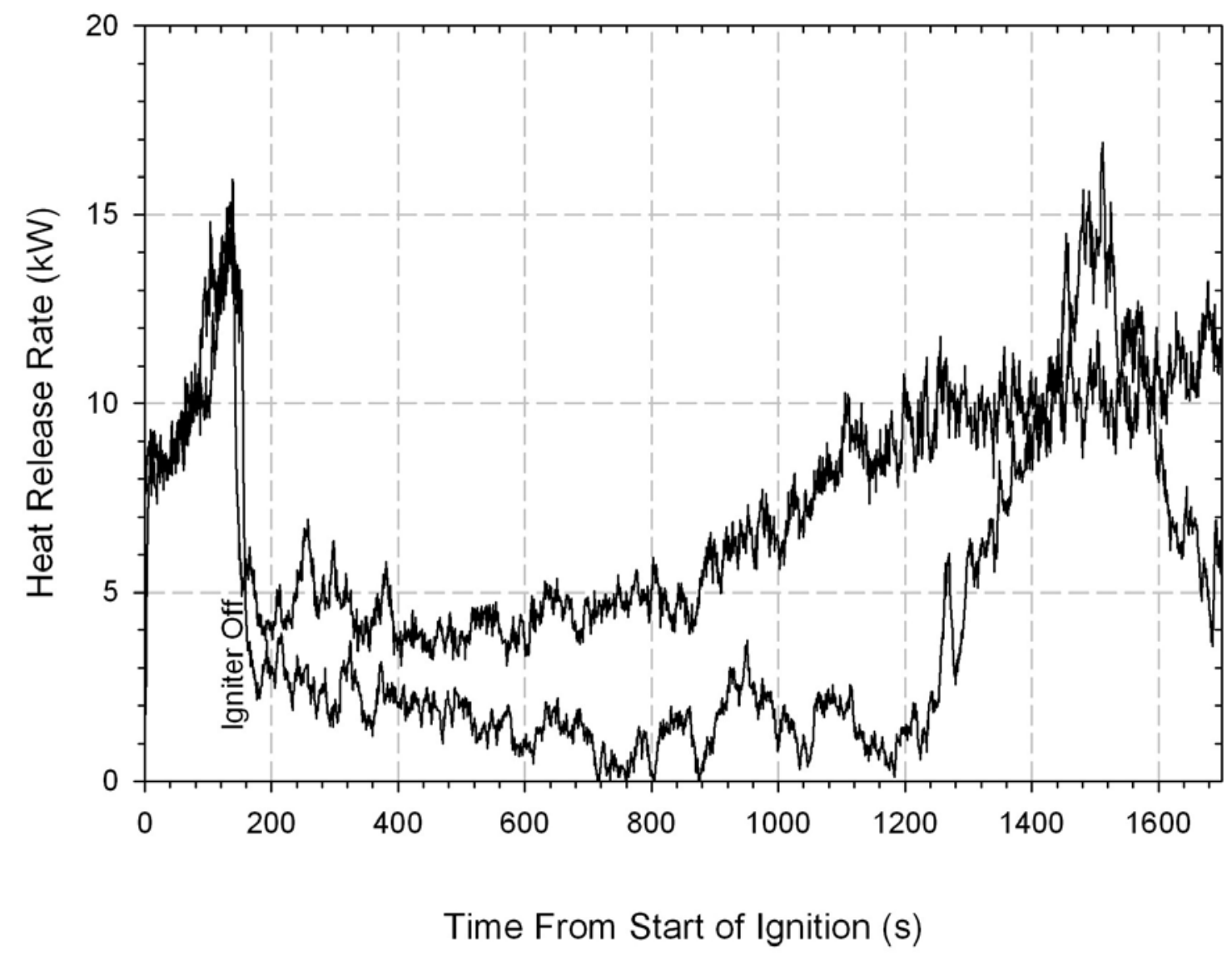

Figure 23. Heat release rate behavior variation in replicate tests of pool fire-assisted, lateral fire spread on a $3 \mathrm{~mm}$ thick, vertical sheet of polypropylene, $76.5 \mathrm{~cm}$ above a catch surface. 


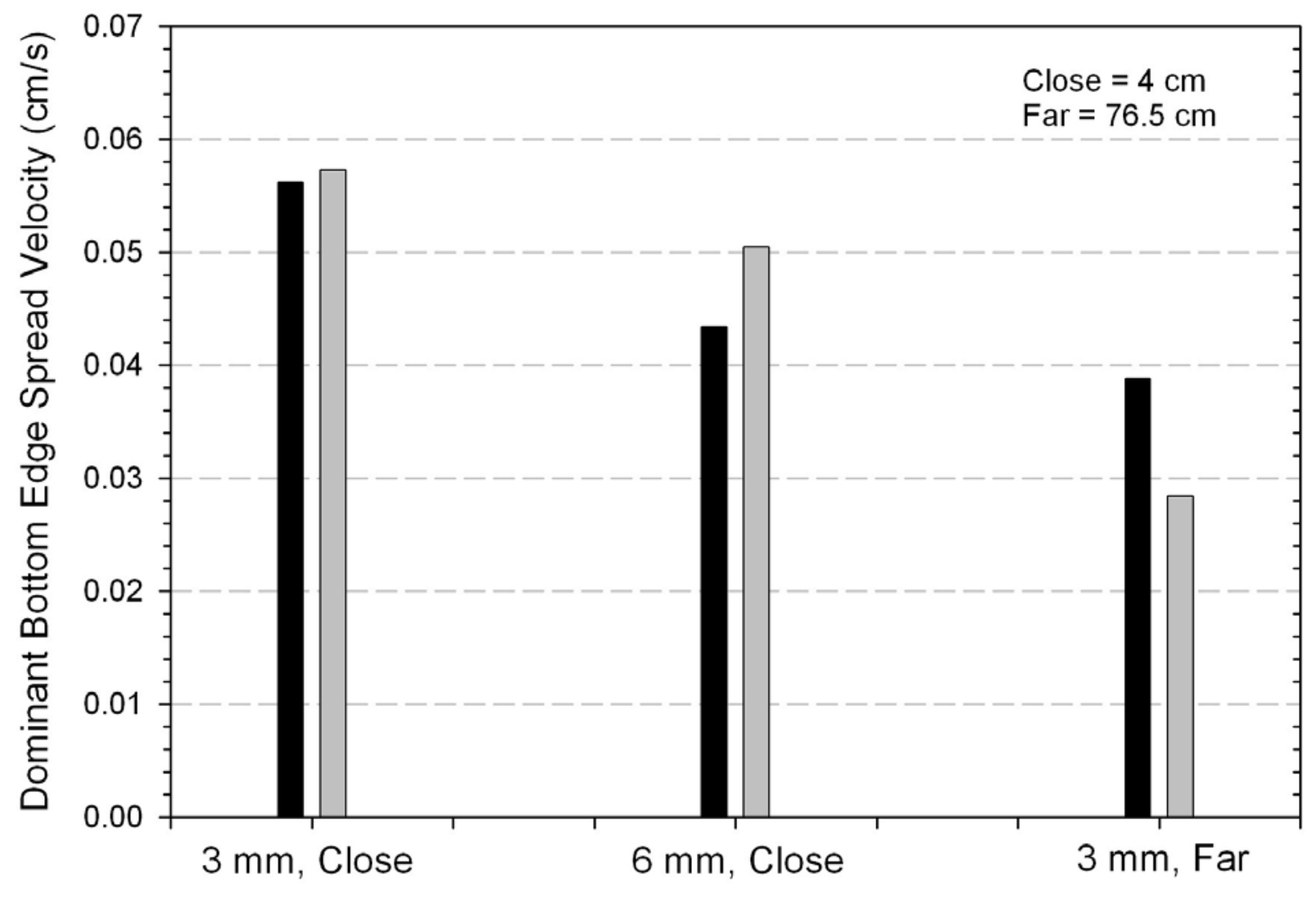

Figure 24. Replicate results for bottom edge flame spread velocity variation with height above catch surface and sample sheet thickness; pool fire-assisted lateral fire spread on vertical polypropylene sheets. 


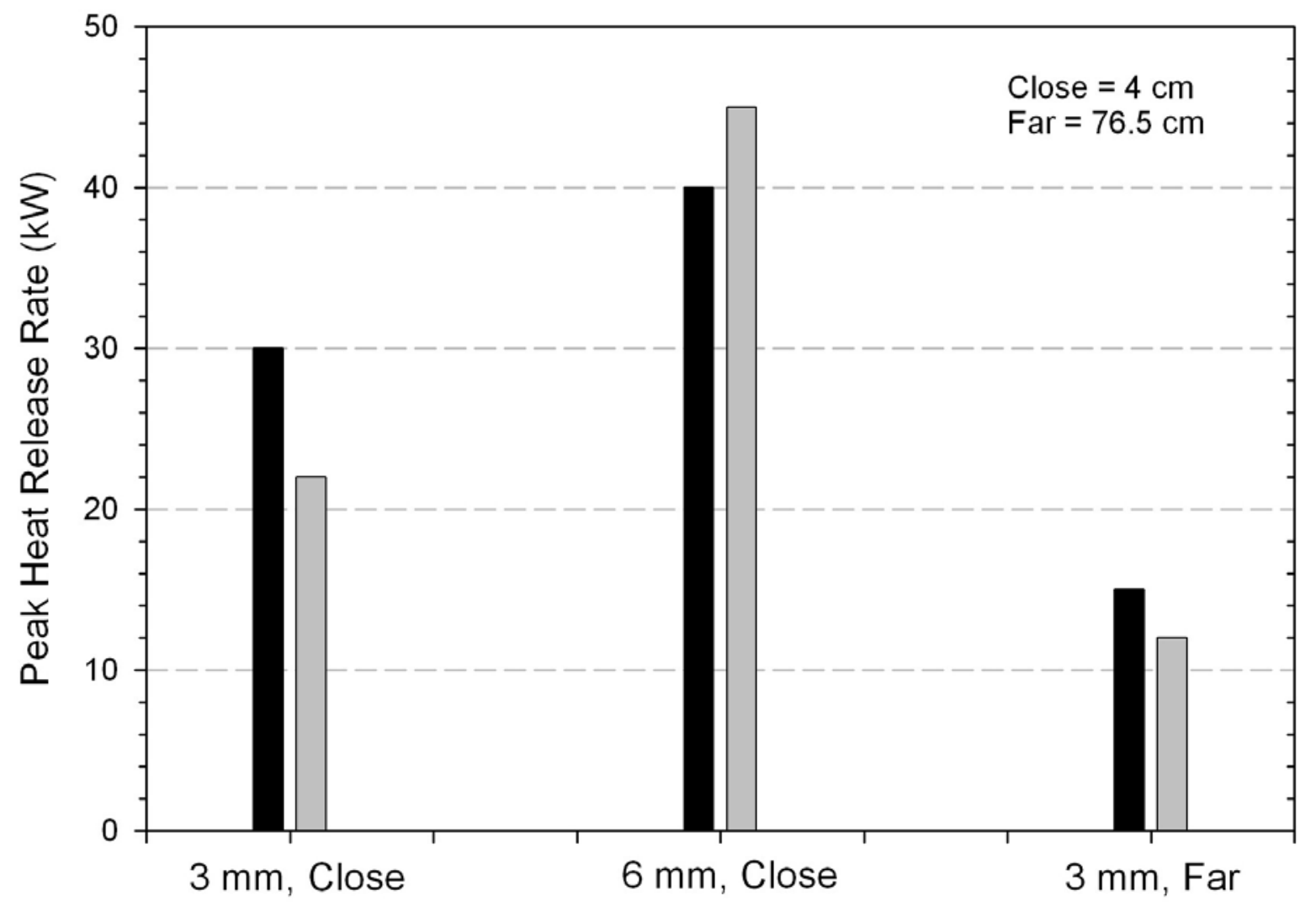

Figure 25. Replicate results for peak HRR variation with spacing above catch surface and sample sheet thickness; pool fire-assisted lateral fire spread on vertical sheets of polypropylene. 


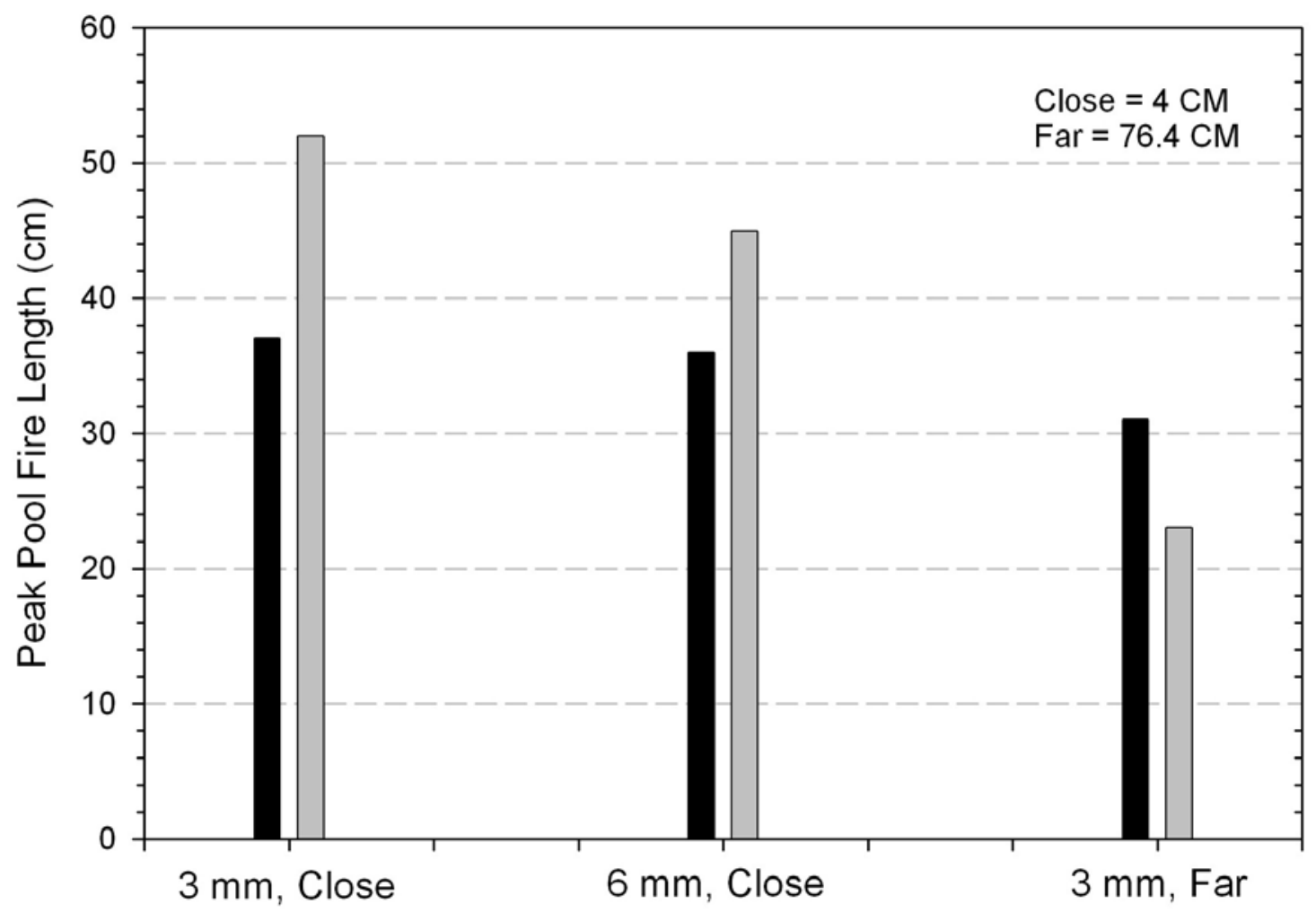

Figure 26. Replicate results for variation of peak pool fire length with spacing above the catch surface and with sample sheet thickness; pool fire-assisted lateral firespread; vertical sheet of polypropylene. 


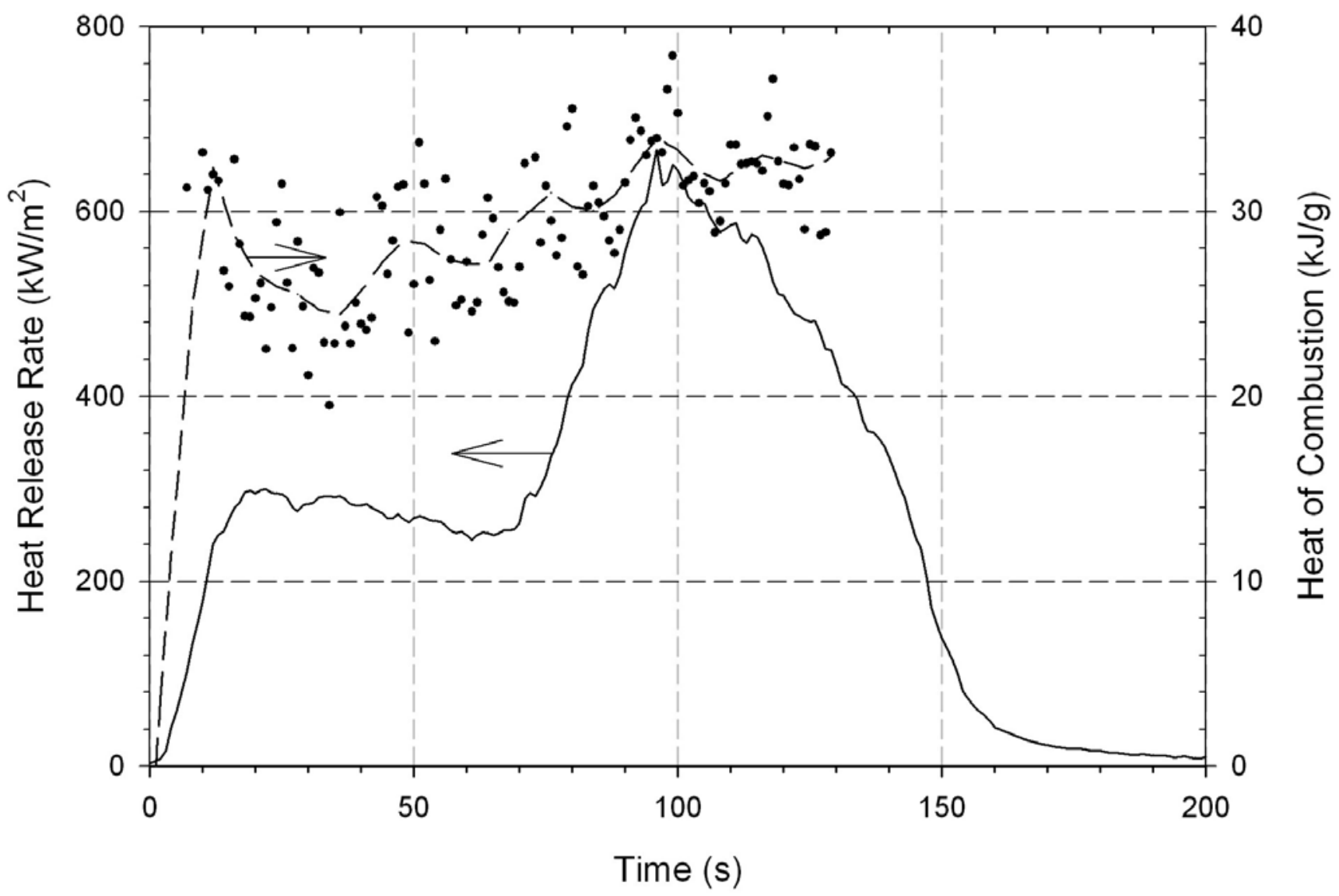

Figure 27. Heat release rate and calculated heat of combustion for NFR polyurethane foam subjected to an incident radiant flux of $35 \mathrm{~kW} / \mathrm{m}^{2}$. 


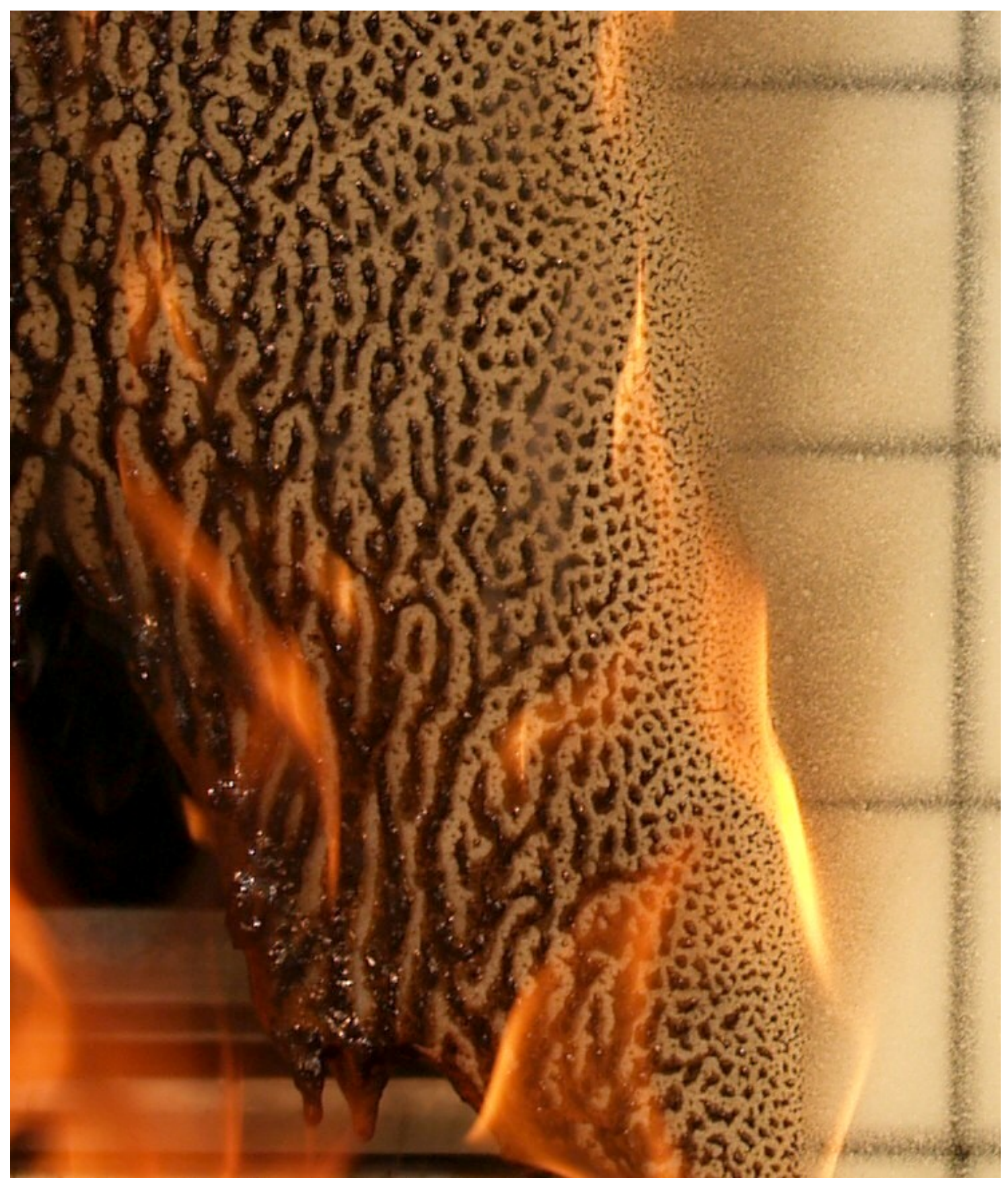

Figure 28. Close-up of burning zone on side of polyurethane foam slab showing melt bead coalescence and flow; Z' foam. Flame zone is moving from left to right in photo. See Fig. 29 for overall view. 


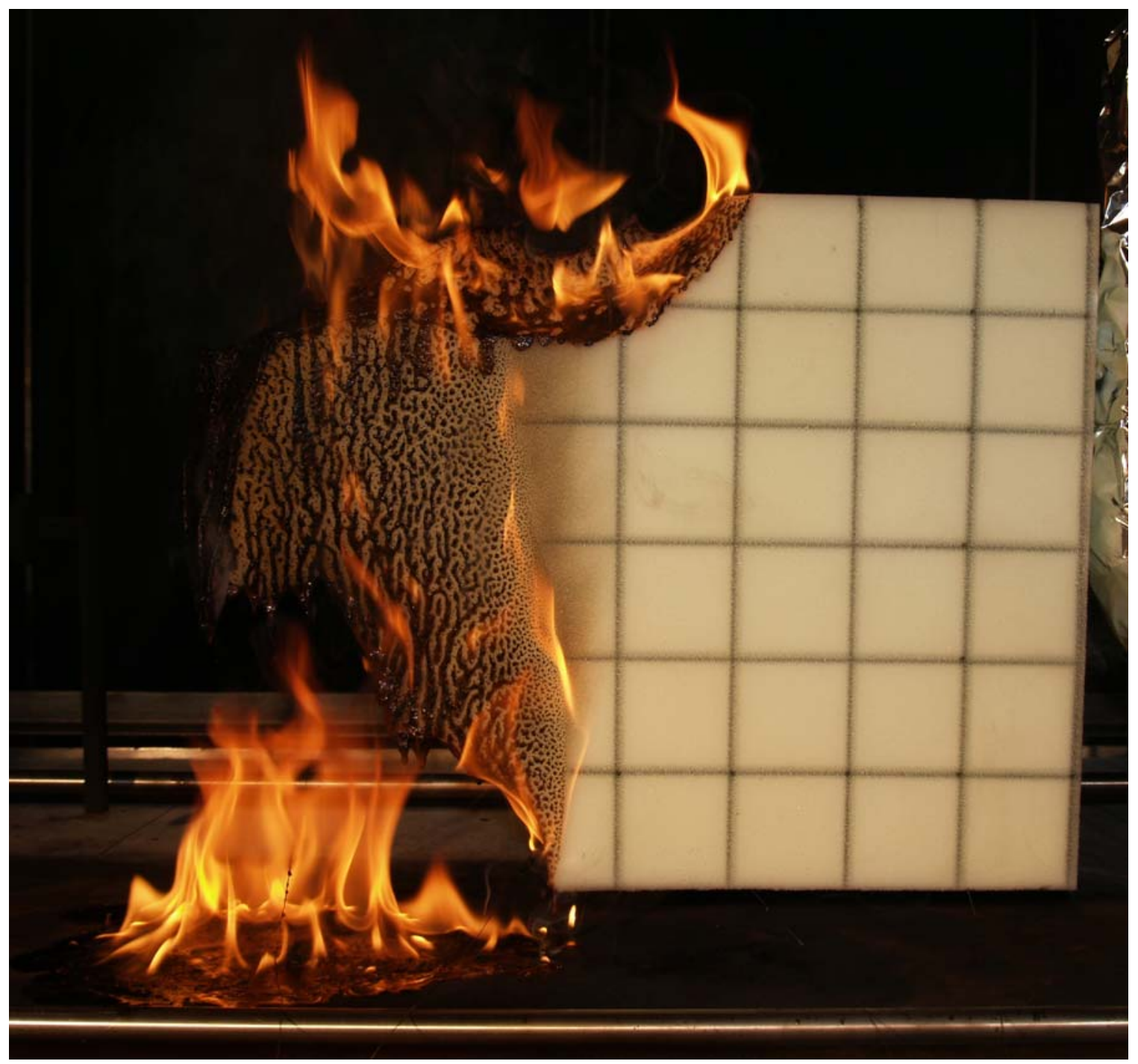

Figure 29. Side view of single vertical slap of flame-retarded Z'' foam burning from left to right. Note preferred spread on top surface where flow wake can create longer residence time for reactions. 


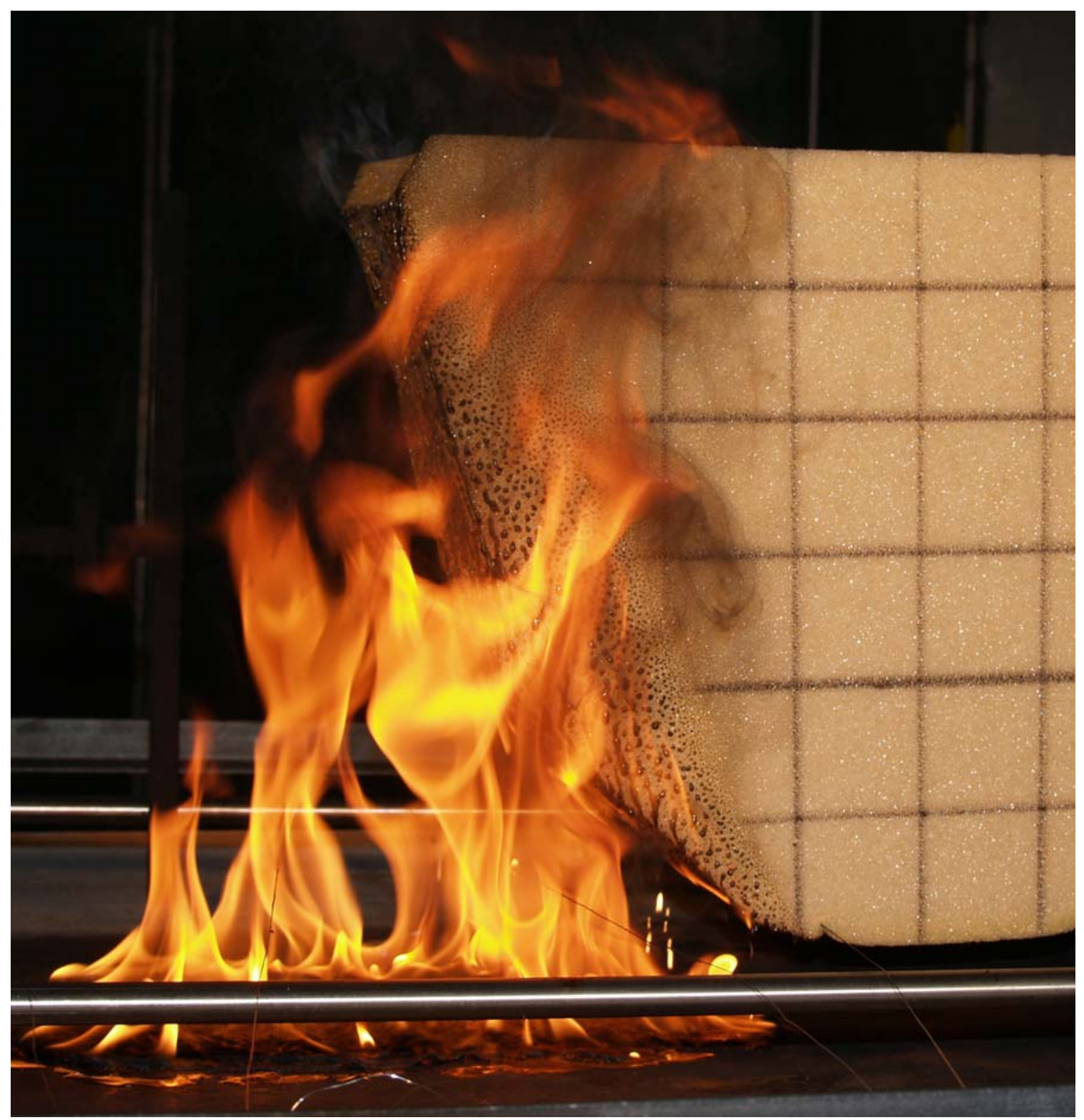

Figure 30. Side view of single vertical slab of L foam, burning from left to right, showing dominance of pool fire for this viscoelastic foam. 


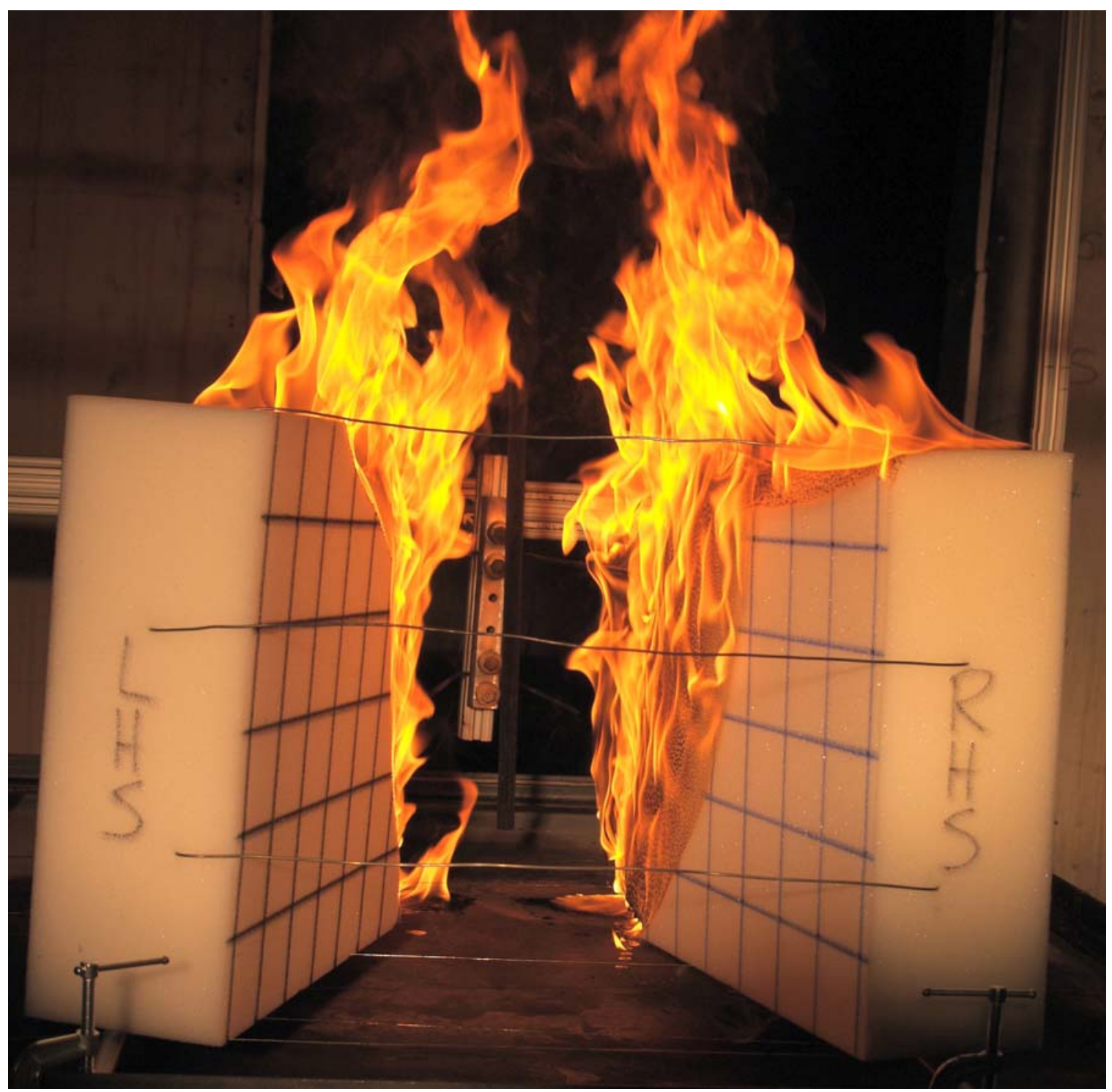

Figure 31. Vee test of NFR polyurethane foam showing minimal pool fire contribution to first half of test. Stabilization wires added to outer end of Vee are evident in picture. 


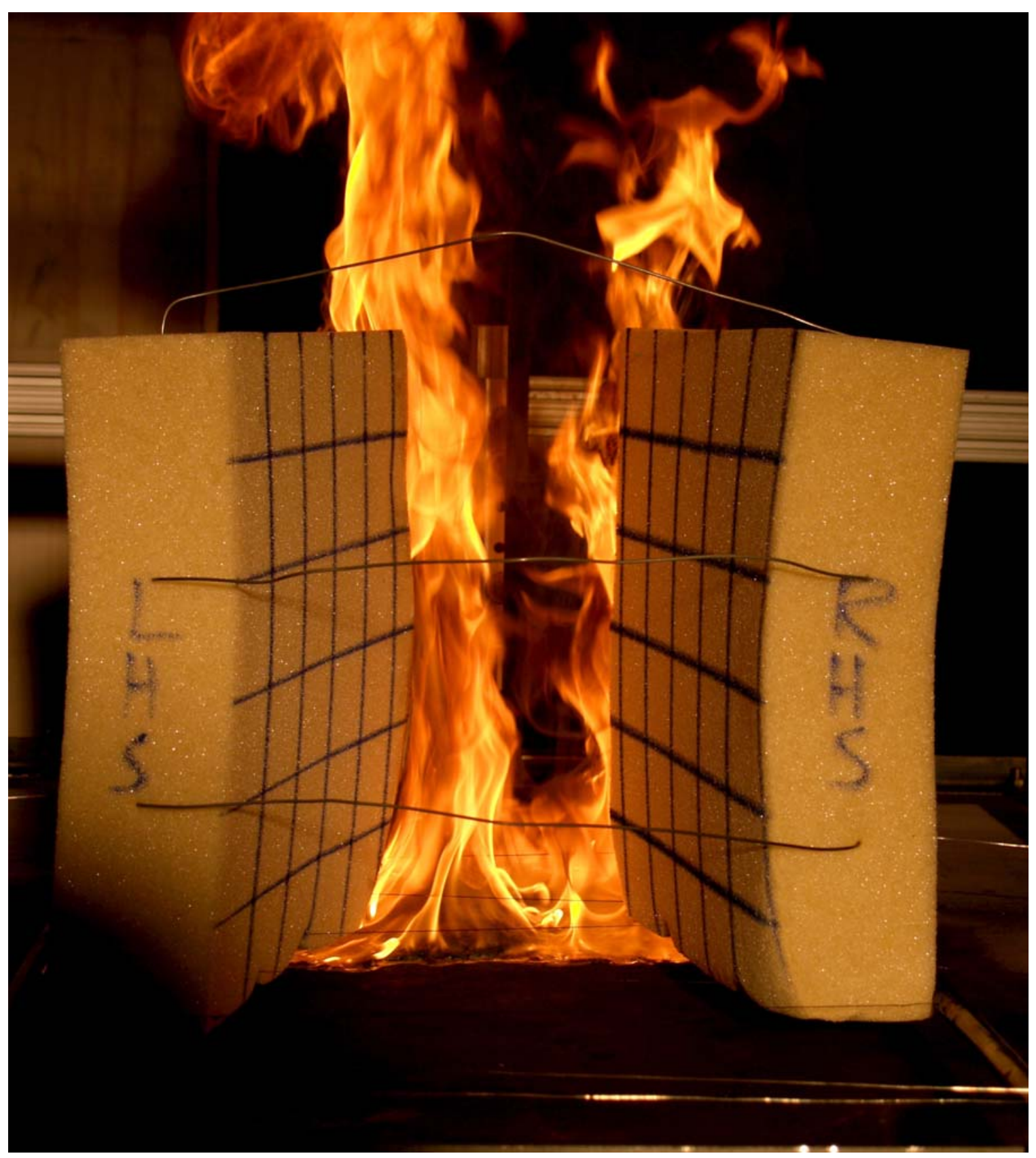

Figure 32. Vee test of L viscoelastic polyurethane foam, showing strong contribution from melt pool fire. Compare Fig. 31. Note differing shapes of flame fronts on interior surfaces of foam slabs. 


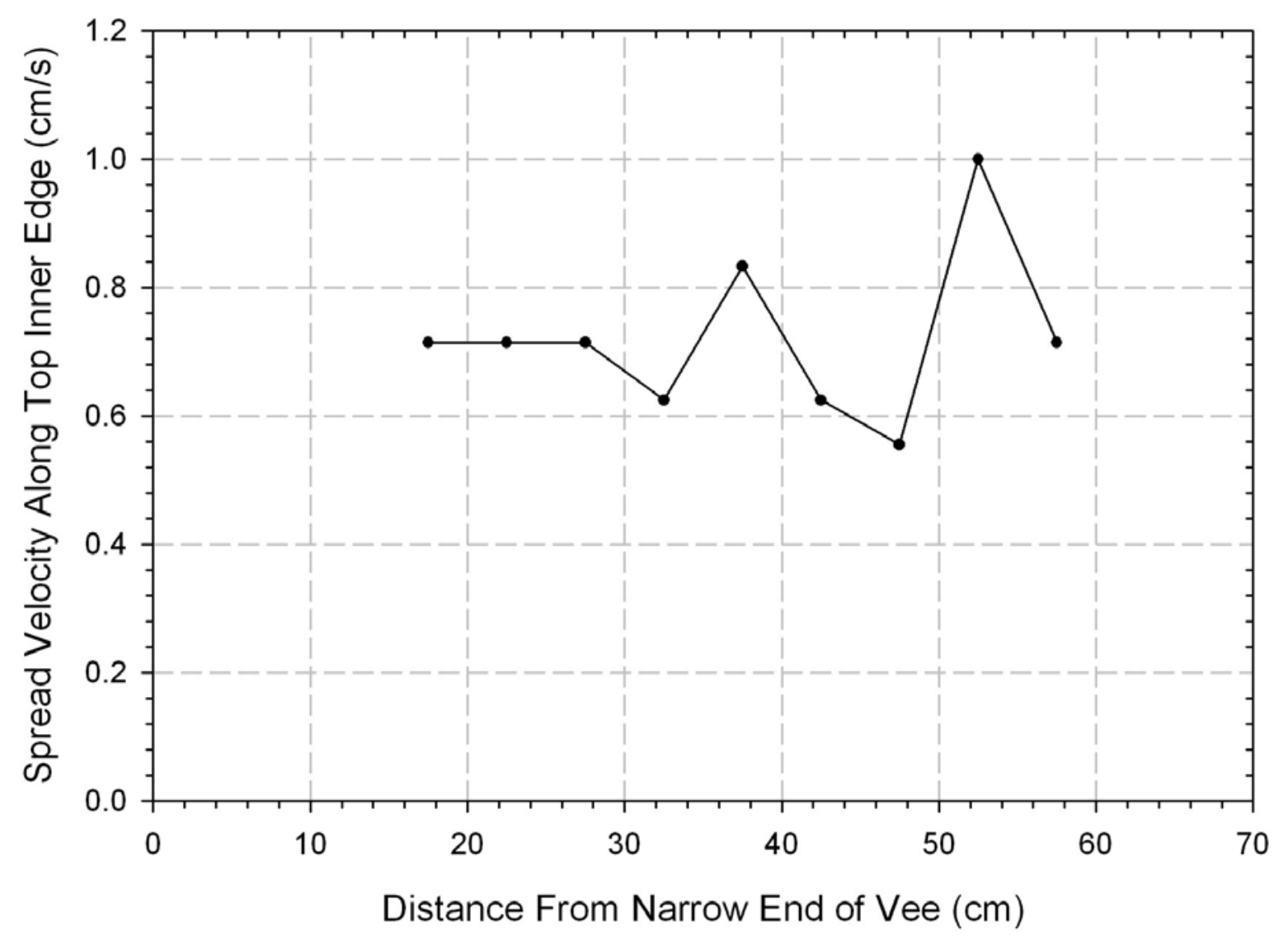

Figure 33. Flame spread velocity along inner top edge of left foam slab; NFR polyurethane foam in $30^{\circ}$ Vee configuration. 


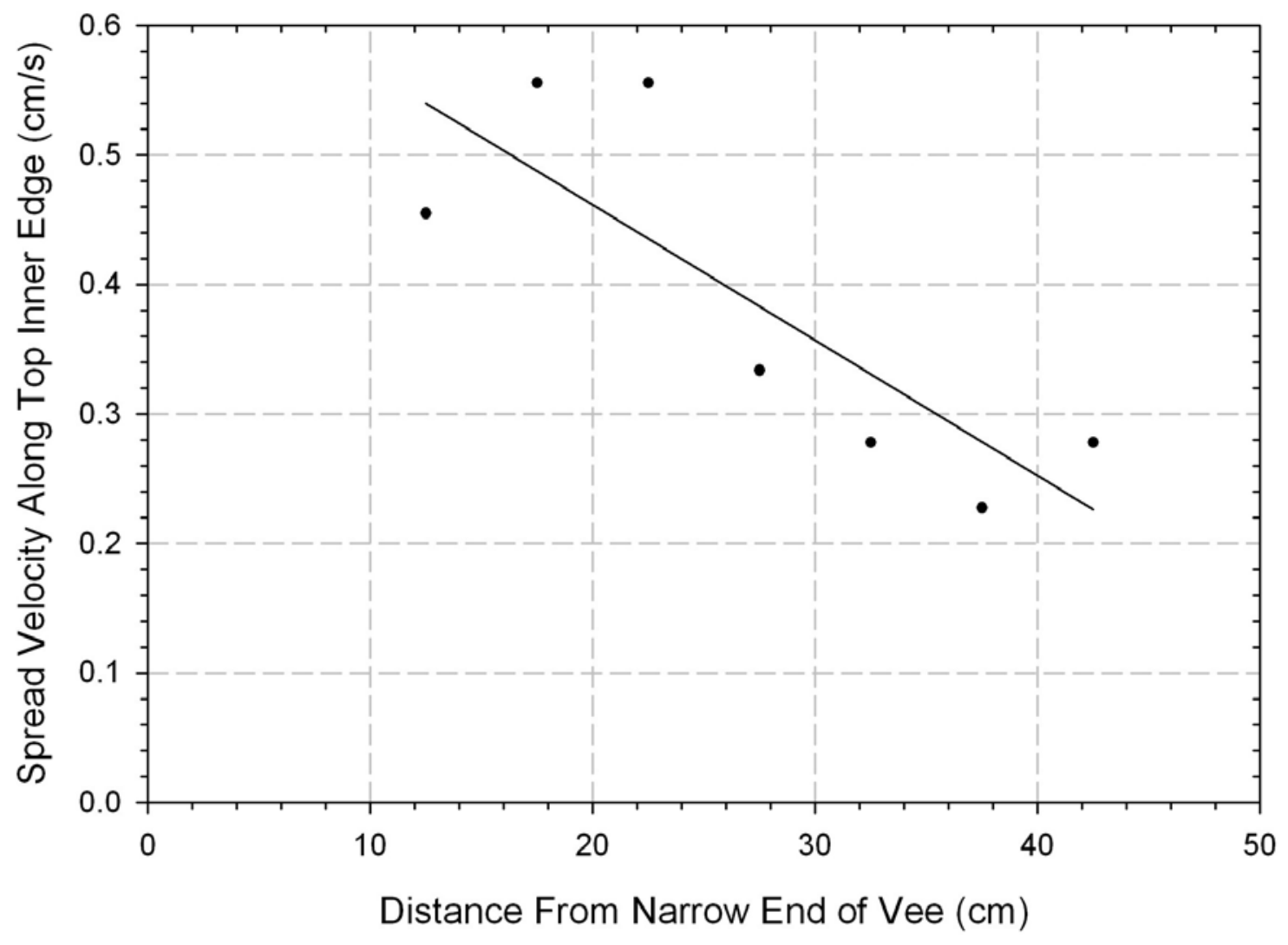

Figure 34. Flame spread velocity along inner top edge of left foam slab; Z" FR polyurethane foam in $30^{\circ}$ Vee configuration; close to catch surface. 


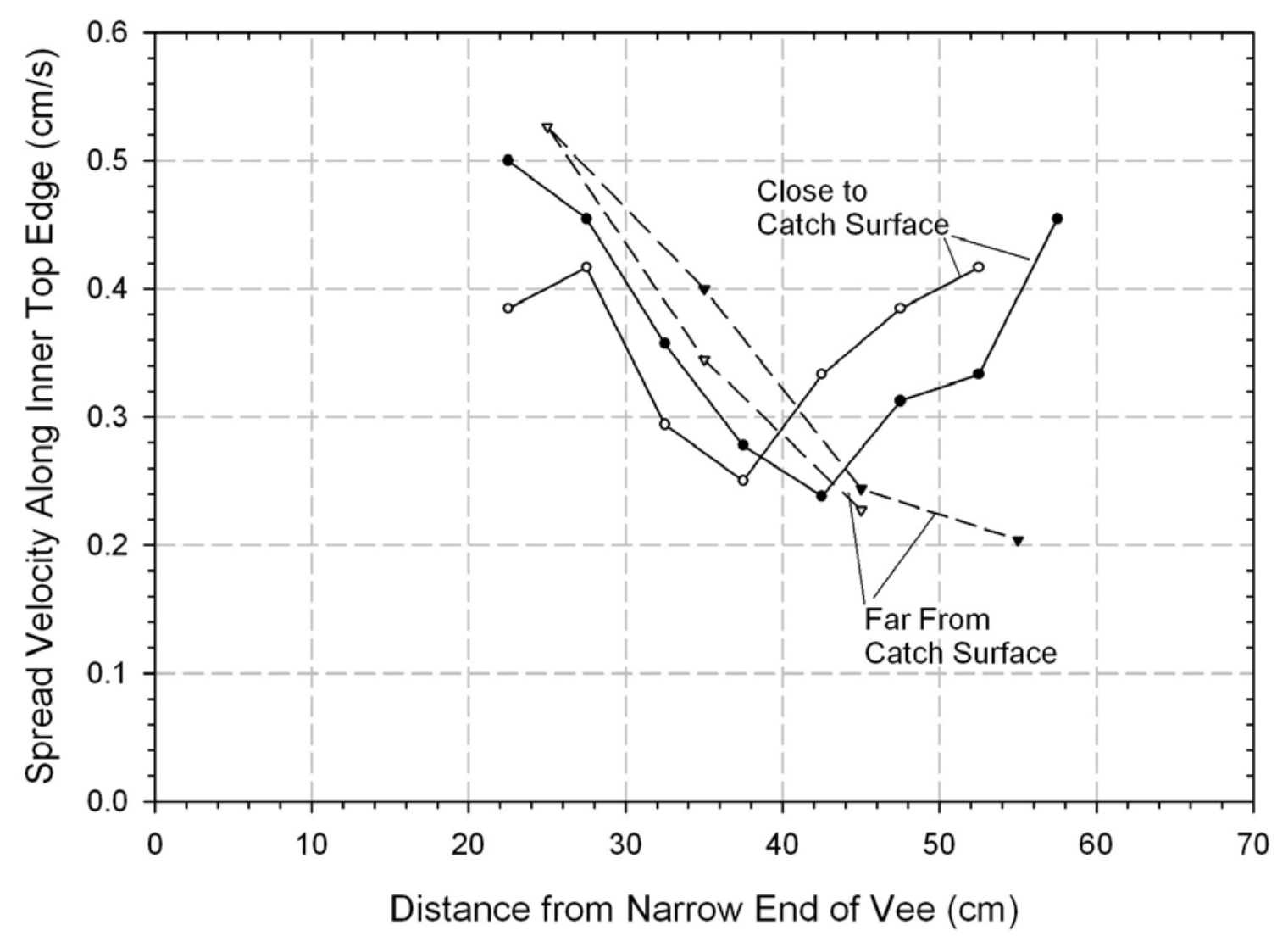

Figure 35. Flame spread velocities along inner top edge of left foam slab; ZO FR foam in $30^{\circ}$ Vee configuration; near to and far from catch surface. 


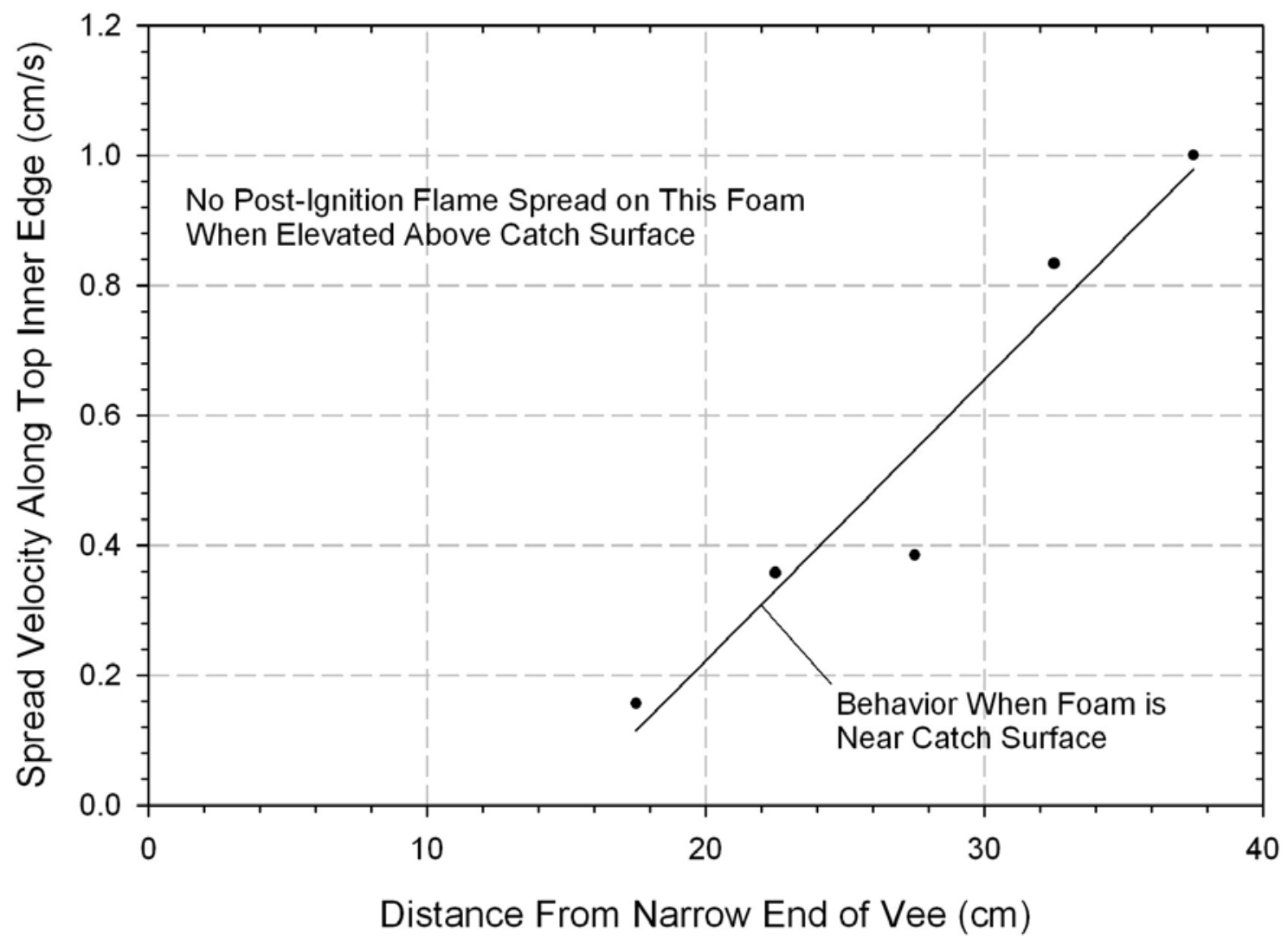

Figure 36. Flame spread velocity along inner top edge of left foam slab; $L$ viscoelastic polyurethane foam in $30^{\circ}$ Vee configuration, close to catch surface. 


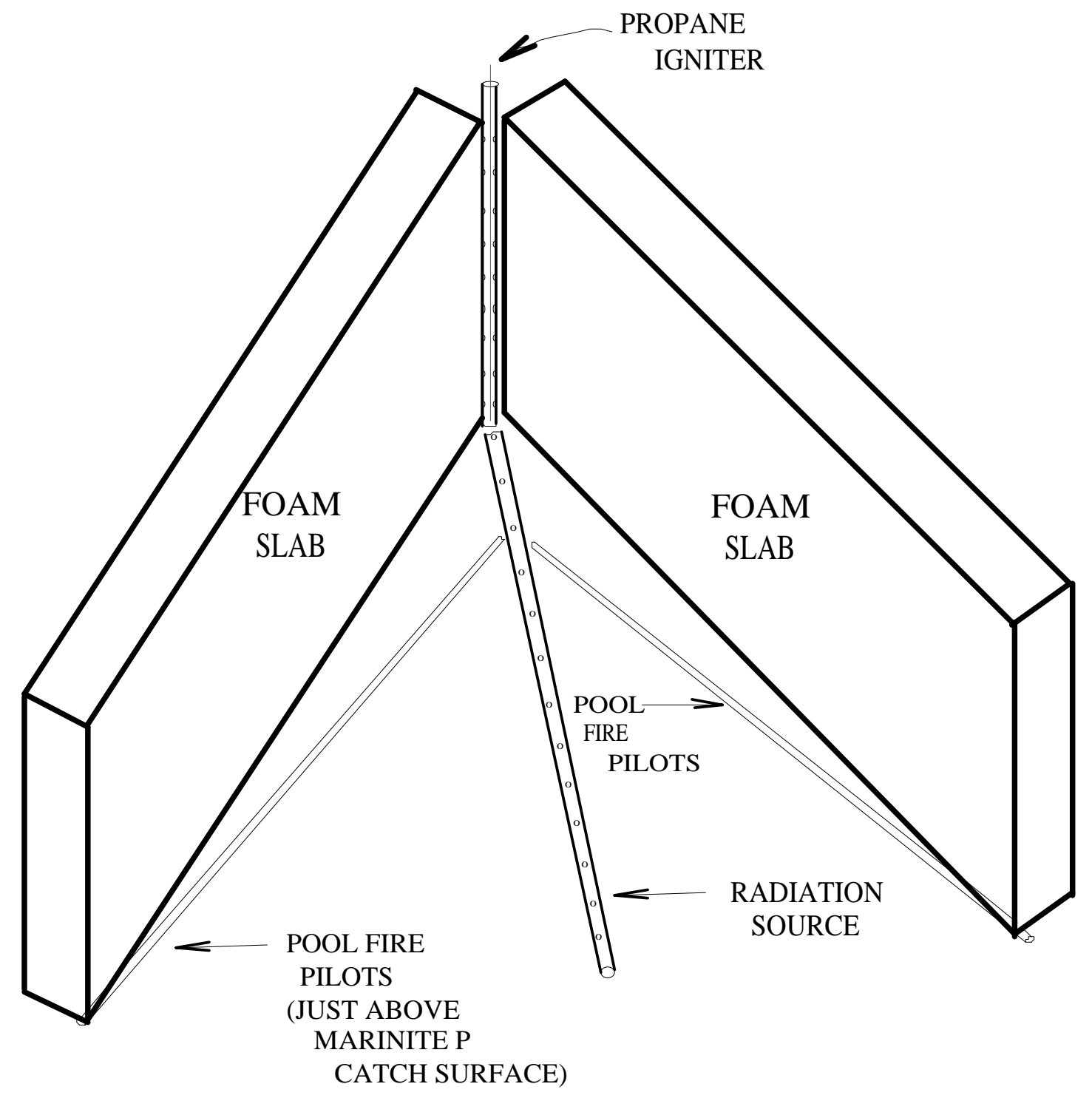

Figure 37. Potential foam flammability test configuration. 


\section{Appendix 1}

\section{A Simplified Steady-State Model of a Thermoplastic Undergoing Gasification and Melt Flow}

It is of interest to see to what extent the behavior of a thermoplastic material, subjected to a constant incident heat flux, can be predicted by a steady-state model based on simplified heat and mass balances. The specific problem is a vertical slab of thermoplastic heated uniformly on one vertical face with the opposite face being sufficiently far away that the material behaves as if it is thermally-thick. This is the intermediate problem addressed by REI in the sequence leading to a full 3-D fire growth model. Here, the heat flux is assumed to come from radiation (though it could, as well, come from a flame attached to the heated face). We are modeling experiments performed on both polypropylene and polystyrene in the Cone melt/drip apparatus, as discussed in the main body of this report. There a steady-state is assured by using a thick sample that is fed forward as it melts and gasifies so that its heated face is essentially stationary and the flux it sees is thus constant. REI is modeling the full transient problem from initially cold solid to a steadily regressing surface as a result of gasification (following thermal degradation of the initially high molecular weight polymer) and melt flow downward off of the heated face. Here, for simplicity, we focus only on the ultimate steady-state regression process that the sample achieves when it is fed forward at the same rate as its surface regresses (due to melt flow off the vertically-oriented face and simultaneous gasification from that face).

A virtual steady-state is achieved experimentally in all of the cone calorimeter-based melt/gasification experiments that have been done, thus this aspect of the model posed here is not a major simplification of reality. However, there are definite two-dimensional aspects to the sample behavior which this model ignores or simplifies. For example, the sample face tends to recede somewhat faster at the top than elsewhere and the melt flow layer varies somewhat in temperature, velocity and thickness with height on the sample face. The goal of the simplified model posed here is to see if the major behavioral trends observed in the experiments can be captured. If so the model may produce useful insights as to controlling factors.

Model Description. Figure A1.1 is a sketch of the system being considered. The radiant flux on the heated surface is spatially uniform and constant in time. The thermal wave does not reach the back of the sample in the time scale of interest. As a result of the heating on one face, the polymer there increases in temperature, causing its melt viscosity to decrease. The onset of thermal degradation lowers the mean molecular weight and this lowers the viscosity still further. Gravity causes the lowest viscosity outer layers to flow downward. Eventually the temperature is high enough to degrade the polymer to the point where small molecules can escape into the gas phase. Thus both melt flow and gasification remove mass and heat from the system. Surface re-radiation and convective heat losses also remove a part of the incoming heat. 
Figure A1.2 is a sketch of this system as it will be treated here. The system in Figure A1.1 will achieve a temporary steady-state when the incoming radiant heat flow is matched by the sum of the several heat loss paths shown in Fig. A2.2. This steady-state behavior will persist until the thermal wave in the solid begins to reach its rear surface. The melt flow rate and the gasification rate will increase after the onset of the radiant flux until they rise to their steady-state values. In Fig. A2.2 the solid thermoplastic is fed into the system from the left at a mass flow rate that matches the sum of the steady melt flow and gasification rates. It is this steady-state behavior which will be approximated with the following assumptions.

1) The polymer melt viscosity is only a function of temperature and that function can be described by the empirical results described in the main body of in this report.

2) There is a finite melt layer whose temperature decreases with depth below the heated surface. The thickness of this layer can be prescribed by the assertion that the back of the layer corresponds to the melt viscosity rising to a fixed multiple of that viscosity that exists at the surface temperature. (This viscosity rise is caused by the temperature decrease across the layer depth.)

3) Gasification occurs from the outer surface of this falling melt layer (with no bubble formation).

4) The mean velocity of this falling melt layer is given by a balance between gravity and viscous drag.

5) The behavior of a large heated surface can be captured by considering a typical unit area on that surface (which we will take to be at mid-height).

6) The melt flow layer is thin compared to the overall thermal wave. That overall wave is therefore taken to follow the one-dimensional steady-state temperature distribution.

The meaning of some of these assumptions is made clearer when the model equations are stated.

Overall energy balance at the sample surface (Eqn. A1.1):

$$
\alpha q_{\text {in }}-\varepsilon \sigma\left(T_{s}^{4}-T_{0}^{4}\right)-\hbar_{\text {conv }}\left(T_{s}-T_{0}\right)=m_{\text {melt }} C_{p}\left(T_{\text {avg }}-T_{0}\right)+\left(A_{s} \exp \left(-E_{s} / R T_{s}\right)\right)\left(Q_{g}+C_{p}\left(T_{s}-T_{0}\right)\right)
$$

This is taken on unit area of the sample surface in a "representative" location. Here $q_{\text {in }}$ is the radiant flux (cal/ $\left./ \mathrm{cm}^{2} \mathrm{~s}\right)$ incident on the sample face. This flux is assumed to be $100 \%$ absorbed ( $\alpha=1.0$ ) and that absorption is taken to occur at the sample surface. In the absence of melt flow the presence of a steady-state would make it irrelevant whether the incident flux was absorbed exactly at the surface or below it. In actuality the flux is absorbed over a depth of the order of $1 \mathrm{~mm}$ or more (at least for polypropylene, as measurements have shown; see Appendix 4) and this may interact somewhat with the temperature profile in the melt layer; here any such interaction is ignored ${ }^{91}$. The second

\footnotetext{
${ }^{91}$ This in-depth absorption can be included in this model; its only effect is to make Eqn (A1.3) somewhat more complex since, for polypropylene, at least, some of the incoming radiation passes through the thin
} 
term in the above equation describes the radiative loss from the heated surface which is at the temperature $T_{s}$ (Kelvin), interacting with the room at temperature $T_{0}$. The surface emissivity, $\varepsilon$, is also taken to be unity. The third term describes the natural convection heat loss from the sample face; the convective heat transfer coefficient, $\hbar_{\text {conv }}$, is obtained from a standard handbook heat transfer correlation (the value used here is $2.5 \times 10^{-4}$ $\mathrm{cal} / \mathrm{cm}^{2} \mathrm{~s} \mathrm{~K}$ ). The sum of the three terms on the left hand side of Eqn (A1.1) is the net heat flux into the sample surface. That net heat goes into the melt flowing from the sample face and into gasifying a portion of the polymer melt. The melt heat content is the product of its mass flow rate, $m_{\text {melt }}(\mathrm{g} / \mathrm{s})$, its heat capacity, $C_{p}(\mathrm{cal} / \mathrm{g} \mathrm{K})$ and its average temperature, $T_{\text {avg }}$ (above room temperature). Here the average temperature of the melt, over its depth, is taken to be the average of the surface temperature and the temperature at the back of the melt layer, defined below. The last term on the right describes the heat absorbed by the gasification process; $Q_{g}$ is the heat required to gasify unit mass of the melt at the surface temperature (here taken as $300 \mathrm{cal} / \mathrm{g}$ for all cases examined). This gasification process is also, in reality, occurring over some finite (though very small) depth in the polymer melt below the surface. Because the activation energy of that reaction (as measured with thermogravimetry, as described in the main body of this report) is large, we can apply the following approximation, which derives from laminar flame theory [Ref. A1.1]:

$$
\begin{aligned}
& \text { Net Gasification Rate/Unit Area }\left(g / \mathrm{cm}^{2} s\right)=\int_{-\infty}^{0} A_{\text {tga }} \exp \left(-E_{\text {tga }} / R T(x)\right) d x \\
& \qquad\left[\left(\lambda_{s} / C_{p}\right)\left(R T_{s}^{2} / E_{t g a}\right)\left(\left(A_{t g a} \exp \left(-E_{t g a} / R T_{s}\right)\right) /\left(T_{s}-T_{0}\right)\right)\right]^{0.5}
\end{aligned}
$$

Here $\lambda_{s}$ is the thermal conductivity of the polymer melt, $R$ is the universal gas constant, $A_{\text {tga }}$ and $E_{\text {tga }}$ are the pre-exponential factor and activation energy, respectively, for polymer gasification, derived from thermogravimetric measurements. Note that the reaction is taken to be zero-order in polymer concentration because bubbling, typically a minor aspect of the gasification processes examined in this study, is ignored. In light of the above approximation, the gasification kinetic factors in Eqn (A1.1) can be expressed in terms of their thermogravimetric counterparts as follows:

$$
\begin{aligned}
& E_{s}=E_{\text {tga }} / 2 \\
& A_{s}=\left[\left(\lambda_{s} / C_{s}\right)\left(R T_{s}^{2} / E_{\text {tga }}\right)\left(\rho_{s} A_{\text {tga }} /\left(T_{s}-T_{0}\right)\right)\right]^{0.5}
\end{aligned}
$$

melt layer. It will shift all of the solutions somewhat but should not introduce any new qualitative trends. Since we are not trying to make a quantitative model here, the in-depth absorption is ignored. 
Here $\rho_{s}$ is the polymer melt density, taken here as equal to the original polymer resin density. Note that while the activation energy for the surface reaction is simply one half that for the volumetric reaction, the pre-exponential factor is modified considerably (in effect, accounting for the very small depth over which the reaction is actually occurring).

The second model equation derives from the assumption that the melt layer has a finite thickness specified by making the viscosity at the back of the melt layer a fixed multiple of that at the front of the melt layer.

$$
\mu\left(T_{\delta}\right)=\phi \mu\left(T_{s}\right)
$$

Here $\mu\left(T_{\delta}\right)$ is the viscosity at the back of the layer where the temperature is $T_{\delta}, \phi$ is a constant (and a parameter of the model), $\mu\left(T_{s}\right)$ is the melt viscosity at the surface of the melt layer. The value of $\phi$ has been taken to be 25 for most of the model cases examined. In actuality the viscosity of the melt is a continuous function of temperature and thus there could be finite flow at virtually any depth in the polymer. This equation recognizes the fact that increasing viscosity in depth implies a decreasing flow velocity and the flow at some depth has a negligible impact on the problem over the time scale of interest (essentially the time for the surface to regress through one thermal layer thickness). Equation (A1.2) is an ad hoc expression of this fact. It is informed by the fact that an isothermal, gravity-driven boundary layer has an average velocity that varies inversely with the first power of the fluid viscosity [Ref. A1.2].

The next model equation can be derived from a steady-state heat balance on the flowing melt film alone but it arises also from the assumption that the overall thermal wave in the polymer is largely unchanged by a thin melt layer flowing down the sample face.

$$
\left(T_{\delta}-T_{0}\right) /\left(T_{s}-T_{0}\right)=\exp \left(-\left(m_{m e l t} C_{p} / \lambda_{s}\right) \delta_{a}\right)
$$

Here $\delta_{a}$ is the average melt layer thickness on the sample face (taken as the value at the mid-height of the face). One can easily show that the one-dimensional temperature profile in a gasifying material follows this exponential decay with a characteristic depth that is the inverse of $\left(m_{\text {melt }} C_{p} / \lambda_{s}\right)$. Here, as noted above, we assume that this profile holds also for this problem where there is a thin melt layer flowing down the sample face. Then Eqn (A1.3) says that the depth of the melt layer is related to the temperature at the back of that layer by the above relation.

The next model equation simply expresses an overall mass balance on the flowing melt film at the mid-height of the sample face:

$$
\rho_{s} V_{m} \delta_{a}=(h / 2)\left(m_{\text {melt }}-m_{\text {gasif }}\right)
$$


Here $V_{m}$ is the average downward velocity of the flowing melt layer, $h$ is the height of the sample face and $m_{\text {gasif }}$ is the flux of mass from unit area of the face due to the gasification reaction. This equation brings in information on the actual sample size and accounts approximately for the fact that the melt layer varies in thickness with height on the sample face.

The final equation in the model relates the average melt flow velocity to the melt viscosity. Here we take advantage of an available solution that applies to a fluid layer with a depth-dependent viscosity analogous to that here (but not precisely the same). Ref. A1.3 gives an expression for average fluid velocity in a falling film for a fluid whose viscosity is an exponentially-decaying function of temperature. Most polymer melts can be described by such a temperature function over at least a limited part of the temperature range of interest; here we have used fitted polynomials instead, but we adopt this available solution nonetheless as an approximation. The solution is the same as that for an isothermal film except that it includes a correction factor that is a function of the melt viscosity at the inner and outer surfaces of the film. In the present context it is re-cast to give the following relation:

$$
\delta_{a}=\left[\left(\mu\left(T_{s}\right) h /\left(2 \rho_{s}^{2} g f\right)\left(m_{m e l t}-m_{\text {gasif }}\right)\right]^{0.333}\right.
$$

Here $g$ is the acceleration due to gravity and $f$ is the noted correction factor for the temperature dependence of the melt viscosity over the depth of the melt layer. It is a complex function of the ratio $\mu\left(T_{\delta}\right) / \mu\left(T_{s}\right)$ (i.e., $1 / \phi$, from Eqn (A1.2); see Ref. A1.3). This factor is typically of the order 0.04 in the model solutions described here; it thus has about a factor of three effect on the value of $\delta_{a}$.

Model Solution. This set of algebraic equations is solved for the unknowns $T_{s}, T_{\delta}$, $\delta_{a}$ and $V_{m}$. The equations are non-linear and require an iterative solution that involves two Newton-Raphson iterative solution loops for individual equations within the overall, multi-equation iteration process. As a first step, the non-melting solution is obtained for $T_{s}$ to provide an estimate for the $T_{s}$ value for the more general case with melting. The more accurate two-segment polynomial fits to the temperature-dependent melt viscosity (described elsewhere in this report) are problematical in the iteration scheme (particularly for temperatures near the patching of two segments) and therefore they are replaced by somewhat less-accurate single polynomial fit equations (as appropriate to each polymer of interest).

Using the available input data for both temperature-dependent viscosity and for gasification kinetics, it is found that model solutions are not always available (i.e., the iteration scheme does not converge) without some adjustment of at least one parameter. The model has been applied to both PP702N polypropylene and to PS 666D polystyrene. 
It is found that the solutions do not exist for the polystyrene unless the value of $A_{s}$ is cut by a factor of 4 or more. For the polypropylene, on the other hand, solutions do exist for the nominal parameter set; lack of solutions was encountered only when the value of $A_{s}$ was increased to more than four times the value derived from the thermogravimetry experiments. For both polymers there was an incentive to increase the value of $A_{s}$ because this brought the fraction of mass lost as melt more in line with the experimental results (see below). As discussed in the main body of the report and somewhat further below, both the kinetic parameters and the viscosity are used in a domain that is a considerable extrapolation beyond the conditions under which they were obtained. This may be the source of some of these problems; this is explored somewhat below.

Model Results and Discussion. First consider the effect of the model parameter $\phi$ in Eqn (2) which was somewhat arbitrarily (but plausibly) set at a value of 25. Varying this value from 20 to 30 over the range of incident heat fluxes of interest $\left(20 \mathrm{~kW} / \mathrm{m}^{2}\right.$ to 45 $\mathrm{kW} / \mathrm{m}^{2}$ ) gives very little change in the solutions for such variables as the surface temperature and the total mass flow (sum of melt flow plus gasification rate). The greatest sensitivity is at the low heat flux end where this range of values of $\phi$ causes the surface temperature to vary by about $1.2 \mathrm{~K}$ and the total mass flow to vary by about $3 \%$. At the high end of the heat flux range the variations in both variables are about half as much. Thus the solutions are rather insensitive to the value of $\phi$ and we retain a value of 25 throughout the rest of the study.

Figures A1.3a and A1.3b show a set of model solutions for PP702N polypropylene. Note that the mass loss rate values are for a $100 \mathrm{~cm}^{2}$ sample face $(10 \mathrm{~cm}$ tall by $10 \mathrm{~cm}$ wide, the same as the experimental samples), obtained by multiplying the model results for unit area by a factor of 100 . For the results in these figures the value of $A_{s}$, the preexponential factor for the gasification reaction, was increased by a factor of 4 above that corresponding to the thermogravimetric experiments, as mentioned above. This increase was made to bring the fraction of mass lost as melt flow somewhat closer to the experimental values. Comparison of this prediction with the actual experiments (Figs. 15) shows that the melt fraction is still somewhat higher than experiment. The model gives no convergence if the value of $A_{s}$ is raised any further. (This issue is addressed further below.) Overall the solutions are not dramatically changed by increasing the value of $A_{s}$ by a factor of 4 . For example, at an incident heat flux of $30 \mathrm{~kW} / \mathrm{m}^{2}$, the factor of 4 increase lowers the total mass loss rate by $12 \%$ and lowers the surface temperature by $18 \mathrm{~K}$; the fraction lost as melt goes down to 0.80 from 0.93 . The overall comparison with experiment is thus not radically affected.

Comparing Figs. A1.3a and A1.33b with Figs. 15a, b, c, one sees that the model gets all of the trends with varied heat flux correct. Thus, as expected, an increase in heat flux drives up the surface temperature and this drives up the overall mass loss rate from the polymer sample. The mass lost via melt also increases as the increased surface temperature lowers the melt viscosity and allows the melt to flow away faster. Note that 
the fraction of total mass that is lost via melt flow decreases; evidently the temperature sensitivity of the gasification process trumps that of the melt flow process (both are affected by chemical kinetic processes so this is not a foregone conclusion and it may not be a universal trend for all polymers).

Further comparison of Figs. A1.3a and A1.3b with Figs. 15 shows that, for this polypropylene, the quantitative agreement between model and experiment is surprisingly good given the fact that the model is one-dimensional and the real experiment twodimensional. There may be a fortuitous element to this level of agreement but, overall, it adds an element of confidence that the model may be of some use in evaluating the behavior of such systems. The melt layer thickness (varying from about $1 / 2 \mathrm{~mm}$ at the highest flux to about $2 \mathrm{~mm}$ at the lowest flux) is of the same order as was inferred during the experiments (no direct measurements were made). The average melt flow velocity (varying from $1 / 4 \mathrm{~mm} / \mathrm{s}$ at the lowest flux to $1 \mathrm{~mm} / \mathrm{s}$ at the highest flux) is lower than the measured surface values for this polymer (e.g., ca. $2 \mathrm{~mm} / \mathrm{s}$ at mid-height for $30 \mathrm{~kW} / \mathrm{m}^{2}$ ). The measured values are the maximum and the predicted values are the average over the depth of the melt layer; Ref. A1.3 indicates the difference between the average and the peak flow velocity for an analogous, variable-temperature melt flow is a factor of two. This observation partially explains the difference but implies that the model prediction of flow velocity is still low by roughly a factor of two.

The predicted surface temperatures in Fig. A1.3b (mixed melting and gasification case) tend to be not far from experiment (ca. $20^{\circ} \mathrm{C}$ low; Fig. 15b) at the low and mid fluxes but are about $45{ }^{\circ} \mathrm{C}$ below experiment at the highest flux. The experimental measurement is most difficult at this highest flux, so its accuracy is somewhat questionable, as discussed in the main body of this report.

Figure A1.3b includes surface temperature predictions for two limiting cases of the steady-state model, pure gasification and pure melting. Figure A1.3c repeats the limiting case surface temperature results and also includes the limiting case total mass flow predictions. We, of course, have no comparable experimental data for these situations since these processes cannot be switched off and on. Fig. A1.3b shows that when both routes for heat dissipation are available, the surface temperature is lowered significantly, as one might intuitively expect. Figure A1.3c shows that, in spite of the very comparable surface temperatures for these two limiting cases, the pure melting case yields a substantially greater mass loss rate from the sample surface since it is an energetically less costly path. Comparison of Figures A1.3a and A1.3c shows that the mixed case, with both melting and gasification, does not yield still greater mass loss because the two paths are competing for the available energy - a relatively small amount of gasification removes a substantial amount of energy that could have gone into a relatively large amount of melt flow . Thus the mass loss rate in the mixed case falls somewhat below the pure melting case, in keeping with the large melt fraction shown in Fig. A1.3a.

Polystyrene 666D is a polymer resin that is both significantly less thermally stable than the above polypropylene and that has a significantly higher viscosity over the relevant temperature range. Figs A1.4a, b and c show the model predictions for this resin. Here 
the value of the pre-exponential factor in the gasification reaction, $A_{s}$, had to be cut by a factor of four below that corresponding to the thermogravimetry measurements on this polymer in order to get convergent solutions. The results in Fig. A1.4, when compared with experimental results (figs. 16), are again better than one might expect given the simplified nature of the model. The trends are again in agreement with experiment and the absolute values of mass flows are comparable to experiment (ca. 50\% lower). The surface temperatures are about $40 \mathrm{~K}$ higher than experimental values across the heat flux range. The fraction lost as melt is fairly close to experiment. We have no experimental values for layer thickness and flow velocity with which to compare the model but the predicted values of these are of the same order as with polypropylene and thus are not implausible.

The same observations made above about competition between heat dissipation paths apply to this polystyrene as well.

The noted limitation on the domain of available model solutions set by the value of the pre-exponential factor, $A_{s}$ was examined further. Note that the solutions are based on parameters for both melt viscosity and for gasification kinetics that could not be measured in conditions most relevant to the actual experiments being modeled. Thus the melt viscosity was measurable only to temperatures between 300 and $350{ }^{\circ} \mathrm{C}$ whereas the model solutions give surface temperatures from $350{ }^{\circ} \mathrm{C}$ to $450{ }^{\circ} \mathrm{C}$. The viscosity extrapolation to these higher temperatures is somewhat uncertain, especially given that the extrapolation is occurring on a semi-log plot. Also, the heating rates at which the gasification kinetics were measured $\left(0.5\right.$ to $\left.5^{\circ} \mathrm{C} / \mathrm{min}\right)$ are well below those in the experiments ( 25 to $150{ }^{\circ} \mathrm{C} / \mathrm{min}$, calculated from the steady-state model solutions). Increased heating rate pushes a reaction to higher temperatures where the controlling mechanism could possibly change; here it is assumed (unavoidably) that there is no change. These two sources of uncertainty imply not only that the absolute values of the model parameters are uncertain but also that the relative temperature dependencies of the two competing processes at the sample surface (mass loss by melt flow and by gasification) may be somewhat incorrect and that competition thereby skewed. This skewing of the competition may, in turn, limit the range of model solutions. ${ }^{92}$ To test this idea, the viscosity -temperature relation for PD702N polypropylene was somewhat modified to increase its rate of decay with temperature. Thus the experimental relation was multiplied by a linear function of temperature that went from unity at $230{ }^{\circ} \mathrm{C}$ to 0.33 at $427^{\circ} \mathrm{C}$. Examination of the process by which the actual melt viscosity data are extrapolated to higher temperatures indicates that this high temperature reduction by a factor of three is not unreasonable. When this modified viscosity-temperature function is inserted in the model, the range of values for $A_{s}$ for which steady-state solutions can be found is increased by $50 \%$. This supports the idea that the limitations on the range of

\footnotetext{
${ }^{92}$ Interestingly, it is found that there is no difficulty in finding solutions to either of the limiting cases of the model (pure gasification or pure melting). The difficulty comes when the two processes compete. The gasification process cannot be so strong that it strips away the melt layer but the limitation on its magnitude seems to come well before this.
} 
model solutions are, at least to some extent, a result of deficiencies in the input parameters.

It is of interest to note the distribution of incoming energy among the various sinks, as computed from the steady-state model. We do this for the polypropylene since it seems to agree somewhat more closely with experiment. Fig. A1.5 shows the distribution at the low and high end of the incident heat flux range. Note that re-radiation always accounts for a significant fraction of the energy budget, as does melt flow. Increased incident heat flux (up into the range provided by flames) markedly increases the fraction lost via gasification of the polymer, at the expense of the "passive" paths of re-radiation and convection. (Of course, if the sample were actually burning, there would be no convective heat loss.)

The concept of a heat of gasification is frequently used to model the rate of gasification of a solid subject to a steady heat flux on its surface. This is the amount of heat needed to convert unit mass of the solid at room temperature to unit mass of gas at the surface temperature. The concept does not apply rigorously to charring solids since they are not capable of steady gasification, though it is sometimes used regardless. From a surface energy balance on the steadily regressing surface, one has:

$$
q_{\text {net }}=q_{\text {in }}-q_{\text {loss }}=m L
$$

where $q_{\text {in }}$ is the incident heat flux on the regressing surface and $q_{\text {loss }}$ is the net loss from the heated surface via re-radiation and convection; $m$ is the steady mass loss rate from the surface via gasification (equal to the gasification reaction rate at the surface) and $L$ is the heat of gasification. From its definition, $L$ is given by the following

$$
L=m\left[C_{p}\left(T_{s}-T_{0}\right)+Q_{g}\right]
$$

Comparison of the above with Eqn (A1.1) shows that they are basically the same except for the heat that goes into the melt flow. If the above is re-arranged to show the relation between $m$ and the incident heat flux, the result is the equation for a straight line with a slope that depends on $L$ :

$$
m=\left(q_{\text {in }}-q_{\text {loss }}\right) / L
$$

Inspection of Fig A1.3c or Fig. A1.4c for the pure gasification cases shows that a linear relation like this tends to hold. However, note that the pure melting case also follows a linear relationship with a greater slope. The mixed gasification plus melting cases follow yet another line with an intermediate slope. As soon as melt flow is allowed, the response of sample mass loss to incident heat flux is no longer a direct measure of heat of gasification. This implies, for example, that thermoplastic samples will not behave the same in a device such as the cone calorimeter when tested in horizontal and vertical 
modes. This is yet another facet of how and why the flammability characteristics of thermoplastic materials are uniquely difficult to assess.

The pure melting case is one extreme example of what one might do to a thermoplastic material to alter its flammability - shift the competing melt and gasification paths so far toward melting that all of the solid melts away from a heat source without ever getting hot enough to generate ignitable gases. There are real materials that behave in this manner. Unfortunately, this is no general guarantee of fire-safe behavior since the melt inevitably accumulates on some horizontal surface where it can be ignited by any falling bits of flaming material (not necessarily the thermoplastic material) typically found in any real product - the melt can no longer escape when it is laying on a horizontal surface and it may burn vigorously, possibly even yielding a self-feeding pool fire.

An alternative fire-resisting treatment of a thermoplastic might be to greatly increase its melt viscosity to at least keep molten fuel from enlarging the burning area and spreading flames to new locations (at the expense of somewhat enlarged flames at the original fuel location). Melt viscosity can be increased by the addition of fine particle solids to polymer resins. $^{93}$ The model can give some information on how responsive this type of system is to an increase in melt viscosity. Here again convergence limitations show up. For the polypropylene, the value of the pre-exponential factor was reduced to that which corresponds to the value deduced for this resin from thermogravimetry (rather than 4 times this as in the above solutions). Only a factor of 9 increase in the melt viscosity (at all temperatures) could be accommodated before convergence limitations re-surfaced, but the results still show how this system would respond to attempts to suppress melt flow by increasing melt viscosity. The results at the lowest and highest incident heat fluxes are summarized in Table A-1; the reference case is that with the nominal, measured melt viscosity-temperature relation.

Table A1-1. Effects of a Factor of Nine Increase in Melt Viscosity

\begin{tabular}{|c|c|c|c|c|}
\hline $\begin{array}{c}\text { Incident Heat } \\
\text { Flux } \\
\left(\mathrm{kW} / \mathrm{m}^{2}\right)\end{array}$ & $\begin{array}{c}\text { Surface } \\
\text { Temperature } \\
\text { Change }\left({ }^{\circ} \mathrm{C}\right)\end{array}$ & $\begin{array}{c}\text { Change in Avg. } \\
\text { Melt Flow } \\
\text { Velocity }\end{array}$ & $\begin{array}{c}\text { Change in Melt } \\
\text { Layer } \\
\text { Thickness }\end{array}$ & $\begin{array}{c}\text { Change in Melt } \\
\text { Flow Rate }\end{array}$ \\
\hline 20 & Up 3.1 & Down $37 \%$ & Up $56.5 \%$ & Down $1 \%$ \\
\hline 45 & Up 6.8 & Down $50 \%$ & Up $80 \%$ & Down $6.8 \%$ \\
\hline
\end{tabular}

The picture that emerges from Table A1-1 is that of a system that is quite resistant to changes in viscosity; the effect of an order of magnitude increase in viscosity on melt flow rate is practically negligible. Surprisingly, the resistance to change comes more through adjustments in the melt flow layer than in the viscosity itself. One would expect

\footnotetext{
93 As a practical matter, thermoplastics are usually formed by molding processes that require a low to moderate melt viscosity, so a very large increase in viscosity in the temperature range used for thermoforming (e.g., $200^{\circ} \mathrm{C}$ to $250^{\circ} \mathrm{C}$ ) would be impractical. Some more subtle (presumably chemical) means would be needed to increase melt viscosity at temperatures above the thermoforming range, in response to impending ignition conditions.
} 
the system to have resisted change by having the surface temperature go up and thereby drive the local melt viscosity back down; here this seems to be a secondary effect. In any event an implication of these results is that it would take several orders of magnitude in viscosity change to substantially suppress the melt flow from a thermoplastic material. Thus this approach to modifying the flammability behavior of thermoplastics is not an easy one.

Summary. The complex, time-dependent behavior of a vertical slab of a thermoplastic material subjected to a constant heat flux on one face, tends toward a quasi-steady mass loss behavior if the sample is thermally thick. That behavior is still inherently twodimensional but, if the polymer yields a low viscosity melt and, thereby, a thin downward flow of melt over its face, the behavior can be approximated as one-dimensional. It is then approximately describable by a set of algebraic equations which determine the relevant temperatures and mass loss paths. The model can capture the competition between mass loss by melt flow and mass loss by gasification. It reveals that any attempts to shift this competition call for large changes in model parameters and thus the flammability of thermoplastics is not easily altered via such an approach.

\section{Appendix 1 References.}

A1.1) Glassman, I., Combustion, Academic Press, New York (1977), p. 74

A1.2) Bird, R., Stewart, W. and Lightfoot, E., Transport Phenomena, Wiley and Sons, New York (1960), p. 40

A1.3) Bird, R., Stewart, W. and Lightfoot, E., ibid, p. 327 

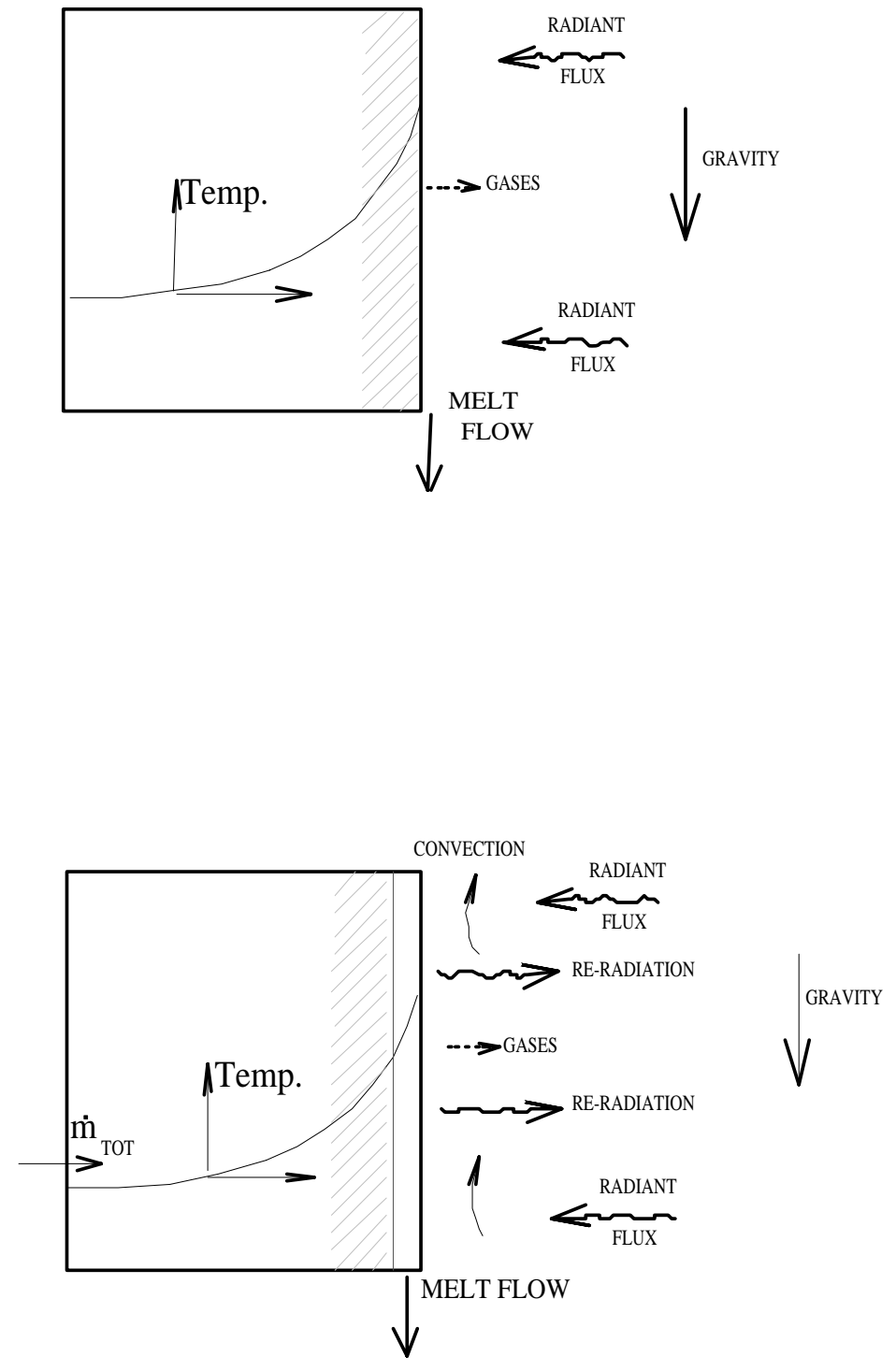

Figure A1.1 (top). Schematic of 2-D thermoplastic slab heated on one face.

Figure A1.2 (bottom). Schematic of the energy and mass flows at the steady-state condition. 


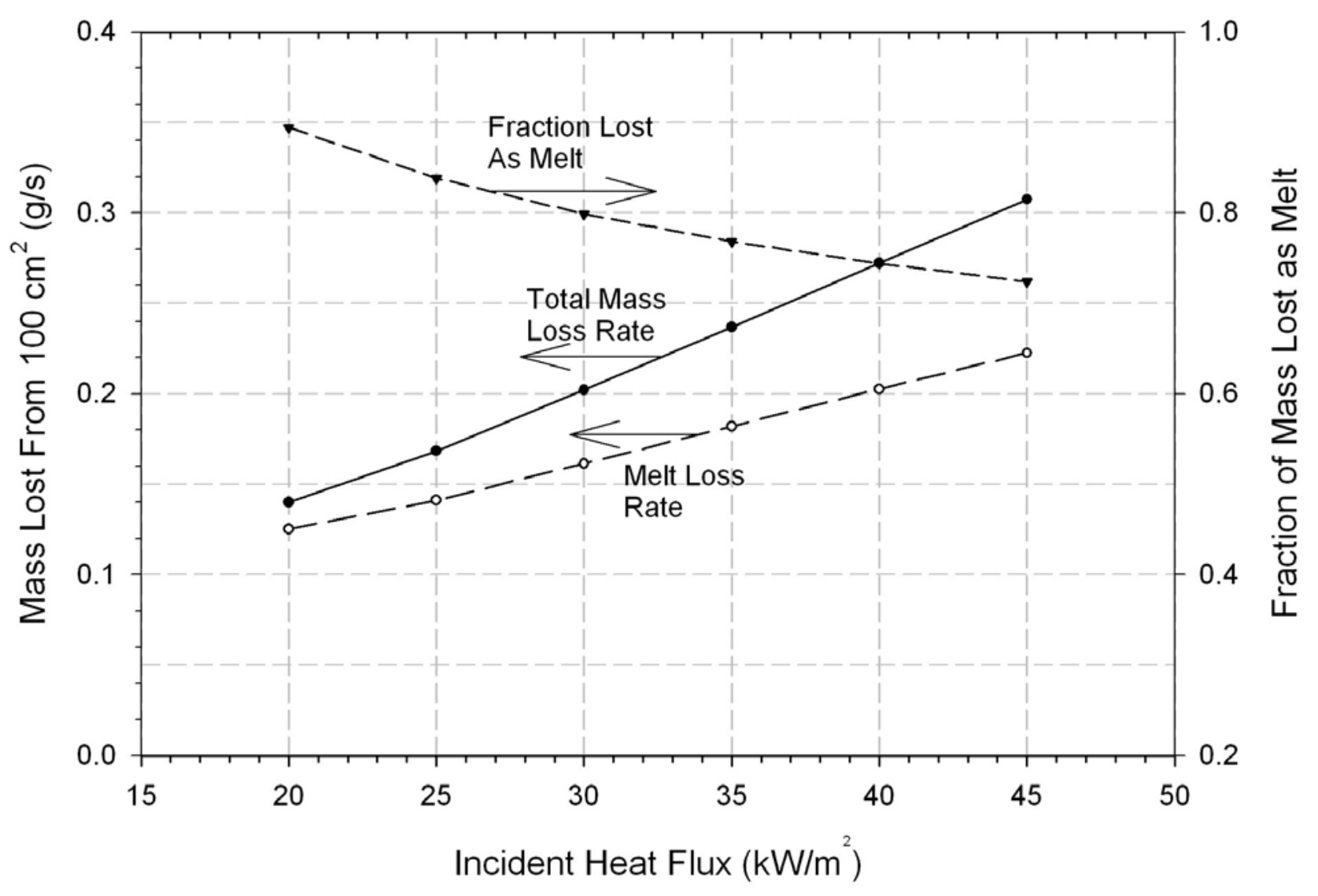

Figure A1.3a Steady-state, 1-D model prediction of combined melting and gasification mass loss rate for PD702N polypropylene. 


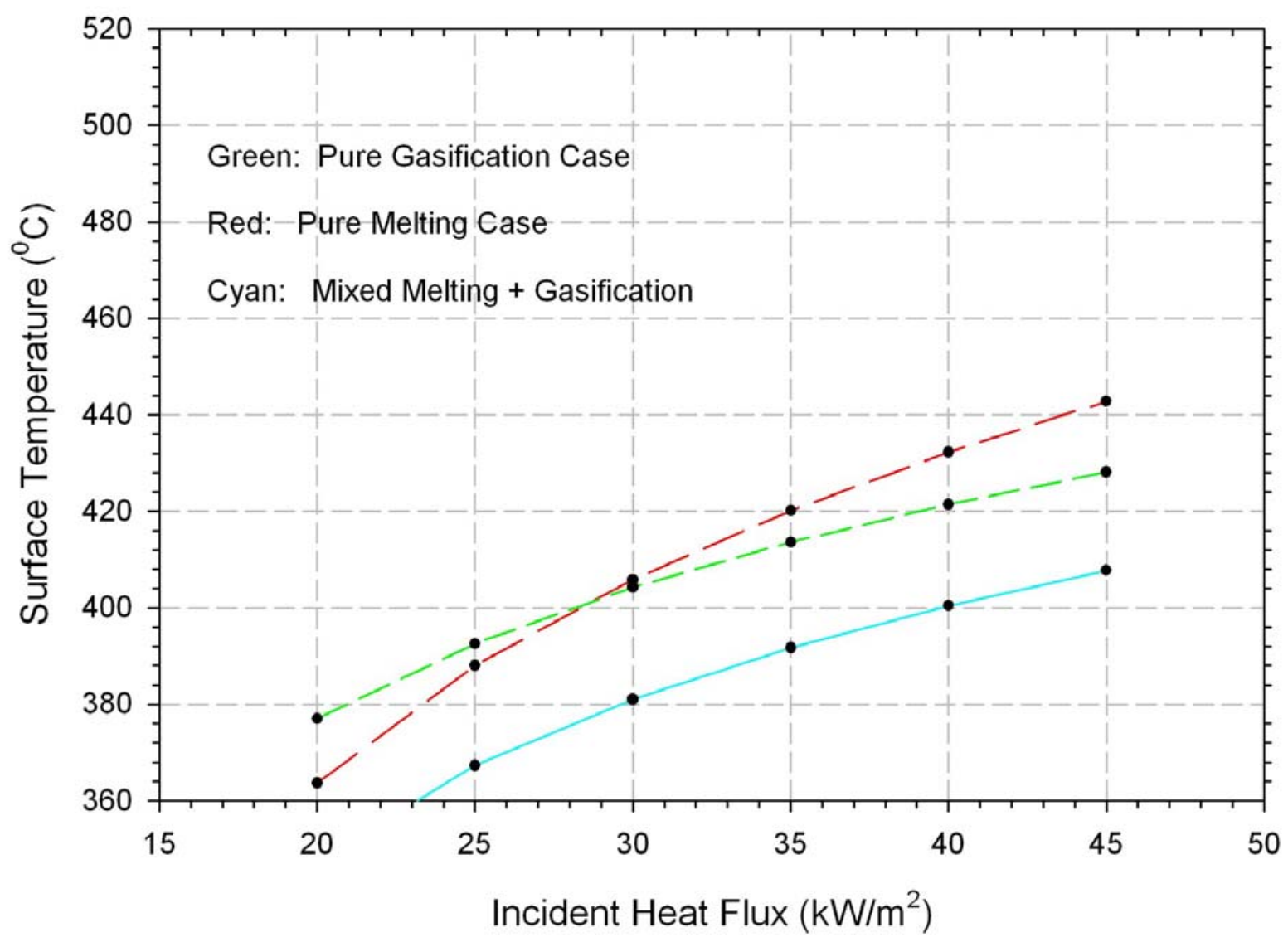

Figure A1.3b. Surface temperature prediction of 1-D, steady-state model; limiting cases and mixed case; PD702N polypropylene. 


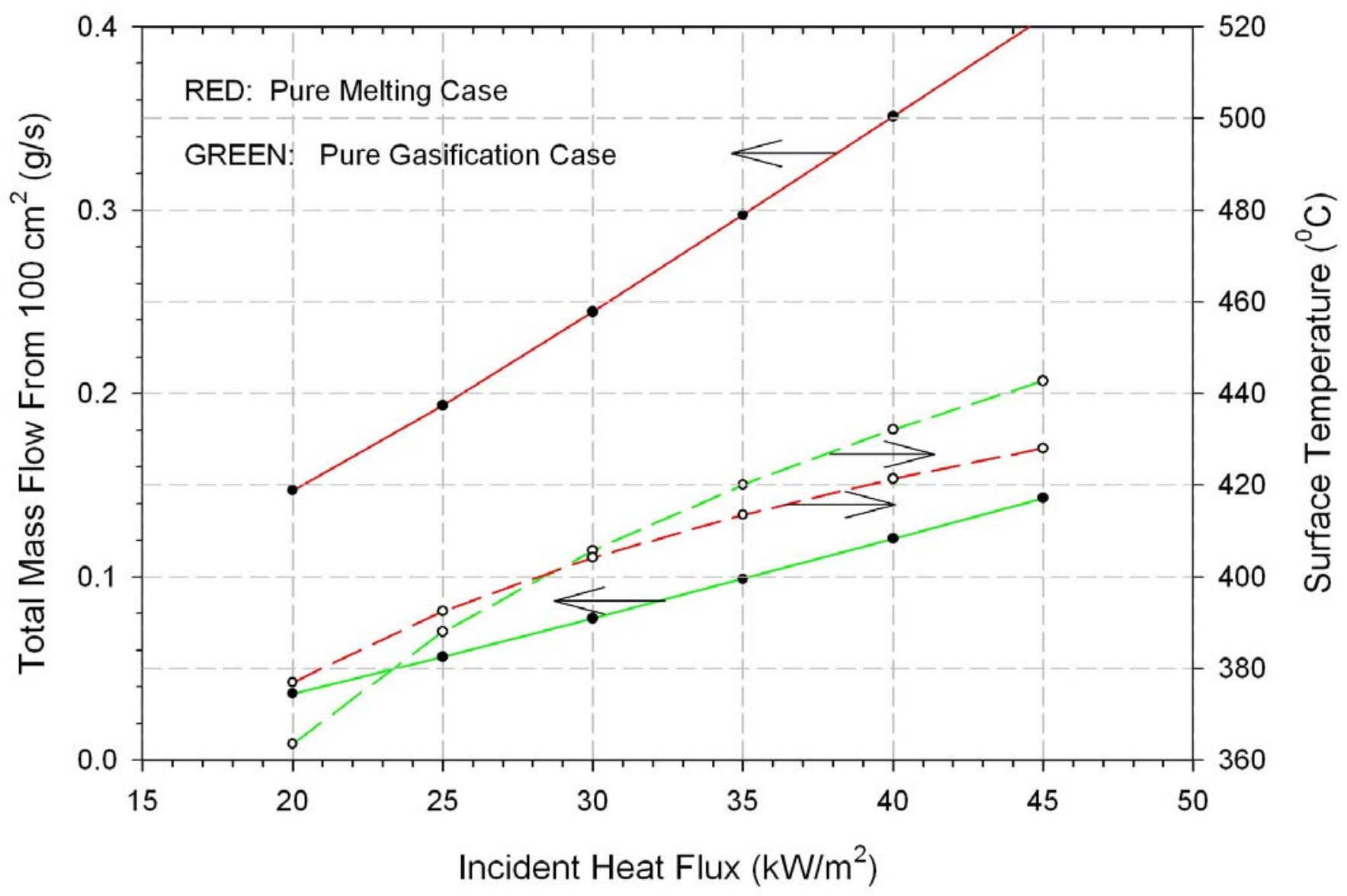

Figure A1.3c. Behavior of limiting cases of steady-state model prediction for PD702N polypropylene. 


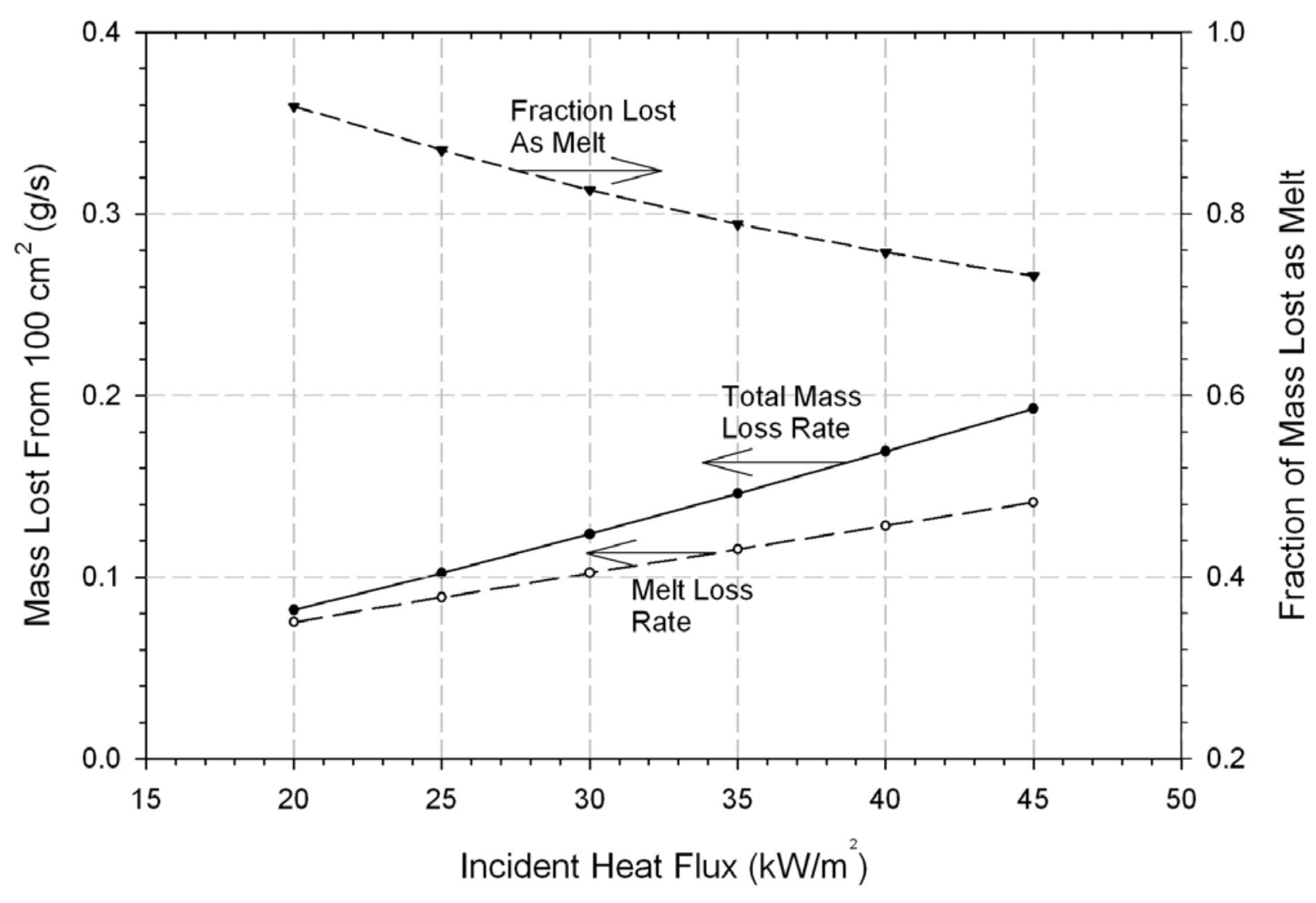

Figure A1.4a. Mass loss rate prediction of 1-D, steady-state model; mixed melting and gasification case for PS 666 polystyrene. 


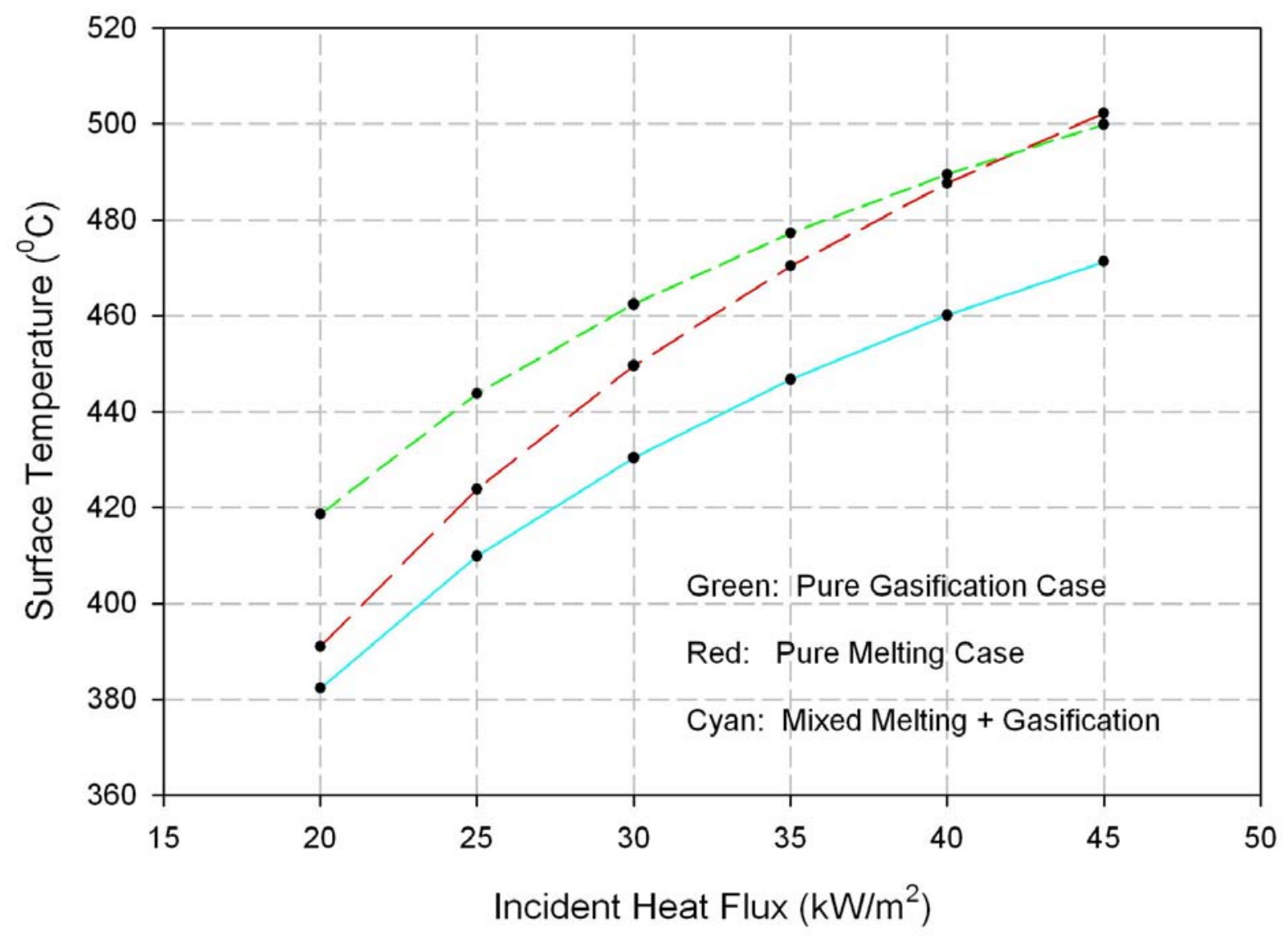

Figure A1.4b Surface temperature prediction of 1-D, steady-state model; limiting cases and mixed case; PS 666 polystyrene. 


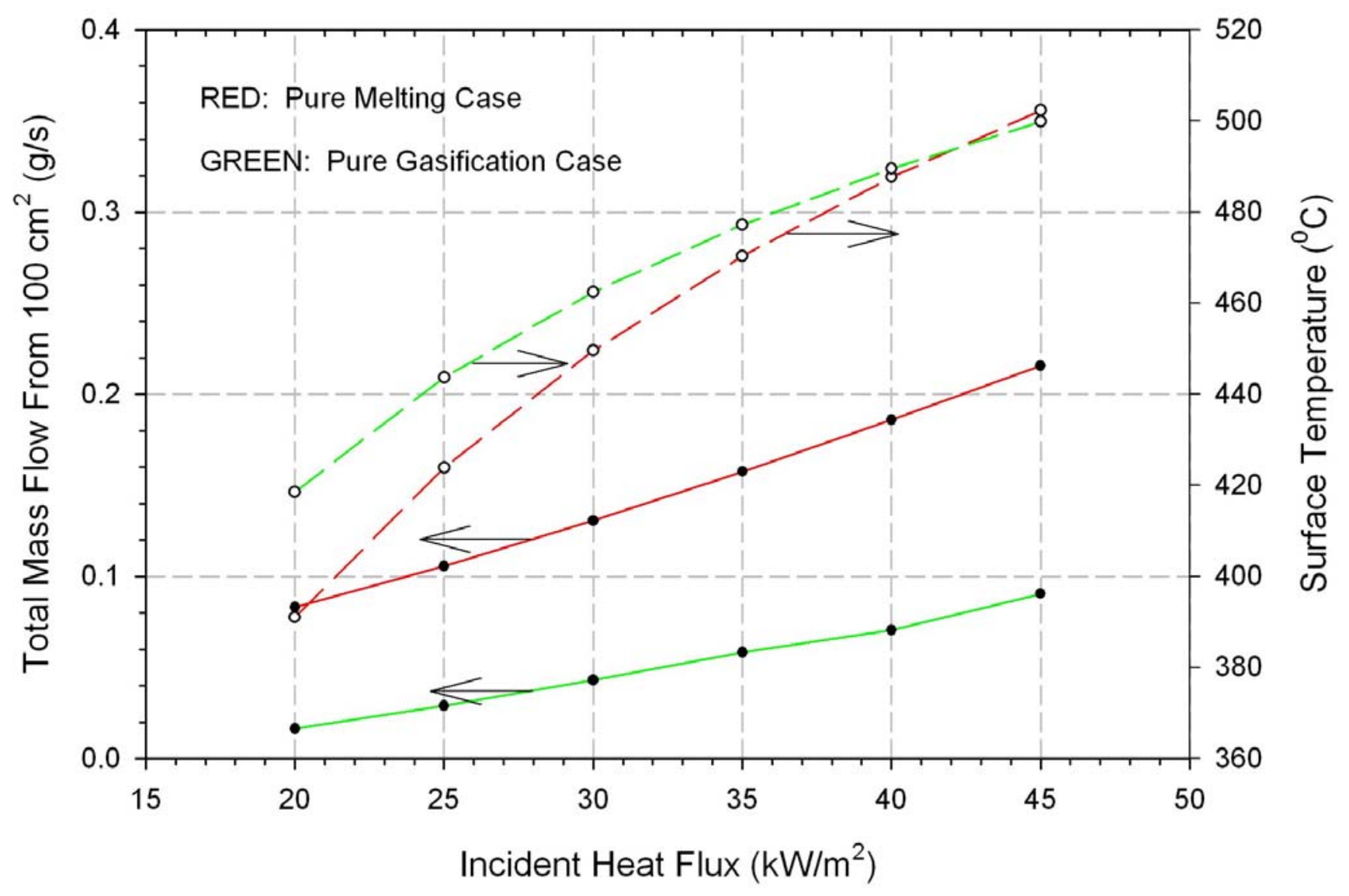

Figure A1.4C Limiting case behavior predictions of 1-D, steady-state model for PS 666 polystyrene. 


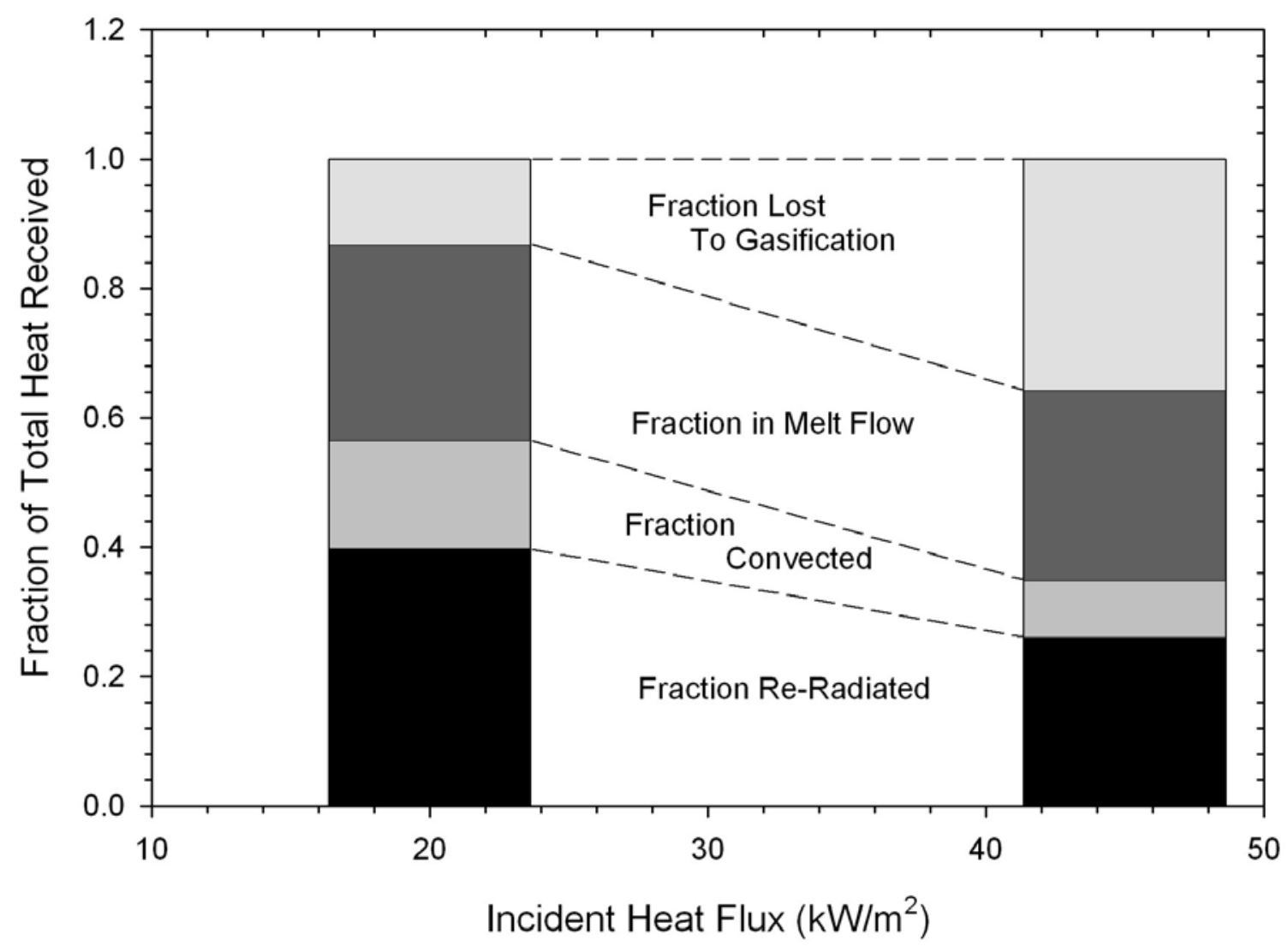

Figure A1-5. Prediction of 1-D, steady-state model for fractional distribution of incoming heat lost via various paths; PD702N polypropylene. 


\section{Appendix 2}

\section{Condition for a Self-Feeding Pool Fire}

It was noted in the main text that a worst case condition for a material which sheds flaming melt material is that its pool fire plume grows to the point where it strikes the object and thereby substantially increases the melt flow rate to itself because such a situation is potentially subject to an exponential growth in fire size. ${ }^{94}$ We call this a self-feeding pool fire situation. Note that a very low density material like a polyurethane foam will also tend to regress away from the impinging pool fire plume even as it feeds melt to it and this can mitigate the self-feeding tendency to a certain degree. Here we do not attempt to factor in all of the possible complications, but rather, we want to infer how the self-feeding condition varies with the size of the fire on the object. By confining our analysis to the condition at which self-feeding just begins to occur (taken as the condition when the pool fire plume tip [Ref. A2.4] just reaches the bottom of the object), we can infer results that should hold for both full density and low density thermoplastic materials.

Consider a burning thermoplastic object that is at some height directly above its pool fire and, as a result of its burning, is losing some fraction of its mass as flaming melt feeding that pool fire. It feeds the pool fire at the rate

$$
m_{\text {feed }}=\gamma m_{o b j}=\gamma \dot{Q}_{o b j} / H_{c, o b j}
$$

Where $m_{\text {feed }}$ is the mass flow rate $(\mathrm{kg} / \mathrm{s})$ of melt into the pool fire, $\gamma$ is the fraction of melt that the object creates as it burns, $m_{o b j}$ is the total mass loss rate of the burning object, $\dot{Q}_{o b j}$ is the heat release rate of that burning object and $H_{c, o b j}$ is its heat of combustion. This creates a pool fire below the object whose quasi-steady diameter is given by a simple mass balance

$$
d_{\text {pool }}=\left[4 \gamma\left(\dot{Q}_{o b j} / H_{c, o b j}\right) / \pi \dot{m}_{p o o l}\right]^{0.50}
$$

where $d_{\text {pool }}$ is the diameter (m) of the pool fire and $\dot{m}_{\text {pool }}$ is the mass loss rate per unit area $\left(\mathrm{kg} / \mathrm{m}^{2} \mathrm{~s}\right)$ of the pool fire due to its own burning. The burning rate of a pool fire can be estimated from [Ref A2.1]

$$
\dot{m}_{\text {pool }}=0.015 f\left[1-\exp \left(-k \beta d_{\text {pool }}\right)\right]
$$

\footnotetext{
${ }^{94}$ We are considering a geometry (pertinent to chairs or mattresses at some distance above a floor) in which the object which is the source of the melt is directly over the horizontal catch surface on which the pool fire exists. Other possibilities exist such as a thermoplastic object sitting on a horizontal catch surface with a pool fire next to it. In this case there is always an interaction and a tendency to self-feed.
} 
where $f$ is a fraction whose base value is about 0.20 for pool a thin pool fire on a solid surface [Ref A2.2] and which we want to adjust for possible feedback between the pool fire and the object fire. The parameters $k \beta$ are based on a mean beam length estimation of feedback from the pool fire plume to the pool; we set their product equal to the value $\left(3 \mathrm{~m}^{-1}\right)$ given in Ref. A2.3 for polymethylmethacrylate (a somewhat oxygenated molecule that comes closest to our complex, somewhat sootforming flame gases). This pool fire has a plume height (flame tip height) given by the following turbulent fire plume correlation [Ref. A2.4]

$$
L_{f} \equiv h_{o b j}=-1.02 d_{p o o l}+0.235\left(\dot{Q}_{p o o l}\right)^{0.40}
$$

where $L_{f}$ is the flame tip height and it is set equal to $h_{o b j}$, the height of the bottom of the burning object above the surface on which the pool fire is occurring; $\dot{Q}_{p o o l}$ is the heat release rate $(\mathrm{kW})$ of that pool fire. That heat release rate can be expressed in terms of the other parameters from above

$$
\dot{Q}_{\text {pool }}=\dot{m}_{\text {pool }}(\pi / 4)\left(d_{\text {pool }}\right)^{2} H_{c, \text { pool }}
$$

where $H_{c \text {,pool }}$ is the heat of combustion of the melt in the pool, taken here as being equal to the heat of combustion of the object itself, $H_{c, o b j}$.

Given the above set of relations, one can pick a value for the heat release rate from the object, $\dot{Q}_{o b j}$, solve for the pool fire diameter (this requires a Newton-Raphson iteration to solve Eqns A.2.2 and A.2.3 together), then find the object height at which the pool fire plume tip is just reaching it.

Figures A2.1 and A2.2 show the results of such calculations for a material with a heat of combustion of a typical polyurethane ( $30 \mathrm{MJ} / \mathrm{kg})$. Recall that the melt fraction from polyurethanes was found to vary substantially. Here we have used values of 0.50 and 0.75 . In the main text it was also shown that the fire plume on the object can send a significant amount of radiation onto the pool fire boosting its burning rate. Thus we have also shown calculations for the case in which this effect doubles the pool fire burning rate.

As expected, both Figures show that the larger the fire in the object the larger is the objects height above the catch surface at which the pool fire can interact with, and begin to boost, that object fire. Doubling the pool fire burning rate roughly doubles the reach of the fire plume. Increasing the object melt fraction by $50 \%$ has only a weak effect on the reach of the fire plume. Note that all of the separation distances fall between values used in the foam tests reported in the main text.

The implications of these plots for scaling down a potential test method for polyurethane foam are discussed in the main text. 


\section{Appendix 2 References}

A2.1 Gottuk, D. and White, D. "Liquid Pool Fires" Section 2, Chapter 15 in the SFPE Handbook of Fire Protection Engineering, $3^{\text {rd }}$ Edition, National Fire Protection Association, Quincy, Massachusetts, p. 2-310

A2.2 ibid, p. 2-311

A2.3 Babrauskas, V., “Heat Release Rates”, Section 3, Chapter 1, ibid, p. 3-26

A2.4 Heskestad, G., "Fire Plumes, Flame Height and Air Entrainment,” Section 2 Chapter 1, ibid, p. 2-3 


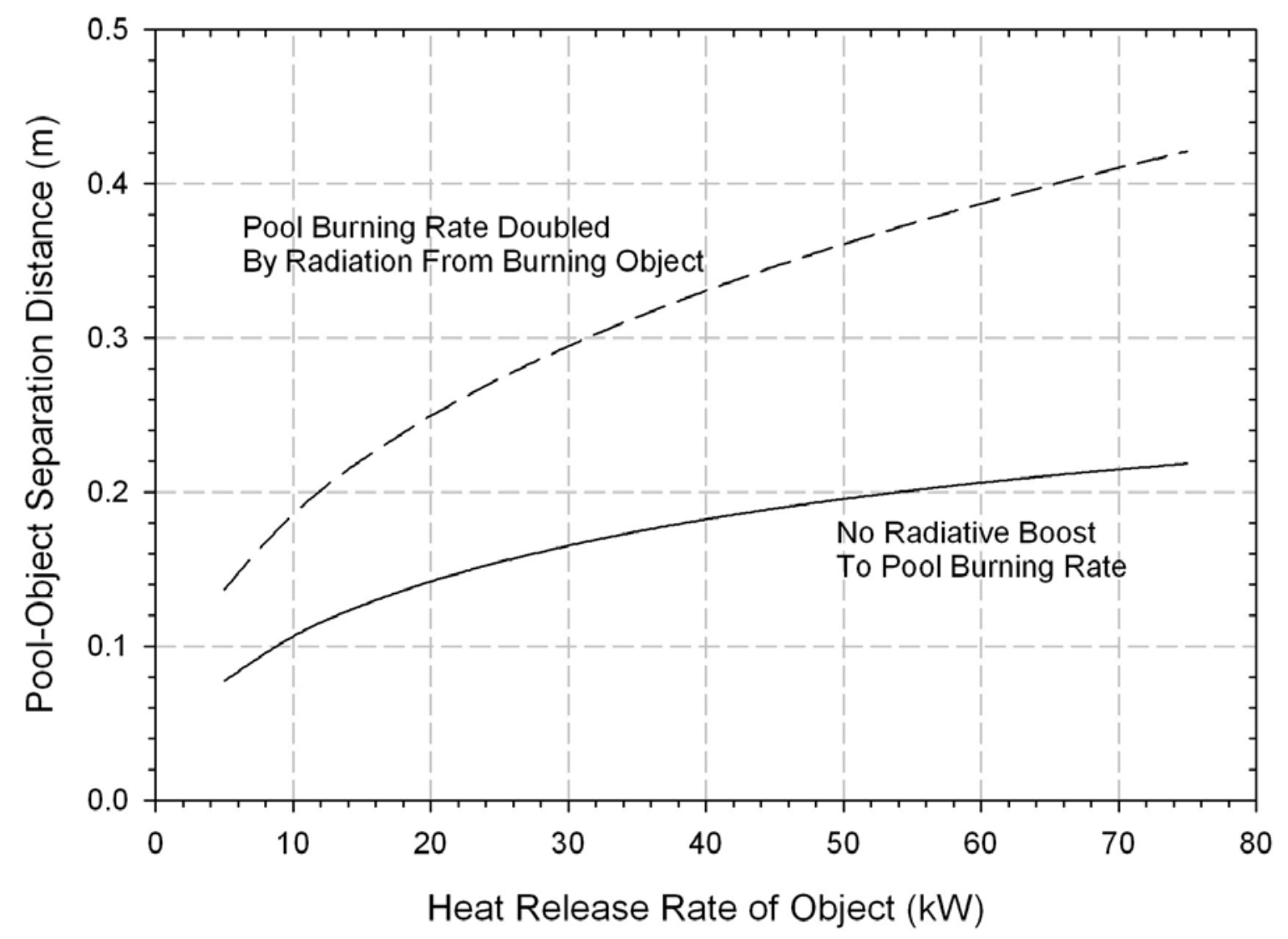

Figure A2.1 Estimate of object height above its pool fire at which self-feeding of pool fire begins (object melt fraction $=0.50$ ). 


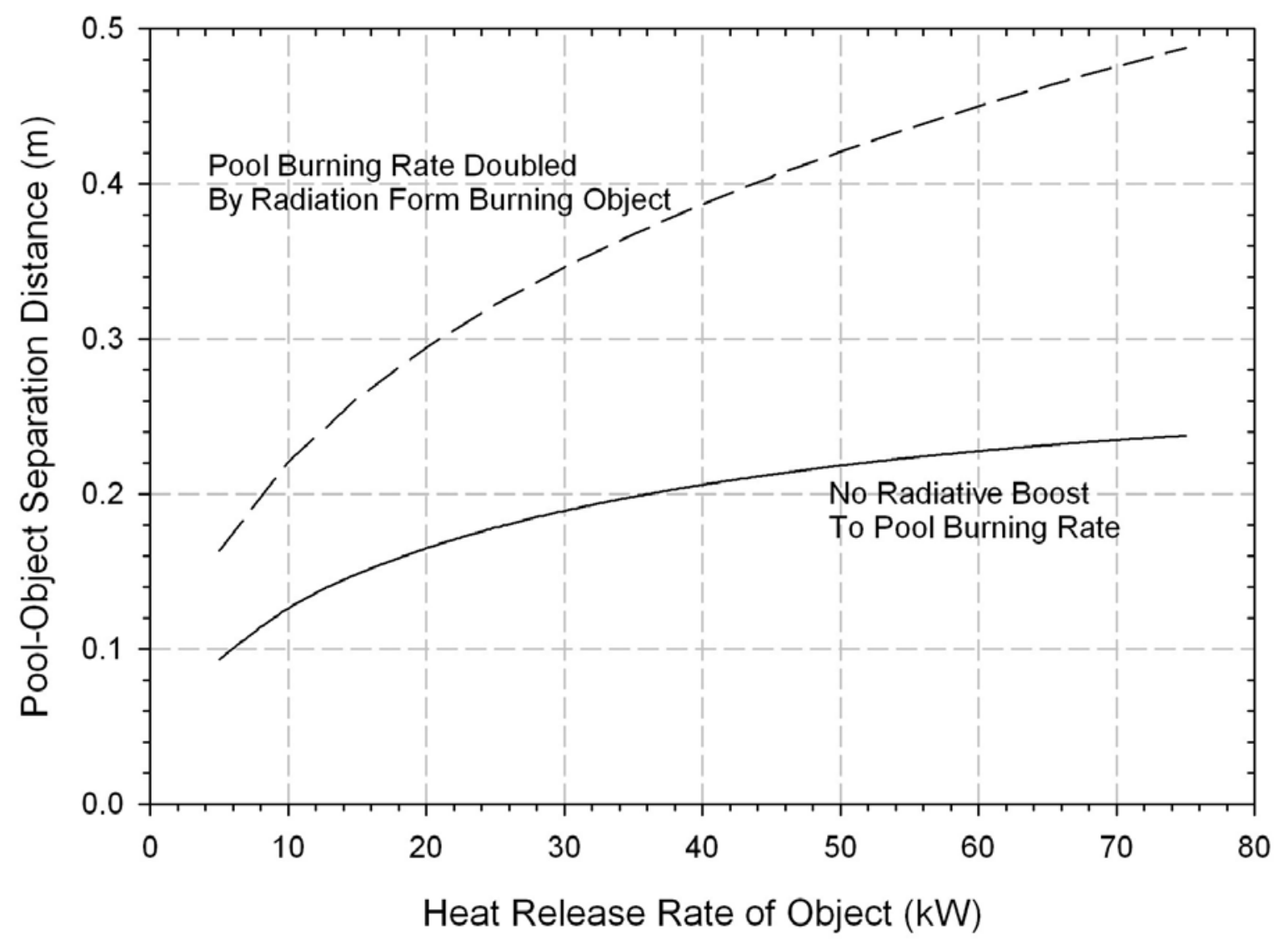

Figure A2.2 Estimate of object height above its pool fire at which self-feeding of pool fire begins; (object melt fraction $=0.75$ ). 


\section{Appendix 3}

\section{A Limited Exploration of an Alternative Approach to TG Kinetics}

In the review process for this report, one of the reviewers (M. Nyden) suggested an alternative approach to inferring kinetic parameters for gasification of a polymer or its melt from weight loss data obtained by thermogravimetry. Its attraction is that it is capable of using (nearly) all of the thermogravimetry data obtained at several heating rates rather than just the data at the peak rate of weight loss as in the Kissinger method utilized in the main body of this report.

If the thermogravimetry sample is assumed to be a collection of molecules that, at any given point in the linear heating process, are at the same temperature and are reacting to that temperature by degrading in an effectively single, first order, overall reaction step in a manner independent of any mass transfer processes ${ }^{95}$, then at all times during the weight loss process, regardless of heating rate, we can write:

$$
d m / d t=k\left(m-m_{R}\right)
$$

which says that the rate of sample mass loss is proportional to the first power of the remaining mass minus some non-participating residual mass, $m_{R}$ (if any). Here the proportionality constant is the kinetic rate constant whose parameters ( $A$ and $E$ ) we seek to characterize:

$$
k=A \exp (-E / R T)
$$

If the above assumptions about the sample hold true, we can solve for $k$ in Eqn (A3.1) to get:

$$
k=\left(1 /\left(m-m_{R}\right)\right)(d m / d t)
$$

In this manner, one can use the derivative of the entire sample mass loss curve to calculate a running value of the kinetic rate constant for all mass loss data at all available heating rates. If the sample is "well-behaved" the resulting set of values for $k$ can be plotted versus the inverse of the absolute temperature and one will find unique values for the pre-exponential factor, $A$, and the effective activation energy, $E$. Nyden [Ref. A3.1] found this approach to work for a polyisobutylene sample at four heating rates, obtaining an essentially unique pair of values for the two kinetic parameters for weight loss rate from that polymer.

Here we investigated this approach for a sample of polypropylene melt generated at

\footnotetext{
${ }^{95}$ Such processes might limit the rate of escape of volatile molecules formed by the degradation reactions. These assumptions are common to any kinetic analysis of thermogravimetry data.
} 
$20 \mathrm{~kW} / \mathrm{m}^{2}$ with a gas-fired panel as a radiant heater. Thermogravimetry data for this degraded polymer were obtained at three heating rates, $0.5,2$ and $5{ }^{\circ} \mathrm{C} / \mathrm{min}$. The mass vs time data were differentiated and used in Eqn A3.3 to calculate values of $k$ versus temperature at all three heating rates.

A semi-log plot of these results, in terms of $k$ vs. (1/T) is shown in Fig A3.1. In this form, the slope of the curve is proportional to the effective activation energy and the intercept yields the pre-exponential factor. Also shown on the graph is a linear fit to the total data set (all three heating rates).

It is clear in Fig A3.1 that all three curves have significant curvature, tending toward a higher slope at higher temperatures (left side of the graph). For the three heating rates, the change in slope is not clearly related purely to temperature, nor, one can show, is it related purely to the extent of the reaction. Generally, however, it occurs in the temperature range from $370{ }^{\circ} \mathrm{C}$ to $405^{\circ} \mathrm{C}$.

In general, a one step kinetic rate law has one more available parameter, the reaction order. That is, a more general version of Eqn 3.1 is

$$
d m / d t=k\left(m-m_{R}\right)^{n}
$$

where $n$ is the reaction order. Here, however, we have no data manipulation procedure that yields a value of reaction order. A trial and error process was therefore used to investigate the issue of whether values of $n$ other than unity (larger or smaller) had an effect on the curvature seen in Fig A3.1, i.e., could a different choice of this additional parameter yield a straighter line in this type of plot? Thermogravimetry results from a heating rate of $2{ }^{\circ} \mathrm{C} / \mathrm{min}$ were used for this purpose. The result was that values from 0.50 to 1.50 only made the plot of $k$ vs. (1/T) look worse. Values less than unity tended to introduce a new, reverse curvature in the plot at high temperatures. Values above unity increased the overall upward curvature seen in Fig A3.1. We infer that unity is the most appropriate value for this parameter and that the curvature in Fig A3.1 is fundamental. (It should be noted that a reaction order very near unity was reported for polypropylene degradation in Refs A3.2 and A3.3)

If the curvature is real then the reaction process is not as simple as Eqn A3.1 assumes. Either the effective activation energy varies (evidently more so with temperature than with extent of reaction ${ }^{96}$ ) or the system requires two or more sequential reactions to describe its mass loss behavior. Either would complicate the overall melt fire modeling problem.

The use of the average line fitted over all three heating rates shown in Fig A3.1 yields a unique value for both the activation energy $(170 \mathrm{~kJ} / \mathrm{mol})$ and the pre-exponential factor $\left(1.19 \cdot 10^{10} \mathrm{~s}^{-1}\right)$. This value of activation energy falls within the wide range of values

\footnotetext{
${ }^{96}$ There are data reduction schemes in the thermal analysis literature which can yield an effective activation energy as a function of extent of reaction [e.g., Ref. A3.4].
} 
reported in the literature for polypropylene (A3.2, A3.3). This pair of values does predict weight loss curves that fall in the approximately correct temperature range $\left(350^{\circ} \mathrm{C}\right.$ to 450 ${ }^{\circ} \mathrm{C}$ ). Recall, however, that the shift of the reaction with heating rate is a function of activation energy. Since this simple description uses an average activation energy, it is not quantitatively correct with regard to the shift in the position of the curves with increasing heating rate. This is not particularly troublesome when matching just the thermogravimetry results. However, the kinetic parameters are to be used in a melt fire model in which the heating rates will be substantially higher (a factor of ten or more higher than in thermogravimetry). Given this, it is possible that the balance of gasification of a melt and the flow of the melt could be seriously miscalculated if the activation energy for gasification is substantially incorrect. One possible way of avoiding this, short of using a more complex, multi-step gasification description, would be to use the activation energy one would infer from Fig A3.1 (or its analog for another material) at the lower temperature, lower conversion end of the weight loss process. This has more of a chance of putting the gasification in proper competition with other processes in a model of burning, though it may still incorrectly estimate the amount gasified.

Overall, it appears that this alternative approach to inferring kinetic parameters is more informative than the Kissinger method used in the main body of this report. However, the additional information it brings can point to a need for increased complexity in the modeling description.

\section{Appendix 3 References}

A3.1 Jee, C., Guo, Z., Stoliarov, S. and Nyden, M., "Experimental and Molecular Dynamics Studies of Thermal Decomposition of a Polyisobutylene Binder," Acta Materialia 54, pp. 4803-4813 (2006)

A3.2 Gersten, J., Fainberg, V., Hetsroni, G. and Shindler, Y., "Kinetic Study of the Thermal Decomposition of Polypropylene, Oil Shale and Their Mixture," Fuel 79, pp. 1679-1686 (2000)

A3.3 Bockhorn, H., "Kinetic Study of the Thermal Degradation of Polypropylene and Polyethylene," Journal ofAnalytical and Applied Pyrolysis 48, p. 373 (1999)

A3.4 Friedman, H. 1964-1965. J. Polym. Sci. C 6: 183-95 


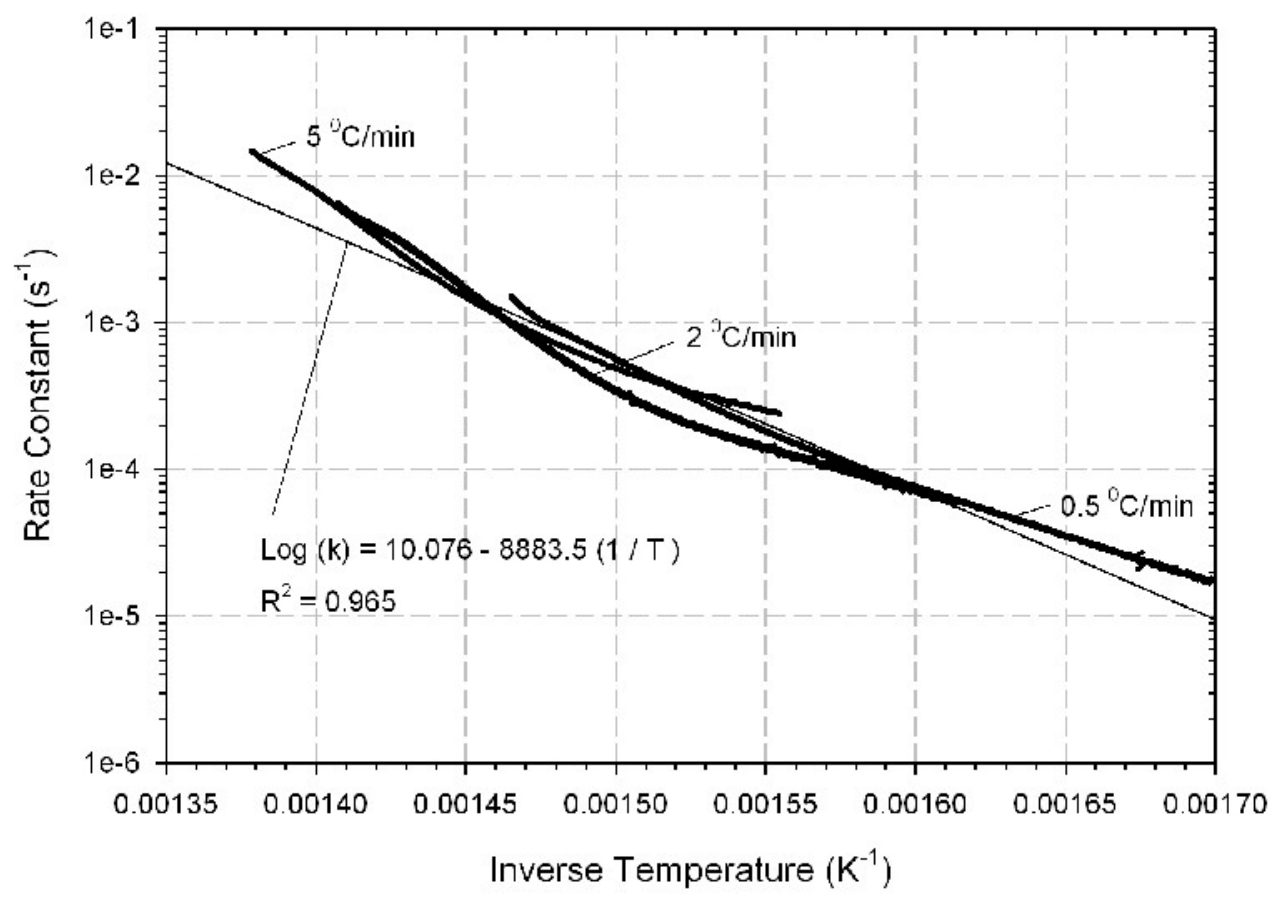

Figure A3.1 PD702N Melt Residue from Test B1 at $20 \mathrm{~kW} / \mathrm{m}^{2}$; Linear Fit to Total Data at Three Heating Rates; Conversion on all Curves Between 0.05 and 0.95 


\section{Appendix 4}

\section{Cone Radiation Absorption In-Depth in Polymer Resins}

The following measurements were carried out after the main body of the text of this report was written. It was noted there that, in the various cone calorimeter-based polymer melt/gasification experiments, in-depth absorption of the cone radiation had a potential influence on the results. However, the only data available on this issue that appeared relevant to the polymers used here were obtained with a different apparatus (a larger diameter cone heater), operated at a different temperature, and the polymer resins came from a different source. To rectify this, we carried out a measurement of radiation penetration on the specific polypropylene and polystyrene resins used throughout the bulk of this report and we did this in conditions directly relevant to the conditions reported in the main body of this report.

The exact geometry and source temperature affect the extent of radiation penetration below a polymer surface. The geometry determines the range of angles over which the radiation strikes the polymer surface. Thus, a ray striking the surface at, for example, $45^{\circ}$, penetrates a lesser distance in the direction normal to the sample surface than does a ray striking the surface at $90^{\circ}$. The cone heater provides radiation over a range of angles and that range depends on the spacing between the cone and the irradiated sample surface. Furthermore, the cone heater can be regarded as a gray-body radiator. The peak of the radiation spectrum it emits then roughly follows Wien's Displacement Law, moving to shorter wavelengths as the cone temperature is turned higher; this alters the amount of radiation interacting with peaks in the infrared absorption spectrum of a polymer and thus the amount of radiation absorbed up to any given depth. In the experiments reported in the main text, the distance between the base of the cone heater and the polymer sample surface was fixed at $7.6 \mathrm{~cm}$ and the radiant flux was varied by changing the cone heater temperature. Here we used the same cone heater distance and we focused on the cone heater temperature (ca. $680{ }^{\circ} \mathrm{C}$ ) that provided an incident heat flux of $30 \mathrm{~kW} / \mathrm{m}^{2}$, the middle value in the preceding experiments.

The physical set-up for these measurements was simple. The cone heater, oriented horizontally, was placed $7.6 \mathrm{~cm}$ above a thin sheet of the polymer resin of interest. Just below (2 mm) the back surface of the sample, a Schmidt-Boelter total heat flux gage (6 mm diameter) was placed (on the cone heater centerline). This type of flux gage has a time response of 0.1 to $0.2 \mathrm{sec}$. according to the manufacturer and was previously calibrated to a heat flux accuracy of approximately $\pm 3 \%$. The high incident heat flux meant that the sample was heated rapidly. The $2 \mathrm{~mm}$ spacing above the flux gage minimized the conductive flux from the warming sample to the gage but it did nothing to halt sample re-radiation. To establish the position of what was therefore an upward shifting baseline, the cone radiation was chopped at ca. $1 / 2 \mathrm{~Hz}$ using a handheld piece of sheet metal. This permitted acquiring 10-15 seconds of absorption data before the sample began to degrade. 
The sheet samples were made by hot pressing the polymer beads. This did not provide a very flat sample and it left a few bubbles in random locations. Since circles of only about $6 \mathrm{~mm}$ diameter were needed for each measurement (on a sheet that was 7.6 to $10.2 \mathrm{~cm}$ across), clear, bubble-free areas were selected and marked so that they could be placed over the flux gage. The local thickness of these areas was measured with a micrometer ( $0.01 \mathrm{~mm}$ resolution). Duplicate sheets of each resin with nominal thicknesses of 0.8 $\mathrm{mm}, 1.6 \mathrm{~mm}, 3.2 \mathrm{~mm}$ and $6.4 \mathrm{~mm}$ were made; each was tested in at least two locations. The resins were PD702N and 6523 polypropylene plus 663 and 666D polystyrene.

The raw data in this experiment are affected by reflection of radiation at two surfaces the front and back of the resin sample. That is, the amount of radiation reaching the heat flux gage is diminished both by the reflection process and by the absorption process that is the real point of interest. A model of the heating of the polymer by radiation needs information on both the loss of incident radiation by reflection at the front surface of the sample and on the deposition of the remaining radiation in the depth of the sample.

These polymer resins are dielectric materials whose reflectivity is dictated by their refractive index (A4.1). In general, the reflection of light at the surface of a dielectric material is a function of the angle of incidence and that function, in turn, depends on whether the light is polarized. Here the light is unpolarized and the range of incidence angles ( 0 to ca. $\left.45^{\circ}\right)$ is well within the range $\left(0\right.$ to ca. $\left.60^{\circ}\right)$ for which the reflectivity of unpolarized light is independent of angle. Both polystyrene and polypropylene have refractive indices of about 1.4 to $1.6^{97}$; based on this we used a value of single-surface reflectivity of $4 \%$. The raw data from the measurements are thus divided by a factor of 0.92 (i.e., $\left.(1-r)^{2}\right)$ to obtain the amount of radiation actually deposited within the polymer sample. $^{98}$

The main interest here is the deposition of radiant heat within the polymer bulk. This is obtained by differentiating the measured attenuation function obtained here (and multiplying by the heat flux that penetrates the outer surface of the material). This becomes the radiant source term in a transient energy equation for a polymer sample. The results for these measured attenuation functions for the four resins examined here are shown in Figures A4.1 to A4.4.

In all cases it was possible to fit the data very well with a double exponential decay expression, as shown on each plot. A simple interpretation ${ }^{99}$ of this form comes from the nature of the near to middle infrared spectra of these types of polymers. Both polypropylene and polystyrene are weak absorbers out to about $5 \frac{1}{2}$ microns except for a strong absorption band centered at about $3 \frac{1}{2} 2$ microns. The cone heater radiation at 680 ${ }^{\circ} \mathrm{C}$ can be expected to peak at about 3 microns. Thus a substantial portion of the radiation just above 3 microns plus that portion above about $5 \frac{1}{2} 2$ microns is strongly absorbed and

\footnotetext{
${ }^{97}$ We ignore the anomalous behavior of refractive index in the neighborhood of strong absorption lines.

${ }^{98}$ We also ignore the higher order terms that come from considering the possibilities for multiple internal reflections.

${ }^{99}$ We note that this fitting function also has four adjustable constants so the good fit is also enabled by this flexibility.
} 
everything else is very weakly absorbed. The figures show that about half of the energy is deposited in the first half millimeter and the rest is spread over the next several millimeters.

Not surprisingly, the absorption curves for the two polypropylenes are similar to each other. The same can be said for the two polystyrenes. The real surprise is that the polypropylenes and the polystyrenes are so similar. We do not have infrared spectra on these specific resins but the available spectra for these types of resins (cf., Sadtler Standard Spectra) indicate that polystyrene has a more complex and broader absorption band around $3 \frac{1}{2}$ microns, compared to that for polypropylene. Evidently such differences have a relatively small impact for the conditions studied here.

A concern for polypropylene is that at room temperature up to $165^{\circ} \mathrm{C}$, it has two phases, one of which is crystalline. This renders it a scattering medium, at least in the visible portion of the spectrum. If it scatters in the infrared also, its attenuation function could be expected to change appreciably from that measured here for temperatures above the crystalline melting point. We had no data on the crystallite size in our samples but we note that if they were of the order of 1 micron or less, scattering in the infrared would be negligible (even though appreciable in the visible). A search of available polypropylene IR spectra (Sadtler Standard Spectra) showed no signs of the kind of inclined baseline in non-absorbing, short wavelength regions (1-2 microns) that scattering tends to cause. An attempt was made to perform our cone radiation attenuation experiments at temperatures above $165^{\circ} \mathrm{C}$ by laying the sample on top of a layer of zinc selenide (an infrared transparent support surface) to prevent it from sagging onto the top of the flux gage. The samples always underwent severe physical distortions and dimensional changes by the time the crystalline phase melted so no useful data could be obtained in this manner. At this point we have only the rather weak inference from the available infrared spectra that scattering in not an issue with polypropylene.

\section{Reference for Appendix 4}

A4.1 F. Jenkins and H. White, Fundamentals of Optics, 3rd Edition, McGraw-Hill Book Company, New York (1957), p. 511 


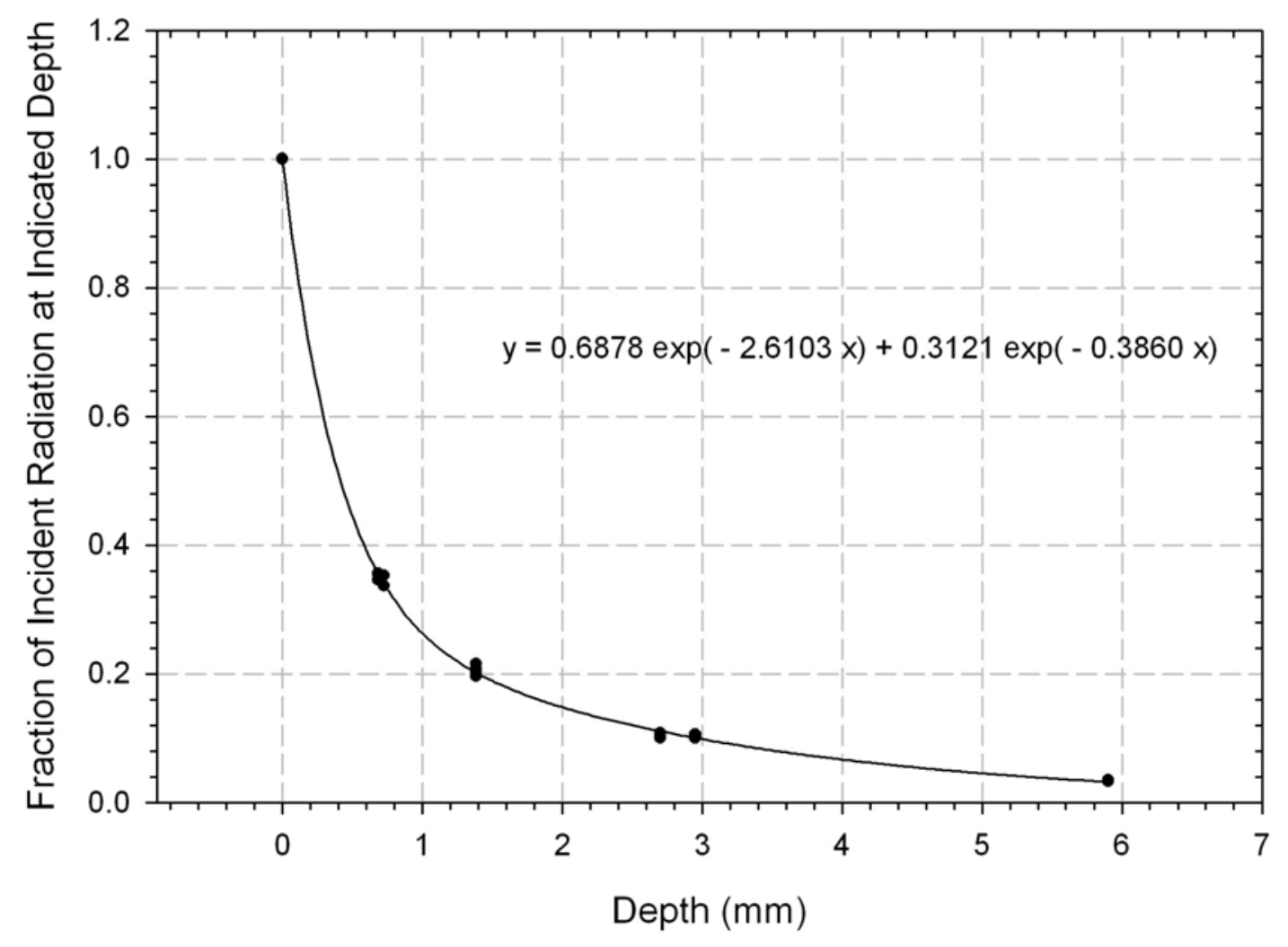

Figure A4.1 Double Exponential Fit to PD702N Polypropylene Cone Radiation Absorption In Depth 


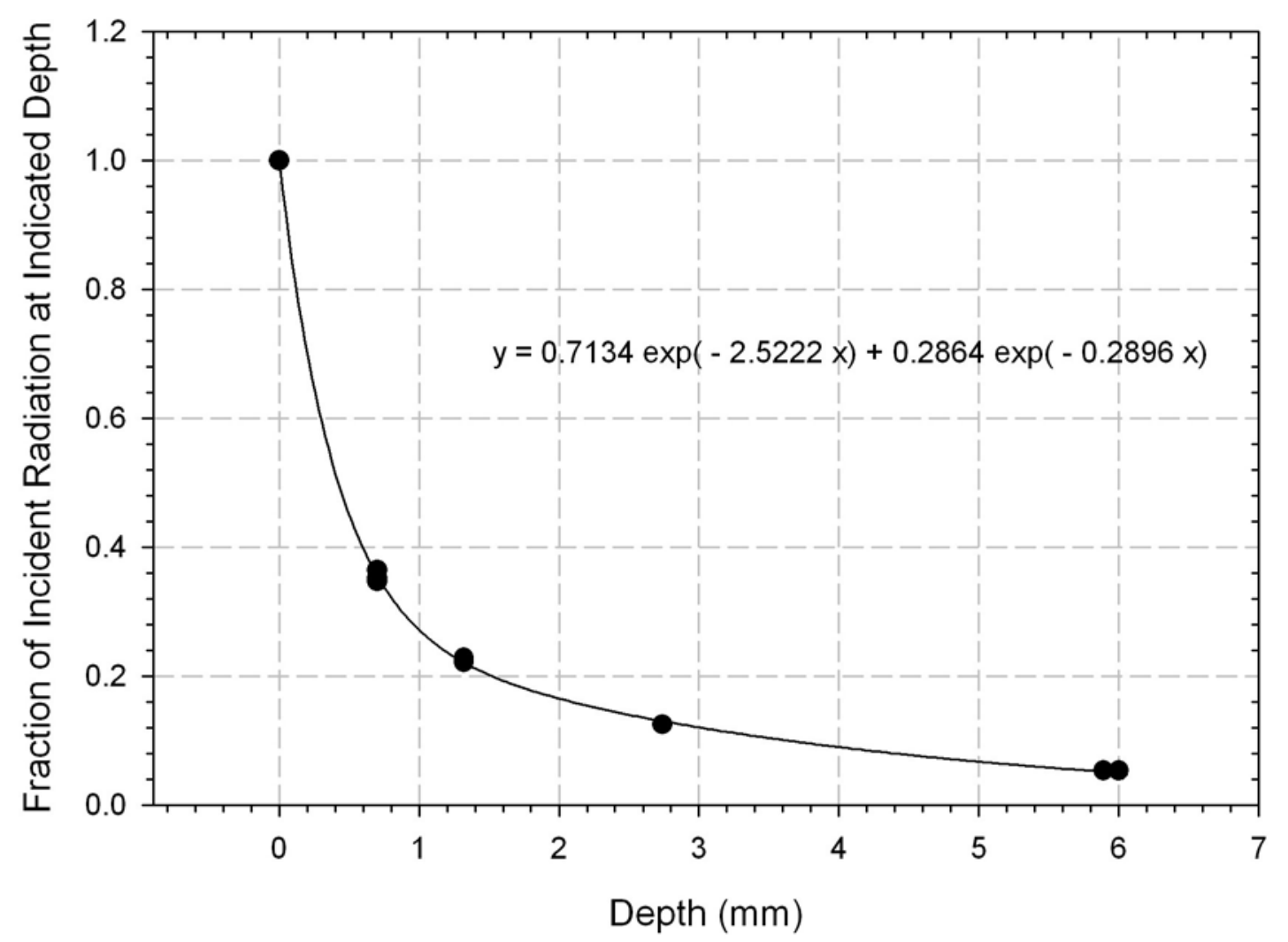

Figure A4.2 Double Exponential Fit to PP6523 Cone Radiation Absorption In Depth 


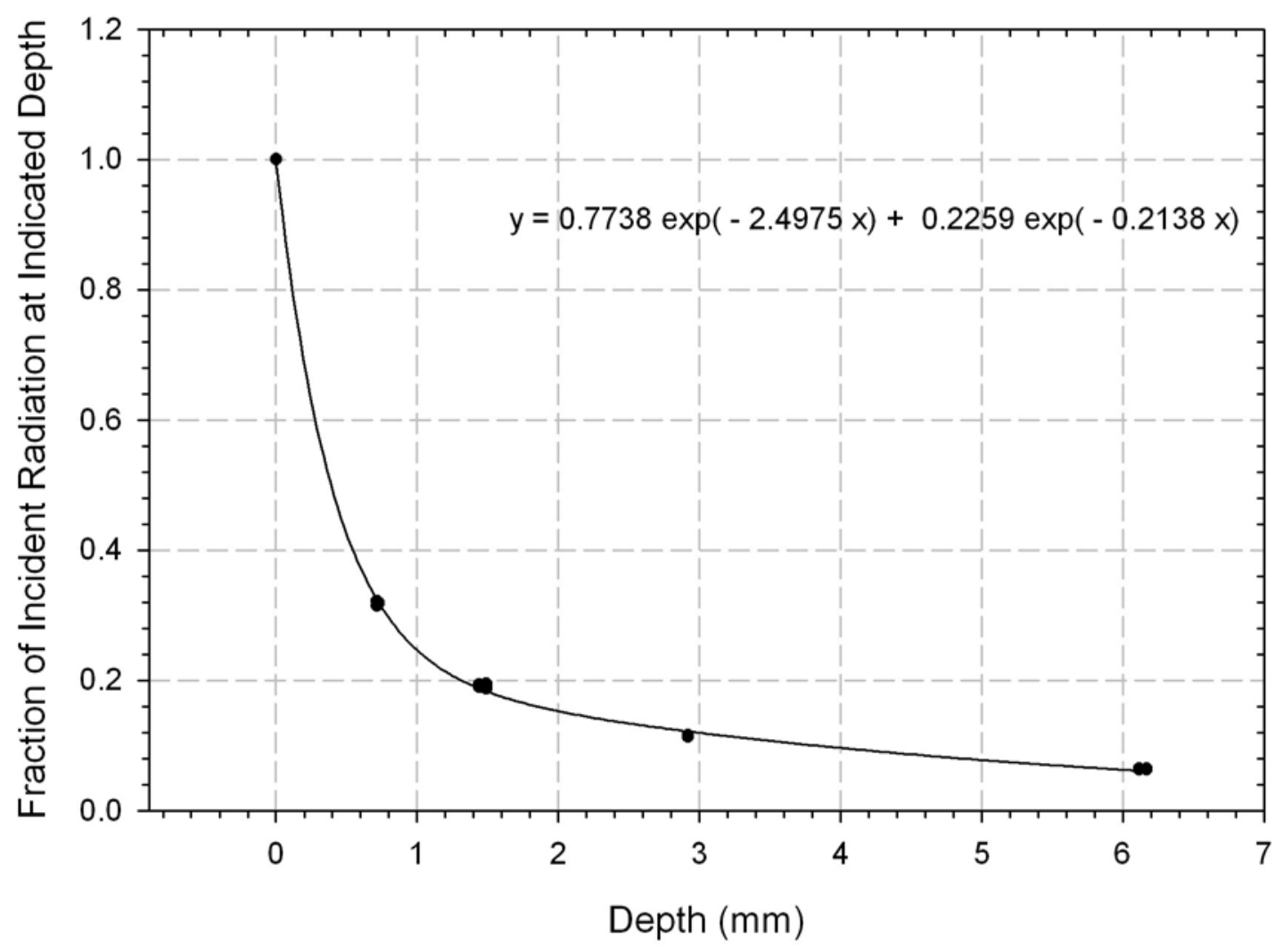

Figure A4.3. Double Exponential Fit to PS663 Polystyrene Cone Radiation Absorption In Depth 


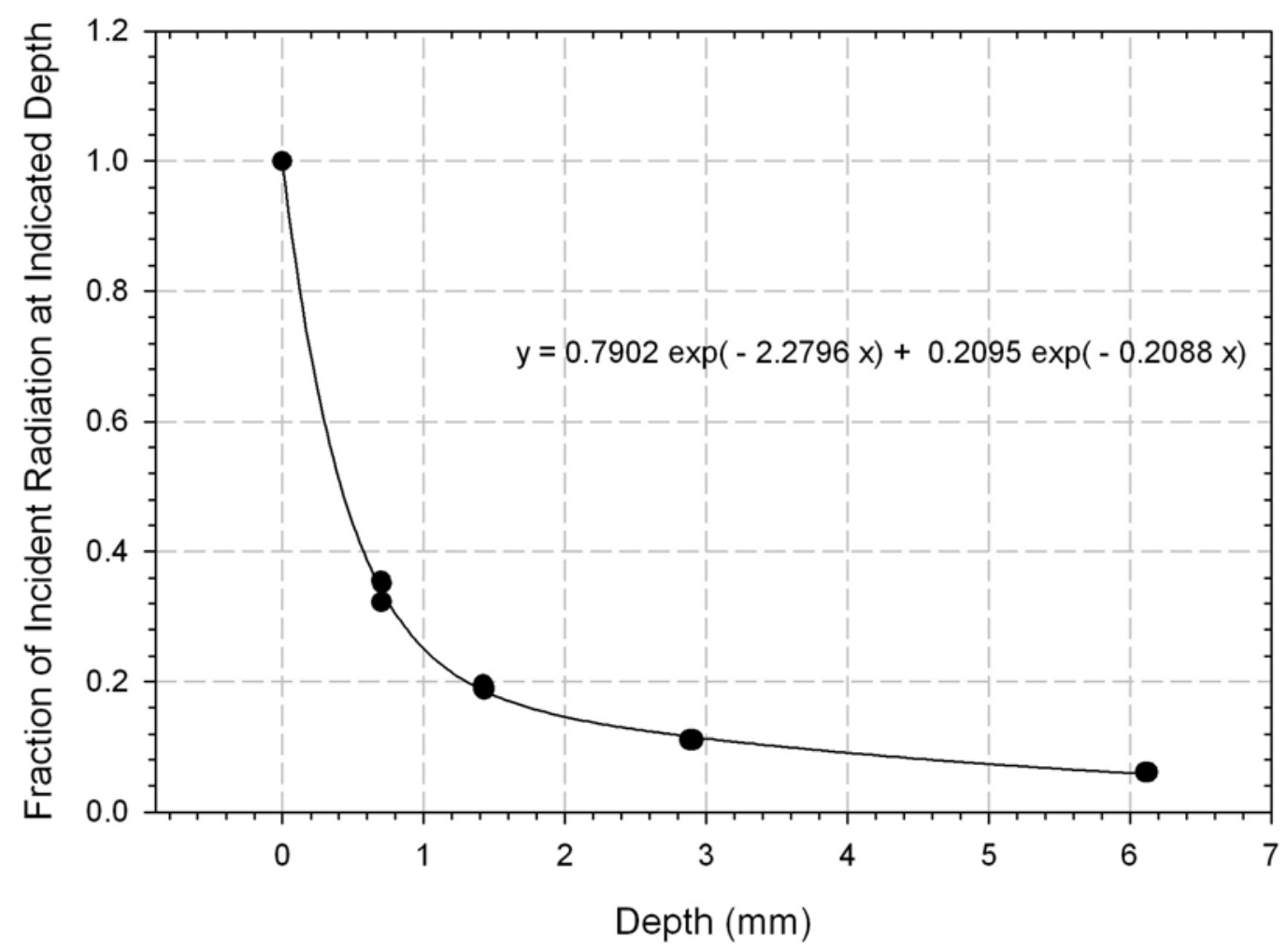

Figure A4.4 Double Exponential Fit to PS 666D Polystyrene Cone Radiation Absorption In Depth 